\title{
USING BIM TO CALCULATE ACCURATE BUILDING MATERIAL QUANTITIES \\ FOR EARLY DESIGN PHASE LIFE CYCLE ASSESSMENT
}

BY

\author{
BRIAN BERG \\ Supervisor \\ Dr Michael Donn
}

\begin{abstract}
A Thesis
Submitted to the Victoria University of Wellington

In Fulfilment of the Requirements for the Degree of

Master's of Building Science

Majoring in Sustainable Engineering Systems
\end{abstract}

Victoria University of Wellington

2014 


\section{Dedication}

To my friends, I appreciate you.

Using BIM To Calculate Accurate Building Material Quantities For Early Design Phase LCA

Author: Brian Berg 


\section{ACKNOWLEDGEMENTS}

Michael Donn, my supervisor. Thank you.

Liz Root, for going above, and beyond to provide the building case study information, without which this research would not have been possible. Thank you.

David Dowdell, for your help and most importantly, your patience. Thank you.

Samuel and Haruka, for everything. Thank you.

My morning, afternoon, and anytime in-between coffee crew.

The Building Research Association of New Zealand (BRANZ), thank you for the scholarship financial support.

The New Zealand Green Building Council, thank you for providing the building case study information.

Using BIM To Calculate Accurate Building Material Quantities For Early Design Phase LCA 


\section{ABSTRACT}

This research simplifies the calculation of the Initial Embodied Energy (iEE) for commercial office buildings. The result is the improved integration of Life Cycle Assessment (LCA) assessments of building materials into the early stages of the building design process (sketch design). This maximises the effectiveness of implementing design solutions to lower a building's environmental impact.

This thesis research proposes that building Information Models (BIM) will make calculating building material quantities easier, to simplify LCA calculations, all to improve their integration into existing sketch design phase practices, and building design decisions. This is achieved by developing a methodology for using BIM LCA tools to calculate highly detailed material quantities from a simple BIM model of sketch design phase building information. This is methodology is called an Initial Embodied Energy Building Information Model Life Cycle Assessment Building Performance Sketch (iEE BIM LCA BPS). Using this methodology calculates iEE results that are accurate, and represent a sufficient proportion (complete) of a building's total iEE consumption, making them useful for iEE decision-making.

iEE is one example of a LCA-based indicator that was used to test, and prove the feasibility of the IEE BIM LCA BPS methodology. Proving this, the research method tests the accuracy that a BIM model can calculate case study building's building material quantities. This included developing; a methodology for how to use the BIM tool Revit to calculate iEE; a functional definition of an iEE BIM LCA BPS based on the environmental impact, and sketch design decisions effecting building materials, and elements; and an EE simulation calibration accuracy assessment methodology, complete with a function definition of the accuracy required of an iEE simulation to ensure it's useful for sketch design decision-making.

Two main tests were conducted as part of proving the iEE BIM LCA BPS' feasibility. Test one assessed and proved that the IEE BIM LCA BPS model based on sketch design information does represent a sufficient proportion (complete) of a building's total iEE consumption, so 
that are useful for iEE decision-making. This was tested by comparing the building material quantities from a SOQ (SOQ) produced to a sketch design level of detail (truth model 3), to an as-built level of detail, defined as current iEE best practices (truth model I). Subsequent to proving that the iEE BIM LCA BPS is sufficiently complete, test two assessed if a BIM model and tool could calculate building material quantities accurately compared to truth model 3 . The outcome was answering the research question of, how detailed does a BIM model need to be to calculate accurate building material quantities for a building material LCA (LCA) assessment?

The inference of this thesis research is a methodology for using BIM models to calculate the $\mathrm{iEE}$ of New Zealand commercial office buildings in the early phases of the design process. The outcome was that a building design team's current level of sketch design phase information is sufficiently detailed for sketch design phase iEE assessment. This means, that iEE and other LCA-based assessment indicators can be integrated into a design team's existing design process, practices, and decisions, with no restructuring required. 


\section{TABLE OF CONTENTS}

I THESIS RESEARCH AIMS AND OBJECTIVES ........................................ I5

I.I Introduction .................................................................................................................

1.2 Context, And Problem Statement ......................................................................15

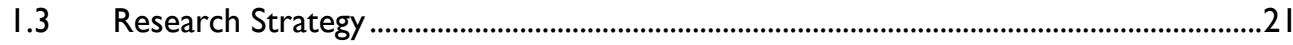

I.3.I The Research Problem, Aim, Question, And Hypothesis .....................................21

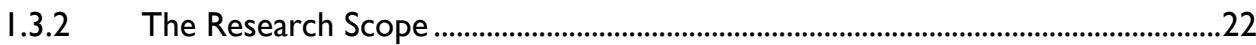

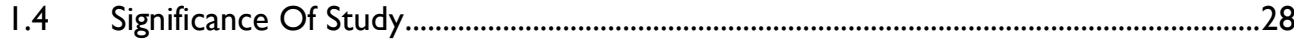

2 CALCULATING ENVIRONMENTAL IMPACT IN THE BUILT

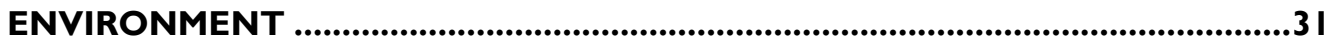

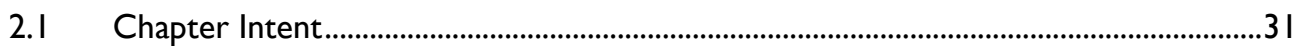

2.2 Calculating And Designing To Reduce A Building's Environmental Impact.................32

2.2.I What Is Environmental Impact?..................................................................................32

2.2.2 The Building Design Process And Informed Decision-Making ...............................35

2.2.3 Informed Decision-Making, Building Performance Simulation Tools, And The

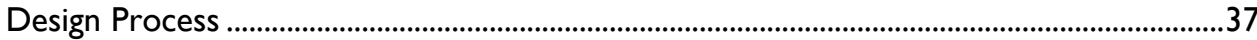

2.3 The Problem With Existing Building Material LCA Assessments ..................................38

2.3.I Reducing Building Material LCA Calculation Complexity.......................................40

2.3.2 LCA Tools For Calculating Building Material Coefficients .......................................40

2.3.3 BIM LCA Tools ............................................................................................................4

2.4 How Effective Are BIM LCA Tools? .................................................................................4

2.4.I Are BIM LCA Tools Capable Of Improving Integration?.......................................43

2.4.2 BIM LCA Tools, Capable But Used Ineffectively......................................................44

$2.5 \quad$ How To Use BIM LCA Tools Effectively? …………………………………………….....48

2.5.I The Building Performance Sketch (BPS) ...................................................................48

2.5.2 A BIM LCA Building Performance Sketch (BPS) ....................................................48

2.5.3 Sketch Design Decision-Making And Simulation Accuracy .....................................49

2.6 The Problem, Calculating Material Quantities ....................................................................... I

Using BIM To Calculate Accurate Building Material Quantities For Early Design Phase LCA 
2.6.I Testing Sketch Vs. Detailed Models For Calculating Building Material

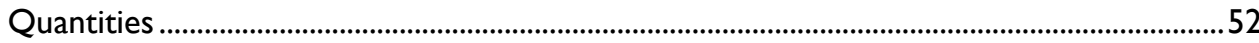

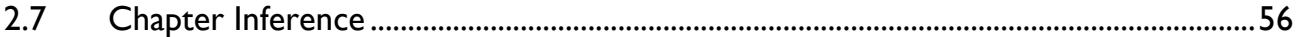

3 RESEARCH METHODOLOGY ....................................................................... 57

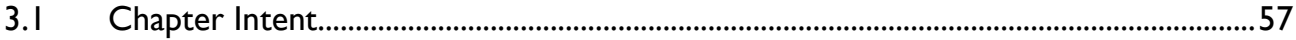

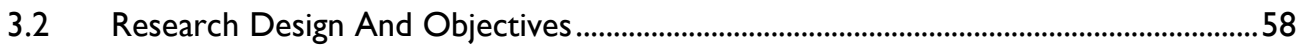

3.2.I The Thesis Hypothesis Testing Process.....................................................................58

3.2.2 The Relationship Between LCA And EE ...............................................................60

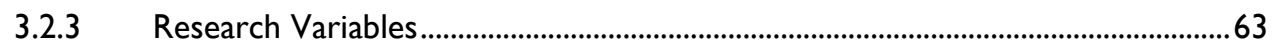

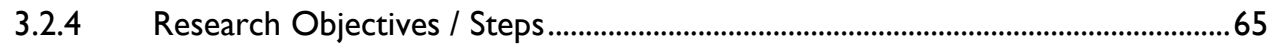

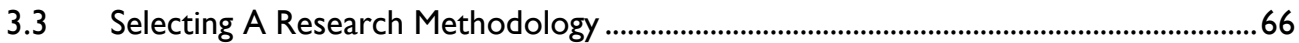

3.3.I Prevalent Research Methodologies In EE ...................................................................66

3.3.2 Selected Research Methodology: Single-Case Study....................................................68

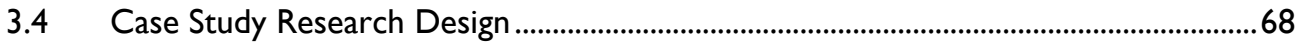

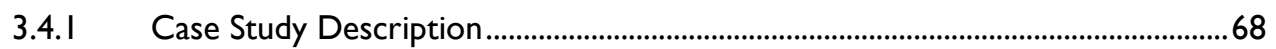

3.5 Limitations Of Case Study Research Design .......................................................................69

3.5.1 Research Generalisability And Representativeness....................................................70

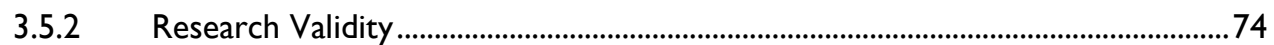

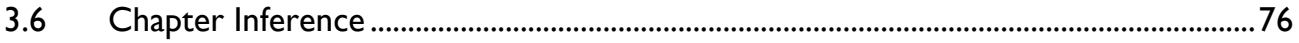

4 THE METHODOLOGY OF THE BIM LCA BPS ........................................... 77

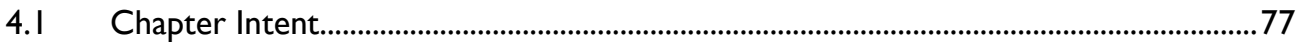

4.2 Defining An iEE BIM LCA BPS Model ................................................................................78

4.2.I What To Model For A BIM LCA BPS Of iEE ......................................................

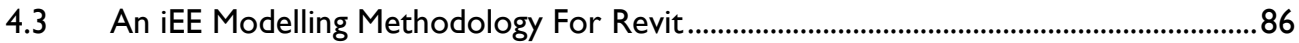

4.3.1 Selecting A Building Material Coefficient Database..................................................89

4.3.2 Sketching EE In The Revit BIM Tool ............................................................................98

$4.4 \quad$ Chapter Inference ............................................................................................................. 05

5 THE ACCURACY ASSESSMENT FRAMEWORK FOR THE BIM LCA BPS 106

5.I Chapter Intent 106

Using BIM To Calculate Accurate Building Material Quantities For Early Design Phase LCA 
5.2 Defining Simulation Accuracy, And Precision ........................................................... 107

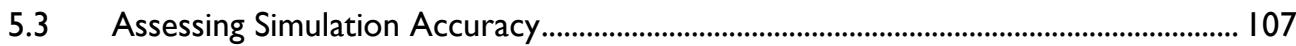

5.4 Existing Calibration Accuracy Assessment ....................................................................... 109

5.5 Developing An EE Calibration Method ...................................................................... I I4

5.5.I Defining The 'True' Value Of A Building's EE Consumption ............................... I I4

5.5.2 Defining 'How Close' Is Close Enough: EE Maximum Calibration Tolerances 115

5.5.3 The Functional Definition Of EE LCA Calibration Tolerances 117

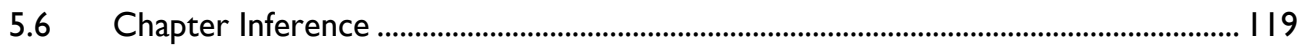

6 ACCURACY ASSESSMENT RESULTS AND DISCUSSION ..................... 20

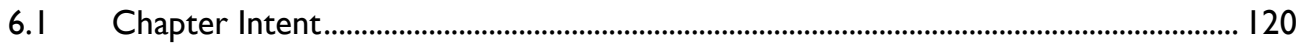

6.2 Test One: Is A Sketch Design iEE BPS Assessment Complete Enough?................... I2I

6.2.I Why Test Completeness? ..................................................................................... I 2 I

6.2.2 Selecting Truth Model EE Material Coefficients .................................................. 122

6.2.3 Calculating Truth Model Building Material Quantities.......................................... 129

6.2.4 Calculating EE Truth Models ........................................................................... 133

6.3 Test Two: Does A BIM Model Calculate Accurate iEE BIM LCA BPS Results?...... I43

6.3.I A Recap Of The Testing Process: ................................................................... 143

6.3.2 Pre-Calibration Accuracy Assessment Of The Revit iEE BIM LCA BPS .......... I43

6.3.3 Post Calibration Accuracy Assessment Of The iEE BIM LCA BPS Method ... I 48

6.4 Test Three: Is The Revit iEE BIM LCA BPS Model Robust?........................................ I 55

6.4.I EE \& Embodied Carbon Dioxide ............................................................................ 155

6.4.2 Cancellation Errors In The BIM Geometry ……................................................... I 57

6.5 Modelled Detail Of The Pre-Calibration Revit iEE BIM BPS ..................................... I 58

6.5.I How Detailed Is The Revit Pre-Calibration BIM Model?.................................... I59

6.5.2 How Was Revit Used To Construct The iEE BIM BPS? ..................................... 167

7 THESIS CONCLUSIONS ..................................................................... 7 |

7.I Conclusions Surrounding The Failings Of BIM LCA Tools ........................................ I7 I

7.2 Proving The Thesis Hypothesis......................................................................................... 173

7.2.I Conclusions: Is A Sketch Design iEE BPS Assessment Complete Enough?..... I73 
7.2.2 Conclusions: Does A BIM Model Calculate Accurate iEE BIM LCA BPS Results? 175

7.3 Answering The Thesis Research Question: ................................................................... 176

7.3.I How Detailed Is An Accurate iEE BIM LCA BPS Model? ..................................... 176

7.4 iEE And LCA Conclusions Beyond This Research.......................................................... 177

$7.5 \quad$ Key Outputs Of Thesis Research ……………………………………………………...... 178

7.6 BIM Conclusions Beyond This Research ...................................................................... 179

Level Of Development Specification ................................................................................................20

Using BIM To Calculate Accurate Building Material Quantities For Early Design Phase LCA

Author: Brian Berg 


\section{LIST OF FIGURES, GRAPHS, AND TABLES}

Table I.2: An Example Of The Relationship Between LCl and LCIA Results.............................. 16

Figure 1.2: BIM Maturity Diagram ...............................................................................................19

Table 1.3.2: The BIM LCA BPS Framework Applied To Y.L. Langston \& Langston (2012).......22

Table 2.2.I: Building Energy Consumption Throughout The Different Life Cycle Stages...........33

Table 2.2.2: Design Phases for Different Building Design Frameworks...........................................36

Figure 2.2.3a: Structure of Performance Criteria ..............................................................................37

Figure 2.2.3b: The MacLeamy Concept .........................................................................................38

Figure 2.4.2a: Building Smart Graph Promoting the Advantages of the BIM Concept.................46

2.5.3: Measures Of Simulation Reliability For Design Decision-Making..........................................50

Figure 2.6.I: The Tally BIM LCA Tool's Example Tutorial Model....................................................53

Table 2.6. I: Comparing BIM Level Of Modelled Detail .....................................................................54

Table 3.2.2: EE Material Coefficient Calculation Methods ...............................................................61

Graph 3.2.2: A Comparison of the Different EE Material Coefficient Calculation Methods ....62

Table 3.2.3a: The Dependent and Independent Variables in Thesis Research Design.................63

Table 3.2.3b: The Intervening Variables in Thesis Research Design ................................................64

Table 3.2.3c: The Control Variables in Thesis Research Design .....................................................64

Table 3.2.3d: The Confounding Variables in Thesis Research Design .............................................65

Table 3.2.4: Thesis Research Objectives.......................................................................................66

Graph 3.3.I: Research Methodologies Prevent In EE Research......................................................67

Table 3.4.I: Case Study Building Description ...................................................................................68

Table 3.5. Ia: The New Zealand Commercial Building Stock Classification ......................................7I

Table 3.5. Ib: The Built Form Typology of Strata 5 New Zealand Commercial Buildings .........72

Table 3.5. Ic: Energy Use Intensities For Commercial Buildings .......................................................73

Graph 3.5.I: The Relationship between OE and Life Cycle EE for Non-Residential Case Studies

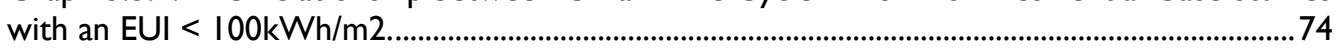

Table 4.2: The Building Element Distribution of Initial EE.............................................................. 80

Table 4.2. Ia: A Framework for Defining the Building Elements Constituting an iEE BIM LCA BPS. 
4.2. Ib: The Working Definition of the Decisions and Building Information Available During Sketch Design

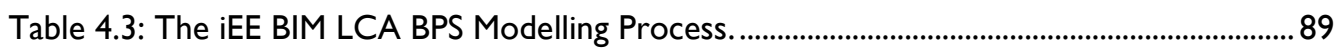

Table: 4.3.Ib: Quality Assurance Uncertainty Assessment Tools Assessed Against Section

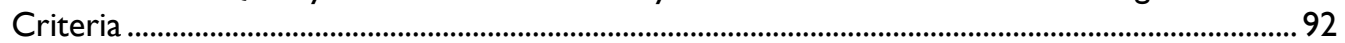

Table 4.3.2e: Selection Data Quality Indicators for EE Material Coefficients .............................. 95

Table 4.3.2f: EE Material Coefficient Selection Data Quality Pedigree Matrix Tool .................... 97

Figure 4.3.2a: BIM Maturity Diagram ........................................................................................................ 99

Figure 4.3.2b: BIM Tool Revit Modelling Tools............................................................................... 100

Table 4.3.2a: The Calculated Quantity Information Available Using Revit ................................. I0I

Table 4.3.2b: A Solution for the Material Quantity Format Problem ........................................... I0 I

Table 4.3.2c: UniClass 2.0 Classification Code Structure ............................................................ 103

Table: 4.3.2d: iEE and LCA Results Format Guidelines............................................................ 104

Figure 5.4: Generalised Simulation Calibration Methodology/Process. .......................................... I I I

Table 5.4a: Acceptable Calibration Tolerances ...................................................................... II

Table 5.4b: Equation for Calculating the Mean Bias Error (MBE) .............................................. I I 3

Table 5.4c: Equation for Calculating the Coefficient of Variation of Root Square Mean Error (CV(RSME)) ....................................................................................................................... 113

Table 5.3.3a: Accepted Inaccuracies in Building Cost Planning ..................................................... I I 7

Table 5.3.3b: Functional Definition of Calibration Accuracy and Precision Tolerances............ I I 9

Table 6.2.2b: Data Indicator Pedigree Matrix Assessment of Alcorn's Hybrid Process / Inputoutput EE coefficients......................................................................................................................... $/ 23$

Table 6.2.2c: Data Indicator Pedigree Matrix Assessment of Crawford's Hybrid Input-output / Process EE coefficients (2004).................................................................................................. 124

Table 6.2.2d: Data Indicator Pedigree Matrix Assessment of European LCA Database.......... 125

Graph 6.2.2: Export and Import (NZ\$ million) of Selected Building Products in 2011 ........... 127

Table 6.2.2e: EE Building Material Coefficients Used In This Research ......................................... 128

Table 6.2.3: Case Study Building Truth Models I-3, The Building Materials Assessed............. I 30

Table 6.2.3b: Case Study Building Truth Models I-3, The Building Elements Assessed .......... I 3 I

Table 6.2.4a: The iEE Results Of Thesis Case Study Building Truth Models............................... I 34

Graph 6.2.4a: iEE Material Analysis For Case Study Building Truth Model I-3........................ I 135

Table 6.2.4b: Truth Model Calibration Assessment at Material Breakdown Level ................... I 36

Table 6.4.2c: Elemental Analysis Of iEE Case Study Building Truth Models I And 3 ............... I 37 
Graph 6.2.4b: iEE Elemental Analysis For Case Study Building Truth Models 2 And 3 137

Table 6.3.2d: iEE Savings From Structural Design Changes .......................................................... 138

Table 6.2.4f: Analysis Of iEE Savings Versus OE Savings................................................................ 442

Table 6.3.2a: Pre-Calibration Accuracy Assessment at Material Level Analysis .......................... 44

Table 6.3.2b: Pre-Calibration Accuracy Assessment at Elemental Level Analysis...................... 144

Table 6.3.2d: Difference In Building Materials Heat Strengthened Glass Sheets And Autex GreenStuff R3.2 Insulation ...................................................................................................... 145

Graph 6.3.2a: Pre-Calibration iEE BIM LCA BPS Material Analysis ............................................. 146

Graph 6.3.2b: Pre-Calibration iEE BIM LCA BPS Elemental Analysis ........................................... 147

Table 6.3.3a: Post Calibration Accuracy Results of Revit iEE BPS Compared to Truth Model

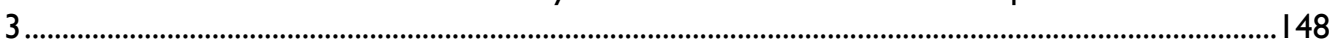

Graph 6.3.3a: Calibrated iEE BIM LCA BPS Material Analysis........................................................ 50

Graph 6.3.3b: Calibrated iEE BIM LCA BPS Elemental Analysis ................................................ I5 I

Table 6.3.3b: iEE LCA Results Expressed per BIM Object (Revit Family Type) ......................... 153

Table 6.3.3c: iEE LCA Results Expressed per Building Material per BIM Object (Revit family

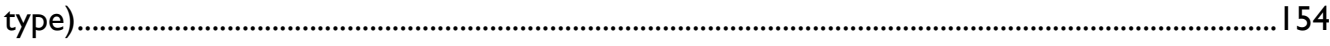

Table 6.3.3d: iEE LCA Results Expressed per Building Element .................................................... 54

Table 6.4. Ia: Revit Calculated iEE Results Using Crawford's (2004) Hybrid EE Database...... 156

Table 6.4.Ib: Revit Calculated ECO2 Results Using Alcorn's (2010) Hybrid ECO2

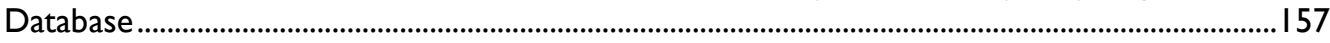

Table 6.5.Ia: BIM Modelled Detail Of iEE BIM LCA BPS................................................................. 16 I

Table 6.5. I b: Modelled Detail Of BIM Objects In The iEE BIM LCA BPS ..................................... 163

Table 6.5.I c: The Modelled of the Timber Stud Exterior Wall ................................................... 165

Figure 6.5.2a: Revit Material Browser................................................................................................... 168

Figure 6.5.2b: Solutions For Quickly Sketching Detailed BIM Objects ........................................ 169

Figure 6.5.2c: The Modelled Detail of the Double Skin Façade BIM Object ............................... 170

Appendix 4.0 Table 4.2. Ia: The Working Definition of the Decisions and Building Information Available During Sketch Design.

Appendix 4.0 Table 4.2.Ia: The Working Definition of the Decisions and Building Information Available During Sketch Design

Appendix 4.0 Table 4.2. Ia: The Working Definition of the Decisions and Building Information Available During Sketch Design........................................................................................................... 197

Table 4.3.I a: Sources of Uncertainty and Variability in LCA Data.............................................. 198

Table 4.3. I c: Data Quality Pedigree Matrix ........................................................................................... 199 


\section{ABBREVIATIONS}

BIM - Building Information Model

iBIM - Integrated Building Information Model. This is a level three BIM maturity model

BIM LCA BPS - Building Information Model Life Cycle Assessment Building Performance

Sketch

BPS - Building Performance Sketch

Cv(RSME) - Coefficient of Variation of Root Square Mean Error

DQI - Data Quality Indicator

DQIPM - Data Quality Indicator Pedigree Matrix

ECO2 - Embodied Carbon Dioxide

EDDST - Early Design Decision Support Tool

EE - Embodied Energy

iEE - Initial Embodied Energy

iEE BIM LCA BPS - Initial Embodied Energy Building Information Model Life Cycle

Assessment Building Performance Sketch

EE DQIPM - Embodied Energy Data Quality Indicator Pedigree Matrix

EPD - Environmental Product Declaration

EUI - Energy Use Intensity

Using BIM To Calculate Accurate Building Material Quantities For Early Design Phase LCA

Author: Brian Berg 
GFA - Gross Floor Area

IDP - Integrated Design Process

LCA - Life Cycle Assessment

LCl - Life Cycle Inventory

LCIA - Life Cycle Impact Assessment

MBE - Mean Bias Error

NLA - Net Lettable Floor Area

Using BIM To Calculate Accurate Building Material Quantities For Early Design Phase LCA

Author: Brian Berg 
Chapter One:

\section{THESIS RESEARCH AIMS AND OBJECTIVES}

\section{I.I Introduction}

How detailed does a Building Information Model (BIM) need to be to calculate accurate material quantities for a building material Life Cycle Assessment (LCA) assessment? Answering this question, Initial Embodied Energy (iEE) was used to define, how accurate a LCA calculation must be for early design phase assessment, and to develop a BIM modelling methodology to achieve it.

\section{I.2 Context, And Problem Statement}

"Every building is potentially immortal"

Stewart Brand (1994, p. II).

\section{LCA Environmental Framework}

Brand (1994) writing in the context of a building's future adaptability describes the idea that buildings can last a long time. He touches on a key point; buildings inherently outlive their original occupants. The minimum lifespan of a commercial office building in New Zealand is 50 years. Therefore, the decisions made during the design process have an environmental impact that lasts many years.

This increased awareness of a buildings lasting environmental impacts is changing how they are designed. Life Cycle Assessment (LCA) is an environmental framework that measures the environmental consumption, and impact of different processes and products, including buildings. A building LCA measures the environmental impact of all the activities and processes, throughout the four stages of a building's lifespan. This is from the (I) manufacturing of building materials and products; (2) the construction of those materials and products into a building; through the (3) operation, and maintenance; and finally the (4) 
demolition and disposal processes. The results are described as Life Cycle Indicators ( $\mathrm{LCl})$, and Life Cycle Impact Assessment (LCIA) categories.

LCls are environmental indicators that measure the environmental consumption of activities and processes. Whereas, $\mathrm{LCIA}$ categories translate the $\mathrm{LCl}$ results into a measure of their environmental impact. Table 1.2 lists typical $\mathrm{LCl}$ results that are the inputs for calculating the $\mathrm{LCIA}$ results. The difference is that $\mathrm{LCl}$ results are environmental indicators that describe 'how much' a building consumes, whereas LCIA describes 'how much' of an environmental impact those $\mathrm{LCl}$ results have. To illustrate the difference between $\mathrm{LCl}$ and $\mathrm{LCIA}$, consider that two buildings have the same operative energy consumption e.g. LCl result, however, one is powered by renewable energy generation sources, the other by a non-renewable fossil fuels. The fossil fuel powered building will have the larger LCIA result despite both buildings $\mathrm{LCl}$ operative energy results being equal.

Table 1.2: An Example Of The Relationship Between LCI and LCIA Results

\begin{tabular}{|l|l|}
\hline \multicolumn{1}{|l|}{ LCI Input and Output Data / Results } & \multicolumn{1}{|c|}{ LCIA Impact Category } \\
\hline Carbon Dioxide $\left(\mathrm{CO}_{2}\right)$ & \multirow{2}{*}{ Global Warming } \\
\hline Nitrogen Dioxide $\left(\mathrm{NO}_{2}\right)$ & \\
\hline Methane $\left(\mathrm{CH}_{4}\right)$ & \\
\hline Other Green House Gases & \\
\cline { 1 - 1 } Source: & \\
Table 3.3 (Crawford, 20II, p. 56) citing SAIC 2006. \\
\hline
\end{tabular}

Often the scope of a building LCA is limited to measure only specific lifecycle stages or specific LCls. This kind of LCA assessment is commonly called a streamlined LCA. One common example of a streamlined LCA assessment is an EE (iEE) assessment of building materials. As a type of $\mathrm{LCl}$-based indicator, iEE measures the energy consumption of the activities, and processes, involved in producing building materials during the manufacturing lifecycle stage of a building. A building material $\mathrm{LCl}$ assessment, like iEE, is calculated by multiplying material coefficients that measure environmental consumption, by the quantities of each material and product used throughout the whole building (Equation I). This is called a whole building material LCA assessment (hereby referred to as simply an LCA assessment). Equation 2 shows this same process applied to iEE. 


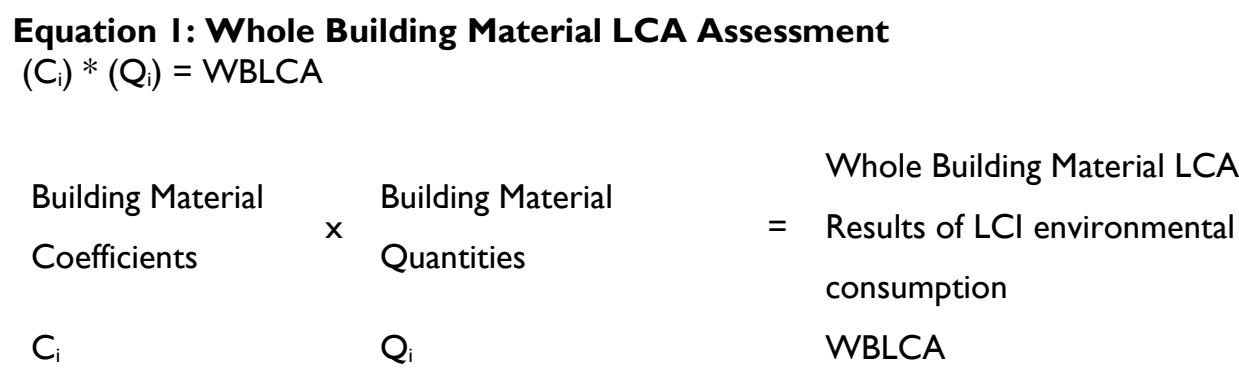

Equation 2: Whole Building Initial EE Assessment Source: Equation I (Wang \& Shen, 2013, p. I66)

$\left(\mathrm{EEC}_{\mathrm{i}}\right) *\left(\mathrm{Q}_{\mathrm{i}}\right)=$ WBiEE

EE Coefficients

EEC
Quantities

$Q_{i}$
$=$ Whole Building iEE Results

WBiEE

Due to their size, and complexity, buildings use a large number of different materials and products. This makes conducting a LCA assessment difficult. The difficulties calculating building material quantities has long been one of the principle causes of building LCA complexity. This has limited the use of building material LCA assessment in building design to reduce environmental impact.

\section{Building LCA Tools}

Building material LCA tools were developed to reduce building material LCA calculation complexity. They aim make it easier for building designers to calculate building material quantities. However, being capable of producing results does not make them effective. To be effective, building material LCA tools must be integrated, and used in the early sketch/concept phases (hereby referred to as sketch design) of the design process. This is called integration. Effective integration is when building material LCA tools are used in a manner that adapts them to integrate within the day-to-day realities of work practices, processes, and with other building design tools building that designers actually use during sketch design. Building material LCA tools must be capable of rapidly testing different design, 
whilst ensuring the simulation results are accurate and trusted enough to enable the design team to make informed design decisions.

Most existing building LCA tools fail to meet requirements of effective integration. The difficulties in calculating building material quantities is a primary reason. In response, LCA tools that utilise a BIM (BIM) were developed. These tools are called BIM LCA tools. BIM is a technology used by building designers for digitally representing geometric (3D physical), and non-geometric (functional) information or metadata. It promotes knowledge sharing, and early design phase building performance assessment to assist design decision-making. This definition has three ideas; the BIM concept, the BIM tool, and the BIM model.

\section{The BIM Concept For Using BIM LCA Tools}

The BIM concept defines how to use a BIM model, a BIM tool is the computer software used to construct the BIM model, and a BIM model is the 3D digital visualization of building information produced by the BIM tool. A BIM model consists of BIM objects, and BIM geometry. BIM objects deal with materials and products at an individual level. A BIM object is an assembly of these materials to represent a specific construction system. Embedded within each of BIM object is metadata information such as LCA material coefficients. Therefore, the information able to be calculated from a BIM model depends on the data embedded into the BIM objects. BIM geometry is the assembly of all the BIM objects into the building's overall form.

The BIM concept prescribes constructing a very detailed BIM model called a single integrated BIM model, also known as an Information BIM or Interoperable BIM (iBIM). An iBIM model has all the design team's information, for all areas of building performance and building design embedded using interoperability. This makes it a Level 3 BIM maturity model. The BIM maturity levels (illustrated in Figure I.2), describe the level of interoperability a BIM model is capable of. Ranging from levels I to 3 , level I is $3 D$ CAD. Level 2 has some interoperability capabilities, but still requires each design member to construct and maintain their own specific BIM models for their area of building design. At this level, the BIM D's; 4D (Time) BIM, 5D (Cost) BIM, and 6D (Facilities Management) BIM are capable information outputs. From a building performance assessment perspective, often a specific BIM model is required specialising in energy, daylighting, or LCA. These BIM models are often simplified to the 
specific requirements of what they are assessing. The move from BIM maturity levels 2 and 3 effects how the BIM model is constructed e.g. how the BIM objects, geometry, and LCA information is input into the model. This has no effect on what information is put in. Therefore it does not affect the capabilities of the BIM LCA, provided that the required information is entered into the model at the phase of the design process it needs to be, it doesn't matter how it gets there.

Figure I.2: BIM Maturity Diagram

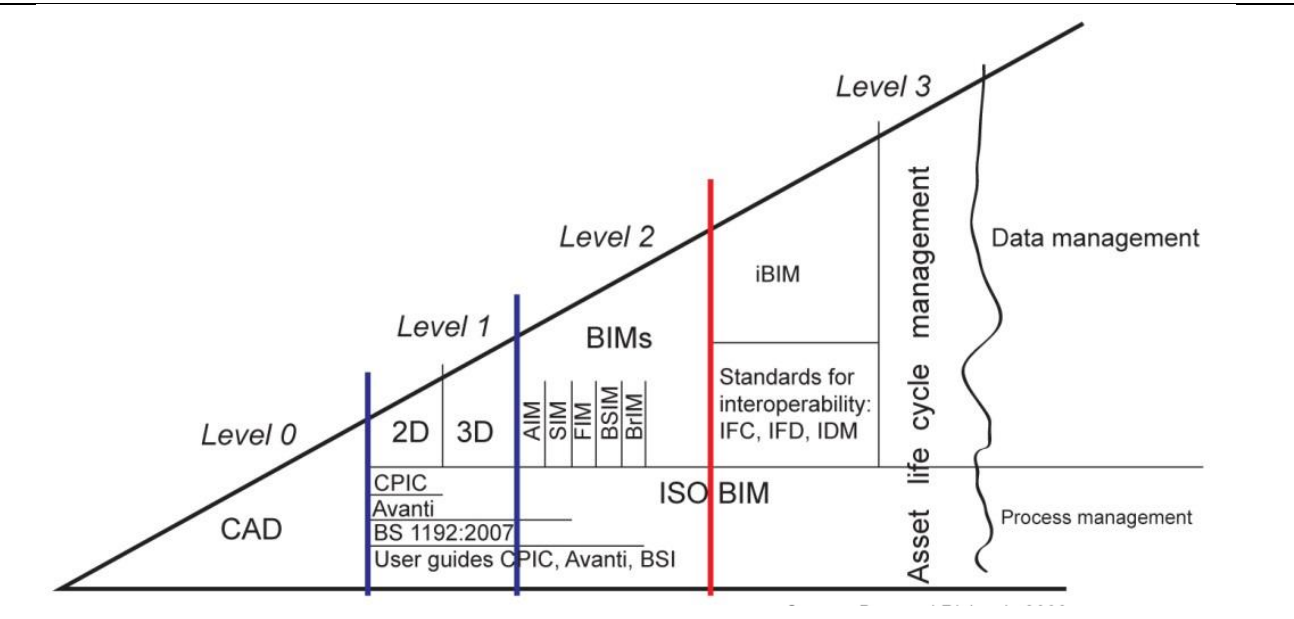

\section{Notes:}

AIM - Architectural Information Model SIM - Structural Information Model FIM Facilities Information Model BSIM - Building Services Information Model BrIM - Bridge Information Model IFC - Industry Foundation Class IFD - International Framework Dictionary IDM - Information Delivery Manual

\section{Reference:}

Sinclair (2012, p. 5) citing Bew and Richards 2008

BIM LCA tools were specifically developed to make calculating building material quantities easier by calculating them directly from a BIM model. A BIM LCA tool uses the building form and construction information embedded in a BIM model. This is information that is typically produced by existing design processes and practices. When supplemented with LCA specific information, BIM LCA tools function as a user-friendly interface between the building designer (modeller), and the building material LCA calculation process. This enables a LCA 
assessment to be conducted using design tools, and practices that building designers already use and do.

Compared to non-BIM LCA tools, BIM LCA tools allow better integration of the LCA environmental framework into the design process. They have all the necessary capabilities, but lack a methodology for how to integrate and use them effectively during sketch design. The BIM concept is ineffective for this purpose because constructing the required iBIM models is too time consuming.

\section{The Building Performance Sketch For Using BIM LCA Tools}

As a response, to solve the issues with the BIM concept, Donn et al,. (20I2) developed the Building Performance Sketch (BPS). The BPS abandons the BIM concept's idea of using an iBIM model to calculate all areas of building performance. Instead, it dictates using one model to calculate one area of building performance. This means the model can be simpler so that design iterations can be tested faster, and more easily, without comprising simulation accuracy. As a result, for each area of building performance, a unique BPS model must be created that is sufficiently detailed to calculate results that are accurate enough for building designers to make design decisions. The limitation of using the BPS concept to solve the methodology issues with BIM LCA tools is that Donn et al,. (20I2) did not define what an iEE BPS is. Missing are definitions for:

- The measurable criteria of iEE simulation accuracy for decision-making.

- What must building information must be modelled, and how detailed it must be to produce results that satisfy decision-making simulation accuracy requirements?

Resolving the ineffective integration of BIM LCA tools by developing an iEE BPS focuses on the relationship between the calculation of building material quantities, the detail of the BIM model's objects and geometry, and the overall accuracy of the simulation results. This is placed in the context of sketch design, where simulations must be quick, easy, but most importantly accurate. Therefore the problem statement of this research is:

There is a need to define the detailed required of a BIM model to calculate building material quantities for an accurate building material LCA assessment during sketch design. 


\section{I.3 Research Strategy}

\section{I.3.I The Research Problem, Aim, Question, And Hypothesis}

The building material LCA assessment process is too complex, causing poor and ineffective integration into building designer's sketch design processes, practices, and decisions. This has limited their use of the LCA framework as a design tool for assisting building designers to lower the environmental impact of building designs (Bribián, Usón, \& Scarpellini, 2009; Crawford, 20I I; International Energy Agency, 2004a).

BIM LCA tools have been developed, specifically to resolve these problems of poor integration of LCA into the design process. They have the requisite capabilities, but this research argues that they are used incorrectly, which causes excessive modelling time and effort, resulting in their failure to achieve effective integration. This incorrect use is caused by not having a robust methodology for how to use them to effectively integrate the LCA environmental framework for building materials into early concept/sketch design. Lacking a methodology, one must be developed.

Therefore, the aim of this thesis research is:

To improve the integration of LCA into the early phases of the design process (sketch design) by developing a methodology for using BIM LCA tools.

The fundamental principle in developing a methodology for the correct usage of BIM LCA tools is making the calculation process easier, by reducing modelling time, and maintaining required simulation accuracy for decision-making. Within the BIM LCA calculation process, constructing the BIM model to calculate building material quantities is the largest contributor to modelling time. The BIM model must be sufficiently detailed to produce accurate results, but simple enough to be quickly, and easily constructed. Defining how detailed a BIM model must be to achieve this, is the critical definition in developing a methodology for the use of BIM LCA tools that enables their effective into early concept/sketch design.

Therefore, the research question of this thesis is:

Using BIM To Calculate Accurate Building Material Quantities For Early Design Phase LCA 


\section{How detailed does a BIM model need to be to calculate accurate building} material quantities for a building material LCA (LCA) assessment?

The Building Research Association of New Zealand (BRANZ), is currently conducting a research project titled "Whole Building Whole of Life" (WBWL). The project is developing a type of LCA environmental framework (product category rules) for a New Zealand called Environment Product Declaration (EPD). The output of this study is a database of LCI material coefficients for New Zealand building materials, and products. 13 different LCIA, and 7 different $\mathrm{LCl}$-based environmental indicators have been identified as preferred outputs to help building designer facilitate sustainable design. However, at this time, the New Zealand construction industry does not have the building material or product coefficients for each of the 20 indicators. Developing these indicators, and simultaneously testing the detail required of a BIM model for each could easily form a thesis for each. Instead, this research focusses on a single LCl-based indicator, iEE ( $\mathrm{iEE}$ ), to prove the feasibility of using a BIM LCA tool to produce an accurate LCA-based result.

Therefore, the hypothesis of this thesis is that:

\section{Defining the accuracy required for EE (iEE) simulations, a BIM model of sketch design detail will calculate building material quantities accurately enough for a building material LCA assessment.}

Testing this hypothesis, the BIM calculated material quantities are compared to a Schedule Of Quantities (SOQ) that is defined as $100 \%$ accurate by normalising them both to iEE values. The iEE difference between the two is the measure of the BIM model's simulation accuracy. If high enough, this proves the BIM calculated material quantities are sufficiently detailed.

\section{I.3.2 The Research Scope}

Developing a methodology for how to use BIM LCA tools during sketch design focuses this thesis research scope on calculating building material quantities. Other problems such as inaccuracies in LCl material coefficients exist. However, it's the complexities involved in calculating building material quantities that is the largest obstacle effecting building designers. Therefore, this thesis tests the detail required of a BIM model to calculate the accurate 
quantities of building materials using iEE, not on an assessment of the environmental impact (LCIA), or the sustainability of any one building.

The complexity, and time restrictions of a master's thesis have prescribed scope restrictions to this research. These are discussed in the sections.

\section{Initial Embodied Energy And LCA}

Limiting the calculation of LCA results to only iEE effects the generalisability of the research conclusions defining the modelled detail required for a BIM LCA BPS. Different environmental indicators have different intensities of environmental consumption, and impact for the same materials. If this thesis hypothesis was tested for a different environmental indicator, for example Embodied Carbon Dioxide $\left(\mathrm{ECO}_{2}\right)$, the BIM LCA BPS may require a different level of modelled detail to achieve simulation accuracy requirements. The robustness testing in Chapter Section 6.4 assesses this risk to determine if it is a problem.

By using Alcorn's (2010) database of EE material coefficients, the scope of the resulting $\mathrm{iEE}$ assessment is defined by the scope of the hybrid process/input-output method of measuring the EE of building materials. This defines the iEE assessment as 'cradle to (factory) gate' assessment. All the life-cycle stages outside of the manufacturing phase e.g. construction, operation, and demolition are excluded. This is a common EE scope exclusion in published research.

\section{Simulation Accuracy}

At the core of BIM LCA integration issues and defining an iEE BPS model is simulation accuracy. In building performance simulation, accuracy is the measure of 'how close' simulation results (values) are to the measured performance of the building in reality. These measurements of reality are called the 'true values'. Simulation accuracy is the product of all the simulation errors in the simulation data inputs, and calculation processes. For building material LCA assessments, these are errors in the material coefficients, and the material quantities.

Neither LCA nor iEE have definitions for 'true value' or 'how close'. Chapter Section 5.5.3 defines the 'true value' of $\mathrm{iEE}$ consumption as the product of the multiplication of hybrid $\mathrm{EE}$ 
material coefficients by the building case study's 'truth model' SOQ database. Defining 'how close' is more ambiguous. It is governed by decision-making, building project performance goals, and the specific design process phase an iEE assessment simulation is being conducted in. The earlier in the design process, the less accuracy is required, as poorer design resolution, and the higher likelihood of design changes, both allow fine tuning of the design to meet performance goals. This thesis research uses the Mean Bias Error (MBE) values between $\pm 10-20 \%$, and Coefficient of Variation of Root Square Mean Error (Cv(RSME)) values between $15-30 \%$ as the metrics for describing, and assessing simulation accuracy, and precision respectfully. The MBE values are derived from cost planning requirement for sketch design phase assessment. This is the most appropriate basis for LCA, and iEE. The $\mathrm{Cv}(\mathrm{RSME})$ is from OE calibration.

\section{Truth Model Material Quantities Database}

The completeness of the 'truth model' database of building material quantities is a scope limitation. This database is not a complete inventory of every individual material, or building product used in the final building. It was assembled to a level of completeness to meet existing best practice standards. Therefore, calibrating the iEE BIM LCA BPS models to match, defines them as accurate to the current best practice methods for calculating a building's material quantities. A study of how detailed building material quantities must be for an iEE assessment is a separate research question. Answering this question would redefine established best practices. This is not the aim of this thesis. This thesis' intent is to make achieving best practice easier.

\section{BIMs (BIM) And Interoperability}

The BIM models developed in this thesis correspond to BIM maturity level 2. A fully interoperable level $3 \mathrm{BIM}$ model was not required, as project sharing between different project participants was not needed. Consequently, interoperability supporting BIM standards such as IFC, and IFD, were not adhered to. Instead the native file structure of the selected BIM tool, AutoDesk's Revit 2014 was used. This has no effect on testing the level of detail required of the BIM model to calculate accurate building material quantities. 
Conclusions drawn from the New Zealand National BIM Survey (Construction Information Ltd, 2013) state the New Zealand construction industry does not currently use BIM maturity level 3 BIM models. This thesis' intent is to develop conclusions that can be used in current industry practices. As a result, level 3 BIM is not appropriate. Currently the New Zealand construction industry lacks the tools required to use of level 2 BIM models to their full capabilities. Lacking are tools and standards such as; an ISO 12006-2 compliant building classification system; a national BIM standard; a standard defining of BIM level of detail; and a national BIM library of objects with metadata product information embedded in the BIM objects. Where necessary to test this thesis hypothesis, has used standards such as the UK's UniClass 2.0 (an ISO 12006-2 compliant building classification system), and the USA's Level of Development Specification For BIMs (Level of Development Specification, 20I3) have been used.

\section{Design Process}

Since no two buildings are the same the unique nature of buildings compared to other mass produced products, means defining a single design process that describes all building projects is impossible. Each is different to cater to the unique challenges and performance requirements of a building. This thesis develops a functional definition of the design process based on generic building design frameworks such as; the American Institute of Architects (AIA) (American Institute of Architects (AIA), 2007); the Royal Institute of British Architects (RIBA) Plan of Work prior to 2013 (Ostime, 20I3); and the New Zealand Construction Industry Council (NZCIC) (New Zealand Construction Institute Council (NZCIC), 2004). This working definition defines the for this thesis' methodology the information available at each phase of the design process.

The design process defines the information about building form, construction, and materials, at each phase of the design process. This information is used to construct BIM models to test if the information produced by existing design processes and practices used by the building design team in the early phases of the design process is detailed enough to produce an accurate LCA result. This determines at what phase of the design process BIM LCA can be integrated. As an alternative to defining the design process, accessing the specific building documentation for each phase to determine the information available at each phase would 
remove this potential error. However, this would not be transferable to other building projects due to the unique nature of building projects, project design teams.

Using the functional definition of the design process means there will be discrepancies between the information this thesis has assumed to be available, and the information that is available in other building projects. This may affect the iEE assessment simulation accuracy possible at each phase of the design process. Checking the influence of using the functional definition of design process compared to the actual design process documentation was not possible due to data restrictions. The original sketch, concept, and developed documentation were no longer available to construct BIM model representations.

\section{Sketch Model Detail}

The BPS concept is a solution to the problem of poor integration of LCA due to excessive LCA calculation complexity. It directs the development of a method for how to use BIM LCA tools to construct a BIM model faster, and easier. This is to reduce LCA calculation complexity, whilst ensuring the simulation results produced are accurate enough for informed decision-making. This BIM model is called a BIM LCA BPS (BIM LCA BPS) model. A BIM LCA BPS model is not a fully detailed representation of a whole building. It is simplified to only include:

- The building elements that are influenced by the design decisions that building designers must make in the early phases of the design process to be effective for lowering a building's environmental impact.

- The building elements that can be calculated in existing BIM LCA tools. Currently, neither the BIM LCA tools, IMPACT or Tally, can calculate LCA results for building services. This is due to a lack of robust and comprehensive LCA data on building services components (IMPACT, n.d.; KT Innovations, PE International, \& AutoDesk, 2014).

This limits the scope of the BIM LCA tool's LCA assessment to only the building elements listed in Table I.3.2. Different researchers have different scopes, and therefore different level of completeness in their iEE LCA assessments. With no definition of best practice available, completeness levels can vary considerably. A literature review of published LCA and iEE 
research case studies identified the scope depends on the individual researcher, who often for practicality reasons excludes certain building elements from the assessment. For example, the researchers Treloar et al., (200I) and Y. L. Langston \& Langston (20I2) reported iEE studies of Australian buildings at an element level breakdown, averaged to $11.7 \mathrm{GJ} / \mathrm{m} 2$ and $25.0 \mathrm{GJ} / \mathrm{m} 2$ respectfully. The large difference between the two figures is due to differences in the completeness, and the scope of their respective iEE assessment. Treloar et al., (200I) states for practicality reasons, only 14 building elements were assessed, compared to $Y$. L. Langston \& Langston's (20I2) 43. Accounting for these differences, and comparing only the same building elements, their respective figures are $11.0 \mathrm{GJ} / \mathrm{m} 2$ and $12.2 \mathrm{GJ} / \mathrm{m} 2$. This equating to a difference of $9.8 \%$. This is a difference acceptable in areas of building performance such as operative energy, and cost planning, for what is considered reasonable.

Table I.3.2 applies the BIM LCA BPS framework to Y. L. Langston \& Langston (20I2) reported $\mathrm{iEE}$ results to determine if the BIM LCA BPS represents a large enough proportion of total iEE to be useful for decision-making. The results show that the elements defining a BIM LCA BPS contribute $40.1 \%$ of the iEE and $9.2 \%$ of the recurrent iEE of a whole building e.g. all 25 building elements (excluding all building service elements) (Y. L. Langston \& Langston, 2012). While not a complete building, the $40.1 \%$ still represents a significant proportion of a building. The low recurrent iEE shows decisions about these building elements that are made in the early phases of the design process, have long last environmental impacts.

Table 1.3.2: The BIM LCA BPS Framework Applied To Y.L. Langston \& Langston (20I2)

Source: Adapted from Table 3: Statistical Summary for EE by Element (Y. L. Langston \& Langston, 2012, p. 13).

\begin{tabular}{|c|c|c|c|c|c|c|}
\hline \multicolumn{3}{|c|}{ AIQS 2002 Classification } & \multicolumn{2}{|c|}{ Initial Embodied Energy } & \multicolumn{2}{|c|}{ Recurrent Embodied Energy } \\
\hline $\begin{array}{l}\text { Building } \\
\text { Element } \\
\text { Number }\end{array}$ & Building Element Name & $\begin{array}{c}\text { Building } \\
\text { Element } \\
\text { Code }\end{array}$ & Mean GJ/m2 & $\begin{array}{c}\text { Element } \\
\text { Proportion } \\
\text { Total Mean } \\
\text { (all } 25 \\
\text { Elements) } \\
\end{array}$ & Mean (GJ/m2) & $\begin{array}{c}\text { Element } \\
\text { Proportion } \\
\text { Total Mean (all } \\
25 \text { Elements) }\end{array}$ \\
\hline 5 & Roof & $\mathrm{RF}$ & 2.3 & $10.6 \%$ & 0.62 & $2.1 \%$ \\
\hline 1 & Substructure & SB & 2.3 & $10.5 \%$ & 0.00 & $0.0 \%$ \\
\hline 6 & External Walls & EW & 1.6 & $7.5 \%$ & 1.18 & $3.9 \%$ \\
\hline 3 & Upper Floors & UF & 1.6 & $7.4 \%$ & 0.00 & $0.0 \%$ \\
\hline 7 & Windows & WW & 0.5 & $2.3 \%$ & 0.94 & $3.1 \%$ \\
\hline 2 & Columns (Framed Buildings) & $\mathrm{CL}$ & 0.4 & $1.7 \%$ & 0.00 & $0.0 \%$ \\
\hline \multicolumn{3}{|c|}{ Total of all Building Elements Influenced by Sketch Design } & 8.6 & $40.1 \%$ & 2.74 & $9.2 \%$ \\
\hline
\end{tabular}

Using BIM To Calculate Accurate Building Material Quantities For Early Design Phase LCA 


\section{BIM Modelling Time}

The measurement, and assessment of BIM modelling time is excluded from this research scope. Despite being an important factor in the IEE BIM LCA BPS for improving the integration of LCA into sketch design, modelling time is hugely biased by the individual modeller's level of experience with the BIM tool, as well as the complexity of the building being modelled. The modeller for this thesis research (Brian Berg), has prior experience in BIM modelling using Graphisoft's ArchiCAD BIM tool, but none with Revit. This means the modeller has an understanding of the principles of BIM modelling, but lacks the specific knowledge of the actual BIM tool (Revit) used for this research. This thesis' modelling time is therefore be biased due to his inexperience. This makes it is impossible to draw confident conclusions of the time required to construct an iEE BIM LCA BPS model from only a single sample size e.g. one building, and one modeller.

The modelling time savings enabled by the iEE BIM LCA BPS are the reduction in model detailed required, and the fact that a BIM model produced during sketch design, based on only the information available at sketch design can produce an accurate iEE or other LCAbased result. This means that building designers can simply use the BIM models they already construct for LCA building performance assessment, with very minimal additional modelling work required.

\section{I.4 Significance Of Study}

One intended outcome of this research, is the development of a reliable, and consistent methodology for calculating accurate building material quantities. Proven through EE calibration, the iEE BIM LCA BPS method is quality assured to produce material quantities to a detail equivalent to current best practice methods. On a practical level, the primary outcome is the definition of the detail required of a BIM model. This definition can be used in existing BIM LCA tools such as IMPACT (IMPACT, n.d.), and Tally (KT Innovations et al., 20I4). This research identified the problem where not defining the required BIM model detail limits the effectiveness of these tools to act as Early Design Decision Support Tools (EDDST). These tools show a BIM model detailed for building construction accuracy. Not one defined by LCA accuracy as this thesis research does. Constructing the BIM model on non LCA based research may result in inaccurate simulations, or simulations that take too 
long to be effective as early design phase assessment tools. Evidence from literature review research supports the identified need for accurate simulation results to improve early design phase building performance assessment (Bribián et al., 2009; Donn, Selkowitz, \& Bordass, 2012).

An immediate application of the developed methodology for using BIM to calculate accurate building material quantities is the contribution to the BRANZ Whole Building Whole of Life research project. The contribution to the Whole Building Whole of Life research project is centred on their second research question: "What would be an appropriate office building benchmark to provide the reference case for whole building whole of life assessment in New Zealand?" (Dowdell, 2013, p. 55). Developed using iEE, this methodology is suitable for calculating material based LCl's and LCIA for whole building LCA assessments. This is the methodology for calculating the material quantities of their benchmark buildings.

A secondary outcome of this thesis is a methodology of calculating accurate iEE results in the early phases of the design process. This is important for minimising a building's EE consumption, as once the building is constructed, the iEE consumption is made. Recurring EE from maintenance and replacement of material is also committed too. This highlights the importance of making EE informed design decisions early in the design process as their impact extends to the lifespan of the building.

Despite traditionally being a small part of the building lifecycle energy consumption, EE is important to sustainable design. Findings from various studies (Ibn-Mohammed, Greenough, Taylor, Ozawa-Meida, \& Acquaye, 2013; Treloar, McCoubrie, Love, \& lyer-Raniga, 1999; Yung, Lam, \& Yu, 20I3) have suggested in non-residential commercial office buildings the contribution of iEE is $10.47 \mathrm{GJ} / \mathrm{m}^{2}$ of Gross Floor Area (GFA). This is approximately $15 \%$ of the total lifecycle energy consumption of a building over 50 years, or the equivalent 7.8 years of annual operative energy (Yung et al., 20I3, p. 49). Researchers often argue that the construction industry's move towards low or zero operative energy buildings will make EE calculations more important (International Energy Agency, 2004b). This is true, where a building with low, or even zero operational energy, but high iEE may not necessarily be the best option from an environmental sustainability perspective. However, evidence from literature (Berggren, Hall, \& Wall, 20I3) shows that when operative energy consumption is 
lower than $45 \mathrm{kWh} / \mathrm{m}^{2}$ in non-residential commercial office buildings the iEE exceeds $50 \%$ of life cycle energy. 
Chapter Two:

\section{CALCULATING ENVIRONMENTAL IMPACT IN THE BUILT ENVIRONMENT}

\section{I Chapter Intent}

An increasing awareness of the building industry's environmental impact is driving the shift towards sustainable building design. This is changing the way the buildings are designed, constructed, and operated. More than ever, building designers are required to consider the environmental impact of their design decisions as part of the building design process. With this change, new tools, and design practices are required to assist building designers in making design decisions to lower the environmental impact of their building designs. LCA (LCA) is one method for doing this.

The previous Chapter introduced the background context, and the research strategy of this thesis. It stated, that due to the poor integration of BIM LCA tools into the early phases of the design process, LCA is rarely used by building designers. The aim of this Chapter is to develop a set of requirements, that when satisfied, will ensure LCA is effectively integrated into the sketch design phase. The information gained from this Chapter will under-pin the development of a methodology for how to correctly use BIM LCA tools for sketch design phase building material assessments, making it an effective early design decision support tool (EDDST).

This Chapter aim will be met by exploring the ideas behind what building designers require of an early design decision support tool, the building material LCA calculation process, and a critique of existing BIM LCA tools. Structurally, this Chapter consists of five sections to meet this Chapter aim. Chapter Section 2.2 examines the measurement, calculation, and design decisions building designers face as part of the building design process for more sustainable buildings. Chapter Section 2.3, and 2.4, discuss the problems with the existing LCA calculation process and the BIM LCA tools that have been developed to solve them. 
Subsequently, Chapter Section 2.5, discusses how BIM LCA tools must be used to be effective, developing a set of requirements with simulation accuracy, and building material quantities the predominate areas of focus. This is the development of the requirements for effective integration, and the framework for structuring the methodology for their use. Finally, Chapter Section 2.6, examines the specific problem of excessive modelling time, for calculating building material quantities from a BIM model. This leads onto the development of the research design in Chapter 3.0.

\subsection{Calculating And Designing To Reduce A Building's}

\section{Environmental Impact}

\subsection{What Is Environmental Impact?}

An environmental impact is a change and the associated consequences to the environment, caused by the direct activities of the development and production of a product or service (Sidoroff, 2004b, p. 6). An environmental impact is measured by the environmental indicators produced as part of an environmental framework (Alcorn, 20I0; Crawford, 20I I).

Environmental frameworks, such as LCA (LCA), provide a consistent, and comprehensive system, for measuring and describing the environmental impact caused by the manufacturing, construction, operation, and demolition activities throughout the life cycle of building (International Energy Agency, 2004b, p. I).

The building industry is becoming more aware of the environmental impact of buildings. A building's total lifespan is divided into four lifecycle stages separated by system boundaries; manufacturing, construction, operation, and demolition. In most building LCA studies, the focus is limited to calculating the environmental impact and indicators of the manufacturing, and operational phases. Table 2.2.I shows throughout the four lifecycle stages the difference between the indirect energy consumed and sequestered in building materials (EE), and the direct energy consumption (operative energy). 
Table 2.2.1: Building Energy Consumption Throughout The Different Life Cycle Stages

Sources: (Alcorn, 2010; Manish K. Dixit, Culp, \& Fernández-Solís, 2013; Manish K. Dixit, Fernández-Solís, Lavy, \& Culp, 20I2; Manish Kumar Dixit, Fernández-Solís, Lavy, \& Culp, 2010; Yung et al., 2013)

\begin{tabular}{|c|c|c|}
\hline Building Lifecycle Stage & $\begin{array}{l}\text { Indirect Energy: The EE } \\
\text { of Building Materials }\end{array}$ & $\begin{array}{l}\text { Direct Energy: } \\
\text { Operative Energy } \\
\text { Consumption }\end{array}$ \\
\hline $\begin{array}{l}\text { Manufacturing: } \\
\text { Cradle to Factory Gate }\end{array}$ & $\begin{array}{l}\text { Creating raw building } \\
\text { materials and products. }\end{array}$ & None. \\
\hline $\begin{array}{l}\text { Construction: } \\
\text { Including transport of raw } \\
\text { building materials and } \\
\text { products to site. }\end{array}$ & $\begin{array}{l}\text { Using the raw materials and } \\
\text { products, and constructing } \\
\text { them into building elements, } \\
\text { or components that make } \\
\text { up the finished building } \\
\text { product. Construction and } \\
\text { transport adds an additional } \\
4 \% \text { and } 10 \% \text { respectfully to } \\
\text { the total iEE (Yung et al., } \\
20 \mid 3) \text {. }\end{array}$ & Site operative energy. \\
\hline Operation & $\begin{array}{l}\text { Maintenance, and material } \\
\text { replacement. }\end{array}$ & $\begin{array}{l}\text { Running building equipment, } \\
\text { e.g. lighting, appliances, } \\
\text { computers, Heating, } \\
\text { Ventilation, Air- } \\
\text { conditioning, and Cooling } \\
\text { (HVAC). }\end{array}$ \\
\hline Demolition & $\begin{array}{l}\text { Removal, disposal, and } \\
\text { decomposition of building } \\
\text { materials. }\end{array}$ & Site operative energy. \\
\hline
\end{tabular}

Using BIM To Calculate Accurate Building Material Quantities For Early Design Phase LCA 


\section{Embodied And Operative Energy}

Embodied Energy (EE) is the energy consumed in all activities necessary to support a process, and comprises of two primary components, a direct and an indirect component (Baird \& Chan, 1983; Manish Kumar Dixit et al., 2010). In context of the building industry, direct energy is energy consumed onsite and offsite by processes such as construction, prefabrication, assembly, transportation and administration. Whereas, indirect energy is the energy consumed in manufacturing building materials, renovation, refurbishment and the demolition and disposal of the building materials (Manish Kumar Dixit et al., 2010).

A building's energy consumption is viewed as the most important environmental indicator, and subsequently, it is the most commonly reported (International Energy Agency, 2004b, p. 3). Typically, in the majority of the existing building stock, the operational lifecycle stage has, and continues to have, the largest environmental impact accounting for about half of the total energy consumed by developed countries (International Energy Agency, 2004b, p. 3).

Depending on a building's typology characteristics, in commercial office buildings for example, operative energy can be represent approximately $85 \%$ of the total energy at the end of a 50 year lifespan, with EE accounting for $15 \%$ which includes transport $0.5 \%$, and construction 1.3\% (Berggren et al., 2013, 2013; Ibn-Mohammed et al., 2013; Treloar et al., 1999; Yung et al., 2013). Expressed as a number of years of total annual operational energy (approximately $81.7 \mathrm{kWh} / \mathrm{m} 2 \mathrm{GFA}$ ), the EE is 7.8 (Yung et al., 2013, p. 49). 


\subsubsection{The Building Design Process And Informed Decision-Making}

\section{The Building Design Process}

Design is a process for problem solving, capable of producing an infinite number of different solutions to a single problem (Haponava \& Al-Jibouri, 2010; Lawson, 2006). Building design frameworks suggest what design decisions to consider, and when those decisions should be made by to deliver a successful building (Löhnert, Dalkowski, \& Sutter, 2003). There are many different building design frameworks available. Despite their differences, they all are tools to assist the administration, and management of building projects, to achieve the best built outcome in regards to the project goals and time, cost and quality (Emmitt, 2007). As such, they all generally align with one another. Tables 2.2 .2 shows this alignment for a sample collection of different building design frameworks. This presents the working definition used in this thesis research for describing the building design process, and each design phase. 
Table 2.2.2: Design Phases for Different Building Design Frameworks

\begin{tabular}{|c|c|c|c|}
\hline \multicolumn{2}{|c|}{$\begin{array}{l}\text { TRADITIONAL BUILDING DESIGN } \\
\text { PROCESS FRAMEWORKS }\end{array}$} & \multicolumn{2}{|c|}{$\begin{array}{l}\text { INTEGRATED PROJECT DELIVERY } \\
\text { (IPD) / EARLY DESIGN BUILDING } \\
\text { DESIGN FRAMEWORKS }\end{array}$} \\
\hline $\begin{array}{l}\text { NZ Construction } \\
\text { Industry Council *I }\end{array}$ & $\begin{array}{l}\text { American Institute of } \\
\text { Architects (AIA) } * 2\end{array}$ & $\begin{array}{l}\text { RIBA Plan of Work } \\
2013 * 3\end{array}$ & $\begin{array}{c}\text { AIA Integrated } \\
\text { Project Delivery } * 4\end{array}$ \\
\hline \multicolumn{2}{|c|}{ Defining client, and project design problems, requirements, as project performance goals. } & & \\
\hline- & - & Strategic Definition & Conceptualization \\
\hline \multicolumn{4}{|c|}{$\begin{array}{l}\text { The development, and testing, of different building design iterations comprising of different building solutions for } \\
\text { solving design problems and achieving project performance goals. Design concepts are developed into firm } \\
\text { schemes, where the relationship and size of spaces, and facilities is defined, but limited to only key building } \\
\text { elements. At the conclusion of this phases, a concept design is selected. }\end{array}$} \\
\hline Preliminary Design & Schematic Design & Concept Design & Criteria Design \\
\hline \multicolumn{4}{|c|}{$\begin{array}{l}\text { The selected concept design is developed so each component, not just key elements is clearly defined. Typically, } \\
\text { sketch details are produced. }\end{array}$} \\
\hline Developed Design & Design Development & Developed Design & Detailed Design \\
\hline \multicolumn{4}{|c|}{$\begin{array}{l}\text { Building documentation such as plans, and specifications are produced for all building elements to not to a level } \\
\text { that they are directly be able to be 'built' from. Design variations to anything but detail at this phase are very } \\
\text { disruptive and expensive and often result in further problems, as the project has become very complex and it is } \\
\text { hard to identify all the ramifications of changes. Detailed design is the phase most commonly used to obtain a } \\
\text { tender for the construction of the works. }\end{array}$} \\
\hline Detailed Design & Construction Documents & Technical Design & $\begin{array}{l}\text { Implementation } \\
\text { Documents }\end{array}$ \\
\hline \multicolumn{4}{|c|}{$\begin{array}{l}\text { Notes: } \\
* \text { * (New Zealand Construction Institute Council (NZCIC), 2004) } \\
\text { *2 (American Institute of Architects (AIA), 2007, 2008) } \\
\text { *3 (Ostime, 20I3) } \\
\text { *4 (American Institute of Architects (AIA), 2007) }\end{array}$} \\
\hline
\end{tabular}

Using BIM To Calculate Accurate Building Material Quantities For Early Design Phase LCA 


\subsubsection{Informed Decision-Making, Building Performance Simulation Tools, And The Design Process}

For building designers, decision-making to select building solutions to lower environmental impact, are defined by project performance goals. These define when, and what makes a building design iterative successful. Performance goals are a requirement of all building design frameworks. To set performance goals, the main criteria, sub criteria, and the performance indicators must be defined. Figure 2.2.3a illustrates the relationship of these terms. Each describes a performance goal in an increasingly specific quantifiable units of measurement, concluding with performance indicators. These evaluate whether, or how well a design iteration (a collection of building solutions) achieves the performance goals. Developing a good design requires calculating building performance indicators to solve both the sub and main criterion. This is called an integrated solution (Attia, 2012; Donn et al., 2012; International Energy Agency, 2004a).

\section{Figure 2.2.3a: Structure of Performance Criteria}

Adapted from Figure titled Describe, Select and Structure Criteria (International Energy Agency, 2002, p. 8)

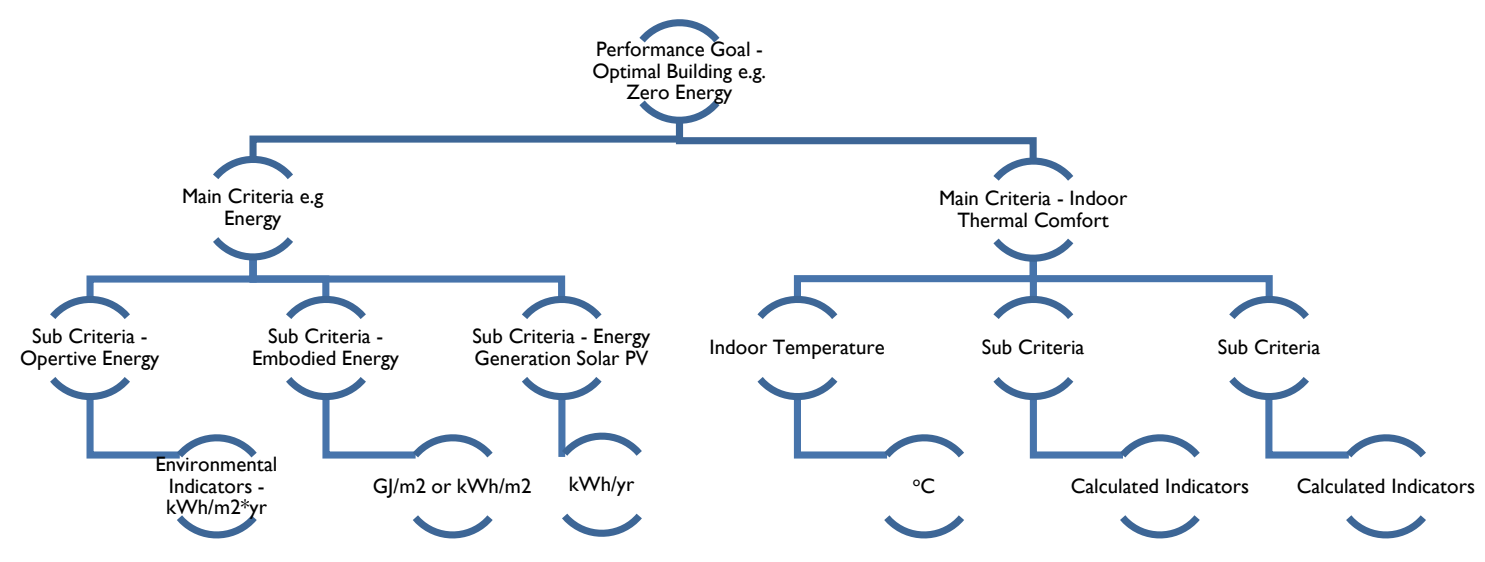

Environmental impact is one facet of building performance, with iEE and OE both being examples of performance indicators. Building performance simulation tools calculate performance indicators prior to the building's construction and operation. They are most effective for assisting with decision-making during sketch design. Figure 2.2.3b shows this is 
when the effective ability of a building designer to make design decisions is highest, while the cost of implementing these decisions is at its lowest (American Institute of Architects (AIA), 2007; Donn et al., 2012; Emmitt, 2007; International Energy Agency, 2004a; Löhnert et al., 2003). This is a trend in building performance simulation called the MacLeamy concept.

Figure 2.2.3b: The MacLeamy Concept

Source: (American Institute of Architects (AIA), 2007; Donn et al., 20I2; Löhnert et al., 2003)

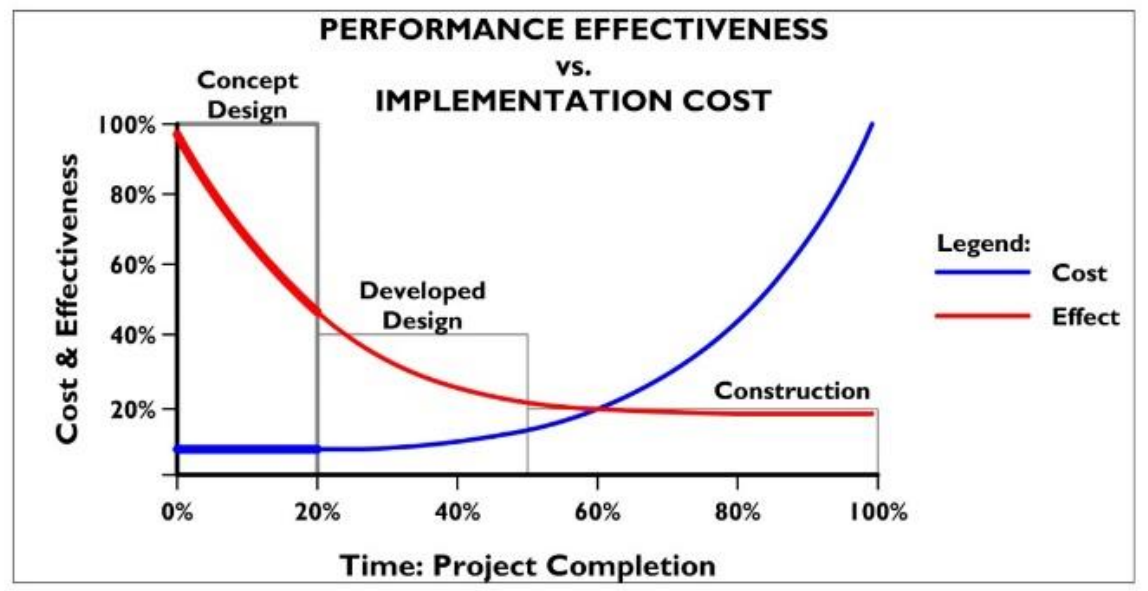

\subsection{The Problem With Existing Building Material LCA}

\section{Assessments}

Process Integration (hereby referred to as integration) deals with the functional integration of design tools into the design process (Augenbroe, 2002, p. 892). It is the development of methods for how to most effectively use a simulation tool for a specific purpose, within a specific phase of the building design process, and within specific design activities. These are all key ideas in the MacLeamy concept for the effective use of building performance simulation tools.

The poor integration of LCA has led to these assessments of building materials not being conducted until after sketch design, making LCA an ineffective design tool. The principle is the excessive complexities in conducting a building material LCA assessment. This has meant that the information needed to conduct a building material LCA assessment has not been 
readably available for building designers during sketch design (Alcorn, 2010; Bribián et al., 2009; Crawford, 20I I; Optis \& Wild, 2010; Sidoroff, 2004a; Yohanis \& Norton, 2006; Yung et al., 2013).

The LCA calculation process itself is simple. As equation I shows, it is the multiplication of building material coefficients by building material quantities. As a result, the complexities associated with calculating the building material coefficients, and building material quantities are the root cause of poor integration, and LCA being ineffective.

\section{Equation I: Whole Building Material LCA Assessment $\left(C_{i}\right) *\left(Q_{i}\right)=$ WBLCA}

$\begin{array}{ll}\begin{array}{ll}\text { Building Material } \\ \text { Coefficients }\end{array} & \begin{array}{l}\text { Building Material } \\ \text { Quantities }\end{array} \\ C_{i} & Q_{i}\end{array}$

Whole Building Material LCA

$=$ Results of $\mathrm{LCl}$ environmental consumption

WBLCA

The complexities of calculating building material coefficients, and building material quantities, has meant these roles have traditionally been provided by specialist consultants acting as consultant members of the design team. A LCA practitioner calculates the LCI material coefficients, and a Quantity Surveyor (QS) calculates the building material quantities. In this capacity, the influence of LCA results on the building's design is limited. Often this LCA is not conducted until the later phases of the design process, by which time the building design is mostly resolved. Therefore, the scope of the LCA is limited to an analysis of a flawed design, and the ability to integrate effectual design changes is limited. Instead, building material LCA needs to be conducted by AEC practitioners who have direct control over the building design from the very beginning (Bribián et al., 2009). Architects and engineers are ideally suited (Bribián et al., 2009). They are involved in the earliest stages of the building project's conception, and have direct influence on the building design throughout the design process. They make the design decisions surrounding the type, and quantities of materials used in a building through material selection for aesthetics, durability, quality of finish, and the built form's spatial design efficiency. This compliments the idea presented by Y. L. Langston \& Langston (2008), where, the best and simplest strategy for reducing the environmental impact of building materials is simply, building less. 
To facilitate architects, and engineers (hereby referred to as the design team) conducting building material LCA in the early phases of the design process, the complexities of the calculation process must be reduced. Building material LCA tools are the solution. However, simply developing building material LCA tools does not ensure they integrate effectively. Effective integration (hereby referred to simply as integration) into the early phases of the design process as per the MacLeamy concept, means developing tools that are adapted to fit within the day-to-day realities of work practices, processes, and into building design tools building designers actually use (Augenbroe, 1992, 2002; Donn et al., 2012; International Energy Agency, 2004a). They must be capable of rapidly testing different design iterations, whilst ensuring the simulation results are accurate and trusted enough to enable the design team to make informed design decisions to achieve project performance goals (Augenbroe, 1992, 2002; Donn et al., 2012; International Energy Agency, 2004a)

\subsection{Reducing Building Material LCA Calculation Complexity}

Reducing the complexity of the building material LCA calculation process requires making the calculation process easier, without comprising simulation accuracy. Existing LCA tools reduce complexity by making it easier for building designers to access the two inputs in the building material LCI calculation process (equation I); building material coefficients, and building material quantities. This divides LCA tools into two categories; those that focus on building material coefficients; and those that calculate building material quantities, such as material coefficient LCA tools; and those that calculate building material quantities and multiply them by material coefficients. These are called whole building assessment tools. There are two types, those that are BIM based, and those that are not.

\subsubsection{LCA Tools For Calculating Building Material Coefficients}

Material coefficient LCA tools calculate $\mathrm{LCl}$ and LCIA results of individual building material and products. They are databases of $\mathrm{LCl}$ coefficients for common building materials and products. They alleviate integration problems by improving the accessibility of building $\mathrm{LCl}$ material coefficients. In the past, conducting a building LCA also required developing the necessary LCl material coefficients. This limited building LCA to specialist building researchers. The advent of building material LCA databases removes this requirement. This 
makes the calculation process much easier than traditional LCA practices, widening the scope of use to building designers.

Accuracy and data quality issues are minimised as databases use best practice calculation methodologies such as the ISO I4040 series, EDP, and quality assurance processes, to calculate material and product coefficients. However, there are now many different databases of $\mathrm{LCl}$ material coefficients. Factors such as age of the database, and the country of origin effect the suitability of their use in specific contexts (Huijbregts, 1998; Sidoroff, 2004a; Weidema \& Wesnæs, 1996) making their selection a critical decision building designers must make. Research has proven that using LCA databases that are do not match the country where the building materials are produced has a significant impact of the LCA results, and therefore design decision-making (Nebel, n.d.). The problem exists in current LCA practices, that there is no tool that assists building designers with making with choice. This is a contributing cause of excessive LCA calculation complexity. Therefore as part of this thesis to improve LCA integration into sketch design, a tool for assisting building designers with making this decision must be developed.

Issues with the material coefficient calculation methods are still debated by LCA researchers. However, a consensus has been reached, where standard best practice requires a building designers to simply select and use an appropriate database to access the required material coefficients for their building designs. In this way, material coefficient LCA tools do not solve LCA coefficient calculation methodology issues. Instead they remove complexity by simplifying and organising the calculation process as it pertains to material coefficients (Bribián et al., 2009; Crawford, 201 I).

\subsubsection{BIM LCA Tools}

BIM LCA tools such as IMPACT (developed by the British Research Establishment (BRE)) and Tally (developed by KT Innovation's and supported by PE International and AutoDesk) (IMPACT, n.d.; KT Innovations et al., 20I4) are plugin applications, integrating the Ecoinvest (IMPACT) and GABI (Tally) material coefficient LCA tools into Autodesk's Revit BIM tool.

BIM LCA tools were developed to reduce building material LCA calculation complexity by making the calculation of building material quantities, and the specification of LCl material 
coefficients to those quantities easier. Consequently, by integrating building material LCA into a BIM tool, this enables these calculations to be conducted using design tools building designers already use, which greatly improves the integration of building material LCA into the design process.

The calculation of building material quantities using a BIM model and tool to calculate material quantities is the most important complexity reducing improvement provided by a BIM LCA tool. The calculation process is the same for any other BIM model with non-geometrical functional information called metadata embedded within BIM objects. The building designer constructs the BIM objects, assigns the LCI material coefficients metadata to each material, and then assembles (modelling) the BIM objects into the building's overall form to makeup the BIM geometry (Hjelseth, 20I0, p. 280). The BIM objects define which materials and $\mathrm{LCl}$ material coefficients are used in the building, and the BIM geometry, the information for how much materials and material coefficients are used in the building (IMPACT, n.d.; KT Innovations et al., 20I4). Finally, building material quantities are calculated from the completed BIM model (e.g. the BIM objects and geometry) and multiplied by the LCI material coefficient specified using BIM tool's proprietary material quantities calculation tool. This process is illustrated in equation 3. 
Equation 3: BIM LCA Tool Calculation Process $\left(C_{i}\right) *\left(Q_{i}\right)=W B L C I$

\begin{tabular}{|c|c|c|c|}
\hline Equation I: & $\begin{array}{l}\text { Building Material } \\
\text { Coefficients } \\
\qquad \mathrm{C}_{\mathrm{i}}\end{array}$ & $\begin{array}{c}\text { Building Material } \\
\text { Quantities } \\
\mathrm{Q}_{\mathrm{i}}\end{array}$ & $\begin{array}{c}\text { Whole Building LCl } \\
\text { Results } \\
\text { WBLCl }\end{array}$ \\
\hline $\begin{array}{l}\text { Equation 3: } \\
\qquad \text { BIM } \\
\text { Calculation } \\
\text { Process }\end{array}$ & $\begin{array}{l}\text { LCA database e.g. } \\
\text { integrated use of } \\
\text { ATHENA Level I } \\
\text { LCA tool. }\end{array}$ & $\begin{array}{l}\text { Calculated from the } \\
\text { BIM objects and BIM } \\
\text { geometry assembled } \\
\text { into a BIM model of } \\
\text { the building's form } \\
\text { using the BIM tools } \\
\text { proprietary material } \\
\text { quantities calculation } \\
\text { tools. }\end{array}$ & $\begin{array}{l}\text { The automated } \\
\text { calculation result. }\end{array}$ \\
\hline
\end{tabular}

\subsection{How Effective Are BIM LCA Tools?}

\subsection{Are BIM LCA Tools Capable Of Improving Integration?}

BIM LCA tools reduce calculation complexity to solve the problems of poor integration by enabling the calculation process to be conducted in a BIM tool. This improves the accessibility of $\mathrm{LCl}$ material coefficients, and building material quantities. Using the BIM tool enables the design team to calculate building material quantities, and assign LCA material coefficients, using a design tool they already use, and are familiar with. This integrates LCA into a design team's existing skills, knowledge base, and daily work practices and processes, enabling LCA calculations to be conducted much easier and quicker. Consequently, this removes the need for specialist LCA practitioners, and QS consultants, and reduces the need for specialised knowledge extending only to being able to assign material coefficients based on matching material descriptions.

BIM LCA tools have all the functional capabilities to be effective and well integrated into sketch design. They fulfil many of the requirements defined by numerous researchers 
(Augenbroe, 1992, 2002; Donn et al., 2012; International Energy Agency, 2004a) for what makes design tool effective during sketch design. However, being capable of calculating results more easily does mean a BIM LCA tool satisfies these requirements. The critical issue is answering are BIM LCA tools effective at improving integration, is answering; are BIM LCA tools used correctly so they produce accurate simulation results quickly?

\subsubsection{BIM LCA Tools, Capable But Used Ineffectively}

The way BIM LCA tools are used, or misused is causing the outstanding issues of poor integration, and calculation complexity. To date, no research has established if the existing methods of using BIM LCA tools can produce accurate simulation results. However, an assessment of whether they satisfy the other requirements of effective integration is possible. Integrating LCA into BIM also integrates the BIM concept for how to use a BIM tool. The BIM concept is a form of process integration prescribing how to use BIM tools and models within the design process (Augenbroe, 2002, p. 892). It advocates using interoperability to integrate the use of BIM tools and models into the early phases of the design process in compliance with the ideas the MacLeamy concept.

The interoperability capabilities of the BIM tool and model make this integration possible (Augenbroe, 2002). BIM interoperability has two facets, technology, and culture. From the technology perspective, interoperability is the ability of computer programs to communicate electronic data and information, and to manage the use of this information (Grilo \& JardimGoncalves, 2010, p. 525; Jones, 2007, p. 4). The cultural perspective is interpreted differently as, "the ability to implement and manage collaborative relationships among members of crossdisciplinary build teams that enables integrated project execution” (Jones, 2007, p. 4).

Although technology based interoperability is an important part of simulation tool integration, it is still only the means to assist doing what is required (Augenbroe, 2002). The cultural perspective links the technology that is interoperability, with the need for structuring how, what, and when to use it within the design process, design activities, and design team. This is the true integration of BIM into the design process (Augenbroe, 2002). Being BIM capable, BIM LCA tools are capable of both of these types of integration. The BIM model and tool has 
full technology interoperability capabilities, but it is the BIM concept that dictates how to use the BIM LCA tool.

Arguably, the BIM concept's interoperability decreases building performance simulation time by improving knowledge sharing between the design team members through the use of a single integrated BIM (iBIM) Level 3 maturity model.

The iBIM model reduces simulation time in the iterative testing/improvement or refutation process (Donn et al., 2012, p. 188). This is the process of creating the initial BIM model of the building's design (the conjecture), then testing design solutions, accepting or rejecting them based on their performance. From the initial BIM conjecture model, all the information for all building performance assessments can be extracted. Using two-way interoperability, where communications from either program can be used to change an update the other with no loss of information (Pazlar \& Turk, 2008, p. 378), each building performance conjecture model can be automatically created for each specific area of building performance, for each simulation program. This is called a BIM performance 'view' (Donn et al., 20I2, p. 190). Iterative analysis of the initial conjecture is conducted in each simulation program identifying the best design solutions. Completing the two-way interoperability, the best design solution is uploaded back into the single integrated BIM model. Figure 2.4.2a shows how this shifts the time in the design process when more effort is required to be spent on early design rather than later the later phases. 
Figure 2.4.2a: Building Smart Graph Promoting the Advantages of the BIM Concept

Source: (Donn et al., 2012, p. 189)

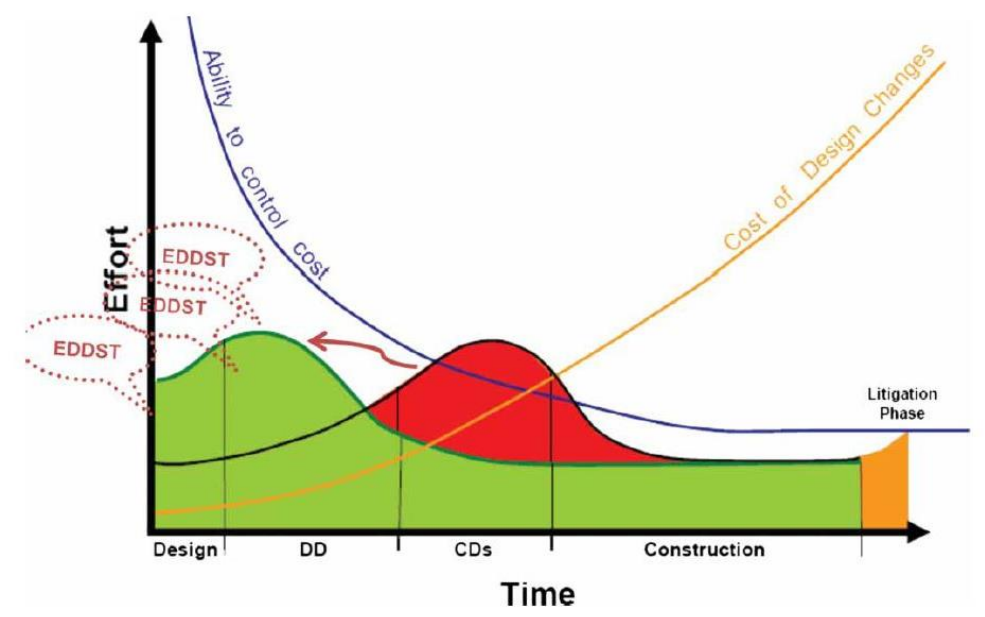

\section{How The BIM Concept Works Within The Design Process}

The BIM concept facilitates early design phase building performance assessment by requiring an iBIM model. Constructing this iBIM model, requires all the information, for all areas of building performance assessment, to be embedded by the design team by ready for sketch design. Doing this restructures the design processes, practices, and activities, around the BIM concept rather an integrating the use of BIM into them.

This restructure is the future direction the AEC industry is headed in developing new design process frameworks based on Integrated Design Processes (IDP) such as, the AIA Integrated Project Delivery (American Institute of Architects (AIA), 2007), and the RIBA Plan of Work 2013 (Ostime, 20I3). These IDPs are design frameworks were developed specifically to facilitate the MacLeamy concept, through the use of the BIM concept. As such, they all specify constructing an iBIM model for conducting building performance assessments.

Traditional building design frameworks were developed to provide a standardised best practice guidance defining the building information required, when it is required, and how detailed it must be. This is all based on design decision making, to ensure that the decisions that must be made, can, and are made by the time they are required. By comparison, IDP frameworks do not do this. Along with the BIM concept, they only state that the information 
must be available by a certain time in the building design process. Neither provide any guidance for what information must be embedded into the BIM model to conduct the building performance assessments they specify as a requirement. Instead, IPD frameworks advocate creating project specific requirements, or defer to independent BIM standards such as the BuildingSmart's Standard of Processes (formerly known as the Information Delivery Manual or IDM) to specify this information (BuildingSMART UK, n.d.; Hjelseth, 20I0).

This is not effective integration. Integration is not just making very detailed information available earlier in the design process which is what the BIM concept, and IPDs advocate. The problem is none of these standards define what information, how detailed this information must be, when it must be available, and how this translates into BIM objects and geometry. They are simply frameworks for managing the BIM modelling process, not for doing building performance assessments.

\section{The Ineffectiveness Of The BIM Concept}

The promise of BIM is the ability to make design decisions in the early phases of the design process, through time savings provided by improved sharing of information and knowledge. However, in practice, this is not true. This ineffectiveness is a failure in the cultural facet of BIM interoperability caused by the BIM concept, not the technological interoperability capabilities of BIM tools.

Using an iBIM for sketch design building performance does not save enough time to maximise the benefits of simulation. This is because constructing the iBIM takes too long (hereby referred to as BIM modelling time), to the point where, the delivered time savings do not payback the initial time investment spent constructing it (Donn et al., 20I2; Leite, Akcamete, Akinci, Atasoy, \& Kiziltas, 20I I).

The cause of excessive BIM modelling time is that too much information is required to be modelled in the iBIM. This is caused by modellers not knowing what they have to model, or how detailed the iBIM model has to be at each phase of the design process, for each area of building performance being assessed. Because of this, a BIM concept for using BIM LCA tools does not enable effective integration of building performance assessment. 


\subsection{How To Use BIM LCA Tools Effectively?}

\subsection{The Building Performance Sketch (BPS)}

The BIM concept is ineffective for sketch design integration of building performance assessment because of the excessive modelling time required to construct an iBIM model. Excessive modelling time is caused by having to construct an iBIM model that has the required information for all building performance assessments such as, thermal, lighting, and building material LCA, embedded to calculate accurate results for each.

Simplifying the BIM model will reduce modelling time. This is a rejection of the BIM concept in favour of the Building Performance Sketch (BPS) concept of integration developed by Donn et al., (20I2). The BPS prescribes using simulation tools more effectively, to examine different design options quickly, to facilitate design decision-making (Donn et al., 20I2). It advocates constructing a BPS model that is detailed enough to produce simulation results of one area of building performance, that are accurate enough for decision-making, and no more (Donn et al., 2012). The result, decreased modelling time and effort, while achieving simulation accuracy requirements (Donn et al., 20I2).

\subsubsection{A BIM LCA Building Performance Sketch (BPS)}

Applied to BIM LCA tools, the BPS concept satisfies many of the requirements for their effective integration into sketch design. The BPS concept defines in theory how BIM LCA tool should be used. However, in practice, it has not being applied to BIM LCA tools. Donn et al., (20I2) developed requirements that act as a guiding framework, but not the specific details for developing a BPS for BIM LCA tools. Several critical definitions that define what a BIM LCA BPS is are missing, and must be developed. These are:

- How accurate is accurate enough for informed decision-making about building material LCA simulation results?

- What is evidence based decision-making?

- What information is needed for a BIM LCA BPS?

- Is the information needed available in the early phases of the design process, and to the level of detail required to produce accurate results?

Using BIM To Calculate Accurate Building Material Quantities For Early Design Phase LCA 
- How does this information translate into a BIM model?

- What building materials, and elements, need to be modelled as BIM objects and geometry in a BIM LCA BPS model?

- How does detailed do the BIM objects and geometry of the BIM LCA BPS model need to be to produce accurate results?

- Is BIM LCA BPS results worth doing, e.g. do it produce information that building designers can use?

These questions are critical to determining if a BIM LCA BPS satisfies the outstanding requirements of effective integration of:

Can a BIM tools use be adapted to fit within established work practices, and processes, that building designers actually use during sketch design, whilst ensuring the simulation results are accurate and trusted enough to enable the design team to make informed design decisions?

\subsubsection{Sketch Design Decision-Making And Simulation Accuracy}

Good sketch design decisions are critical to a building's design achieving its performance goals. A good sketch design decision is one, that despite being based on uncertain building information, it is the same decision that would have been made if based on the detailed information available later in the design process (Emmitt, 2010; International Energy Agency, 2004a; Löhnert et al., 2003). Critical to making a good sketch design decision is knowing the decisions that must be made during sketch design, and those that can be made later in the design process. Some modifications such as fine tuning, and optimisation of sketch design decision can be made later in the design process, but to meet performance goals, the fundamentals of a building's design that are decided upon at sketch design cannot change (Augenbroe, 2002, p. 897).

Good decisions about building performance, are based on the performance indicators calculated by building performance simulation tools. To base decisions on these results, the building designer must trust them (Attia, 2012, p. 9; Donn, 1999; Hand, Crawley, Donn, \& Lawrie, 2008). Trust is based on measures of simulation reliability presented in Table 2.5.3. This makes these the critical components in a simulation methodology for achieving effective 
decision-making (CIBSE, 1998, 2006; Donn, 1999; Donn et al., 20I2; Hand et al., 2008, p. 675).

2.5.3: Measures Of Simulation Reliability For Design Decision-Making

\begin{tabular}{|c|c|}
\hline $\begin{array}{c}\text { Measures Of } \\
\text { Simulation Reliability }\end{array}$ & Definition \\
\hline Simulation completeness & $\begin{array}{l}\text { It is a measure of the simulation scope, or how much of a } \\
\text { building's total consumption the simulaion results represent. }\end{array}$ \\
\hline Simulation accuracy & $\begin{array}{l}\text { The measure of 'how close' simulation results (values) are to } \\
\text { the measured performance of the building in reality (ASHRAE, } \\
2002 \text { ). These measurements of reality are called 'true values'. } \\
\text { Simulation accuracy is the product of all the simulation errors } \\
\text { caused by uncertainties. }\end{array}$ \\
\hline Simulation precision & $\begin{array}{l}\text { An expression of the closeness of agreement among repeated } \\
\text { measurements of the same physical quantity (ASHRAE, 2002, } \\
\text { p. 9) accounting for offsetting or cancellation errors that occur } \\
\text { when a model is over or under simulating results. }\end{array}$ \\
\hline Simulation robustness & $\begin{array}{l}\text { A simulation robustness assessment is a type of sensitivity } \\
\text { analysis. It identifies any unexpected sensitivities or hidden } \\
\text { errors in simulation inputs, and in the simulation calculation } \\
\text { process, which may arise in different design iterations or } \\
\text { scenarios (Hopfe \& Hensen, } 201 \text { I, p. 2804). Robustness } \\
\text { assessment tests to ensure that slight changes in the simulation } \\
\text { inputs do not result in an unacceptable level of simulation } \\
\text { accuracy, or not achieving performance goals (CIBSE, I998, } \\
\text { 2006). }\end{array}$ \\
\hline
\end{tabular}

Using BIM To Calculate Accurate Building Material Quantities For Early Design Phase LCA 


\subsection{The Problem, Calculating Material Quantities}

The root cause of ineffective integration is simulation complexity, and poor simulation accuracy. A common difficulty with any building performance simulation is assessing the required simulation inputs that are project specific. These are inputs that vary from building to building, such as building form, and location.

A building material LCA assessment only has two simulation inputs; $\mathrm{LCl}$ material coefficients, and building material quantities. $\mathrm{LCl}$ material coefficients are not project specific. They are standard inputs in any LCl or LCA calculation, meaning, they are not calculated to specifically for a single building project. BIM LCA tools have an inbuilt database of material coefficients. This makes the access and management of these data inputs easier for building designers, removing many of the complexity causing problems involving the LCA material coefficients. Discussed in Chapter Section 2.3.I, these are the accuracy, data quality, and selection of the most appropriate LCA database for a specific building project.

In contrast to LCl material coefficients, building material quantities are project specific. They are a LCA simulation input the building designer must calculate specifically for every building design. The current method for their calculation is to employ a $\mathrm{QS}$ to produce a SOQ (SOQ). This has not changed over the last 30 years since Baird and Chan (1983) were one the first to use it to analyse the distribution of EE throughout a building. A SOQ, also referred to as a bill of materials, is an itemised list of the building works, and materials required to construct a building. Produced for cost planning purposes, a SOQ is sufficiently detailed to achieve cost estimation requirements range from $\pm 20 \%$ for concept design, to $\pm 2 \%$ for detailed design ((Holm, Schaufelberger, Griffin, \& Cole, 2005) cited in (Samphaongoen, 20I0)), rather than LCA requirements. Calculated through measurement from the post design contract documentation e.g. contract drawings and specifications (Ashworth, Hogg, \& Higgs, 2007; Emmitt, 2007; Ferry, Brandon, Ferry, \& Kirkham, 2007; C. A. Langston, 2005), a complete SOQ can only be produced late in the design process, typically after the competition of the detailed design phases (refer to Table 2.2.2 for a definition of design phases) of the project for the start of the tender period (Brook, 2004; Ferry et al., 2007). 
Unlike other product LCAs, such as plastic bottles, buildings consist of many different materials, and products. These combine together making each building design unique. This uniqueness, and other factors, such as; the sheer number of different materials and products in a building; and the long lifespan of buildings; makes calculating building material quantities the leading source of LCA calculation complexity, and the ineffective integration of BIM LCA tools into the design process (Bribián et al., 2009; Crawford, 20 I I; International Energy Agency, 2004a).

\subsection{Testing Sketch Vs. Detailed Models For Calculating Building Material Quantities}

BIM LCA tools make the process of calculating building LCA results less complex, and therefore easier. This is primarily by making the calculation of material quantities easier. However, currently there is no definition for how to use a BIM LCA tool to produce accurate building material quantities, and subsequently producing accurate building material LCA results. The definitions missing are; which BIM objects and geometry must be modelled; and how detailed they need to be to produce accurate results is missing. Therefore, it is unproven if BIM LCA tools can accurately calculate the building material quantities needed for a building material LCA assessment. Without this, the effective integration of building material LCA assessment into the early phases of the design process using BIM LCA tools cannot be achieved.

To date, no research has investigated this issue, and neither IMPACT nor Tally define this. As a precedent, the example BIM model shown in the Tally BIM LCA tutorial videos (refer Figure 2.6.I) is reasonably detailed (KT Innovations et al., 20I4), arguably they need to be to calculate the building material quantities required for an accurate whole building LCA assessment. 
Figure 2.6.I: The Tally BIM LCA Tool's Example Tutorial Model

Source: Tally Tutorial Video (KT Innovations et al., 2014)
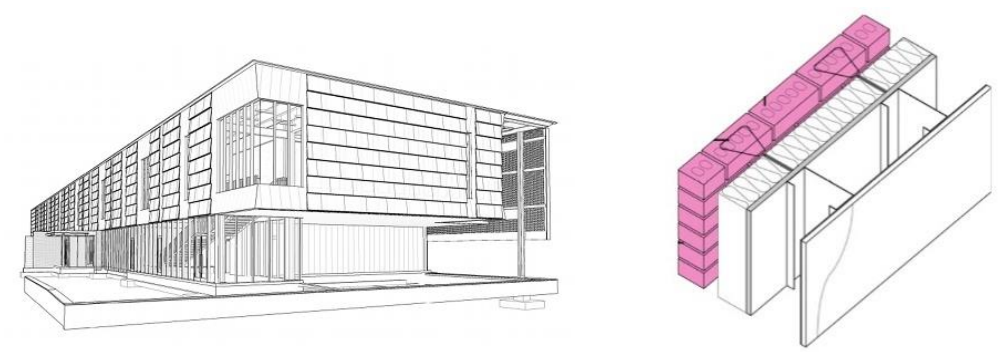

However, in actual practice a BIM model constructed to this level of detail is likely to take too long for early design phase assessment. Leite, Akcamete, Akinci, Atasoy, \& Kiziltas (20II) conducted a study investigating the modelling effort required for constructing different BIM model construction assemblies to different levels of detail complexity. They reported taking 67.5 hours to construct a BIM model of a 5 storey, $17560 \mathrm{~m} 2$ gross floor (approximate, assumed gross floor area) commercial building to a level of detail classified as 'precise' using the BIM Level of Detail version classification system (equivalent to approximately a level 400 in the Level Of Development standards classification). Precise is equivalent to a level expected of final working drawings e.g. RIBA Plan of Work technical design (Ostime, 20I3).

While it is difficult to compare the modelling time of two different buildings, Table 2.6.I shows the Tally example models modelled complexity of brick wall is of a similar complexity level as an in-between level of those used to illustrate the precise and fabrication levels of detail in Leite et al. (201I). From this general comparison, it indicates that conservative estimates of the time to construct the Tally example BIM model could be between the 67.5191.5 hours. Regardless of the actual figure, this proves that to construct a BIM model to the detail suggested by the Tally tutorials, 67.5 hours e.g. approximately one and a half 40 hours working weeks for a single design iteration is too slow for an early design phase building material LCA assessment. 
Table 2.6.I: Comparing BIM Level Of Modelled Detail

\begin{tabular}{|l|l|l|}
\hline $\begin{array}{c}\text { Tally Example Model } \\
\text { (KT Innovations et al., } \\
\text { 20 I4). }\end{array}$ & \multicolumn{2}{|c|}{ Example Level of BIM Complexity from Leite et al. } \\
(20I I).
\end{tabular}

Therefore, in order to satisfy the requirements of the effective integration of building material LCA assessment into the early phases of the design process as per the MacLeamy concept, a methodology for the use of BIM LCA tools to produce accurate building material quantities, and therefore LCA results is needed. The critical component in addressing this need, is the calculation of accurate building material quantities. Influencing this are the definitions of; what building information must be modelling; determining whether this information is available during sketch design; determining how detailed the BIM objects and geometry representations of this information must be to calculate it accurately; and defining how 
accurate is accurate enough so that building designers can make informed design decisions. These formulate the hypothesis of this thesis research where;

By defining the accuracy required for iEE simulations, a BIM model appropriately detailed for sketch design phase assessment will calculate building material quantities accurately enough for whole building LCA.

Quantifying differences in BIM modelled detail is conducted by expressing the differences in the calculated material quantities normalised into environmental impacts e.g. LCI or LCIA indicators. This research is positioned in the context of the New Zealand construction industry. Therefore, the most complete and robust (to current best practices) LCl based material indicators currently available are the $\mathrm{EE}(\mathrm{EE})$ and Embodied Carbon Dioxide $\left(\mathrm{ECO}_{2}\right)$ published by Alcorn (20I0). This focuses the study to the calculation of the $\mathrm{LCl}$ sustainable indicator of EE at a whole building level.

The impact of basing this research in the context of the New Zealand construction industry is that neither IMPACT nor Tally's respective LCl databases, Ecoinvest or Gabi, are New Zealand specific. Research has proven that using two databases instead of New Zealand specific material coefficients has a significant impact of the detailed analysis and design recommendations (Nebel, n.d.). Nebel (n.d.) concluded, that when conducting an LCA assessment to achieve very strict building performance goals e.g. high levels of simulation accuracy, or for to represent locally manufactured building products or materials produced by specific manufactures, the generic material coefficients from international LCA database, Ecoinvest or Gabi, should not be based within the New Zealand context.

This means neither tool can be used in this research. Using a country specific LCl databases is important, as depending on a countries energy mix, and technology for producing building materials and products including which are produced overseas and imported, different building materials will have a greater proportional environmental impact. This will therefore require them to be modelled to a greater level of detail. Excluded from using these tools, a methodology is required for using a Level 2 BIM maturity model and BIM tool to calculate building material quantities for the purposes of an EE assessment. This is required prior to addressing the need to define the detailed required of a BIM model to calculate building

Using BIM To Calculate Accurate Building Material Quantities For Early Design Phase LCA 
material quantities for a best practice compliant EE assessment in the early phases of the design process as one example of a whole building LCA assessment.

\subsection{Chapter Inference}

BIM LCA tools were developed in response to the problem of excessive calculation complexity, and the ineffective integration of LCA into the early phases of the design process. Critiquing their use, this chapter concluded they are technical capable of producing results, but are currently being used incorrectly, consequently not satisfying the requirements of effective integration. The specific cause was identified as excessive modelling time brought on by the BIM concept's single integrated BIM model, and the lack of a best practice method for how to conducting an accurate sketch design phase LCA assessment which defined:

- What building material information i.e. individual materials, and their quantities, must be modelled?

- How detailed the BIM model must be to represent and calculate it?

Lacking these definitions, the BIM concept advocates modelling every aspect of the building in the highest level of detail possible during each phase of the design process. As a result, instead of resolving the problem that LCA remains unused by most building designers, it was found that the current BIM concept contributes to it. In respect to meeting the requirements of effective integration, the BIM concept is fundamentally is flawed. Therefore, to realise the thesis aim, an alternative methodology concept must be applied to BIM LCA tools. The BPS concept (BPS) developed by Donn et al., (2012) was identified as the most appropriate. Being derived from the requirements of effective integration, developing a BIM LCA BPS would achieve effective integration of LCA into sketch design. However, a critique of the BPS framework concluded that it too lacked the same specific details as the BIM concept for definitions the best practice methods of how to conducting an accurate sketch design phase LCA assessment. Translated, these became the thesis hypothesis, whereby, defining the accuracy required for iEE simulations, a BIM model of sketch design detail will calculate building material quantities accurately enough for a building material LCA assessment. 
Chapter Three:

\section{RESEARCH METHODOLOGY}

\section{I Chapter Intent}

This thesis addresses the problem that:

The current methods of using Building Information (BIM) LCA (LCA) tools do not enable the effective integration of the LCA environmental framework for building materials into the early phases of the design process.

Solving this problem, a methodology for the correct usage of BIM LCA tools must be developed. A successful methodology is one where, the requirements of effective integration are satisfied. This is achieved by reducing modelling time, whilst maintaining the simulation accuracy. Within the BIM LCA calculation process, constructing the BIM model to calculate building material quantities is the largest contributor to modelling time. Defining how detailed a BIM model must be to produce accurate enough results, is the critical definition in developing a successful methodology for the use of BIM LCA tools. This requires answering the research question of:

\section{How detailed does a BIM model need to be to calculate accurate building material quantities for a building material LCA assessment?}

This research focusses on iEE (iEE), to prove the feasibility of using a BIM LCA tool to produce an accurate LCA-based result, answering the research question, and solving the research aim. EE (iEE) is a $\mathrm{LCl}$-based indicator, commonly calculated as part of a larger LCA building study. Using iEE as one example of a LCA result, this Chapter describes the design of the thesis' research methodology for testing the hypothesis that: 
Defining the accuracy required for EE (iEE) simulations, a BIM model of sketch design detail will calculate building material quantities accurately enough for a building material LCA assessment.

\subsection{Research Design And Objectives}

\subsection{The Thesis Hypothesis Testing Process}

This thesis addresses the problem that the integration of LCA framework into the sketch design phase of the design process is ineffective. This has been an obstacle limiting building design team's use of the LCA framework as a design tool for reducing a building's environmental impact. Chapter 2.0 identified that excessive calculation complexities, specifically those involving the calculation of accurate building material quantities, are a leading cause.

While numerous LCA tools, such as BIM LCA tools like IMPACT and Tally, have been developed to resolve this problem, they remain ineffective. The gap in LCA knowledge this thesis fulfils is the development of a methodology for using BIM LCA tools, to ensure they quickly, and easily, calculate accurate building material quantities so they can be effectively integrated into sketch design. The outcome of this methodology is an iEE BPS model. This is a simplified BIM model, constructed from sketch design information that reduces reducing modelling time, and effort. This thesis' hypothesis specifically tests if the iEE BPS model is sufficiently detailed to calculate building material quantities for an accurate building material LCA assessment.

The research design to test the hypothesis is centred on 3 key ideas. Firstly, what is an iEE sketch design phase BIM model? This is answered by defining which building elements can, and must be modelled to incorporate iEE results into sketch design phase design decisions? As well as, how detailed can they be modelled using the building information available at sketch design? The outcome is the definition of an iEE BIM LCA BPS model. Secondly, does the iEE BIM LCA BPS model calculate enough of a buildings total iEE to be effective for informed decision-making? Thirdly, is the iEE BIM LCA BPS model sufficiently detailed be to produce iEE results accurate enough for informed decision-making. This defines if the iEE BIM LCA BPS model is sufficiently detailed. 
In building performance, simulation accuracy is defined as the indication of 'how close' the calculated results (values) are to the 'true values' of the quantities in question (ASHRAE, 2002, p. 7). Accuracy assessment of the BIM calculated iEE LCA BPS is the comparison of its calculated building material quantities to those defined as $100 \%$ accurate or the 'true value'. These 'true value' material quantities are called a truth model. They are is defined by what can be practically measured using available best practice methods. The difference between the two models, is the accuracy measurement. To be defined as sufficiently accurate, the resultant accuracy measurement between the BIM iEE LCA BPS and the truth model must be within a defined range that expressing 'how close'. This determines whether the BIM model as part of the iEE LCA BPS is detailed enough to calculate building material quantities.

Comparing BIM modelled detail, differences in material quantities, and the significance of inaccuracies, both the calculated BIM quantities, and the 'truth' model quantities are normalised to a LCA results expressed at a whole building level, and at an individual building element and material level. Normalising is the conversion of building material quantities to a LCA result using equation I.

\section{Equation I: Whole Building Material LCA Assessment} $\left(C_{i}\right) *\left(Q_{i}\right)=$ WBLCA

\begin{tabular}{|c|c|c|c|c|}
\hline & & & & Whole Building Material LCA \\
\hline Coefficients & $x$ & $\begin{array}{l}\text { Building Material } \\
\text { Quantities }\end{array}$ & $=$ & $\begin{array}{c}\text { Results of } \mathrm{LCl} \text { environmental } \\
\text { consumption }\end{array}$ \\
\hline
\end{tabular}

$\begin{array}{lll}C_{i} & \text { WBLCA }\end{array}$

Normalising could use any building material LCA-based indicator. As part of a full building material LCA assessment, the New Zealand construction industry has identified I 3 different LCIA-based indicators, and 7 different LCl-based indicators as preferred results (Dowdell, 2014). This would require normalising material quantities to 20 different LCA-based indicators. However, testing this thesis hypothesis only one is required to prove the feasibility of the iEE BIM LCA BPS methodology. For this purpose, any indicator that fulfils equation I is sufficient. LCl-based indictors satisfy this requirement. They are not a 
complete building material LCA assessment, as they only measure environmental consumption ( $\mathrm{LCl}$ results), not environmental impact ( $\mathrm{LCIA}$ results). The weighting factors that convert $\mathrm{LCl}$ environmental consumption results into $\mathrm{LCIA}$ result measuring environmental impact results are not applied. LCA assessment of this scope are commonly called streamlined LCAs. EE (EE) is one example, and has been selected for this thesis research.

Selection was determined by data availability. Alcorn's (2010) hybrid process/input-output EE database is the only source of LCA data specific to New Zealand that is currently available that uses a current best practice calculation method. This is significant as, hybrid EE calculation methods are the best practice measurement method of the EE of building materials, making them integral part of the 'true value' definition of EE simulation accuracy.

\subsubsection{The Relationship Between LCA And EE}

$\mathrm{EE}$ is one type of $\mathrm{LCl}$-based indicator that is commonly calculated as part of a larger building LCA assessment. It is the sum of energy consumption, in all the activities necessary to in a process, such as creating a building material like concrete. EE comprises of direct and indirect components (Baird \& Chan, 1983; Manish Kumar Dixit et al., 2010). In the building industry, direct energy is energy consumed onsite and offsite, by processes such as, construction, prefabrication, assembly, transportation and administration. Indirect energy is the energy consumed in manufacturing building materials, renovation, refurbishment and the demolition and disposal of the building materials (Manish Kumar Dixit et al., 2010). The EE of building materials is the direct and indirect energy consumption during the manufacturing building lifecycle stage only. This is frequently referred to as a 'cradle to factory gate' LCA assessment.

\section{An EE Calculation: The Calculation Methods Of Building Material Coefficients}

Commonly referred to as a calculation, EE material coefficients are actually measurements of direct and indirect energy consumption. The complexity, detail, and number of inputs and outputs included in a coefficient depends on the definition and scope of the iEE study. Typically, this includes the energy consumption of the direct inputs and outputs of the manufacturing process, and all the inputs and outputs upstream of the material's manufacturing stage (Crawford, 20II, p. 9I). Upstream describes the process throughout a 
building's lifespan that add to the energy impact (e.g. energy consumption) of the building. The furthest upstream are processes in the manufacturing lifecycle stage, whereas the furthest downstream those in the demolition lifecycle stage (Manish Kumar Dixit et al., 2010, p. 1243). Ultimately both are defined by the system boundary scope of each study. EE material coefficients are an expression of this sequestered energy in a material or product expressed per unit of measurement (functional limit). Therefore, they can be thought of as the function representation of an iEE study's definition and scope.

Research to date has focussed on the calculation methods to produce databases of EE material coefficients for common building materials and products. Table 3.2.2 shows the four different iEE calculation methods for EE material coefficients. They are differeniated by different definitions of system boundaries, iEE calculation and scope, and the most accurate data collection methods for the required input and output process. Various researchers (Bribián et al., 2009; Manish K. Dixit et al., 2013, 20I2; Manish Kumar Dixit et al., 2010) have identified these as issues limiting the adoption of $\mathrm{iEE}$ analysis in the construction industry. Current research continues to work towards addressing these issues (Crawford, 2008; Manish K. Dixit et al., 2013, 2012; Manish Kumar Dixit et al., 2010). Examples include, the International Energy Agency's (IEA) Annex 57 the "Evaluation of EE and Carbon Dioxide Emissions for Building Construction” (201 I-20I5). This research developing an internationally agreed framework for calculating EE material coefficient (“Annex 57,” n.d.).

Table 3.2.2: EE Material Coefficient Calculation Methods

\begin{tabular}{|c|c|c|}
\hline Calculation Method & $\begin{array}{l}\text { Approximate } \\
\text { Development }\end{array}$ & $\begin{array}{c}\text { Research Within New } \\
\text { Zealand Context }\end{array}$ \\
\hline Input-Output Analysis & Throughout the 1970's & \\
\hline Process Analysis & $\begin{array}{l}\text { Throughout the 1960- } \\
\text { I970's }\end{array}$ & Baird and Chan (1983) \\
\hline $\begin{array}{l}\text { Hybrid Process / Input- } \\
\text { Output Analysis }\end{array}$ & From 1990's onwards & $\begin{array}{l}\text { Alcorn 1995, 1996, } 2003 \\
\text { and } 2010\end{array}$ \\
\hline $\begin{array}{l}\text { Hybrid Input-Output / } \\
\text { Process Analysis }\end{array}$ & 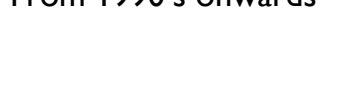 & None \\
\hline
\end{tabular}

Using BIM To Calculate Accurate Building Material Quantities For Early Design Phase LCA 
Graph 3.2.2 shows that the differences between the four EE calculations methods when applied to a building are sizable, ranging from $-66 \%$ to $+27 \%$ centred around the process / input-output method used by Alcorn (2010). Currently the two hybrid methods are best practice (Alcorn, 2010; Crawford, 2008, 20II). Adhering to current best practices is a form of QA to improve simulation accuracy (CIBSE, 1998, 2006), making the use of material coefficients calculated using either hybrid EE calculation method sufficient to satisfy simulation accuracy requirements. Hybrid process / input-output EE material coefficients are available for many common New Zealand building materials. Published by Alcorn in his PhD thesis (2010), this is currently the most accurate and comprehensive source of EE material coefficient for New Zealand construction materials.

\section{Graph 3.2.2: A Comparison of the Different EE Material Coefficient Calculation Methods}

Source: Figure 4.8 (Crawford, 20I I).

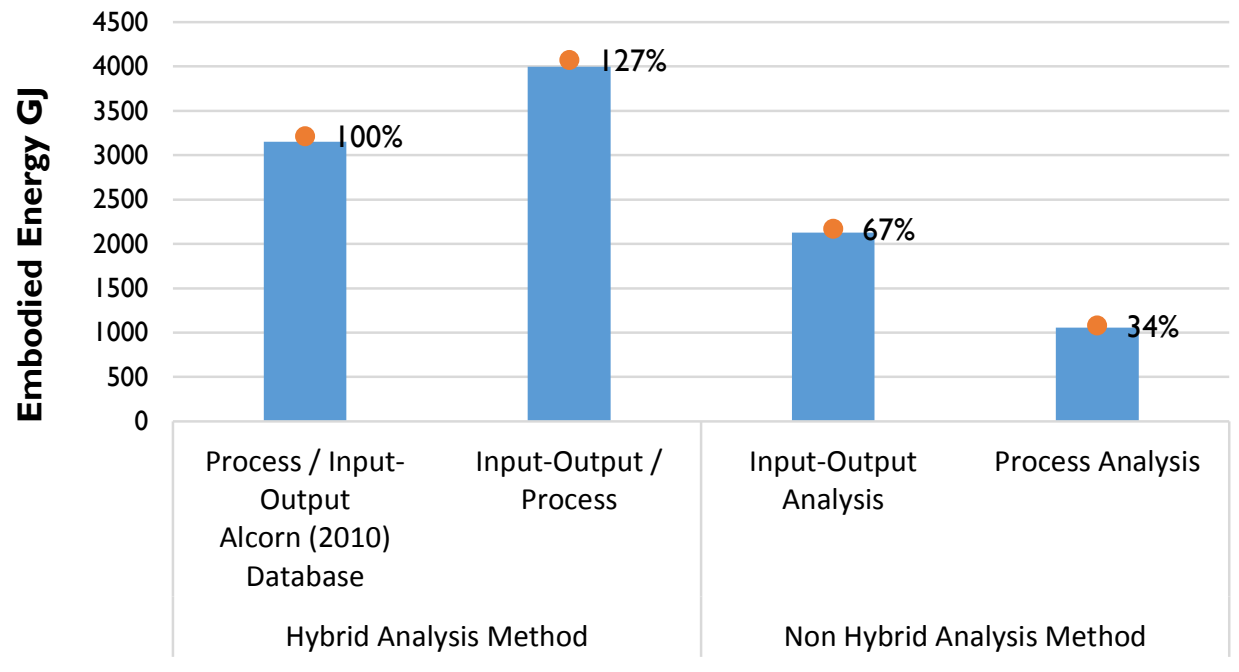

Embodied Energy Calculation Methods 


\subsubsection{Research Variables}

The following research variables have been identified as having an influence on testing the thesis hypothesis. The variables listed below in Tables 3.2.3a-d, are derived from the relationship of building material quantities and iEE described in equation I, and the research design for testing the thesis hypothesis.

Table 3.2.3a: The Dependent and Independent Variables in Thesis Research Design

\begin{tabular}{|c|c|c|}
\hline Variable & Research Design & $\begin{array}{c}\text { Variable Controlled / } \\
\text { Managed }\end{array}$ \\
\hline $\begin{array}{l}\text { Dependent } \\
\text { variable: } \\
\text { What is being } \\
\text { tested? }\end{array}$ & $\begin{array}{l}\text { - BIM modelled detail. This is the } \\
\text { calculation of building material } \\
\text { quantities that are normalised into } \\
\text { iEE to enable their comparison to } \\
\text { the truth model set of material } \\
\text { quantities. }\end{array}$ & $\begin{array}{l}\text { - The variable being tested. } \\
\text { Results are expressed using } \\
\text { the Level Of Development } \\
\text { (LOD) specification defining } \\
\text { both the metadata and 3D } \\
\text { detail of BIM objects (Level } \\
\text { of Development } \\
\text { Specification, 20I3) }\end{array}$ \\
\hline $\begin{array}{l}\text { Independent } \\
\text { variable: } \\
\text { All the variables that } \\
\text { influence the result. }\end{array}$ & $\begin{array}{l}\text { - iEE results. } \\
\text { - The BIM tool. } \\
\text { - LOD specification. } \\
\text { - The iEE BIM BPS definition. } \\
\text { - The maximum acceptable } \\
\text { calibration tolerances defining } \\
\text { accuracy and precision. } \\
\text { - The truth model building material } \\
\text { quantities. }\end{array}$ & - See below. \\
\hline
\end{tabular}

Using BIM To Calculate Accurate Building Material Quantities For Early Design Phase LCA 
Table 3.2.3b: The Intervening Variables in Thesis Research Design

\begin{tabular}{|c|c|c|}
\hline \multicolumn{3}{|c|}{ Managing The Independent Variables } \\
\hline Variable & Research Design & $\begin{array}{l}\text { Variable Controlled / } \\
\text { Managed }\end{array}$ \\
\hline $\begin{array}{l}\text { Intervening } \\
\text { variable: } \\
\text { A subset or } \\
\text { component of } \\
\text { certain independent } \\
\text { variables. }\end{array}$ & $\begin{array}{l}\text { The BIM tool: } \\
\text { - BIM modelling techniques. } \\
\text { - LOD specification. } \\
\text { iEE results: } \\
\text { - EE material coefficients (control } \\
\text { variable). }\end{array}$ & $\begin{array}{l}\text { - These variables help } \\
\text { explain the relationship } \\
\text { between BIM detail and } \\
\text { material quantities. }\end{array}$ \\
\hline
\end{tabular}

Table 3.2.3c: The Control Variables in Thesis Research Design

\begin{tabular}{|c|c|c|}
\hline \multicolumn{3}{|c|}{ Managing The Independent Variables } \\
\hline Variable & Research Design & $\begin{array}{l}\text { Variable Controlled / } \\
\text { Managed }\end{array}$ \\
\hline \multirow[b]{2}{*}{$\begin{array}{l}\text { Control variables: } \\
\text { Independent } \\
\text { variables that have } \\
\text { their influence } \\
\text { measured. }\end{array}$} & $\begin{array}{l}\text { iEE results: } \\
\text { - EE material coefficients (control } \\
\text { variable). }\end{array}$ & $\begin{array}{l}\text { - Quality assured through } \\
\text { best practice techniques. } \\
\text { Refer to Chapter 6.2.2. }\end{array}$ \\
\hline & $\begin{array}{l}\text { The truth model building } \\
\text { material quantities. } \\
\text { - The completeness of truth model } \\
\text { 3's material quantities. } \\
\text { - The accuracy of the truth model } \\
\text { 3's iEE result. }\end{array}$ & $\begin{array}{l}\text { - Quality assured through } \\
\text { best practice techniques. } \\
\text { Refer Chapter Section 6.2.3. } \\
\text { - Quality assured through } \\
\text { best practice techniques. } \\
\text { Refer to Chapter 6.2.2. }\end{array}$ \\
\hline
\end{tabular}

Using BIM To Calculate Accurate Building Material Quantities For Early Design Phase LCA 
Table 3.2.3d: The Confounding Variables in Thesis Research Design

\begin{tabular}{|c|c|c|}
\hline \multicolumn{3}{|c|}{ Managing The Independent Variables } \\
\hline Variable & Research Design & $\begin{array}{l}\text { Variable Controlled / } \\
\text { Managed }\end{array}$ \\
\hline $\begin{array}{l}\text { Confounding } \\
\text { variables: } \\
\text { Independent } \\
\text { variables that exist } \\
\text { but their influence } \\
\text { cannot be measured. }\end{array}$ & $\begin{array}{l}\text { The iEE BIM BPS definition: } \\
\text { - The functional definition of the } \\
\text { design process, to establish what } \\
\text { information is available at sketch } \\
\text { design. } \\
\text { - The functional framework of what } \\
\text { design decisions must be made at } \\
\text { sketch design. }\end{array}$ & $\begin{array}{l}\text { - These variables cannot be } \\
\text { tested, but will have an } \\
\text { influence on the } \\
\text { generalisability of this thesis' } \\
\text { research conclusions. }\end{array}$ \\
\hline
\end{tabular}

\subsubsection{Research Objectives / Steps}

Developing a BIM LCA BPS, is developing a method for how to use BIM LCA tools to enable effective integration of the LCA environmental framework into the concept phase of the design process. The thesis hypothesis is testing the critical issue of, how detailed does the BIM LCA BPS model need to be to produce building materials quantities for an accurate building material LCA assessment at concept design. However, Chapter Section 2.5.2, identified a number of secondary problems with developing a BIM LCA BPS concept:

- How accurate is accurate enough for informed decision-making about building material LCA simulation results?

- What is evidence based decision-making?

- What information is needed for a BIM LCA BPS?

- Is the information needed available in the early phases of the design process, and to the level of detail required to produce accurate results?

These were due to the authors of the BPS concept, Donn et al,. (2010), developing the BPS requirements to only be a guiding framework for what one should do. This framework does not provide specific details defining how to conduct a BPS assessment of specific areas of 
building performance, such as building material LCA. Table 3.2.4 translates these issues in thesis research objectives. These objectives are the thesis methodology tasks that must be completed prior to testing the thesis hypothesis.

Table 3.2.4: Thesis Research Objectives

\begin{tabular}{|l|l|}
\hline $\begin{array}{l}\text { Research } \\
\text { Objective I }\end{array}$ & $\begin{array}{l}\text { Define what a BIM LCA BPS model is. } \\
\text { Objective 2 }\end{array}$ \\
\hline $\begin{array}{l}\text { Research } \\
\text { BIM tool Revit for conducting a iEE LCA building assessment, } \\
\text { including: } \\
2.1 \quad \text { Calculating building material quantities. } \\
2.2 \text { Applying Equation 2, the multiplication of building material } \\
\text { coefficients by building material quantities to calculate and } \\
\text { analyse iEE and LCA results. } \\
2.3 \text { Selecting building material coefficients. } \\
\text { Objective 3 }\end{array}$ & $\begin{array}{l}\text { Develop the accuracy assessment framework to test if the BIM LCA } \\
\text { BPS produces simulation results sufficiently accurate for evidence } \\
\text { based decision-making. }\end{array}$ \\
\hline
\end{tabular}

\subsection{Selecting A Research Methodology}

\subsection{Prevalent Research Methodologies In EE}

This to ensure the selected research methodology is the most appropriate to solve the specific research problem (Flyvbjerg, 2006, pp. 27-28), selection should be problem driven, methodology driven (Feagin \& Orum, 199I). Graph 3.3.I presents the findings of a literature review of published research identifying the most appropriate research methodologies used in iEE research. Case study based research methodologies are shown to be the most prominent research methodology used across the three research areas.

A form of qualitative study, case study methodologies are well suited to holistic in-depth investigations where the data required is difficult to obtain, and exploring and understanding 
emerging questions and procedures (Creswell, 2009; Feagin \& Orum, 1991). These factors justify the prevalent use of case study research design as the most in EE research. The specific availability difficulties of calculating EE material coefficients, building material quantities, accessing building cost information, and documentation have traditionally limited the ability of researchers to conduct research using statistically verified sample populations.

Y. L. Langston \& Langston (2008) research method of calculating iEE from project costs using a linear regression formula was accurate for large macro level estimates, such as calculating the iEE of regional building stocks. Its failure to accurately calculate a single building's iEE at any of whole building (single value of buildings iEE consumption), elemental (values of iEE consumption per element), or building material (values of iEE consumption per material) analysis levels, makes it unsuitable as a design tool to facilitate sustainable design. Aligning with this research, the author's conclusion that the variability between the material quantities used in different buildings causes the confidence to drop, reducing the reliability of the method. From this perspective, he need to develop a methodology for calculating accurate building material quantities for calculating the environmental impact of building materials is reinforced. Analysis of iEE at elemental, and material levels, is most appropriately conducted at a case study level, as an in depth investigation is required (Feagin \& Orum, 1991).

\section{Graph 3.3.I: Research Methodologies Prevent In EE Research}

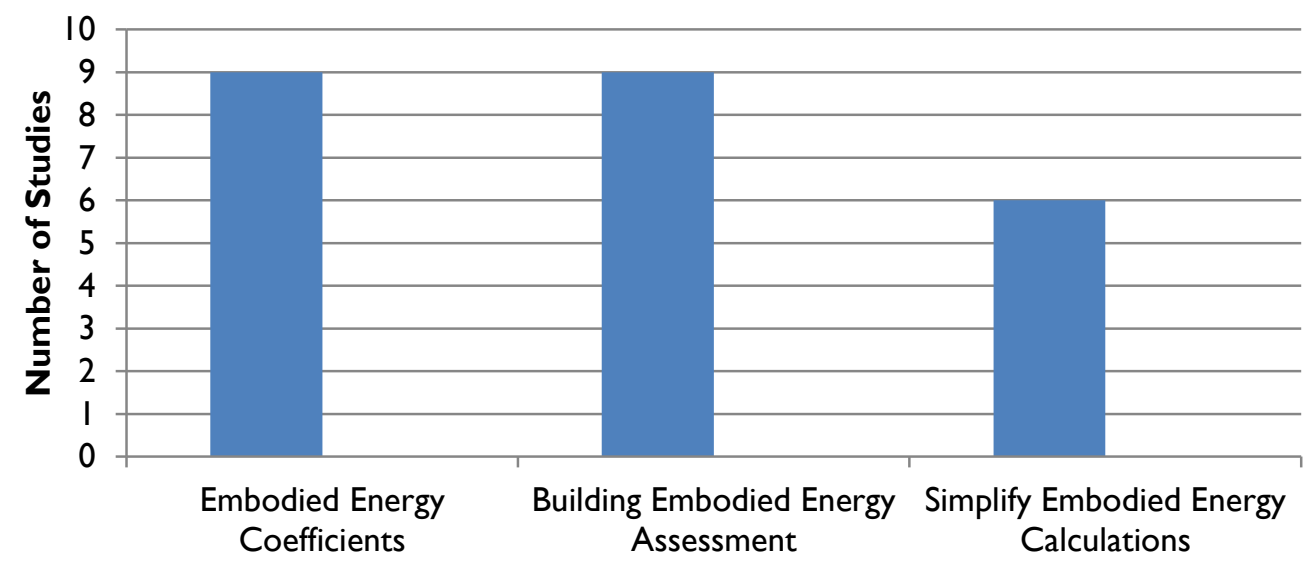

Embodied Energy Research Topic Areas

- Case Study Research Methodology $\quad$ Other 


\subsubsection{Selected Research Methodology: Single-Case Study}

This thesis research, fits into the third topic area, the simplification of iEE calculations. However, with a specific focus on BIM, this is a new area that has not been investigated, making this research as much an exploration to understanding the emerging questions and procedures as it is to solve the research problem. Like the trend in wider iEE research, the research strategy selected for this thesis is the case study assessment. Based on the review of Y. L. Langston \& Langston (2008) research, and issues of the accessibility of the data required to conduct this research, a single-case study research design was identified as the best methodology for this research (Creswell, 2009; Stake, 1995; "Types of Case Studies," 2002; Yin, 1984).

\subsection{Case Study Research Design}

\subsection{Case Study Description}

This research's case study building used to cannot be named for reason of confidentiality. Below Table 3.4.I gives a description of the case study building's characteristics relevant for an EE calculation.

Table 3.4.I: Case Study Building Description

\begin{tabular}{|l|l|}
\hline \multicolumn{1}{|l|}{ Building Characteristics Required for EE Assessment as per Literature Review } \\
\hline Building Use & $\begin{array}{l}\text { Commercial Office Space with underground car } \\
\text { parking }\end{array}$ \\
\hline Building Quality & $\begin{array}{l}\text { 'A' Grade Office Space Refer Appendix 3.0 for } \\
\text { definition (Property Council of New Zealand, } \\
\text { n.d.) }\end{array}$ \\
\hline Gross Floor Area $\left(\mathrm{m}^{2}\right)$ & $\begin{array}{l}10930 \\
\text { Office Space Floor Area }\left(\mathrm{m}^{2}\right)\end{array}$ \\
Basement Car Parking Floor Area $\left(\mathrm{m}^{2}\right)$ & 5400 \\
\hline Number of Stories & 9 \\
Office Space & 4 \\
Car Parking & 5 \\
\hline
\end{tabular}

Using BIM To Calculate Accurate Building Material Quantities For Early Design Phase LCA 


\begin{tabular}{|c|c|}
\hline Primary Structural System & $\begin{array}{l}\text { Basement car parking: Concrete structural floors } \\
\text { with reinforced concrete columns and beams. } \\
\text { Office space: Concrete structural floors with } \\
\text { steel columns and beams. }\end{array}$ \\
\hline Strata Size (Isaacs \& Hills, 20I3) & 5 \\
\hline Country & New Zealand \\
\hline $\begin{array}{l}\text { Energy Use Intensity (EUI) for base } \\
\text { building predicted operative energy } \\
\text { consumption of NLA of } 3368.5 \mathrm{~m}^{2} . * 1 \text {. }\end{array}$ & 33. $1 \mathrm{kWh} / \mathrm{m}^{2} / \mathrm{yr}$ \\
\hline $\begin{array}{l}\text { Adapted base building EUI to account } \\
\text { for energy consumption excluded in } \\
\text { base building estimate of NLA of } \\
3368.5 \mathrm{~m}^{2} . * 2 \text {. }\end{array}$ & $49.7-57.9 \mathrm{kWh} / \mathrm{m}^{2} / \mathrm{yr}$ \\
\hline \multicolumn{2}{|c|}{$\begin{array}{l}\text { Notes: } \\
\text { *I This is the base building energy consumption simulation in fulfilment of the } \\
\text { requirements for GreenStar NZ - Office Design Certificate Rating. Base building is not a } \\
\text { complete EUI, it includes the lighting and small power for common areas only. All it } \\
\text { excludes all small power and lighting in tenant specific areas. } \\
\text { *2 These figures are the additional } 50-70 \% \text { added to the base building EUl to account for } \\
\text { the exclusion of the tenant areas. This is based on the published figures that base building } \\
\text { EUl is typical } 50 \%-70 \% \text { of total building EUI (New Zealand Green Building Council, 2008). }\end{array}$} \\
\hline
\end{tabular}

\subsection{Limitations Of Case Study Research Design}

Concerns for the validity, reliability generalisability, and representability must be managed in this research design (Golafshani, 2003). Validity and reliability are conceptualised as trustworthiness, rigor and quality in qualitative research (Golafshani, 2003). Ensuring research validity is strength of the qualitative research methodology (Creswell, 2009; Levy, 1988; Yin, 1984). The main criticism of case study led research, is its ability to generalise research conclusions beyond the specific case study building to a larger sample (Creswell, 
2009; Flyvbjerg, 2006). The following Chapter Sections of 3.5 manage these issues for this thesis research.

\subsection{Research Generalisability And Representativeness}

While the ability to make generalisations from this single case study is limited, Flyvbjerg, Levy, Tellis and Yin $(2006$; 1988; 1997; 1984) argue it is possible to make generalisations from a single case study, but it depends on the type of generalisations you want to make. Case study research is effective in confirming or challenge existing theories, for revelatory cases of an issue previously inaccessible, or represent a 'unique' or 'extreme case'. This thesis research is investigating a new iEE and LCA research area, making it revelatory.

The generalisability of this research was increased by case study selection (Flyvbjerg, 2006). The typology of the case study building, and the nature of iEE allows the case study building to be representative of both the existing commercial office building stock and for new/future construction of the same typology for the following reasons:

- $\quad$ Based on building typology, Tables 3.5.Ia and 3.5.I b show that the case study building's typology matches many of the building typology parameters and sub parameters.

- The case study building is an a 'green' or low energy commercial office building, reflective of the rising trend in new and future building design.

- Whole building EE does not change significantly between the buildings typical of the existing building stock and 'green' low energy buildings.

The case study matching of construction typologies dominant of the existing strata 4 building stock; being an extreme example of 'green' low energy building design; and the fact that EE does not change significantly as a building's operative energy consumption is lowered; all mean the selected case study building is a good representation of the existing building stock and the current and future trends in building design. The following sections discuss in detail how this is achieved.

Using BIM To Calculate Accurate Building Material Quantities For Early Design Phase LCA 


\section{Case Study Building Typology - Representing The Existing Building Stock}

This section details how the case study building is representative of the strata 4 building in the Zealand existing building stock. Table 3.5. Ia describes the breakdown of the New Zealand commercial building stock classified as BEES buildings; a building that has a large majority of its floor area occupied by office or public retail uses (Isaacs \& Hills, 2013, p. 100). Strata 4 buildings represent approximately $18 \%$ of the total building floor area and $4 \%$ of total number of buildings from the sample of existing commercial buildings in New Zealand classified as BEES buildings (Isaacs \& Hills, 20I3, p. 100). Table 3.5.lb describes the built form typology parameters typical for this BEES building of this strata size. With the exception of the roof cladding parameter, the case building encompasses many of the factors most widely used in New Zealand construction for strata 4 BEES buildings.

\section{Table 3.5. Ia: The New Zealand Commercial Building Stock Classification}

\begin{tabular}{|c|c|c|c|c|c|}
\hline \multirow{2}{*}{ Floor Area Group } & \multicolumn{5}{|c|}{ Building Strata } \\
\hline & $\mathbf{I}$ & 2 & 3 & 4 & 5 \\
\hline Minimum Floor area $\left(\mathrm{m}^{2}\right)$ & 5 & 650 & 1,500 & 3,500 & 9,000 \\
\hline Maximum Floor area $\left(\mathrm{m}^{2}\right)$ & 649 & 1,499 & 3,499 & 8,999 & 111,000 \\
\hline $\begin{array}{l}\text { Approximate number of } \\
\text { 'buildings' }\end{array}$ & 22,915 & 5,963 & 2,617 & $\mathrm{I}, 072$ & 398 \\
\hline Percentage of buildings & $70 \%$ & $18 \%$ & $8 \%$ & $4 \%$ & $1 \%$ \\
\hline Total Floor area $\left(\mathrm{m}^{2}\right.$, millions $)$ & 6.9 & 5.8 & 5.8 & 5.7 & 7.0 \\
\hline Percentage Floor area & $22 \%$ & $19 \%$ & $19 \%$ & $18 \%$ & $22 \%$ \\
\hline Average Floor area $\left(\mathrm{m}^{2}\right)$ & 300 & 967 & 2,200 & 5,270 & 17,530 \\
\hline \multicolumn{6}{|l|}{ Notes: } \\
\hline \multicolumn{6}{|c|}{ Highlighted cell rows show the building typology of the thesis case study. } \\
\hline \multicolumn{6}{|l|}{ Reference: } \\
\hline
\end{tabular}


Table 3.5.I b: The Built Form Typology of Strata 5 New Zealand Commercial Buildings

\begin{tabular}{|c|c|c|}
\hline $\begin{array}{l}\text { Building Typology } \\
\text { Parameter }\end{array}$ & $\begin{array}{l}\text { Building Typology Sub } \\
\text { Parameters }\end{array}$ & $\begin{array}{c}\% \text { of BEES Strata } \\
5 \text { Building } \\
\text { Sample }\end{array}$ \\
\hline \multirow{2}{*}{ Primary Structure } & Steel Frame & $17 \%$ \\
\hline & Concrete Frame & $83 \%$ \\
\hline \multirow{5}{*}{ Wall Cladding } & Glazing & $61 \%$ \\
\hline & Tilt Slab & $19 \%$ \\
\hline & Steel/Zine & $4 \%$ \\
\hline & FC Sheet & $0 \%$ \\
\hline & Other & $16 \%$ \\
\hline Floor & Concrete & $100 \%$ \\
\hline \multirow{2}{*}{ Roof } & Pre-painted Corrugated & $75 \%$ \\
\hline & Other & $25 \%$ \\
\hline \multicolumn{3}{|l|}{ Notes: } \\
\hline \multicolumn{3}{|c|}{ Highlighted cell rows show the building typology of the thesis case study. } \\
\hline \multicolumn{3}{|l|}{ Reference: } \\
\hline \multicolumn{3}{|c|}{$\begin{array}{l}\text { BRANZ Whole Building Whole of Life Stake Holder Presentation (Dowdell, 20I3b, } \\
\text { PP. 27, 28). }\end{array}$} \\
\hline
\end{tabular}

\section{Case Study Building Typology - Representing ‘Green’ Or Low Energy Buildings, An Extreme Case}

Table 3.5. Ic compares the Energy Use Intensity (EUI) of the case study building to the minimum design target for different office building scenarios. Its comparatively low EUI defines the case study building as an 'extreme case' of a sustainable building design within the New Zealand context. It was designed and constructed to achieve New Zealand GreenStar status (for confidentiality reasons, the star rating cannot be published). Therefore, it encompasses many sustainable building solutions and reducing environmental impact was a primary factor in the design and construction decision-making processes. Tenant demands are driving the trend that newly constructed commercial office buildings are 'green' or 'sustainable'. Using a case study building that is also a 'green' building increases the generalisability application of this research to these buildings in the wider New Zealand building stock. 
Table 3.5. I c: Energy Use Intensities For Commercial Buildings

\begin{tabular}{|c|c|c|c|c|}
\hline & \multicolumn{2}{|c|}{$\begin{array}{l}\text { Case Study Building: } \\
\text { Base Building EUI }\end{array}$} & \multirow{2}{*}{$\begin{array}{c}\text { Example } \\
\text { Net Zero } \\
\text { Energy } \\
\text { Building } \\
\text { (NZEB) }\end{array}$} & \multirow{2}{*}{$\begin{array}{c}\text { A Typical } \\
\text { New Zealand } \\
\text { Commercial } \\
\text { Building }\end{array}$} \\
\hline & $\begin{array}{c}\text { Base } \\
\text { Building } \\
\text { EUI }\end{array}$ & $\begin{array}{c}\text { Adapted Base } \\
\text { Building EUI }\end{array}$ & & \\
\hline $\begin{array}{l}\text { Energy Use Intensity } \\
\text { (EUI) } \\
(\mathrm{kWh} / \mathbf{m} 2 / \mathrm{yr})\end{array}$ & 33.1 & $49.7-57.9$ & 47.2 & $100-300$ \\
\hline References & $* I$ & $* 2$ & $* 3$ & *4 \\
\hline \multicolumn{5}{|c|}{$\begin{array}{l}\text { References: } \\
\text { *I This is the base building energy consumption simulation in fulfilment of the } \\
\text { requirements for GreenStar NZ - Office Design Certificate Rating. Base building is not a } \\
\text { complete EUI, it includes the lighting and small power for common areas only. All it } \\
\text { excludes all small power and lighting in tenant specific areas. } \\
\text { *2 These figures are the additional } 50-70 \% \text { added to the base building EUl to account for } \\
\text { the exclusion of the tenant areas. This is based on the published figures that base building }\end{array}$} \\
\hline
\end{tabular}

Whole Building EE does not increase significantly as a building's operative energy decreases (Berggren et al., 2013). Graph 3.5.I illustrates this statement confirming the theory that as a building's operative energy consumption decreases the EE rises (Berggren et al., 20I3).

However, the rate $\mathrm{iEE}$ increases due to design solutions for lowering operative energy consumption is not substantial. iEE normalised to a per $\mathrm{m}^{2}$ GFA to account for building size variation, the small increase indicates relative consistency in building iEE regardless of 'sustainable' building design solutions. This indicates that the iEE embedded within building 
elements will not vary for the EUl's that are typical of the existing building stock and of typical low energy office buildings (100-200kWh/m2 GFA Table 3.5.Ic).

Graph 3.5.I: The Relationship between OE and Life Cycle EE for Non-Residential Case Studies with an EUI $<100 \mathrm{kWh} / \mathrm{m} 2$.

Reference: Figure 7 (Berggren et al., 2013, p. 386)

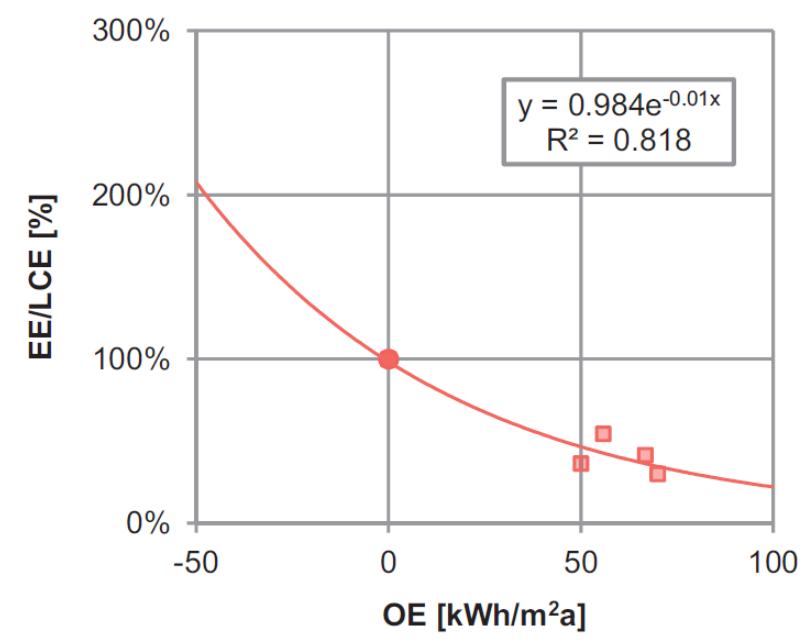

\subsubsection{Research Validity}

\section{Data Triangulation - Robustness Testing}

The validity of this research is tested and ensured through data triangulation. Data triangulation is testing the research hypothesis, using the same method processes, but using different data sources to eliminate potential bias. This answers the question, would using different data sources can the research conclusion? Rephrased this is a question of, does using different data sources for the 'truth' model change the required level of modelled BIM detail to produce an accurate iEE LCA assessment?

Triangulation testing is a test of model robustness. It is testing the influence of that $\mathrm{EE}$ material coefficients had on defining the detail of a BIM model. This robustness test is conducted by simulating the calibrated accurate Revit BIM model, developed using truth model 3, with the Crawford's hybrid input-output / process iEE, and assessing its simulation accuracy compared to truth model 3 using the same material coefficients (Table 3.5.2a). The 
outcome determines whether the research conclusion of the defined BIM level of modelled detail can be extrapolated beyond specific datasets, or if the calibration process needs to be conducted specific to each dataset.

Table 3.5.2a: Thesis 'Truth' Models I-3

\begin{tabular}{|l|l|}
\hline \multicolumn{1}{|c|}{ Truth Models } & \multicolumn{1}{c|}{ Material Quantities } \\
\hline 'Truth' Model I & Data source I: EE building material quantities. \\
\hline $\begin{array}{l}\text { 'Truth' Model 2: } \\
\text { BPS Elements Only }\end{array}$ & $\begin{array}{l}\text { Data source 2: Material quantity estimate from detailed design } \\
\text { cost report. }\end{array}$ \\
\hline $\begin{array}{l}\text { 'Truth' Model 3: } \\
\text { BPS Elements Only }\end{array}$ & $\begin{array}{l}\text { Data source I: Material quantity estimate from detailed design } \\
\text { cost report but simplified to represent only sketch design } \\
\text { phase information. }\end{array}$ \\
\hline
\end{tabular}

\section{Testing The Application To Other Material Based Environmental Indicators}

This research uses iEE as one example of an LCA environmental indicator to define the detail required of a BIM model to calculate accurate building material quantities. A validity concern is whether the defined BIM detail specific to iEE will also calculate the building material quantities required for the accurate assessment of other LCA environmental indicators. The robustness testing of the calibrated Revit BIM model used to calculate Embodied Carbon Dioxide $\left(\mathrm{ECO}_{2}\right)$ tests this concern. The robustness test involves substituting $\mathrm{EE}$ material coefficients for ECO2, and assessing its simulation accuracy compared to truth model 3 using the same material coefficients.

The result of these validity tests is the identification of high risk building materials and elements that are likely to be have a high impact on the $\mathrm{iEE}, \mathrm{ECO}_{2}$ consumption of a building. This means that they may require a high level of modelled detail beyond their proportional influence. Building materials and elements are defined as high risk is defined in a number of ways:

I. They that are likely to have high or low proportion of $\mathrm{iEE}$ or $\mathrm{ECO}_{2}$ relative to the material quantities used. 
2. They that are likely to be highly influenced by other design decisions. Therefore they are likely to change substantially across different design iterations.

3. Their iEE and $\mathrm{ECO}_{2}$ results vary significantly adversely influencing simulation accuracy.

\subsection{Chapter Inference}

This Chapter developed the research design for testing this thesis' hypothesis. It covered the formulation of research objectives, the selection of the case study methodology, case study description, and the control of research design limitations. The developed research objectives require developing quality assurance tools, and processes for improving, and accessing the simulation accuracy of iEE LCA assessments. These form a critical component for developing an iEE BIM LCA BPS methodology for using BIM LCA tools effectively for informed decision-making. 
Chapter Four:

\section{THE METHODOLOGY OF THE BIM LCA BPS}

\section{I Chapter Intent}

The previous chapters defined the need for an Initial EE BIM LCA BPS (iEE BIM LCA BPS) to satisfy the requirements to effectively integrate the LCA assessment of building materials into sketch design phase activities. Critically, it identified that the calculation of accurate building material quantities, and the lack of a methodology for how to use BIM LCA tools are an obstacle limiting the use of LCA in the design process.

The aim of this chapter is to develop the solutions for fulfilling research objectives one and two. Chapter Section 4.2 fulfils research objective one. This is developing a functional definition what the iEE BIM LCA BPS model is, and how detailed it can be at sketch design. Chapter Section 4.3 addresses research objective two. This is the development of the methodology for translating the iEE BIM LCA BPS function definition into a BIM model. This includes selecting the most appropriate EE material coefficient database, and developing a method for how to use Revit to calculate a building design's material quantities, and then multiply them by their respective EE material coefficients to produce an iEE assessment result. The information gained from fulfilling these two research objectives, will be used in testing the thesis hypothesis, to determine how detailed the BIM objects and geometry constituting the iEE BIM LCA PBS model needs to be to calculate accurate LCA-based results.

Following this chapter, Chapter 5.0 develops the simulation accuracy assessment framework used in the thesis hypothesis for testing the iEE BIM LCA BPS methodology developed in Chapter 4.0. The hypothesis tests if, the iEE BIM LCA BPS methodology can calculate accurate LCA-based results of the environmental impact of building materials from sketch design level information quickly, and easily, to satisfy the requirements of effective integration. 


\subsection{Defining An iEE BIM LCA BPS Model}

As Chapter Section 2.4 concluded, the BPS is only a framework for how to use a simulation tool. It dictates in general terms what a simulation tool must deliver, e.g. fast and easy early design phase informed decision-making about building performance. However, for iEE, and LCA assessments using BIM LCA tools it lacks the specific requirements that defining how to do achieve this. One omission, is a definition of what an iEE BIM LCA BPS model is. Since a BPS model accesses only a one area of building performance at a time, its model is different for each building performance area, and each simulation tool. These differences change what simulation related building information must be modelled, including the level of detail required. For $\mathrm{iEE}$, the building information to calculate material quantities is what must be defined. Therefore, defining which building elements, and materials, must be in an iEE BIM LCA BPS model for accurate simulation results during sketch design is the first research objective for developing an iEE BIM LCA BPS methodology.

\section{The Problem: No Definition Of What Must Be Modelled}

Existing research has developed methods for calculating of building material quantities to reduce LCA complexity. These are a precedent for defining an iEE BIM LCA BPS model. These methods have all aimed to reduce the number of different material, and building elements that are calculated by developing rules based on the following parameters:

- Material weight, if the weight of a material is more than $1 \%$ of whole building weight or the use of the material is ranked in the highest 10 materials for the building (Jiao, Lloyd, \& Wakes, 20I2, p. 22).

- The material's cost, and EE intensity, if the material has large influence even if sometimes it does not account for a large proportion of whole building (Jiao et al., 2012, p. 22).

- The reported findings from other published case studies that identify the building elements (Y. L. Langston \& Langston, 20I2; Treloar, Fay, et al., 200I), and materials that contribute the majority of the total iEE (Kofoworola \& Gheewala, 2009, p. 1079). 
These rules appear to be reasonable modelling assumptions, and are part of what defines current best practice LCA iEE assessment methods. However, they are a function of a larger problem. Despite being the best practice method for calculating building material quantities, there is no definition for how detailed, or complete, a SOQ must be to conduct an accurate LCA assessment such as iEE.

The extent of this problem is evident in the large discrepancies between published iEE results by different researchers. A literature review of published LCA and iEE research case studies identified that the completeness of an iEE assessments depends on the individual researcher, who often for practicality reasons excludes certain building elements. Table 4.2 compares Treloar et al., (200I) and Y. L. Langston \& Langston (20I2) reported iEE studies at an element level breakdown, $11.7 \mathrm{GJ} / \mathrm{m} 2$ and $25.0 \mathrm{GJ} / \mathrm{m} 2$ respectfully. The large difference between these two figures is due to differences in the completeness, and scope of their respective iEE assessment. Treloar et al., (200I) states that for practicality reasons, the scope of their assessment was limited to only 14 building elements. By comparison, Y. L. Langston \& Langston (2012) assessed 43 building elements. Accounting for these scope differences by comparing only the same building elements, their respective iEE values are $11.0 \mathrm{GJ} / \mathrm{m} 2$ and $12.2 \mathrm{GJ} / \mathrm{m} 2$, equating to a difference of $9.8 \%$. This is a difference that would be considered reasonable in areas of building performance such as operative energy, and cost planning. 
Table 4.2: The Building Element Distribution of Initial EE

\begin{tabular}{|c|c|c|c|}
\hline \multirow[b]{2}{*}{ Building Element } & \multicolumn{2}{|c|}{ Initial Embodied Energy (GJ/m2) } & \multirow[b]{2}{*}{$\begin{array}{l}\text { Percentage } \\
\text { Difference } \\
\text { (Source I / } \\
\text { Source 2) }\end{array}$} \\
\hline & $\begin{array}{l}\text { Source I: } \\
\text { Mean EE (Treloar et al. } \\
\text { 200 Ib) }\end{array}$ & $\begin{array}{c}\text { Source 2: } \\
\text { Mean EE of } 25.0 \mathrm{GJ} / \mathrm{m} 2 \\
\text { (Y. L. Langston \& } \\
\text { Langston 20I2) }\end{array}$ & \\
\hline I Substructure & 0.7 & 2.3 & $33 \%$ \\
\hline 2 Columns $*$ & 1.4 & 0.4 & $367 \%$ \\
\hline 3 Upper floors $*$ & 5.4 & 1.6 & $339 \%$ \\
\hline 4 Staircases $*$ & 0.1 & 0.3 & $28 \%$ \\
\hline 5 Roof & 0.5 & 2.3 & $22 \%$ \\
\hline 6 External Walls * & 1.3 & 1.6 & $81 \%$ \\
\hline 7 Windows & 0.2 & 0.5 & $44 \%$ \\
\hline 8 Internal walls * & 0.9 & 1.0 & $90 \%$ \\
\hline 9 Wall finishes & 0.1 & 0.9 & $10 \%$ \\
\hline 10 Floor finishes & 0.3 & 0.7 & $44 \%$ \\
\hline I I Ceiling finishes & 0.1 & 0.8 & $16 \%$ \\
\hline Sub total & 11.0 & 12.2 & $90 \%$ \\
\hline 12-14 Other items & $\begin{array}{r}0.7 \text { (An additional } 3 \\
\text { elements) }\end{array}$ & $\begin{array}{r}12.78 \text { (An additional } 32 \\
\text { elements })\end{array}$ & $5 \%$ \\
\hline $\begin{array}{l}\text { Total of listed } \\
\text { elements I- I4 }\end{array}$ & 11.7 & $\begin{array}{r}\text { I2.2 (48.9\%) out of a } \\
\text { total of } 25 \mathrm{GJ} / \mathrm{m} 2\end{array}$ & $47 \%$ \\
\hline \multicolumn{4}{|l|}{ References: } \\
\hline \multicolumn{4}{|c|}{$\begin{array}{l}\text { Source I: The averaged embodied energy of the reported buildings from Table IV Case study } \\
\text { building initial embodied energy results (GJ/m2 GFA). An Analysis of the Embodied Energy of } \\
\text { Office Buildings By Height (Treloar, Fay, llozor, \& Love, 200Ib). }\end{array}$} \\
\hline $\begin{array}{l}\text { Source 2: The averag } \\
\text { Summary for Embodi } \\
\text { Analysis of Thirty Me }\end{array}$ & $\begin{array}{l}\text { ed embodied energy of the re } \\
\text { ed Energy by Element. Buildir } \\
\text { lbourne Case Studies (Y. L. L }\end{array}$ & $\begin{array}{l}\text { eported buildings from Table } \\
\text { ng Energy and Cost Perform } \\
\text { angston \& Langston, 20I2). }\end{array}$ & $\begin{array}{l}\text { 3: Statistical } \\
\text { ince: An }\end{array}$ \\
\hline
\end{tabular}




\section{The Problem Applied To The BPS Concept}

The impact of having no definition for what must be modelled is that building designers don't know what they have to model to produce simulation results that are accurate enough for design decision-making. The main issue is the completeness of the iEE LCA assessment. How complete does it need to be? Does every individual material, down to the number of bolts, washers, and nuts need to be estimated and included to be accurate enough? These are research questions that need to be answered. However, they are not the focus of this thesis research, and are therefore outside its scope. Instead, a BPS aims to make the existing best practice methods easier, not to redefine what they are.

Therefore, applied the iEE BIM LCA BPS, the aim is to easily deliver a SOQ level of material detail, and completeness, based on the information building designers required to make informed design decisions during the sketch design. The BPS concept achieves this by reducing the modelled complexity of the iEE BIM LCA BPS model. This means the issue of completeness becomes a question of whether iEE BIM LCA BPS model is sufficiently detailed for sketch design phase decision-making.

\subsection{What To Model For A BIM LCA BPS Of iEE}

To date, no research has investigated how to calculate building material quantities in the early phases of the design process from sketch design phase information, to a level of detail equivalent to a detailed design SOQ, which produces an accurate LCA or iEE assessment. Lacking standardised requirements, or guidance, for which building elements and materials must be modelled, there is no definition for which building elements and materials must be modelled for a BIM LCA BPS of iEE. Therefore, one must be developed. Table 4.2. I detail questions provide a framework for identifying the building elements that must be modelled in an iEE LCA BIM BPS. These comes from the BPS framework developed by Donn et al., (2012), and the requirements specific to building material iEE LCA assessments. 
Table 4.2. Ia: A Framework for Defining the Building Elements Constituting an iEE BIM LCA BPS

\begin{tabular}{|c|c|}
\hline Topic Area & Questions \\
\hline $\begin{array}{l}\text { Integrating LCA iEE into current design } \\
\text { solutions for lowering a building's } \\
\text { environmental impact. }\end{array}$ & $\begin{array}{l}\text { What design solutions are being made to } \\
\text { lower environmental impact? }\end{array}$ \\
\hline \multirow{2}{*}{$\begin{array}{l}\text { Integrating LCA iEE into the early phases of } \\
\text { the design process. }\end{array}$} & $\begin{array}{l}\text { Which of these design solutions must be } \\
\text { made in the early phases of the design } \\
\text { process? }\end{array}$ \\
\hline & $\begin{array}{l}\text { What building information is available at the } \\
\text { sketch design phase? }\end{array}$ \\
\hline Building material LCA & $\begin{array}{l}\text { Which of these effect building material } \\
\text { selection, and the quantity used in the } \\
\text { building? }\end{array}$ \\
\hline $\begin{array}{l}\text { Simulation accuracy: } \\
\text { Defined in Chapter 5.0, tested and reported } \\
\text { in Chapter } 6.0 \text {. }\end{array}$ & $\begin{array}{l}\text { Is the information available at the sketch } \\
\text { design phase sufficient to meet LCA iEE } \\
\text { simulation accuracy requirements for } \\
\text { informed decision-making? }\end{array}$ \\
\hline
\end{tabular}

\section{A Working Definition Of Design Decisions Made During Sketch Design}

At the core of the BPS is decision-making during the sketch design phase. Developing an iEE BIM LCA BPS model requires defining, the design decisions are made at sketch design, and the information about building elements is available at sketch design. These definitions contribute towards testing the thesis hypothesis by defining, the building elements to model, and their level of detail at the sketch design.

Chapter Section 2.2.2 described the design process in terms of design frameworks. These frameworks simplify the design process into series of design phases. Each phase identifies the key design tasks, design decisions, and the information that must be available in order to progress the design process in an idealised process. Table 2.2.2 presented a summary working definition of the design process used in this thesis research. This was an 
amalgamation of the AIA, NZCIC, and RIBA design process framework documents (American Institute of Architects (AIA), 2008; New Zealand Construction Institute Council (NZCIC), 2004; Ostime, 2013). Using these documents, and their supporting design documentation checklists, a detailed description of what design decisions are made during sketch design phase, and the information available about each building element at this time in the project was defined (refer to Appendix 4.0 Tables 4.2.Ia). This information was defined as a confounding variable in Table 3.2.3d, and therefore must be controlled.

Table 4.2. Ib presents an example of the larger sample of information available in Appendix 4.0 Tables 4.2. Ia. These tables are organised by a rough division of building elemental groupings:

- General

- $\quad$ Site

- Foundation and Substructure

- Superstructure

- Exterior Closure

- Roof
- Interior Closure

- Transportation Systems

- Mechanical Systems

- Electrical and Lighting Systems

- Equipment 


\subsection{I b: The Working Definition of the Decisions and Building Information Available During Sketch Design}

Source: (American Institute of Architects (AIA), 2008; New Zealand Construction Institute

Council (NZCIC), 2004; Ostime, 2013)

\begin{tabular}{|c|c|c|}
\hline & \multicolumn{2}{|c|}{ Design Decisions / Activities / Considerations } \\
\hline & Sketch Design Decisions & Developed Design Decisions \\
\hline \multirow{7}{*}{ ن } & $\begin{array}{l}\text { Selection of key materials and assess the embodied } \\
\text { impacts of building materials over the building's } \\
\text { lifespan. }\end{array}$ & $\begin{array}{l}\text { Specify sustainable materials and products, balancing } \\
\text { life-cycle assessment, maintenance, durability, and cost } \\
\text { - what materials? }\end{array}$ \\
\hline & $\begin{array}{l}\text { Design to minimise the quantity of materials and } \\
\text { construction waste. }\end{array}$ & Determine / select building components and materials \\
\hline & $\begin{array}{l}\text { Determine building plan depths for natural } \\
\text { ventilation, daylight, and views. }\end{array}$ & $\begin{array}{l}\text { Outline specifications that identify major materials and } \\
\text { systems and establish in general their quality levels. }\end{array}$ \\
\hline & $\begin{array}{l}\text { Design solutions to maximise adaptation of building } \\
\text { for use, components, and materials. }\end{array}$ & $\begin{array}{l}\text { Specifications and details of selected materials and } \\
\text { systems }\end{array}$ \\
\hline & $\begin{array}{l}\text { Determine which passive design solutions can be } \\
\text { used to reduce MEP demand. }\end{array}$ & Production of typical construction details \\
\hline & Determine building areas. & \\
\hline & $\begin{array}{l}\text { Determine building volumes, including defining } \\
\text { building floor to floor heights. }\end{array}$ & Building areas and volumes fixed \\
\hline
\end{tabular}

The key conclusion from developing this working definition of sketch design is that iterative testing, and decision-making about the passive design solutions, building size, shape, form, and materiality selection of the buildings thermal envelope that is the primary focus during this period of the design process. Energy efficiency, and renewable energy design solutions, including Heat Ventilation and Air Conditioning (HVAC), and other building services are limited to only outline system selection rather than their specific design. These are design considerations not considered until the developed design phase. This removes the need to consider building elements about building services during sketch design, making them outside the scope of the iEE LCA BIM PBS. Furthermore, the exclusion of building services is a scope limitation imposed by the capabilities of BIM LCA tools. Of the current tools, neither IMPACT nor Tally is capable of calculating LCA results for building services. This is due to a lack of robust and comprehensive LCA data on building services components (IMPACT, n.d.; KT Innovations et al., 20/4). 
The limitation of using this literature review technique to define the design process, sketch design decisions, and the information available at sketch design, is that it is not project specific. This may mean there are discrepancies between what this thesis has assumed to be available during sketch design, and what is actually available in real building projects. This risk is mitigated by the unique nature of buildings, where no two are ever the same. Basing the definition of sketch design information off of an idealised, and industry recommended approach for building design, means the developed BPS is more suitable for being used on building projects other than this thesis case study.

The AIA, and RIBA frameworks were selected because of their strong architectural focus. However, there is a risk that they are potentially biased towards the design activities of architects, and are not specific to the New Zealand construction industry. This risk is controlled by the inclusion of NZCIC's design framework and its design documentation guidelines. This is an independent institute, comprising of the New Zealand Institute of Architects (NZIA), and the Institute of Professional Engineers of New Zealand (IPENZ) as contributing members. The design documentation guidelines they published include separate documents specifically for architecture, electrical, fire protection, HVAC, hydraulic, and structural design activities. This helps to reduce the risk of any bias towards architectural design.

\section{The Definition of A BIM LCA BPS Of iEE}

Table 4.2. Ic presents a refined list of the building elements that must be modelled in an iEE BIM LCA BPS. This is the fulfilment of the first research objective, and confounding variable in the research design. This list was formulated by translating the decisions and information made during sketch design, and assessing whether they influence the selection of building materials, and/or their quantities. Table 4.2. Ic also shows the alignment of the two classification systems that are referenced throughout this thesis:

- Y. L. Langston \& Langston (20I2) reports iEE results using the Australian Institute of Quantity Surveyors (AIQS) Australian Cost Management Manual Volume I.

- The iEE BIM LCA BPS results are reported using the UniClass 2.0 Elemental classification table. The reasoning for selection is discussed in Chapter Section 4.3. 
Table 4.2. I c: Refined List of Elements Required For Modelling

\begin{tabular}{|c|c|c|c|c|}
\hline \multicolumn{3}{|c|}{ AIQS 2002 Classification } & \multicolumn{2}{|c|}{ UniClass 2.0 Elemental Classification } \\
\hline $\begin{array}{l}\text { Building } \\
\text { Element } \\
\text { Number }\end{array}$ & Building Element Name & $\begin{array}{c}\text { Building } \\
\text { Element } \\
\text { Code }\end{array}$ & Building Element Name & $\begin{array}{c}\text { Building } \\
\text { Element } \\
\text { Code }\end{array}$ \\
\hline 2 & Columns (Framed Buildings) & $\mathrm{CL}$ & Structure & EE-15-10 \\
\hline 3 & Upper Floors & UF & Upper Floor & EE-20-40 \\
\hline 5 & Roof & $\mathrm{RF}$ & Roof & EE-20-10 \\
\hline 6 & External Walls & EW & \multirow{2}{*}{ Wall And Barrier Elements } & \multirow{2}{*}{$\mathrm{EE}-25$} \\
\hline 7 & Windows & WW & & \\
\hline \multicolumn{5}{|l|}{ Notes: } \\
\hline \multicolumn{5}{|c|}{$\begin{array}{l}\text { AIQS is the Australian Institute of Quantity Surveyors. The building elements listed are } \\
\text { defined by the Australian Cost Management Manual Volume I. This is the classification system } \\
\text { used by Y. L. Langston \& Langston (20I2). }\end{array}$} \\
\hline \multicolumn{5}{|c|}{$\begin{array}{l}\text { UniClass } 2.0 \text { Elemental classification table. This is the classification system used in this thesis } \\
\text { to organise and report the results of the EE BIM LCA building performance sketch. }\end{array}$} \\
\hline
\end{tabular}

\subsection{An iEE Modelling Methodology For Revit}

An iEE is the multiplication of EE material coefficients $\left(E E C_{i}\right)$ by a building's material quantities $\left(\sum \mathrm{Q}_{\mathrm{i}}\right)$. The iEE BIM LCA BPS is also structured around this basic relationship. It is very similar to the BIM modelling processes used for the BIM LCA tools IMPACT and Tally, where:

- $\quad$ BIM objects are constructed. This includes both the 3D geometric form, and embedding the metadata which defines which individual materials, and LCA building material coefficients are used in the building.

- The BIM objects are assembled (modelled) into the building's overall design form. This is the BIM geometry. The BIM geometry provides the quantity measurement of the amount of individual materials are used in the building.

- Finally, the building material quantities are calculated from the completed BIM model (e.g. the BIM objects and geometry) using BIM tool's proprietary material quantities calculation tool, and are multiplied by the LCA building material coefficients. An inbuilt analysis tool is used to assist with decision-making. 
The iEE BIM LCA BPS calculation process differs from IMPACT and Tally. These tools have inbuilt interfaces, and embedded databases of LCA building material coefficients within AutoDesk's Revit BIM tool. However, as these databases, Ecoinvest and Gabi, are not New Zealand specific, neither of these tools can be used for this thesis research. Therefore a generic methodology that achieves the same result must be developed. This is the fulfilment of the second research objective, parts I-3:

Research Objective 2: Develop a methodology processes, practices and tools for using the BIM tool Revit for conducting an iEE LCA assessment, including:

2.I Selecting building material coefficients.

2.2 Calculating building material quantities.

2.3 Applying Equation 2, the multiplication of building material coefficients by building material quantities to calculate and analyse EE results.

This Chapter Section details the development of this methodology. The methodology works on the same principles as IMPACT and Tally, where:

- 3D BIM objects are constructed with the building material metadata embedded.

- $\quad$ A BIM model using these BIM objects is constructed, this is the iEE BIM LCA BPS model defined in Chapter Section 4.2.I.

- Revit's proprietary material calculators are used to generate a complete list of every building material, and their quantities.

At this point, the process diverges. IMPACT and Tally have the inbuilt results analysis tools, that multiple the building material coefficients by the calculated building material quantities. They do this directly within Revit. The iEE BIM LCA BPS methodology does not have this capability. Instead, an Excel spreadsheet has been created specifically for this thesis research to fulfil this function. Hereby referred to as the LCA results analysis spreadsheet, it includes the necessary tools for the analysis of LCA and EE results. The final modelling stage in the iEE BIM LCA BPS calculation process is: 
- The Revit calculated building material quantities are exported as a text file (TAB Delimited), and then imported into the LCA results analysis spreadsheet. Within this spreadsheet, the database of building material coefficients is stored (in this research, Alcorn's EE hybrid process/input-out). Automated Excel calculation formulas are used to multiply the imported building material quantities by the building material coefficients, which are automatically analysed.

Table 4.3 presents the iEE BIM LCA BPS calculation process as three distinct modelling stages. The following Chapter Sections of 4.3 discuss the development of this process, and the key decisions building designers must make. These decision include:

- Selecting an appropriate EE database of building material coefficients

- The process of using Revit to create the iEE BIM LCA BPS model, and calculate iEE. 
Table 4.3: The iEE BIM LCA BPS Modelling Process.

\begin{tabular}{|c|c|c|c|c|}
\hline \multicolumn{4}{|c|}{ Modelling Stages } & Modelling Tasks \\
\hline \multirow{3}{*}{$\begin{array}{c}\text { Accessing / } \\
\text { Calculating } \\
\text { Simulation } \\
\text { Data } \\
\text { Inputs }\end{array}$} & \multirow[b]{2}{*}{ I } & \multirow{2}{*}{$\begin{array}{l}\text { Using the LCA } \\
\text { results analysis } \\
\text { spreadsheet }\end{array}$} & $\begin{array}{l}\text { Set project performance } \\
\text { goals. }\end{array}$ & None. \\
\hline & & & $\begin{array}{l}\text { Finding simulation data } \\
\text { inputs. }\end{array}$ & $\begin{array}{l}\text { Selecting an appropriate } \\
\text { database of iEE building } \\
\text { material coefficients. Entering } \\
\text { them into the LCA results } \\
\text { analysis spreadsheet. }\end{array}$ \\
\hline & 2 & $\begin{array}{l}\text { Using the } \\
\text { Revit BIM } \\
\text { Tool }\end{array}$ & $\begin{array}{l}\text { Constructing the BIM BPS } \\
\text { model and calculating its } \\
\text { building material quantities } \\
\text { using the BIM tool. }\end{array}$ & $\begin{array}{l}\text { Constructing BIM objects with } \\
\text { the requisite metadata of } \\
\text { building materials embedded. } \\
\text { Constructing BIM geometry. }\end{array}$ \\
\hline $\begin{array}{c}\text { Doing the } \\
\text { Calculation } \\
\text { Process }\end{array}$ & 3 & $\begin{array}{l}\text { Using the LCA } \\
\text { results analysis } \\
\text { spreadsheet }\end{array}$ & Analysing the results & $\begin{array}{l}\text { Exporting the BIM calculated } \\
\text { building material quantities, and } \\
\text { importing them into an Excel } \\
\text { results analysis spreadsheet. }\end{array}$ \\
\hline
\end{tabular}

\subsection{Selecting A Building Material Coefficient Database}

Chapter Section 2.3.2 concluded that selecting an appropriate LCA database of material coefficients is a critical decision building must make that effects design decision-making, and simulation accuracy. Currently, there is no tool that assists building designers with making with decision, making it a contributing cause of excessive LCA calculation complexity.

LCA researchers have written extensively on the development of material coefficients, sources of uncertainties, and variability, and the development of tools that calculate their influence. These are called uncertainty assessment tools. Uncertainty assessment differs from accuracy assessment as the simulation results are not compared to a measured 'true value'. Instead, uncertainty assessment is an analysis of the factors that cause uncertainties, which in turn cause simulation inaccuracies. This makes uncertainty assessment a measure of how uncertain, or the risk that the simulation result may differ from what is predicted. Uncertainties are found in data simulation inputs. Reducing uncertainties in an LCA requires using data inputs that are a better representation of reality. 
However, very little research has focussed on the development of uncertainty assessment tools specifically building designers to evaluate different iEE databases based on the sources of uncertainty and variability (refer to Appendix 4.0 Table 4.3.Ia).

\section{Uncertainity Assessment Tools For Selecting EE Material Coefficient Databases}

To assist building designers assessing uncertainty, and variability, various LCA uncertainty assessment tools have been developed.

Uncertainty assessment tools can be classified into two categories; qualitative or quantitative. Qualitative tools assess data quality against a criteria, usually with a simple scoring system. The Data Quality Indicator Pedigree Matrix (DQIPM) is one example (Weidema \& Wesnæs, 1996). By comparison, quantitative tools calculate the size and impact of data input uncertainties. This is called operationalizing uncertainties.

Various researchers have written extensively on the limitations with the existing LCA uncertainty assessment tools (Björklund, 2002; Heijungs \& Huijbregts, 2004; Huijbregts, 1998; Ross, Evans, \& Webber, 2002). Table 4.3.Ib takes these limitations, and formulates them into a set of criteria for selecting the most appropriate existing LCA uncertainty assessment tools and process for the iEE BIM LCA BPS. Two types of assessment tools, quantitative statistical tools, and the qualitative DQIPM tool are assessed.

Table 4.3. Ib shows, that the DQIPM is the most appropriate tool for assessing the uncertainties in EE material coefficients for the purpose of early design phase EE assessments, and the iEE BIM LCA BPS. This selection was due to statistical quantitative uncertainty tools failing criteria 3, 5, and 9. They all require an uncertainty assessment tool be easy to use, simple, and to produce results quickly which are easily understood by the design team. Failing these criteria means that statistical tools do not achieve the fundamental purpose of the BPS; to help facilitate better decision-making by improving model insight (understanding and confidence in the results) through improved simulation accuracy. To achieve this, complex operationalization of uncertainties is not necessary. Björklund (2002) acknowledges this, and concludes that while traditionally simple tools such as qualitative DQIPM have been dismissed for not being accurate or detailed enough, they may well be the best tool because they are simple enough to actually be used. 
The results of Table 4.3.Ib are evidence supporting Björklund's (2002) conclusion. By default this meant selecting the DQIPM uncertainty assessment tool. Despite being better suited for sketch design assessment, it failed the $9^{\text {th }}$ criteria. However, when the DQIPM tool is used in junction with an accuracy assessment tool, the effects of the model input uncertainties, and error causing inaccuracies are expressed as inaccuracy compared to 'true' value figures.

Provided simulation uncertainties are reduced and the simulation result are within accepted accuracy requirements, the need for the DQIPM tool to comply with this criteria by actually calculating each uncertainty value is mitigated. 
Table: 4.3.I b: Quality Assurance Uncertainty Assessment Tools Assessed Against Section Criteria

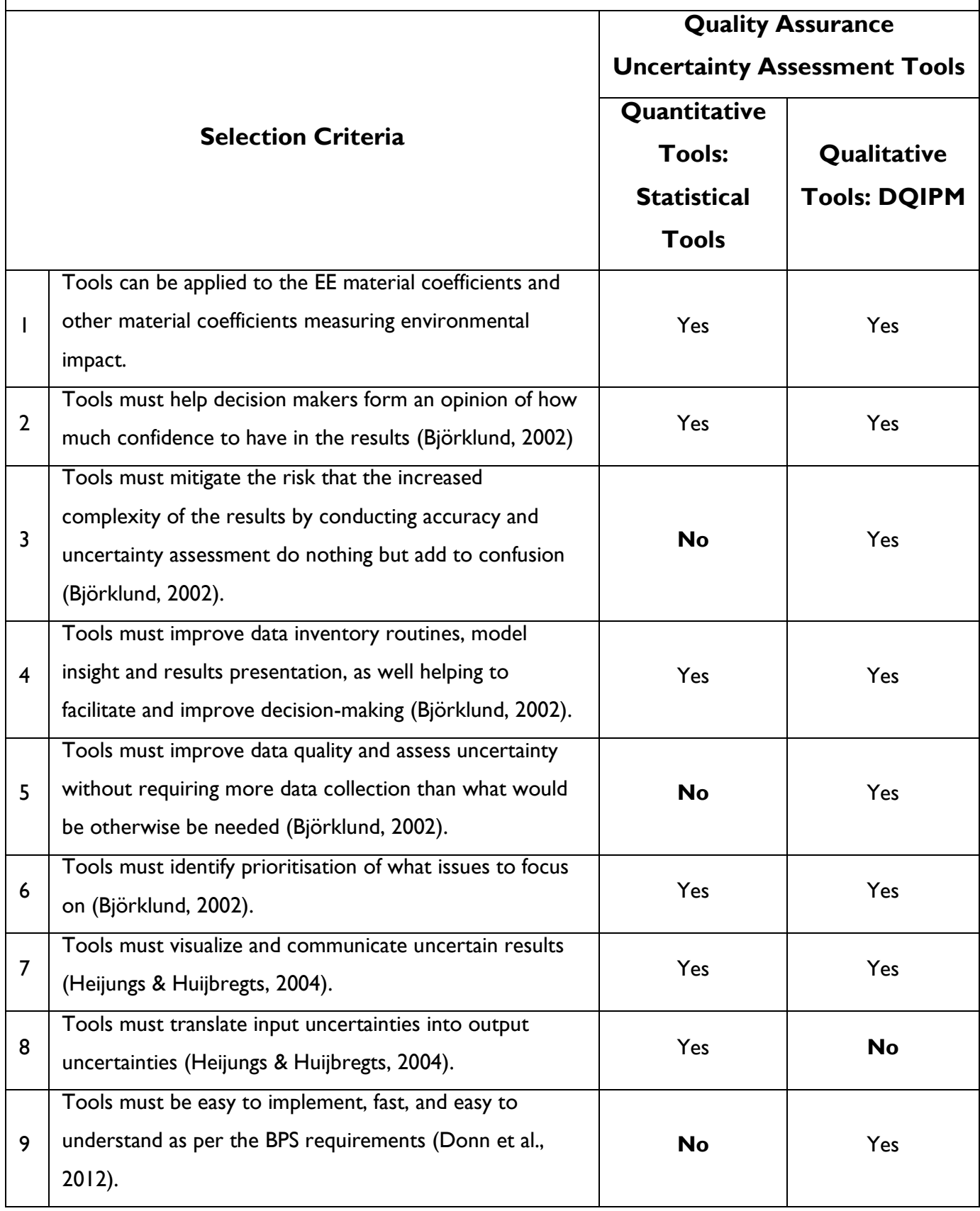

Using BIM To Calculate Accurate Building Material Quantities For Early Design Phase LCA 


\section{The Data Quality Indicator Pedigree Matrix LCA Uncertainty Assessment Tool} Weidema and Wesnæs (1996) original DQIPM tool for LCA (refer Appendix 4.0 Tables 4.3.Ic and 4.3.Id) is used in uncertainty analysis to quickly express the intangible qualitative descriptions in a quantitative assessment result format. Ciroth (2009, p. I586) sums this up succinctly as; the "basic aim is to come from [a] qualitative description of relevant aspects of an object of study to quantitative figures assessing these aspects. The matrix thus is a tool for quantification of qualitative assessment descriptions". Using the pedigree matrix, data is scored across 5 data quality indicators (columns, Table 4.3.2e describes these five different data quality indicators) against the quantification criteria (rows) from I to 5 . A score of I represents the best quality data, whereas a 5 is the lowest quality data. (Ciroth, 2009; Wang \& Shen, 20I3). In practice, according to previous studies ((Wang \& Shen, 20I3) citing Junnila and Horvath, 2003; Maurice et. Al., 2000) scores of 2 and 3 represent "acceptable data quality" and "fair data quality".

These numerical scores are only indicative. They do not calculate uncertainty or represent a certain amount of data quality. Their purpose is to easily survey the data quality to point at possibilities for improvements in data quality, and to trace back sources of uncertainty (Weidema \& Wesnæs, 1996, p. 169). Used in the iEE BIM LCA BPS, the DQIPM helps to compare different data sources by describing which aspects of data quality will influence the accuracy, and reliability of the result. The end result is the identification of which data source of EE material coefficients are the best representation of reality for the subject building. Therefore, it is not critical what the numerical description is, as long as the designers consider all the DQIs, and are consistent in their assessment, and the process results in choosing the right dataset.

\section{Developing An EE Pedigree Matrix}

Weidema \& Wesnæs's (1996, p. 169) original DQIPM was developed to assist in the development of LCA material coefficients by making data quality assessment easier. This was to more easily identify the possible areas for improving the quality of the data inputs, and to trace uncertainties back to their sources.

The iEE BIM LCA BPS does not require this same comprehensive data quality assessment provided by Weidema \& Wesnæs's (1996, p. 169) original DQIPM. Instead, to assist building 
designers in the selection of the most appropriate EE material coefficient databases, building designers only need to be aware of the main factors causing uncertainties, and select a database that minimises these as much as practically possible. They do not need to know or understand uncertainties to a depth of detail that is required to develop, or alter the value of these material coefficients. This is outside the scope of an iEE BIM LCA BPS, and their knowledge. Therefore there is a need to adapt Weidema \& Wesnæs's (1996, p. 169) original DQIPM to meet these specific requirements in fulfilment of this thesis's research objective 2.I. This is an important part of reducing the calculation complexity of LCA, and improving its integration into sketch deign.

Table 4.3.2e details the DQI that must be assessed in the selection of an EE material coefficient database. These derive from the identified sources of uncertainty and variability presented in Appendix 4.0 Table 4.3.2c. They have been simplified down to only assess information about EE material coefficients that is easily understood, and readily available for building designers. Evident by their alignment with both Weidema \& Wesnæs's Data Quality Indicators and the identified sources of uncertainty and variability (Appendix 4.0 Table 4.3.2c), the selected data quality indicators for EE material coefficients cover most causes of data uncertainty. 
Table 4.3.2e: Selection Data Quality Indicators for EE Material Coefficients

\begin{tabular}{|c|c|c|}
\hline $\begin{array}{c}\text { Selection Data Quality } \\
\text { Indicators for EE } \\
\text { Material Coefficients }\end{array}$ & $\begin{array}{c}\text { Best Match with } \\
\text { Weidema \& Wesnæs's } \\
\text { Data Quality Indicators }\end{array}$ & $\begin{array}{c}\text { Aligned with Identified } \\
\text { Sources of Uncertainty } \\
\text { and Variability } \\
\text { (Appendix } 4.0 \text { Table } \\
4.3 .2 \mathrm{c} \text { ) }\end{array}$ \\
\hline $\begin{array}{l}\text { Selection of EE material } \\
\text { coefficient calculation } \\
\text { method. }\end{array}$ & $\begin{array}{l}\text { Completeness / Further } \\
\text { technological correlation }\end{array}$ & $\begin{array}{l}\text { Model uncertainty / } \\
\text { Variability between sources } \\
\text { and objects }\end{array}$ \\
\hline $\begin{array}{l}\text { Select EE material } \\
\text { coefficient databases that } \\
\text { matches were building is to } \\
\text { be constructed or material } \\
\text { are imported from. }\end{array}$ & Geographical correlation & Spatial variability \\
\hline $\begin{array}{l}\text { Select databases developed } \\
\text { to match as closely as } \\
\text { possible to the subject } \\
\text { building. }\end{array}$ & Temporal correlation & Temporal variability \\
\hline $\begin{array}{l}\text { Select databases that are } \\
\text { from a reputable source } \\
\text { e.g. published literature, or } \\
\text { commercial databases. }\end{array}$ & Reliability & Parameter uncertainty \\
\hline
\end{tabular}


Table 4.3.2f shows the EE DQIPM tool. The selection of the indicator scores is derived from the issues specific for EE material coefficients. These are:

Data Quality Indicator A: Defined as best practice in EE assessments, the hybrid EE coefficients are the currently the most complete EE calculation method for measuring the EE of materials. The scoring order was based on Graph 3.2.2 (Crawford, 20I I).

Data Quality Indicator B: This criteria was taken from Weidema \& Wesnæs's (1996, p. 169) original DQIPM. It has been adapted to suit $\mathrm{EE}$, where best practice defines that material coefficients are either country specific or they are not. When a database value is not available for your specific country, a best as possible match must be selected. Looking at the importation of building material to see where the majority come from, or using a global average is feasible alternative. Also consider the countries energy mix of renewable and nonrenewable energy generation. Countries with high non-renewable energy generation will have higher EE material coefficients (Alcorn, 2010; Nebel, n.d.).

Data Quality Indicator C: This criteria was taken from Weidema \& Wesnæs's (1996, p. 169) original DQIPM. As EE is a part of an LCA the criteria is translatable. The crucial assessment is the use of technology and the countries energy generation mix between renewable and non-renewable sources (Alcorn, 2010; Nebel, n.d.).

Data Quality Indicator D: Defined by best practice EE assessment methods used by building researcher, the EE coefficients must have been developed from a reputable source. 
Table 4.3.2f: EE Material Coefficient Selection Data Quality Pedigree Matrix Tool

\begin{tabular}{|c|c|c|c|c|c|c|}
\hline \multirow{2}{*}{\multicolumn{2}{|c|}{$\begin{array}{c}\text { Data Quality } \\
\text { Indicator }\end{array}$}} & \multicolumn{5}{|c|}{ Indicator Score } \\
\hline & & I & 2 & 3 & 4 & 5 \\
\hline $\mathbf{A}$ & $\begin{array}{l}\text { EE material } \\
\text { coefficient } \\
\text { calculation } \\
\text { method }\end{array}$ & Hybrid & Input-output & Process & No Criteria & $\begin{array}{l}\text { Calculation } \\
\text { method } \\
\text { unknown }\end{array}$ \\
\hline B & $\begin{array}{l}\text { Geographical } \\
\text { correlation }\end{array}$ & $\begin{array}{l}\text { Data from area } \\
\text { under study } \\
\text { e.g. country }\end{array}$ & $\begin{array}{l}\text { Data from an } \\
\text { area with } \\
\text { similar } \\
\text { production } \\
\text { conditions e.g. } \\
\text { technology and } \\
\text { energy } \\
\text { generation mix }\end{array}$ & $\begin{array}{l}\text { Data from an } \\
\text { area with } \\
\text { slightly similar } \\
\text { production } \\
\text { conditions e.g. } \\
\text { technology and } \\
\text { energy } \\
\text { generation mix. }\end{array}$ & No Criteria & $\begin{array}{l}\text { Data from } \\
\text { unknown area } \\
\text { or area with } \\
\text { very different } \\
\text { production } \\
\text { conditions }\end{array}$ \\
\hline C & $\begin{array}{l}\text { Temporal } \\
\text { correlation }\end{array}$ & $\begin{array}{l}\text { Less than three } \\
\text { years of } \\
\text { difference to } \\
\text { year of study }\end{array}$ & $\begin{array}{l}\text { Less than six } \\
\text { years } \\
\text { difference }\end{array}$ & $\begin{array}{l}\text { Less than } 10 \\
\text { years } \\
\text { difference }\end{array}$ & $\begin{array}{l}\text { Less than } 15 \\
\text { years } \\
\text { difference }\end{array}$ & $\begin{array}{l}\text { Age of data } \\
\text { unknown or } \\
\text { more than } 15 \\
\text { years of } \\
\text { difference }\end{array}$ \\
\hline D & Reliability & $\begin{array}{l}\text { EE coefficients } \\
\text { sourced from a } \\
\text { reputable } \\
\text { source e.g. } \\
\text { published } \\
\text { literature, or } \\
\text { commercial } \\
\text { database. }\end{array}$ & No Criteria & No Criteria & No Criteria & $\begin{array}{l}\text { Source method } \\
\text { unknown }\end{array}$ \\
\hline
\end{tabular}

Using BIM To Calculate Accurate Building Material Quantities For Early Design Phase LCA 


\subsubsection{Sketching EE In The Revit BIM Tool}

Having fulfilled the research objectives I and 2.I, this Chapter Section addresses research objectives 2.2, and 2.3; the calculation of building material quantities, and iEE from a BIM model. The outcome is the methodology that is going to be used for testing the thesis hypothesis.

\section{BIM Interoperability}

Developing an iEE BIM LCA BPS BIM model requires defining what type of BIM model is required. The different types of BIM models are defined by the different levels of BIM technology interoperability. The level of interoperability is related to the maturity level of the BIM model (illustrated in Figure 4.3.2a). BIM level I is 3D CAD, therefore it is not capable of interoperability. Level 2 BIM maturity models is not an iBIM model. Instead all members of the design team produce and maintain their own BIM models before importing through interoperability one another's BIM model when required. At this level, the BIM D's; 4D (Time) BIM, 5D (Cost) BIM, and 6D (Facilities Management) BIM are capable information outputs (Sinclair, 20I2). Level 3 BIM maturity models are a iBIM models that contains all the information required to conduct multiple performance assessments (Donn et al., 2012, p. 188). This is the same information present in the 4D-6D Level 2 BIM models, just embedded in one model from the projects inception. Interoperability through standards such as IFC is required to do this (Pazlar \& Turk, 2008, p. 378).

The move from BIM maturity Levels 2 and 3 effects how the BIM model is constructed, by effecting how the BIM objects, geometry, and LCA information is embedded into the BIM model. However, this has no effect on what information is required, or the models calculation capabilities. Therefore, either a BIM maturity Level 2 or 3 BIM model can be used for an iEE BIM LCA BPS model. Provided the required information is embedded into the model for sketch design, it doesn't matter how it gets there. 
Figure 4.3.2a: BIM Maturity Diagram

Reference: Sinclair (2012, p. 5) citing Bew and Richards (2008).

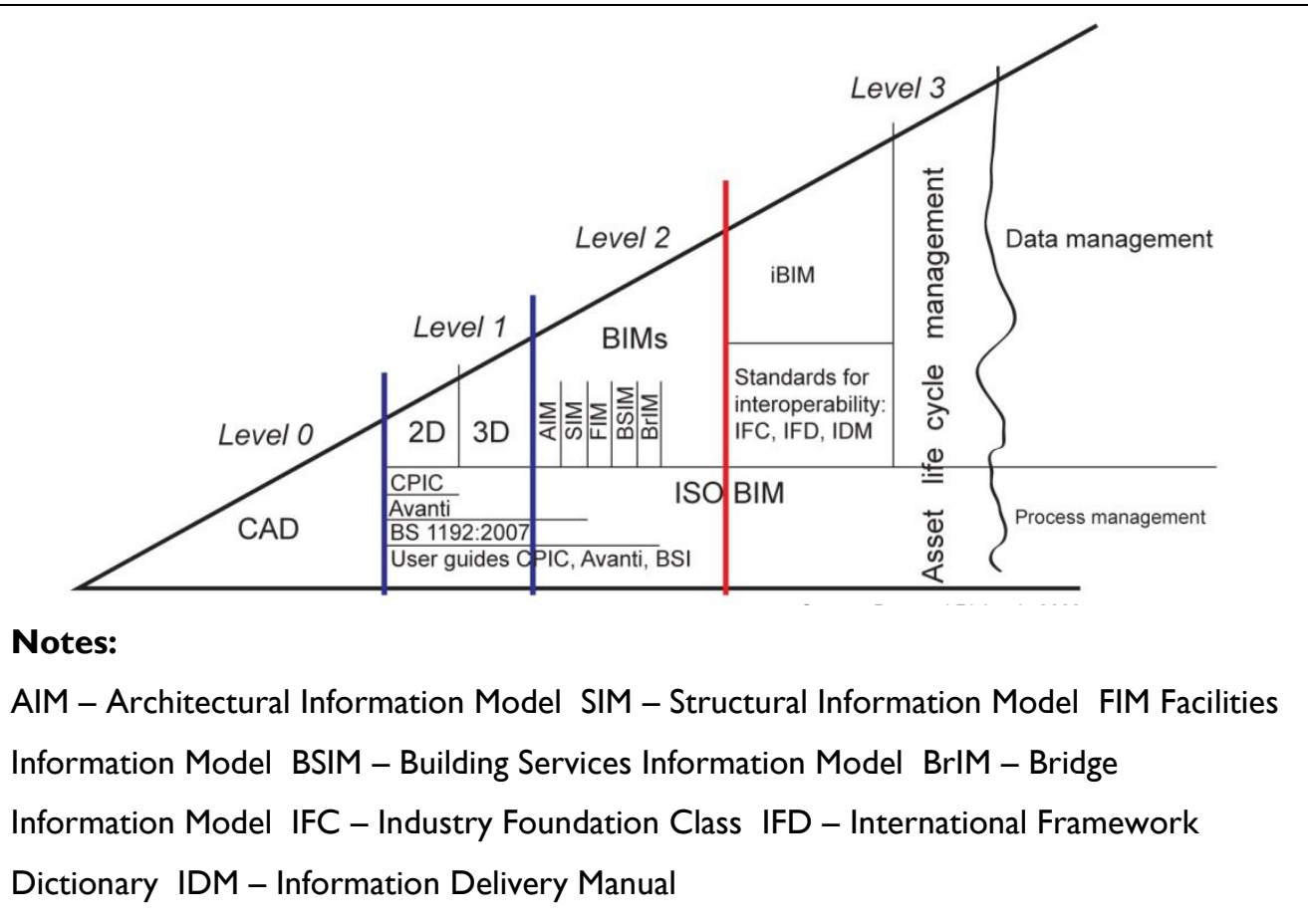

\section{Creating A Level 2 BIM Maturity Model}

Constructing a level 2 BIM maturity model for the IEE BIM LCA BPS, requires taking a building's design that is expressed as project documentation drawings (floor plans, elevation, sections and details), schedules, and specifications, and turning it into a BIM model e.g. BIM objects and BIM building geometry. The distinction between BIM objects and BIM building geometry is related to the hierarchy of how they organise building materials and products. BIM objects are the lower of the two. They deal with materials and products at an individual level, often assembling (also referred to as layering) them into a collection representing a specific construction system. Embedded within each BIM object is metadata such as, the cost, the manufacturer, the building classification system description and code, and material properties like density and EE. In this way the information calculable from a BIM model is entirely dependent of data inputs is entered into the BIM objects. 
The process of constructing a BIM model starts with constructing the BIM objects, and then arranging them into the building's overall form called the BIM building geometry. Methods for constructing BIM objects and geometry depend on the specific BIM tool being used. This thesis research uses AutoDesk's Revit BIM Tool. Therefore BIM objects are created using the 'Family Builder', and the BIM building geometry is constructed (hereby referred to as modelled) using the modelling tools shown in Figure 4.3.2a.

As an alternative to the time consuming task of creating BIM objects, many are freely downloadable from online databases called BIM libraries. One example is the National Building Specification's National BIM Library (The National Building Specification (NBS) \& BIM Technologies Alliance, 2014).

\section{Figure 4.3.2b: BIM Tool Revit Modelling Tools}

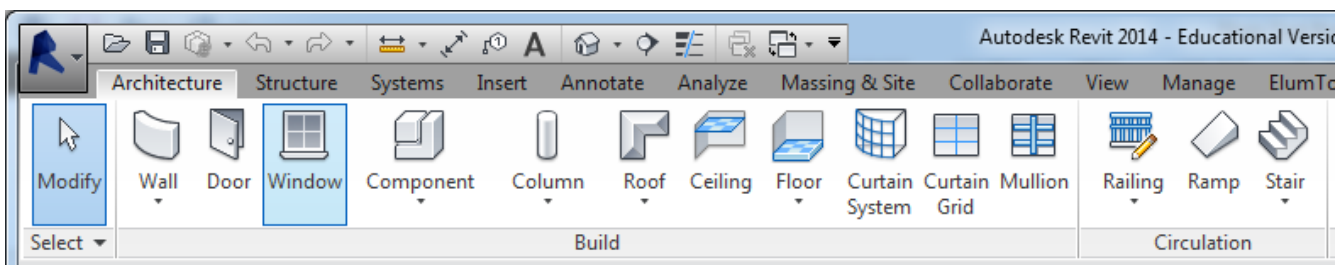

\section{Calculating Building Material Quantities From The BIM Model}

After constructing the BIM objects, and BIM geometry, the subsequent step in the iEE BIM LCA BPS modelling methodology is the calculation of the building material quantities from the BIM model. This is an automated process conducted by using the BIM tool's proprietary scheduling tools.

While using these tools makes the calculation easier, and faster, it also means that the quantities that can be calculated, and the unit format of their description, is limited by the functional capabilities of the BIM tool. Table 4.3.2a lists the Revit building elements (BIM objects), and the quantity information that can be calculated using its Material Takeoff and Schedule / Quantities tools, showing there is a variation in the calculable units of material quantities across the different building elements. For materials such as curtain wall mullians, only the linear length is calculated. This does not match the area, volume, or weight based functional units that EE and other LCA material coefficients are expressed in. This creates a formatting issue that the modeller must resolve as part of the iEE BIM LCA BPS methodology. 
As a solution, for specific materials, the modeller must enter user defined material parameters such as cross sectional area $\mathrm{m}^{2}$, material densities $\mathrm{kg} / \mathrm{m}^{3}$, and material densities $\mathrm{kg} /{ }^{2}$ and volume $\mathrm{m}^{3} / \mathrm{m}^{2}$. Table 4.3.2b shows this solution for curtain wall mullians.

\section{Table 4.3.2a: The Calculated Quantity Information Available Using Revit}

Source: Table 6 Building Element in Autodeck Revit (Wu, Ginige, Wood, \& Wee Jong, 20I4, p. 40).

\begin{tabular}{|l|l|}
\hline \multicolumn{1}{|c|}{ Revit Family Types } & \multicolumn{1}{c|}{ Quantity Information } \\
\hline Wall & Length, area, and volume \\
\hline Roofs & Thickness, area, and volume \\
\hline Ceilings & Perimeter, area, and volume \\
\hline Floors & Thickness, perimeter, area, and volume \\
\hline Curtain Wall Elements & Length, area, mullion lengths, and area \\
\hline Column & Width, depth, and volume \\
\hline Beam & Width, and volume \\
\hline Foundation & Length, width, and volume \\
\hline Doors & Thickness, height, and width \\
\hline Windows & Height, and width \\
\hline
\end{tabular}

Table 4.3.2b: A Solution for the Material Quantity Format Problem

\begin{tabular}{|l|c|c|l|}
\hline \multicolumn{1}{|c|}{ Material } & $\begin{array}{c}\text { Revit Calculated } \\
\text { Units }\end{array}$ & $\begin{array}{c}\text { Required } \\
\text { Unit }\end{array}$ & \multicolumn{1}{|c|}{ Work Around } \\
\hline Curtain Wall Mullians & Linear length, $\mathrm{m}$ & $\mathrm{m}^{3}$ & $\mathrm{~m}^{*}$ cross sectional area $\mathrm{m}^{2}$ \\
\hline Building Membranes & $\mathrm{m}^{2}$ & $\mathrm{~m}^{3}$ & $\begin{array}{l}\mathrm{m}^{2} * \text { weight }(\mathrm{kg}) \text { per } \mathrm{m}^{2} / \\
\text { density } \mathrm{kg} / \mathrm{m}^{3}\end{array}$ \\
\hline
\end{tabular}

\section{Selecting A Building Classification System}

Part of the process of constructing the BIM objects and building geometry is their organisation so that EE material coefficients can be applied, and the iEE results analysed. In current EE and LCA best practices for, results are expressed as the total EE per material, and by an elemental description (Y. L. Langston \& Langston, 2008, 2012; Treloar, Fay, et al., 200I; Treloar et al., 1999). 
Building classification systems are used to provide a standard definition for this organisation using standardised name, and code system for describing data and information, and its relationship to other items. Used within the iEE BIM LCA BPS methodology, a classification name and code must be applied to each material that makes up a BIM object, and to each BIM object that forms the BIM geometry. Within Revit this is best applied as a 'Family Type Parameter'. The outcome is a list of building material quantities that lists for each material, the name and identification code of that material, and the structural and/or construction system's name and identification code it is part of.

Currently, a large number of different manual building classification systems exist within the AEC industry. Many were developed to be country specific. Due to this diversity, coordination between the different classification systems is poor. This is an area of building research currently been investigated, with improvements in integration needed to keep pace with the increasing international trade of building materials, and the use of BIM. ISO I2006-2 is an international standard that was developed to improve the coordination between the multitudes of different classification systems used worldwide. This ISO standard is a framework for structuring building classification systems. It functions to standardise the structuring, labelling terminology, and definitions for manual classification systems (International Standards Organisation, 200I). This splits manual classification systems into two groups; those that are aligned with ISO I2006-2 e.g. UniClass 2.0 and OmniClass, and those that are not e.g. CI/SfB, CAWS, CBI, MasterFormat, UniFormat, and AIQS (Lou \& Goulding, 2008). First published in 200 I, ISO I 2006-2 has largely influenced the future development of manual classification systems; to the point where those not aligned are be reviewed, or phase out and replaced by those that are. For example, CAWS (the European classification system New Zealand's CBI is based on) and UniClass I.4 are being replaced by the UK's UniClass 2.0, while in the USA MasterFormat and UniFormat are being replaced by OmniClass.

In line with this trend in classification system development, the system selected for the iEE BIM LCA BPS must be aligned with ISO 12006-2, and be compatible with BIM modelling systems. This narrows the options to the OmniClass, and UniClass 2.0. For this thesis, UniClass 2.0 was selected. Unlike OmniClass, it has a consistent coding system which makes it easier to integrate into BIM. As Table 4.3.2d shows, UniClass 2.0 consistently uses 3 levels 
of detail within each table, with the coding being consistent at the first level between the different tables. By comparison, OmniClass' is inconsistent. Its classification levels varying depending on the table, the item in question, and the coding is not consistent between the different tables.

Table 4.3.2c: UniClass 2.0 Classification Code Structure

\begin{tabular}{|c|l|l|}
\hline Level & Element Code & Element Description \\
\hline I & EE-25 & Wall And Barrier Elements \\
\hline 2 & EE-25-25 & External Single Skin Walls \\
\hline 3 & EE-25-25-05 & External Single Skin Walls Substructure \\
\hline Level & Element Code & Element Description \\
\hline I & WR-25 & Wall And Barrier Systems \\
\hline 2 & WR-25-25 & Wall Lining Systems \\
\hline 3 & WR-25-25-05 & Acoustic Panel Systems \\
\hline
\end{tabular}

The selection of UniClass 2.0 classification tables for the iEE BIM LCA BPS is based on providing building designers with the analysis tools that existing published case studies use. Therefore the classification tables, building element (EE), product (PR), and material (P from UniClass I.4, as the UniClass 2.0 equivalent was not available at the time of this thesis research) tables are selected. The work results table (WR) would also have been an appropriate alternative to the elements table. It offers greater detail in its classification breakdown by integrating a description of materiality into the item description. This helps provide more specific information to assist the building designer's understanding of the results. However, being more detailed, it is not as conducive as building elements to fast iterative testing, where if a material change is made, the classification must be updated to match. For this reason, work results are not traditionally used in the early phases of the design process.

\section{Developing The LCA Results Analysis Spreadsheet}

A requirement of the iEE BIM LCA BPS is the development of a result analysis tool. This is to fulfil research object 2.3. The LCA results analysis spreadsheet is an excel spread that is used to multiply building material quantities by EE material coefficients, organise the iEE results into 
standard analysis formats for decision-making and in this thesis research the accuracy assessment to the truth models.

Currently there is no standardised best practice method requirements or guidelines for the presentation of EE or LCA assessment results for decision-making. Table 4.3.2d presents the results of a literature review investigating the result analysis formats commonly produced in an EE or LCA assessments. Development of this LCA results analysis spreadsheet is outside the immediate scope of thesis research. However, it is necessary in order to test the hypothesis, and is a critical component of achieving the aim of, improving the integration of LCA into the early phases of the design process (sketch design) by developing a methodology for using BIM LCA tools.

Table: 4.3.2d: iEE and LCA Results Format Guidelines

Source: (Yung et al., 20I3) (Treloar, Love, \& Faniran, 200I)

\begin{tabular}{|l|}
\hline Simulation Analysis Result Format. \\
\hline iEE to operative energy ratio. \\
\hline Normalised per Gross Floor Area (GFA) with definition of GFA stated. \\
\hline Total iEE consumption over building's lifespan. \\
\hline Total iEE consumption normalised annually. \\
\hline iEE consumption expressed as primary energy. \\
\hline iEE consumption expressed as secondary (delivered) energy. \\
\hline Per material defined by a building classification system: \\
\hline Total iEE consumption. \\
\hline iEE consumption normalised over the building's lifespan. \\
\hline iEE consumption normalised over material's lifespan. \\
\hline Per element defined by a building classification system: \\
\hline Total iEE consumption. \\
\hline iEE consumption normalised over the building's lifespan. \\
\hline EE consumption normalised over an element's lifespan. \\
\hline Per site works, structural, non-structure, envelope, finishes and services: \\
\hline Total EE consumption. \\
\hline iEE consumption normalised for the above categories over the building's lifespan. \\
\hline iEE consumption normalised for the above categories over the each categories lifespan. \\
\hline
\end{tabular}

Using BIM To Calculate Accurate Building Material Quantities For Early Design Phase LCA 


\subsection{Chapter Inference}

The BPS (BPS) only provided a framework for how to use building performance simulation tools in a manner that achieved the requirements of effective integration. Lacking were the specific requirements defining what a BPS is for a specific area of building performance, such as iEE. This limitation formulated research objectives one and two, where an iEE BIM LCA BPS must be defined, and a methodology for how to use Revit to conduct one must be developed. This chapter fulfils these two research objectives. The subsequent chapter, Chapter 5.0, develops the accuracy assessment framework for testing the feasibility of this chapter's developed iEE BIM LCA BPS methodology. 
Chapter Five:

\section{THE ACCURACY ASSESSMENT FRAMEWORK FOR THE BIM LCA BPS}

\section{I Chapter Intent}

The previous chapter addressed research objectives one, and two, and developed a methodology for the Initial EE BIM LCA BPS (iEE BIM LCA BPS). The aim of this methodology is to satisfy the requirements to effectively integrate the LCA assessment of building materials into the early phases of the design process. However, it is currently only a conceptual process, the iEE BIM LCA BPS methodology must be tested to prove that is can produce accurate LCA-based simulation results to satisfy the requirement of effective integration.

As chapters 2.0 and 3.0 concluded, there are no methods for assessing the accuracy of a whole building EE or LCA simulation process. The aim of this chapter is to fulfil the third research objective, and develop an EE simulation calibration accuracy assessment methodology. Chapter Sections 5.2 and 5.3 define simulation accuracy assessment, and the need to develop functional definitions for the critical terms of 'how close', and 'true value' for EE and LCA simulation. Chapter Sections 5.4 and 5.5 develop the EE simulation calibration accuracy assessment methodology, defining these terms.

Following this chapter, Chapter 6.0 uses the outcomes from the two methodology development chapters, 4.0 and 5.0, to test the thesis hypothesis. This is to determine if, the iEE BIM LCA BPS methodology can calculate accurate LCA-based results of the environmental impact of building materials from sketch design level information quickly, and easily, to satisfy the requirements of effective integration. 


\subsection{Defining Simulation Accuracy, And Precision}

In building performance, simulation accuracy is defined as the indication of 'how close' calculated results (values) are to their 'true value' measured in reality (ASHRAE, 2002, p. 7). This difference between simulated results and true values is caused by simulation errors. This makes simulation accuracy a measure of the cumulative effects of all the simulation errors. Simulation uncertainty relates to a lack of knowledge surrounding the simulation data inputs. Uncertainties occur when no data of information is available, or if available it is wrong, or ambiguous (Heijungs \& Huijbregts, 2004, p. 2). This lack of knowledge means there is an increased risk of simulation errors causing simulation inaccuracies.

Simulation precision is an expression of the closeness of agreement among repeated measurements of the same physical quantity (ASHRAE, 2002, p. 9). It accounts for offsetting or cancellation errors that occur when a model is over (when results are above their true value) or under (when results are below their true value) simulating results. These are error that are not identified by accuracy assessment, making simulation precision an important compliment to simulation accuracy assessment.

Simulation robustness is a measure of the reliability of simulation results (Hopfe \& Hensen, $201 \mathrm{I}$, p. 2800). A simulation robustness assessment is a type of sensitivity analysis. It identifies any unexpected sensitivities or hidden errors in simulation inputs, and in the simulation calculation process, which may arise in different design iterations or scenarios (Hopfe \& Hensen, 20I I, p. 2804). Robustness assessment tests to ensure that slight changes in the simulation inputs do not result in an unacceptable level of simulation accuracy, or not achieving performance goals (CIBSE, 1998, 2006).

\subsection{Assessing Simulation Accuracy}

Simulation accuracy assessment is the process of comparing simulation results to a true value, using a set of criteria that define the maximum acceptable tolerances that express how close (or accurate) is close enough. The result of this simulation accuracy assessment is the measurement of the margin of error in the simulation. This margin of error is the cumulative effect of all the simulation inaccuracies, caused by simulation uncertainties and errors. The 
cumulative effects of simulation inaccuracies caused by uncertainties, and errors, against a defined 'true' value, and evaluated against a defined maximum acceptable tolerance for measuring the margin of error between simulated results and the 'true' value. In LCA and EE research, past research has been focussed on the development of material coefficients, and their accuracy and uncertainty assessment methods and tools. This research has been conducted at two levels of the calculation process, an individual material level, and a whole building level:

- At an individual level material level, the development of uncertainity assessment methods and tools is specific for the material coefficients. For EE, these tools assessed the individual data inputs used in the calculation method for developing the EE material coefficients.

- A whole building level assessment assesses the impact of using inappropriate EE material coefficients. Wang \& Shen (2013) developed quality assurance methods and tools for assessing the potential impact EE material coefficients formulated from generic data, or from databases not specific to the subject country have on the accuracy of the result. Critically, they do not advocate the level of inaccuracy when the simulation results are no longer suitable for decision-making.

Both of these research levels, extend only to material coefficient and the assessment of their uncertainty. To date, there is no method for assessing the accuracy of a LCA assessment that is the result of multiplying building material coefficients by building material quantities. This is a gap in LCA research that this thesis' third research objective is fulfilling.

Looking to other areas of building performance for precedence, Operative Energy (OE) simulation calibration is a comprehensive form the accuracy assessment used in building design. It is a method of assessing, and ensuring simulations meet predefined accuracy requirements. Critically, it extends beyond determining the deviation of simulation results compared to their 'true value', to include specifying, how far this margin of error can be, while still facilitating informed decision-making (ASHRAE, 2002, p. 7). This makes calibration the most comprehensive, and best practice method of accuracy assessment for accessing simulation accuracy in building performance. 


\subsection{Existing Calibration Accuracy Assessment}

Simulation calibration can only be used in building performance when measured data e.g. a truth model, is available. This makes it unsuitable for new building design, but ideal for testing this thesis' hypothesis. In the iEE BIM LCA BPS methodology, the need for a calibration accuracy assessment is driven by the following reasons:

- Uncertainty assessment tools are not available for reducing simulation inaccuracies in the material quantity simulation inputs. Therefore any uncertainties and errors in this data cannot be reduced, or removed, prior to simulation. This means they are integrated into the calculation result. Therefore they must be dealt with as part of simulation accuracy assessment. To be effective, the iEE BIM LCA BPS must satisfy all the requirements for effective integration outlined in Chapter Section 2.3.

- Simulation calibration is used in this thesis research to define information building designers must model, so that they model only enough information, to a level of detail, that is necessary to calculate accurate iEE results for basing informed design decisions on. Critically, this requires defining how accurate is accurate enough?

To date no research has applied simulation calibration LCA or EE assessments. Therefore, one must be developed. OE simulation calibration provides the basis for achieving this thesis research objective.

There are many different OE simulation calibration available (Bensouda, 2004, p. 5).

However, in essence, they all work towards the same premise. This is assessing the accuracy of an OE model, and making changes to reduce its uncertainties, and errors, to improve its accuracy a level that meets the maximum acceptable calibration tolerances. These maximum acceptable calibration tolerances are set by project specific requirements, or by governing standards such as, the American Society of Heating, Refrigerating and Air-Conditioning Engineers (ASHRAE) Guideline 14 Measurement of Energy and Demand Savings (ASHRAE, 2002) (hereby referred to as ASHRAE Guideline 14:2002). ASHRAE Guideline 14:2002, and documents that specifying achieving its compliance, such as the United States Department Of Energy's M\&V Guidelines: Measurement and Verification for Federal Energy Projects Version 3.0 (US DOE, 2008) (hereby referred to as M\&V Guideline 3.02008 ), are primarily focussed

Using BIM To Calculate Accurate Building Material Quantities For Early Design Phase LCA 
on setting the requirements and acceptable means, for the measurement and calculation of the energy savings achieved by energy conservation measures, and building design solutions. In both documents, calibrated simulation is one means of achieving compliance (Raftery, Keane, \& Costa, 2009, p. I199).

One method of simulation calibration was developed by Raftery et al. (2009). Figure 5.4 shows their calibration methodology. This is divided into two stages, pre-simulation and post simulation. Pre-simulation calibration is the processes of assembling the building information, and data, required to conduct an OE simulation. The critical aspect of this stage is removing or reducing simulation uncertainties, and errors, before they are made. This involves conducting Quality Assurances (QA). Current best practice QA methods, and tools, are defined by documents such as CIBSE AMI I Building Energy and Environmental Modelling (CIBSE Applications Manual II) (CIBSE, 1998), and CIBSE Guide A: Environmental Design (CIBSE, 2006). Often as-built information or real building data is stipulated as a requirement for modelling assumptions. This is to ensure the model represents the real OE performance is as close as possible.

Post simulation calibration involves comparing the simulated results to the actual building performance measurements e.g. constitute the truth model. Following this, adjustment are made to the model to make to meet the established maximum acceptable calibration tolerances. Once met, the model can be declared as calibrated. The most important component of the post calibration methodology is the definition of the maximum acceptable calibration tolerances. 
Figure 5.4: Generalised Simulation Calibration Methodology/Process.

Source: Adapted from Raftery et al. (2009, p. 1200).

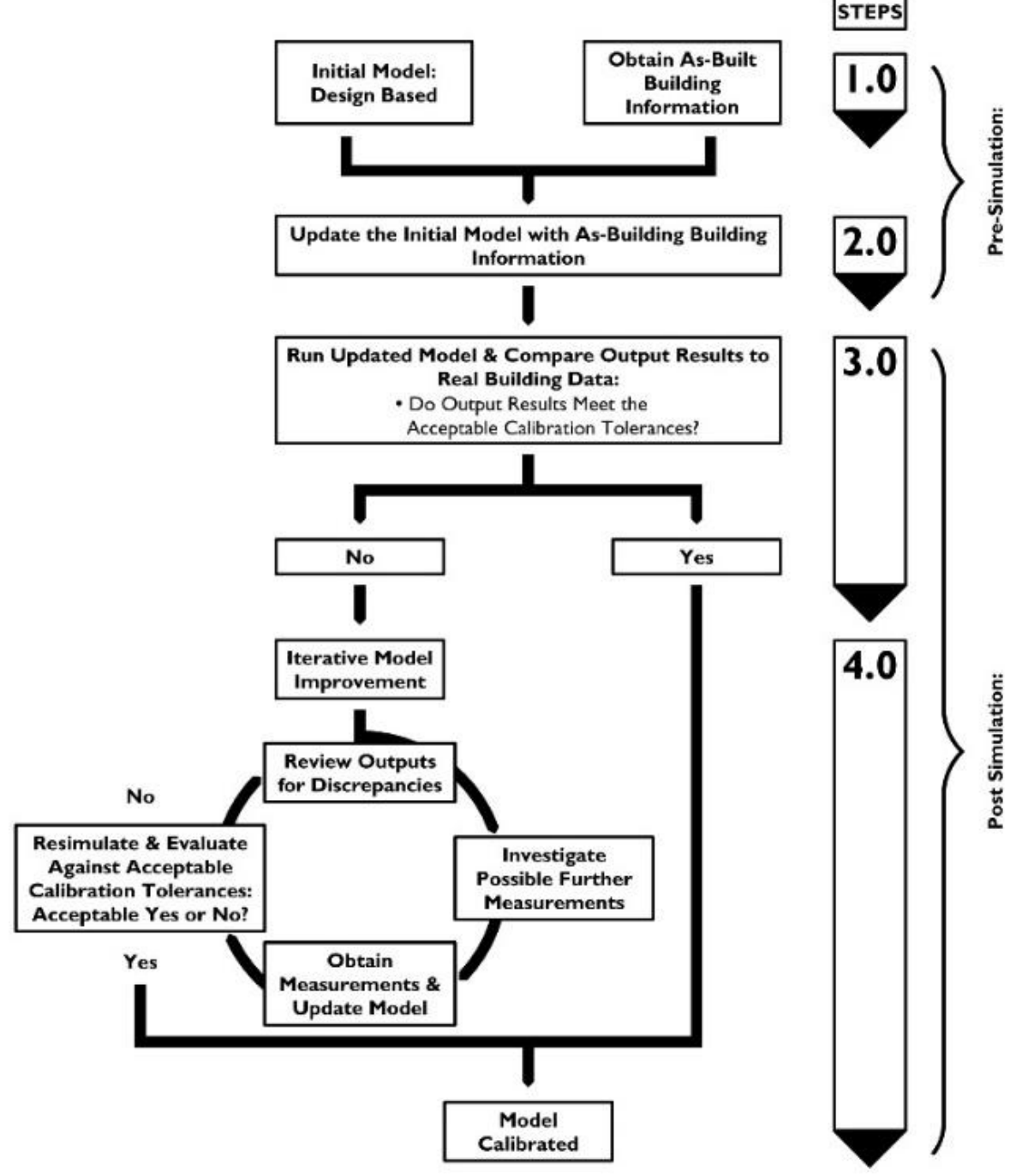

Using BIM To Calculate Accurate Building Material Quantities For Early Design Phase LCA 
Table 5.4a presents the values for two maximum acceptable calibration tolerances metric defined by ASHRAE Guideline 14:2002, and Tables 5.4b and 5.4c show how they are calculated. These are Mean Bias Error (MBE), and the Coefficient of Variation of Root-Mean Squared Error (Cv(RMSE)).

Table 5.4a: Acceptable Calibration Tolerances

\begin{tabular}{|c|c|c|}
\hline Calibration Type & Calibration Metric & $\begin{array}{l}\text { Acceptable Calibration } \\
\text { Tolerance }\end{array}$ \\
\hline \multirow{2}{*}{ Monthly } & $\mathrm{MBE}_{\text {month }}$ & $\pm 5 \%$ \\
\hline & $\mathrm{C}_{\mathrm{v}}\left(\mathrm{RMSE}_{\mathrm{month}}\right)$ & $+15 \%$ \\
\hline \multirow{2}{*}{ Hourly } & $\mathrm{MBE}_{\text {month }}$ & $\pm 10 \%$ \\
\hline & $\mathrm{C}_{\mathrm{v}}\left(\mathrm{RMSE}_{\mathrm{month}}\right)$ & $+30 \%$ \\
\hline \multicolumn{3}{|l|}{ Notes: } \\
\hline \multicolumn{3}{|c|}{ MBE $=$ Mean Bias Error. } \\
\hline \multicolumn{3}{|c|}{$\mathrm{Cv}(\mathrm{RMSE})=$ Coefficient of Variation of root-mean squared error. } \\
\hline \multicolumn{3}{|l|}{ References: } \\
\hline
\end{tabular}

MBE calculates how accurate the simulated results are predicted compared to the measured data truth model (US DOE, 2008, Pp. 4-4, 4-20). Positive values indicate that the model over predicts actual values, while negative values indicate that the model under predicts actual values. However, this MBE assessment is effected by simulation cancellation errors. Simulation cancellation errors occur when the positive and negative differences between simulation and truth model values combine to reduce the MBE. This can provide an incorrect assessment of simulation accuracy, leading to the building designer wrongfully trothing the simulated results. Recognising this potential error in accuracy assessment, the $\mathrm{Cv}$ (RMSE) metric is required.

$\mathrm{Cv}(\mathrm{RMSE})$ is a measure of simulation precision, calculating the standard deviation of the error indicating the overall uncertainty in the model. The $\mathrm{Cv}(\mathrm{RSME})$ metric communicates precision as a single percentage value indicating the overall fit of the simulation results 
compared to the measured results (ASHRAE, 2002, p. 4I). The $\mathrm{C}_{\mathrm{v}}(\mathrm{RMSE})$ value is always positive, with the lower the value the better the calibration (US DOE, 2008, PP. 4-4, 4-20).

Table 5.4b: Equation for Calculating the Mean Bias Error (MBE).

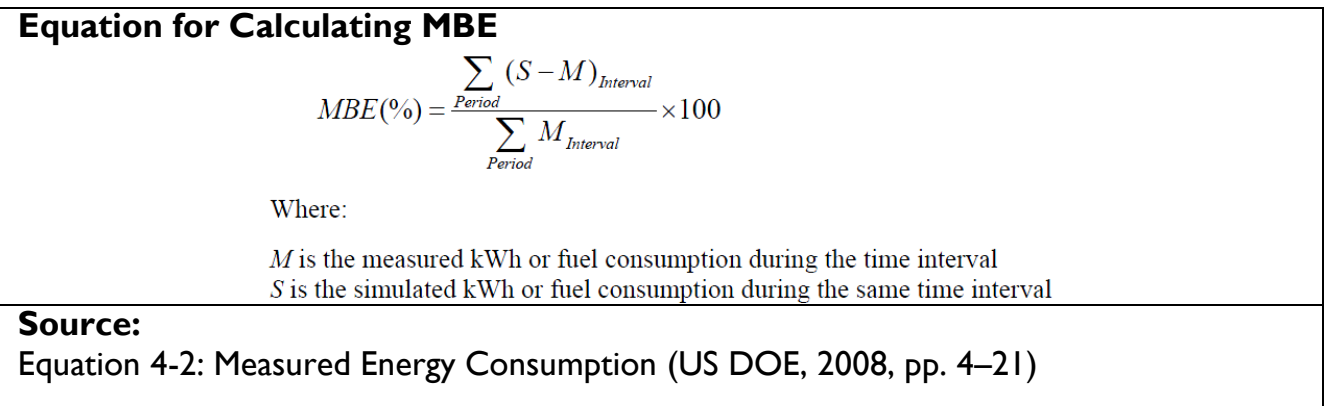

Table 5.4c: Equation for Calculating the Coefficient of Variation of Root Square Mean Error (Cv(RSME)).

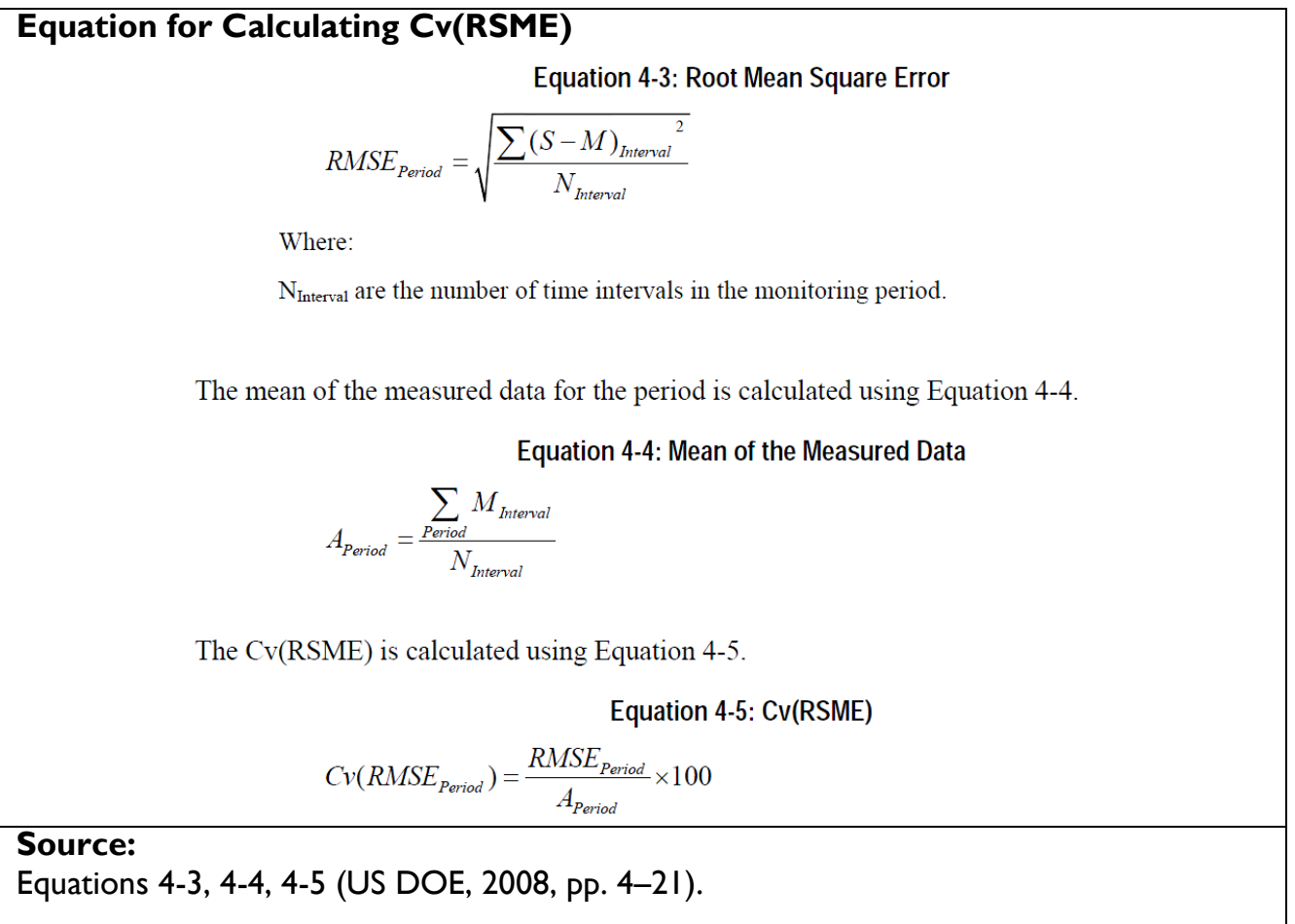

Using BIM To Calculate Accurate Building Material Quantities For Early Design Phase LCA 


\subsection{Developing An EE Calibration Method}

In this thesis research design, simulation calibration is used for testing the thesis hypothesis. This is assessing the accuracy of the iEE BIM LCA BPS simulation results, to identify; the areas required for its improvement; to define when the simulation is accurate enough, and when the BIM model is detailed enough for building design decision-making. Lacking a calibration methodology for LCA or EE, in fulfilment of research object three, one must be developed. Developing a basic EE simulation calibration methodology, the critical definitions required are:

- The definition of EE true values.

- The definition of maximum acceptable calibration tolerances.

\subsection{Defining The 'True' Value Of A Building's EE Consumption}

The 'true value' of a phenomenon is defined by what can be physically, and practically measured by current best practice methods and tools. For a building's iEE, this is the measurement of each building material, multiplied by the quantity used in the building' form. It is the measurement of these two data inputs in reality, not through simulation, that combine to produce the 'true value' for an iEE result. Therefore, defining the 'true' value for a building's total $\mathrm{iEE}$ is a question of, which measurement techniques for the $\mathrm{iEE}$ of building materials, and building material quantities are the most representative of reality?

Measuring the EE of building materials is an impractical task. Chapter Section 4.3.2, identified and discussed the uncertainties effecting measuring the EE of building materials by calculating EE building material coefficients. It is these uncertainties that cause the value of EE material coefficients to different from a material's EE in reality. The EE Data Quality Indicator Pedigree Matrix (EE DQIPM) was developed specifically as part of this thesis research for EE material coefficients to identify the sources of uncertainties in specific EE databases. It helps building designers to select the most appropriate database of EE material coefficients for their building by qualitatively assessing the data quality of an EE database. Scores of I-3 are considered best practice. Using this tool, an EE database that achieves a score within the I-3 range there defines its 'true value' in the context of the definition of accuracy, and EE simulation calibration. 
Measuring the building material quantities used in a constructed building is similarly impractical. A building design is not finalised until after the construction lifecycle stage. Once completed, it is impractical to deconstruct the building and measure the volume quantities of each material used. Like the EE material coefficients, the 'true value' of building material quantities is defined by the best current method of measurement. Chapter Section 2.6 defined this as a SOQ (SOQ). Therefore, a list of building material quantities, measured or calculated, to a level of detail equivalent to a SOQ defines its 'true value' in the context of the definition of accuracy, and EE simulation calibration.

\subsubsection{Defining 'How Close’ Is Close Enough: EE Maximum Calibration Tolerances}

In simulation calibration accuracy assessment, the definition of 'how close' simulation results must be to their 'true value' in reality, is defined by the maximum acceptable calibration tolerances. Developing an iEE BIM LCA BPS calibration methodology requires developing a functional definition for calibration tolerances specifically for iEE. In the wider perspective of this thesis research, the definition of these calibration tolerances define how accurate, and therefore, how detailed the BIM model needs to be calculate accurate building material quantities.

Due to the differences between EE and $\mathrm{OE}$, defining EE maximum calibration tolerances is not simply using those reported by ASHRAE Guideline 14:2002 (ASHRAE, 2002). It is unknown whether the ASHRAE Guideline 14:2002 figures were developed through research experimentation in calibration case studies, or because they were simply convenient statistical metrics and their values seemed sensible. Regardless, contemporary research has proven them to be appropriate. Bensouda (2004) supports the ASHRAE Guideline 14:2002 maximum calibration tolerances, stating that, "[modelling] efforts have been quite successful in achieving simulated results that agreed with the measured consumption, typically to less than $5 \%$ on an annual basis. Agreement within $5-10 \%$ has often been achieved on a monthly basis, and sometimes on a daily basis" (Bensouda, 2004, p. 5). Further evidence supporting their suitability is demonstrated by examining the level of accuracy an OE simulation must function to, relative to the annual OE savings achieved by Energy Conservation Measures (ECMs). For example, Kim (20I0), investigating the ECMs of building envelopes, and 
reported that "increasing the external wall insulation by $60 \%$ will reduce the total building's energy consumption by $1.5 \%$ for high-rise buildings and $1.4 \%$ for low-rise buildings" (Kim, 2010, p. 72). This is a relatively small reduction in a building's annual OE consumption. The risk is that if the OE simulation is not operating at a high enough level of accuracy and precision, these OE savings would have been lost in the margin of error called the performance gap.

\section{Defining Criteria For Selecting Ee Maximum Acceptable Calibration Tolerances}

Lacking EE or LCA simulation calibration research equivalent to Bensoudas (2004), it is unknown whether the ASHRAE Guideline 14:2002 maximum acceptable calibration tolerance values are suitable for testing this thesis' hypothesis. While ASHRAE Guideline 14:2002 gives no guidance for defining these values, other calibration standards do. The M\&V Guideline 3.0 2008 states that, whenever project specific calibration tolerances are required, that "specific calibration goals should be set for each project based on the appropriate level of effort [...]" (US DOE, 2008, pp. 4-20). Critiquing this statement, the key idea is that calibration goals should be based on an "appropriate level of effort". An 'appropriate level of effort' refers the effort level required to calibrate a model. This statement acts as a criteria, functioning to ensure that the values set defining the maximum acceptable calibration tolerance are reasonable. This brings forward the question of, what can be considered a reasonable level of effort for EE or LCA simulation calibration.

Reasonable accuracy requirements can be defined as those that are not overly strict, or too lenient, compared to modelling time constraints, decision-making, and performance goals. In the context of this thesis research, the terms 'reasonable' and 'appropriate' for EE calibration, are defined by how the iEE and LCA are calculated, and what the results are too be used for. The iEE BIM LCA BPS produces results for iterative testing of design decisions in the early phases of the design process. This simulation must be conducted quickly, and easily, to produce simulation results that are accurate enough to allow building designers to make informed design decisions (Donn et al., 2012, p. 203). Therefore the defined values for EE maximum acceptable calibration tolerances must integrate into this process, so they help achieve an iEE BIM LCA BPS, rather than act as an obstacle to it. These statements formulate the criteria for defining the value, but do not define it. 


\subsubsection{The Functional Definition Of EE LCA Calibration Tolerances}

Table 5.5.3a presents a summary of the accuracy assessment criteria used in building cost planning. Cost planning was selected because like EE and LCA, it a building's cost is calculated by multiplying building material coefficients by building material quantities. Furthermore, the best practice method for calculating building material quantities is to use a cost planning SOQ. Using these for figures EE and LCA does come with the risk that they are not suited for EE or LCA. For example, these reported maximum acceptable accuracy margin of errors for a building cost planning assessment are influenced by preliminary and contingency sums. Preliminary and contingency sums are additional building costs used to account to potential under estimating errors, or for unknown risks. Both cover the costs help to account for the ambiguity in cost planning estimates compared to reality. They are not measured works, like material quantities, but expressed as a lump sum or percentage of the total cost usually between 5-20\% (Smith \& Jaggar, 2006). They can include the costs required to complete construction work, such as temporary site works, to anticipated increases in the cost of building materials (Brook, 2004; Ferry et al., 2007; Smith \& Jaggar, 2006). Therefore, their value is highly dependent upon the specific project.

Table 5.3.3a: Accepted Inaccuracies in Building Cost Planning

\begin{tabular}{|l|l|}
\hline Design Phase & $\begin{array}{l}\text { Maximum Acceptable Accuracy Margin of } \\
\text { Error }\end{array}$ \\
\hline Concept Design & $\begin{array}{l} \pm 10-20 \% \text { (Holm et al., 2005) cited in (Samphaongoen, } \\
2010) .\end{array}$ \\
\hline Developed (Scheme) Design & $\begin{array}{l} \pm 5-10 \% \text { (Holm et al., 2005) cited in (Samphaongoen, } \\
2010) .\end{array}$ \\
\hline Detailed Design & $\pm 2-4 \%$ (Holm et al., 2005) cited in (Samphaongoen, \\
& $2010)$. \\
\hline General & $\pm 5-10 \%$ (Smith \& Jaggar, 2006, Pp. 322-323). \\
\hline
\end{tabular}

As Table 5.3.3a shows, only overall accuracy (MBE) is reported, Cv(RSME) measuring precision is not assessed. The numbers reported for building cost planning MBE, range from MBE $\pm 2 \%$ (Smith \& Jaggar, 2006, pp. 322-323) to MBE $\pm 20 \%$ (Brownass, 200I, pp. 24-27). The higher accepted MBE during sketch design is due to design uncertainties. This is where 
the lower design resolution causes the high likelihood of significant changes later in the design process. By comparison, the lowering acceptance of inaccuracy reflected in MBE decreasing through the design process reflects the increasing level of design resolution, and design detail from sketch to detailed design. Because the design is more resolved, and of greater detail, it can be calculated more accurately.

Table 5.3.3b presents the selected maximum acceptable calibration tolerances for this thesis research. The value $\mathrm{MBE}_{\text {Total }} \pm 20.0 \%$ was selected based on the cost planning simulation accuracy requirements for the concept (sketch) design phase. This $M B E_{\text {Total }} \pm 20.0 \%$ is also used in the M\&V Guideline 3.0 2008, where ECMs above a $20 \%$ reduction in the annual OE use do not require a calibration simulation model to calculate their value. With no guidance from other areas of building performance for precision $\mathrm{Cv}(\mathrm{RSME})$ requirements, the ASHRAE Guideline 14:2002 have been retained.

These selected calibration tolerances for EE are only a functional definition. Like the development of the OE ASHRAE Guideline 14:2002 calibration tolerances, these are only based on what logically is an 'appropriate level of effort' for EE. In practice, modellers need to select EE calibration tolerances appropriate to their projects based on the decision-making requirements they set in their performance goals defining the lowest acceptable ECM allowable. In the same way that subsequent calibration studies have confirmed the appropriateness of the ASHRAE Guideline 14:2002 tolerances for OE, an outcome of this thesis research will be determining if the values defined by this research are suitable for EE and LCA beyond this thesis research. 
Table 5.3.3b: Functional Definition of Calibration Accuracy and Precision Tolerances

\begin{tabular}{|c|c|c|}
\hline $\begin{array}{l}\text { Calibration } \\
\text { Metric }\end{array}$ & \multicolumn{2}{|c|}{ EE Maximum Acceptable Calibration Tolerances } \\
\hline $\mathrm{MBE}_{\text {Total }}$ & $\pm 10-20.0 \%$ & $\begin{array}{l}\text { Values for concept design phase (Holm et al., 2005) cited } \\
\text { in (Samphaongoen, 2010). }\end{array}$ \\
\hline $\mathrm{Cv}(\mathrm{RSME})_{\text {Total }}$ & $15.0-30.0 \%$ & $\begin{array}{l}\text { Originally for calibration of monthly measured data } \\
\text { (ASHRAE, 2002, p. 38; US DOE, 2008, pp. 4-22). }\end{array}$ \\
\hline \multicolumn{3}{|c|}{$\begin{array}{l}\text { Notes: } \\
\text { MBE = Mean Bias Error }\end{array}$} \\
\hline \multicolumn{3}{|c|}{$C_{v}(R S M E)=$ Coefficient of variation of the root mean squared error } \\
\hline \multicolumn{3}{|c|}{$\begin{array}{l}M B E_{E l e m e n t} \text { and } M B E_{\text {Material }} \text { do not have defined calibration tolerances. As per operative } \\
\text { energy, as long the } M B E_{\text {Total }} \text { and } C v(R S M E)_{\text {Total }} \text { are satisfied the model is considered } \\
\text { accurate. The } M B E_{E l e m e n t} \text { and } M B E_{\text {Material }} \text { exist to identify possible errors and to inform areas }\end{array}$} \\
\hline
\end{tabular}

\subsection{Chapter Inference}

The BPS (BPS) developed by Donn et al,. (2010) only provided a framework for how to use building performance simulation tools in a manner that achieved the requirements of effective integration. Chapter 4.0 developed the methodology for specific for $\mathrm{iEE}$, for how to conduct an iEE BIM LCA BPS. This chapter developed the EE simulation calibration accuracy assessment methodology for testing to prove iEE BIM LCA BPS feasibility, and if it meets the requirement established in Chapter 2.0 for effective integration. Unknown in EE or LCA research, this chapter defined the functional definitions of the two EE maximum acceptable calibration tolerances that define how close an EE or LCA simulation must be to its true value in reality to be useful for decision-making. 
Chapter Six:

\section{ACCURACY ASSESSMENT RESULTS AND DISCUSSION}

\section{I Chapter Intent}

This Chapter tests the thesis hypothesis, that by defining the accuracy required for iEE (iEE) simulations, a BIM model of sketch design detail will calculate building material quantities accurately enough for a building material LCA assessment.

This uses both the iEE BIM LCA BPS methodology, and the EE calibration accuracy assessment framework developed in Chapter 4.0, and 5.0 to test four main ideas. Chapter Section 6.2, tests whether the information available at sketch design is sufficient to calculate enough of a building's total iEE to be able to be useful as a design tool for lowering a building design's environmental impact. This is a test of the iEE LCA BIM BPS's determining if a building design that has been simplified to make the calculation easier, and faster, is still detailed enough to produce useful results. The iEE results from this test, become the iEE truth models used in the EE calibration accuracy assessment of the Revit iEE BIM LCA BPS modelling methodology. The second test, covered in Chapter Sections 6.3 to 6.5, uses these iEE truth model to determine if a BIM model can produce iEE results that are accurate enough for informed decision-making. Specifically this is an assessment of the modelled detailed required of the BIM objects, and geometry, to produce accurate material quantities. This Chapter is followed by Chapter 7.0, which presents the conclusions to the discussions of these thesis hypothesis testing results in the wider context of LCA research, and the building industry. 


\subsection{Test One: Is A Sketch Design iEE BPS Assessment Complete Enough?}

\subsection{Why Test Completeness?}

This first test, assesses the completeness of an iEE LCA BPS definition. This is one part of the solution to the thesis research problem, that; building material LCA assessments are too complex, requiring too much time and effort to be expended for effective integration during sketch design. Calculating building materials was identified as a primary cause of these problems. As a solution, the iEE LCA BPS is a simplified representation of a building's design. It includes only the building elements that are required for an iEE assessment during sketch design, and no more. The simplification process that defines what must be modelled, uses the framework developed in Chapter Section 4.2. This framework is based which building elements are being influenced, or conversely, influencing the design decisions made during sketch design.

Despite being successful in reducing the modelling time, and effort required for a building material LCA, the BPS must prove to be sufficiently detailed e.g. complete, to be effective as a design tool for reducing environmental impact. This completeness assessment, determines whether an iEE LCA BPS is sufficiently detailed for decision-making about design iterations to lower the environmental impact of a building design.

This completeness assessment has two parts, tests I.I, and I.2. Test I.I, compares truth models I and 2. Truth model I is a full building iEE assessment constructed from an as-built SOQ (SOQ). This is the 'true value' iEE figure for a full building design. Truth model 2 is an iEE LCA BPS constructed from a SOQ of the information available at detailed design.

Comparing these two truth models, test I.I answers the following questions:

Research question I.Ia: How much of a building's total iEE does an iEE LCA BPS represent?

Research question I.Ib: Is this enough to be useful for decision-making to lower environmental impact?

Using BIM To Calculate Accurate Building Material Quantities For Early Design Phase LCA 
Test 1.2 compares truth models 2 and 3 . Truth model 3 is the iEE LCA BPS constructed from a SOQ produced from information available during sketch design only. This is the 'true value' iEE figure for the building elements constituting the iEE BPS model. Comparing truth models 2 and 3 , test 1.2 answers the following question:

Research question I.2: Is the information available at sketch design detailed enough to produce accurate iEE results?

Prior to these tests, the iEE values for each truth model must be calculated. This is the multiplication of EE material coefficients by each truth models respective material quantities. To function as truth models in calibration accuracy assessment, each truth model must be compliant with the current iEE best practice calculation methods. The subsequent Chapter Sections, 6.2.2 and 6.2.3, discuss this process.

\subsubsection{Selecting Truth Model EE Material Coefficients}

Selecting an appropriate database of EE building material coefficients is a critical decision building designers must make. Selection is based on data uncertainty and variability causes, such as age of data, country of origin, and the scope of the calculation method. Some tools exist to help with this selection, but they require specialist knowledge of LCA framework beyond the capabilities of the building design team, or they are too time consuming for sketch design. Chapter Section 2.3.2 concluded that no research currently addresses the need to assist building designers with this decision. This informed a component of second research objective, where as part of developing the methodology for using the BIM tool Revit to calculate iEE, a tool must be developed to make it easier for building designers to select the most appropriate database of EE material coefficients for their $\mathrm{EEE}$ assessment. Fulfilling this objective, Chapter Section 4.3.2 details the development of the EE Data Quality Indicator Pedigree Matrix (EE DQIPM).

This Chapter Section applies the EE DQIPM to the thesis case study building testing its reliability compared to the produced by Weidema \& Wesnæs' (1996) original DQIPM. If the EE DQIPM produces a mean aggregated score that results in the same decision (selection of iEE database) as Weidema \& Wesnæs' (1996) DQIPM, it passes the reliability test. 


\section{EE DQIPM Reliability Test Results}

Tables 6.2.2b and 6.2.2c show the reliability test results of Alcorn's (2010), and Crawford's (2004) EE databases, assessed using the EE DQIPM, and Weidema \& Wesnæs's DQIPM as scored by the author for this research. In scoring these two datasets, consistency is critical. The absolute score is arguably irrelevant, it is the comparison between the two datasets and the justifiable selection of one over the other which is important. In this research, consistency and reliability in scoring the data was ensured by repeating the scoring assessment of other published datasets and comparing the score produced to those published by the original research. In all cases the same dataset was selected.

Both databases scored below an aggregated mean of 3.0 for each tool. This is below the threshold that previous studies ((Wang \& Shen, 2013) citing Junnila and Horvath, 2003; Maurice et. Al., 2000) have defined as representing 'fair data quality'. Both databases, showed small differences between the aggregated mean scores produced by the EE DQIPM and DQIPM. These are small and do not prove that the EE DQIPM tool is unreliable. Comparing the aggregated mean results of the two databases for both tools, Alcorn's iEE database is more appropriate for the case study building than Crawford's. This was expected, and proves that the EE DQIPM produces consistent results, proving its reliability.

Table 6.2.2b: Data Indicator Pedigree Matrix Assessment of Alcorn's Hybrid Process / Input-output EE coefficients.

\begin{tabular}{|l|c|l|c|}
\hline \multicolumn{1}{|c|}{ EE DQIPM Indicators } & Score & \multicolumn{1}{|c|}{$\begin{array}{c}\text { Weidema \& Wesnæs's } \\
\text { DQIPM }\end{array}$} & $\begin{array}{c}\text { Score } \\
\text { method }\end{array}$ \\
\hline Geographical correlation & I & Completeness & I \\
\hline Temporal correlation & $\mathbf{2}$ & Geographical correlation & $\mathbf{2}$ \\
\hline Reliability & I & Temporal correlation & I \\
\hline & & Reliability & $\mathbf{2}$ \\
\hline Aggregated Mean & $\mathbf{I . 3}$ & Aggregated Mean & $\mathbf{I . 4}$ \\
\hline
\end{tabular}

Using BIM To Calculate Accurate Building Material Quantities For Early Design Phase LCA 
Table 6.2.2c: Data Indicator Pedigree Matrix Assessment of Crawford's Hybrid Input-output / Process EE coefficients (2004).

\begin{tabular}{|l|c|l|c|}
\hline \multicolumn{1}{|c|}{ EE DQIPM Indicators } & Score & \multicolumn{1}{|c|}{$\begin{array}{c}\text { Weidema \& Wesnæs's } \\
\text { DQIPM }\end{array}$} & Score \\
\hline $\begin{array}{l}\text { EE material coefficient calculation } \\
\text { method }\end{array}$ & $\mathbf{I}$ & Completeness & I \\
\hline Geographical correlation & $\mathbf{4}$ & Further technological correlation & I \\
\hline Temporal correlation & $\mathbf{4}$ & Geographical correlation & $\mathbf{4}$ \\
\hline Reliability & $\mathrm{I}$ & Temporal correlation & $\mathbf{4}$ \\
\hline & & Reliability & I \\
\hline Aggregated Mean & $\mathbf{2 . 5}$ & Aggregated Mean & $\mathbf{2 . 2}$ \\
\hline
\end{tabular}

Table 6.2.2d shows the result of the EE DQIPM for the five EE databases assessed as part of developing truth models I-3:

I. Alcorn's (2010) hybrid process / input-output EE database. New Zealand specific.

2. Baird and Chan's (1983) mix of input-output, and process EE database. Not New Zealand specific.

3. Bath University's Inventory of Carbon \& Energy (ICE) Version 2.0 EE database (Hammond \& Jones, 20II). Not New Zealand specific.

4. Crawford's (2004) hybrid input-output / process EE database. Australian specific.

5. European Platform on Life Cycle Assessment (EPLCA) (EPLCA, 2014). Global averages from 2007.

These databases were selected because they represent a range of different iEE calculation methods, from different countries, are of different ages, and most importantly, all are freely available for building designers to access. Table 6.2.2d shows that Alcorn's (2010) hybrid database is the most accurate for this thesis case study, scoring below 2.0, making it better than what is considered 'acceptable data quality' ((Wang \& Shen, 2013) citing Junnila and Horvath, 2003; Maurice et. Al., 2000). The ICE database (Hammond \& Jones, 20II) is the second best option, with Crawford (2004), and the EPLCA (2014) databases tied, and lastly Baird and Chan's (1983). 
Table 6.2.2d: Data Indicator Pedigree Matrix Assessment of European LCA Database

\begin{tabular}{|c|c|c|c|c|c|}
\hline DQI & $\begin{array}{l}\text { Alcorn } \\
(2010)\end{array}$ & $\begin{array}{c}\text { Hammond } \\
\text { \& Jones } \\
(2011)\end{array}$ & $\begin{array}{c}\text { Crawford } \\
(2004)\end{array}$ & $\begin{array}{c}\text { EPLCA } \\
(20 \mid 4)\end{array}$ & $\begin{array}{c}\text { Baird \& } \\
\text { Chan } \\
(1983)\end{array}$ \\
\hline $\begin{array}{l}\text { EE material } \\
\text { coefficient } \\
\text { calculation } \\
\text { method }\end{array}$ & 1 & 3 & 1 & 3 & $\begin{array}{c}2.5 \\
\text { (Mix of } \\
\text { input-out } \\
\text { and process) }\end{array}$ \\
\hline $\begin{array}{l}\text { Geographical } \\
\text { correlation }\end{array}$ & I & 4 & 4 & $\begin{array}{c}3 \\
\text { (Global } \\
\text { average) }\end{array}$ & 3 \\
\hline $\begin{array}{l}\text { Temporal } \\
\text { correlation }\end{array}$ & 2 & 1 & 4 & 3 & 5 \\
\hline Reliability & I & I & I & I & I \\
\hline $\begin{array}{l}\text { Aggregated } \\
\text { Mean }\end{array}$ & 1.3 & 2.3 & 2.5 & 2.5 & 2.9 \\
\hline $\begin{array}{l}\text { Ranked } \\
\text { Best } \\
\text { Option }\end{array}$ & I & 2 & 3 & 3 & 4 \\
\hline $\begin{array}{l}\text { Data } \\
\text { Quality }\end{array}$ & $\begin{array}{c}\text { Better } \\
\text { than } \\
\text { acceptable } \\
\text { data } \\
\text { quality }\end{array}$ & $\begin{array}{c}\text { Acceptable } \\
\text { data } \\
\text { quality }\end{array}$ & $\begin{array}{c}\text { Fair data } \\
\text { quality }\end{array}$ & $\begin{array}{c}\text { Fair data } \\
\text { quality }\end{array}$ & $\begin{array}{c}\text { Fair data } \\
\text { quality }\end{array}$ \\
\hline
\end{tabular}

Using BIM To Calculate Accurate Building Material Quantities For Early Design Phase LCA 


\section{Discussion Of EE DQIPM Reliability Test Results}

The iEE DQI PM is a qualitative data uncertainty assessment tool. It does not calculate the size of data uncertainties, or simulation errors. Instead, it minimises uncertainties, and their subsequent simulation errors before they are multiplied by the material quantities and embedded into iEE result causing an inaccuracy. Critically, it prevents inaccuracies, it does not operationalise their impact. The scores produced are only indicative to help compare different datasets to determine which will be the best representation of reality, and therefore be more accurate. Consequently, the numerical description of each DQI category is not critical, as long as the assessor considers all four DQls, is consistent in their assessment, and that the end result facilitates choosing the right dataset.

Comparing the EE DQIPM to Weidema \& Wesnæs's DQIPM was a quality assurance test. Tables 6.2.2c and 6.2.2b show that the two methods conducted in the context of this thesis context produce similar, and consistent results. This proves the EE DQIPM to be reliable. The limitation is that this is only an indicative test. More research must be conducted in the future development of the EE DQIPM tool. However, for this thesis, it meets the requirements of reducing simulation uncertainties in the pre-simulation stage of $\mathrm{iEE}$ calibration accuracy assessment.

Table 6.2.2d showed that Alcorn's (2010) hybrid database is the most accurate for this thesis case study, and Baird and Chan's (1983) database is the least accurate. This proves it is better for New Zealand building designers to use these international EE databases, rather than the older, more outdated database published by Baird and Chan (1983). This was expected. Unexpected were the results for the other four databases. The ICE database (Hammond \& Jones, 20I I) is the next best choice. It is interesting that the Crawford and EPLCA database scores are tied. Table 6.2.2e shows the EE material coefficient values (where available) for each database, for the materials without a material coefficients in Alcorn's (2010) database. Comparing the only materials with values for Crawford and EPLCA, Crawford's Non-Recycled Steel EE coefficient is $35 \mathrm{I} \%$ higher than the value published by the EPLCA. Selecting either of one of these two coefficients will have a large impact on a building's iEE results. Therefore, this material needs to be considered specifically, not just based on the overall EE DQIPM database scores. This illustrates the limitation of the EE DQIPM. It is only suitable as an overview for evaluating iEE databases, and indicating which is 
more suitable compared to others. It is not suitable for specific materials. The risk is that some specific materials may score better or worse than their overall database. This could be due to a countries material imports or exports. For example, Graph 6.2 .2 shows that $30 \%$ of New Zealand structural steel is imported from Australia. Therefore, in some specific building cases, Crawford's Non-Recycled Steel iEE coefficient is more appropriate than the value published by the EPLCA. Recognising this, this thesis has used the EPLCA's global average EE material coefficient, as $70 \%$ of the structural steel sections in New Zealand are not from Australia. This makes it the more appropriate value for this case study building.

Graph 6.2.2: Export and Import (NZ\$ million) of Selected Building Products in 2011.

Source: Figure 3 Export and Import (NZ\$ million) of Selected Building Products in $201 \mathrm{I}$ (Dowdell, 2013, p. 6)

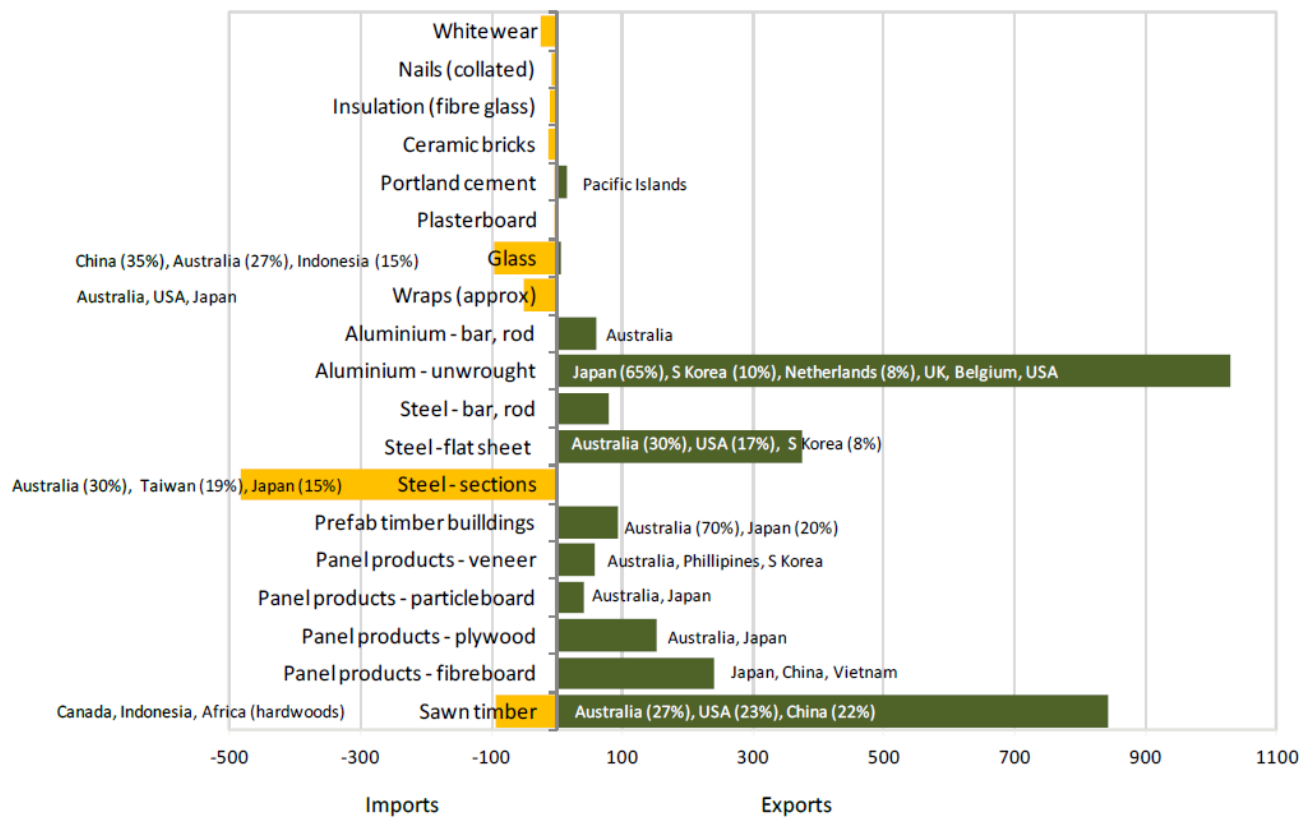

Using BIM To Calculate Accurate Building Material Quantities For Early Design Phase LCA 


\section{Table 6.2.2e: EE Building Material Coefficients Used In This Research}

The highlighted are the EE material coefficients used when the EE material coefficients required are unavailable. Preference is given to the ICE database due to its lower EE DQIPM score.

\begin{tabular}{|c|c|c|c|c|c|c|c|}
\hline & & & \multicolumn{5}{|c|}{ EE Building Material Coefficient $\mathrm{MJ} / \mathrm{m} 3$} \\
\hline \multicolumn{3}{|c|}{ Case Study Building Materials } & Alcorn (2010) & $\begin{array}{l}\text { Hammond \& } \\
\text { Jones (2011) }\end{array}$ & $\begin{array}{c}\text { Crawford } \\
\text { (2004) }\end{array}$ & EPLCA (2014) & $\begin{array}{c}\text { Baird \& Chan } \\
\text { (1983) }\end{array}$ \\
\hline \multirow{7}{*}{ 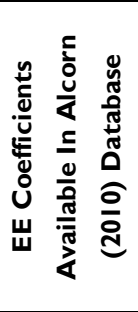 } & P229 & Concrete $30 \mathrm{Mpa}$ & 2,760 & & 5,460 & & 3,750 \\
\hline & P5I4 & Timber, kiln dried, dressed, treated & 4,090 & & 1,100 & & 3,714 \\
\hline & PR-45-52-63 & Plasterboard Panels & 7,080 & & 12,308 & & 5,000 \\
\hline & PR-45-52-25 & Fibre-Reinforced Cement Boards & 13,180 & & 35,000 & & 34,998 \\
\hline & PR-65-35-37 & Heat Strengthened Glass Sheets & 66,880 & & 318,320 & & 42,853 \\
\hline & PR-85-70-17 & Carbon Steel Ribbed Bar Reinforcement & 67,420 & 135,720 & Not Available & & Not Available \\
\hline & P4321I & Aluminium, extruded, anodised & 621,240 & & 675,261 & & 392,140 \\
\hline & P4I3I & Stainless steel & Not Available & 447,930 & 676,103 & Not Available & Not Available \\
\hline \multirow{7}{*}{ 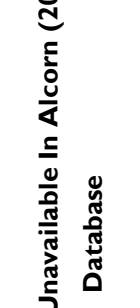 } & \multicolumn{3}{|c|}{ \% Difference Hammon \& Jones to Crawford } & \multicolumn{2}{|c|}{$151 \%$} & & \\
\hline & PR-60-5I-|2-0| & Non-Recycled - Carbon Steel Beams, Columns & Not Available & 167,770 & 546,000 & 155,360 & Not Available \\
\hline & \multicolumn{3}{|c|}{ \% Difference Hammon \& Jones to Crawford } & \multicolumn{2}{|c|}{$325 \%$} & & \\
\hline & PR-65-50-75 & Reinforced Bitumen Membrane Underlays & Not Available & 112,800 & Not Available & Not Available & Not Available \\
\hline & PR-45-97-34 & General And Utility Veneer Plywoods & Not Available & 10,500 & Not Available & Not Available & Not Available \\
\hline & P34I & Asphalt & Not Available & 8,434 & Not Available & Not Available & Not Available \\
\hline & PR-7I-06-03 & Aurex GreenStuff R3.2 & Not Available & 957 & Not Available & 1,204 & Not Available \\
\hline$y_{y}$ & \multicolumn{3}{|c|}{ \% Difference Hammon \& Jones to EPLCA } & \multicolumn{3}{|c|}{$126 \%$} & \\
\hline \multirow{4}{*}{ 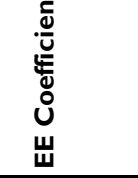 } & PR-7I-06-0I & Aurex GreenStuff RI.8 & Not Available & 802 & Not Available & I,008 & Not Available \\
\hline & PR-7I-06-02 & Autex GreenStuff R2.2 & Not Available & 802 & Not Available & 1,008 & Not Available \\
\hline & PR-7I-06-04 & Autex GreenStuff R0.5 & Not Available & 802 & Not Available & 1,008 & Not Available \\
\hline & \multicolumn{3}{|c|}{ \% Difference Hammond \& Jones to EPLCA } & \multicolumn{3}{|c|}{$126 \%$} & \\
\hline
\end{tabular}

Using BIM To Calculate Accurate Building Material Quantities For Early Design Phase LCA 


\section{The Application To Testing The Thesis Hypothesis}

The iEE building material coefficients are defined as a control variable in this thesis' research design for testing the hypothesis. This makes them a critical data input in the truth models, and calibration accuracy assessment. The control variable is managed by the use of the EE DQIPM tool to ensure the most accurate material coefficients are selected. The limitation is that these are only as accurate as the current best practice methods of measuring iEE can allow. It is inevitable that differences between the truth model EE material coefficients, and their value in reality will exist. For a building designer, aiming to lower environmental impact this is important. However, this impact on testing the thesis hypothesis is limited. As long as the same EE material coefficients are used consistently between the truth models, and Revit models, these inaccuracies are equal, and cancel out. Therefore, any difference between the results is caused by differences in the building material quantities.

\subsubsection{Calculating Truth Model Building Material Quantities}

The data of material quantities for the each truth model was not calculated as part of this thesis. It was independently calculated by the case study building design team as part of the design process. The detail and completeness of each truth model's material quantities is different:

- $\quad$ Truth model I is a full building iEE assessment constructed from an as-built SOQ (SOQ).

- $\quad$ Truth model 2 is the iEE BPS model constructed from a SOQ produced from the information available at detailed design.

- $\quad$ Truth model 3 is the iEE BPS model constructed from a SOQ produced from the information available at sketch design only.

Truth models 2 and 3 have had the iEE LCA BPS simplification framework (developed in Chapter Section 4.2) applied, defining what which building elements must be assessed for a sketch design phase iEE LCA assessment. Table 6.2.3a lists the building materials assessed in each of the three truth models. Table 6.2.3b lists the building elements these materials are part of for truth models 2 and 3. 
Table 6.2.3: Case Study Building Truth Models I-3, The Building Materials Assessed

\begin{tabular}{|c|c|c|c|c|}
\hline \multicolumn{2}{|c|}{ Case Study Building Materials } & \multirow{2}{*}{$\begin{array}{c}\text { Full Building } \\
\text { Truth Model I: As-Built } \\
\text { SOQ }\end{array}$} & \multicolumn{2}{|c|}{ Building Performance Sketch Models } \\
\hline UniClass Code & UniClass Description & & $\begin{array}{l}\text { Truth Model 2: SOQ } \\
\text { Detailed Design }\end{array}$ & $\begin{array}{l}\text { Truth Model 3: SOQ } \\
\text { Sketch Design }\end{array}$ \\
\hline $\mathrm{P} 229$ & Concrete $30 \mathrm{Mpa}$ & Yes & Yes & Yes \\
\hline$|P R-60-5|-|2-0|$ & $\begin{array}{l}\text { Non-Recycled - Carbon Steel Beams, } \\
\text { Columns, Channels And Tee Sections }\end{array}$ & Yes & Yes & Yes \\
\hline PR-65-35-37 & Heat Strengthened Glass Sheets & Yes & Yes & Yes \\
\hline$P 4|3|$ & Stainless steel & Yes & Yes & No \\
\hline P432II & Aluminium, extruded, anodised & Yes & Yes & Yes \\
\hline PR-65-50-75 & Reinforced Bitumen Membrane Underlays & No & Yes & Yes \\
\hline P5I4 & Timber, kiln dried, dressed, treated & Yes & Yes & Yes \\
\hline PR-7I-06-01 & $\begin{array}{l}\text { Autex GreenStuff RI.8 BIB - Batt And Mat } \\
\text { Insulation - Polyester (Pet) Tensile Fabrics }\end{array}$ & Yes & Yes & Yes \\
\hline PR-45-97-34 & General And Utility Veneer Plywoods & Yes & Yes & Yes \\
\hline PR-7I-06-03 & $\begin{array}{l}\text { Autex GreenStuff R3.2 BIB - Batt And Mat } \\
\text { Insulation - Polyester (Pet) Tensile Fabrics }\end{array}$ & Yes & Yes & Yes \\
\hline PR-45-52-25 & Fibre-Reinforced Cement Boards & Yes & Yes & Yes \\
\hline PR-85-70-17 & Carbon Steel Ribbed Bar Reinforcement & Yes & Yes & No \\
\hline PR-45-52-63 & Plasterboard Panels & Yes & Yes & Yes \\
\hline PR-71-06-02 & $\begin{array}{l}\text { Autex GreenStuff R2.2 BIB - Batt And Mat } \\
\text { Insulation - Polyester (Pet) Tensile Fabrics }\end{array}$ & Yes & No & No \\
\hline P34I & Asphalt & Yes & No & No \\
\hline PR-7I-06-04 & $\begin{array}{l}\text { Autex GreenStuff R0.5 MWB - Batt And Mat } \\
\text { Insulation - Polyester (Pet) Tensile Fabrics }\end{array}$ & Yes & No & No \\
\hline PR-75-50-52 & $\begin{array}{l}\text { Medium Density Fibreboard (Mdf) Lining } \\
\text { Boards }\end{array}$ & Yes & No & No \\
\hline
\end{tabular}

Using BIM To Calculate Accurate Building Material Quantities For Early Design Phase LCA 
Table 6.2.3b: Case Study Building Truth Models I-3, The Building Elements Assessed

\begin{tabular}{|c|c|c|c|c|c|}
\hline \multicolumn{2}{|c|}{$\begin{array}{l}\text { Framework: Refined List of Elements } \\
\text { Required For Modelling }\end{array}$} & \multirow{2}{*}{\multicolumn{2}{|c|}{ Framwork Applied To Case Study Building }} & \multicolumn{2}{|c|}{ Framwork Applied To Case Study Building } \\
\hline $\begin{array}{l}\text { UniClass } \\
\text { Code }\end{array}$ & $\begin{array}{c}\text { UniClass Element } \\
\text { Description }\end{array}$ & & & $\begin{array}{c}\text { Truth Model 2: SOQ } \\
\text { Detailed Design }\end{array}$ & $\begin{array}{l}\text { Truth Model 3: SOQ } \\
\text { Sketch Design }\end{array}$ \\
\hline EE-15-10 & Structure & EE-15-10-10 & Structure & Yes & Yes \\
\hline EE-20-40 & Upper Floor & EE-20-40-10 & Upper Floors Structure & Yes & Yes \\
\hline EE-20-10 & Roof & EE-20-10-10 & Roofs Structure & Yes & Yes \\
\hline \multirow[t]{3}{*}{ EE-25 } & \multirow[t]{3}{*}{ Wall And Barrier Elements } & EE-25-20-20 & External Cavity Walls External Skin & Yes & Yes \\
\hline & & EE-25-10-10 & Basement Walls Structure & Yes & Yes \\
\hline & & EE-25-25-10 & External Single Skin Walls Structure & Yes & Yes \\
\hline
\end{tabular}




\section{Discussion:}

The truth model building material quantities are the defining information that formulate truth models $\mathbf{I}-3$. This makes them a critical data input in the truth models, and calibration accuracy assessment. The detail of the material quantities in each truth model defines how detailed the BIM model representation must be. Therefore, the reliability, and the trustworthiness of this data is critical to testing the thesis hypothesis. These material quantities were not calculated as part of this thesis. They were developed as part of the case study building's project documentation. Consequently, they were subject to the quality assurance processes used by the building design team. This means they are considered reliable, complete, and therefore accurate enough to test this thesis' hypothesis.

Their reliability was ensured through the quality assurance systems of the firm and project team. Reliability assessment as part of this research compared the final contract sum to the detailed design estimate (detailed design cost figures include the material quantities from data source 2). The minus $9.6 \%$ difference is less than the $\pm 15 \%$ acceptable margin of error (Bownass, 200I, p. 25) for the developed design (scheme design) phase of the design process. The margin of error drops further to $-2.8 \%$ if the developed design contingency percentage sum is added to the final contract cost. This means the detailed design estimate is within established and recognised industry practices ensures reliability of the data.

While accurate enough to test this thesis' hypothesis, there are limitations with this data beyond this thesis research. These limitations are centred on the reliability, and completeness of the data quantities. Their reliability, and completeness is defined by building cost planning best practices for measuring building material quantities, not building material LCA-based indicators such as iEE. This means these databases were developed to be accurate enough for cost planning, not LCA. This produces the risk that there is an unknown amount of environmental impact not being assessed in a LCA using this data. For example, does a SOQ for LCA need to itemise material quantities to a level of detail accounting for fixings, such as, nuts, bolts, and washers? This is significantly more detailed than best practice cost planning. This highlights the need for future research to define which building materials should be modelled based on iEE and LCA accuracy, not cost planning. 
In this thesis research, this limitation is minimised by the thesis' research scope, where the aim is to make the calculation building materials easier, to a level of detail and accuracy equivalent to current best practice standards e.g. cost planning SOQ. In this case, the material quantities for truth models I and 2 are suitable.

\subsubsection{Calculating EE Truth Models}

The purpose of this Chapter Section is to present the truth model results required to assess the calibration accuracy of the BIM models, and answering the research questions:

Research question I.Ia: How much of a building's total iEE does an iEE LCA BPS represent?

Research question I.Ib: Is this enough to be useful for decision-making to lower environmental impact?

Research question I.2: Is the information available at sketch design detailed enough to produce accurate iEE results?

\section{EE Truth Model Results:}

The iEE truth models results are the end result of the multiplication of EE material coefficients selected in Chapter Section 6.2.2, by building material quantities accessed in Chapter Section 6.2.3. Table 6.2.4a shows the results for each of the three truth models using Alcorn's hybrid iEE database, supplemented where required by the ICE (Hammond \& Jones, 20II), and EPLCA iEE databases (EPLCA, 20I4). 
Table 6.2.4a: The iEE Results Of Thesis Case Study Building Truth Models

\begin{tabular}{|c|c|c|c|c|c|c|}
\hline \multicolumn{7}{|c|}{ Embodied Energy (GJ/m2 GFA) } \\
\hline \multirow[b]{2}{*}{$\begin{array}{c}\text { EE Coefficient } \\
\text { Database }\end{array}$} & \multirow{2}{*}{$\begin{array}{c}\text { Full Building } \\
\text { Truth Model I: } \\
\text { As-Built SOQ }\end{array}$} & \multicolumn{5}{|c|}{ EE LCA Building Performance Sketch Truth Models: } \\
\hline & & $\begin{array}{l}\text { Truth Model 2: Detailed } \\
\text { Design SOQ }\end{array}$ & $\begin{array}{c}\text { \% Difference } \\
\text { Truth Models I } \\
\text { \& } 2\end{array}$ & $\begin{array}{l}\text { Truth Model 3: Sketch } \\
\text { Design SOQ }\end{array}$ & $\begin{array}{c}\text { \% Difference } \\
\text { Truth Models } \\
\text { I \& } 3\end{array}$ & $\begin{array}{c}\text { \% Difference } \\
\text { Truth Models } \\
2 \& 3\end{array}$ \\
\hline (Alcorn, 2010) & 6.0 & 3.6 & $59.6 \%$ & 3.4 & $57.7 \%$ & $96.9 \%$ \\
\hline (Crawford, 2004) & 15.1 & 10.9 & $71.9 \%$ & 7.7 & $50.8 \%$ & $70.7 \%$ \\
\hline \% Difference & $39.4 \%$ & $32.7 \%$ & - & $44.8 \%$ & - & - \\
\hline \multicolumn{7}{|l|}{ Notes: } \\
\hline \multicolumn{7}{|c|}{$\begin{array}{l}\text { Truth model I EE assessment scope: Complete building EE assessment. Building material quantities are of the as-built design collected by the main building } \\
\text { contractor. }\end{array}$} \\
\hline \multicolumn{7}{|c|}{ Truth model 2 EE assessment scope: EE BIM LCA building performance sketch elements only. SOQ equal to detail design level of detail and completeness. } \\
\hline
\end{tabular}

Truth models 2 and 3 are $59.6 \%$, and $57.7 \%$ of truth model I. This is a reduction of $-40.4 \%$ and $-42.3 \%$ respectfully. Truth model 3 is $96.9 \%$ of truth model 2 , or $-3.1 \%$ less. These differences are caused by the differences in the truth models material quantities. The size of the iEE difference indicates the magnitude of this effect. This is called normalisation. As expected, truth models 2 and 3 are significantly lower than truth model I. This is because they have had the iEE BPS simplification framework applied to reduce their detail to be equivalent to detailed, and sketch design respectfully. Graph 6.2.4a shows the iEE per building material for all three truth models. Truth model I assesses more materials than truth models 2 and 3 , but these are materials that are not influenced, or influencing the design decisions being made at sketch design. 
Graph 6.2.4a: iEE Material Analysis For Case Study Building Truth Model I-3

\section{Truth Model's Embodied Energy Per Building Material}

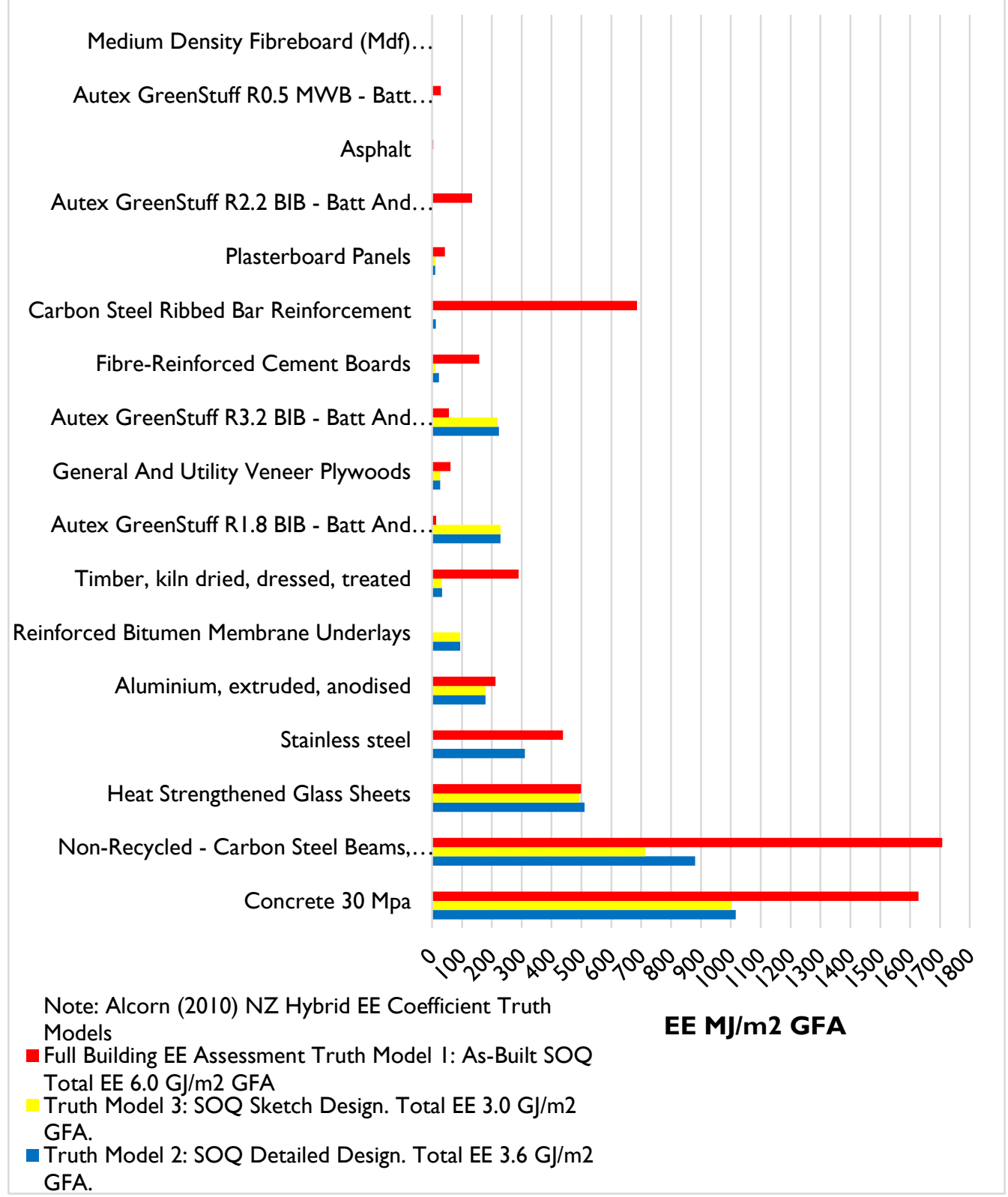

Using BIM To Calculate Accurate Building Material Quantities For Early Design Phase LCA 
Table 6.2.4b shows the results of applying the calibration accuracy assessment criteria to compare the three truth models. This is an assessment at a material level breakdown of the accuracy of the results presented in Graph 6.2.4a. As expected, neither truth model 2 or 3 pass the $M B E_{\text {material }}$ or $\mathrm{Cv}(\mathrm{RSME})_{\text {material }}$ meet the requirements of $\pm 10-20 \%$ and $15-30 \%$ respectfully, compared to truth model I. This is expected as they purposely do not assess the same level of material detail. Comparing truth models 2 and 3, the $M B E_{\text {material }}$ difference of $15.2 \%$ meets the $\mathrm{MBE}_{\text {material }}$ requirement, and can be defined as accurate. However, it fails the precision test where $54.7>30.0 \%$. This is because truth model 3 is again, purposefully less detailed. Accessing only the building materials the $M B E_{\text {material }}$ and $\mathrm{Cv}(\mathrm{RSME})_{\text {material }}$ results are $6.7 \%$, and $22.1 \%$ respectfully, both inside the calibration requirements.

Table 6.2.4b: Truth Model Calibration Assessment at Material Breakdown Level

\begin{tabular}{|l|c|c|c|c|}
\hline \multicolumn{4}{|c|}{ Material Level Breakdown: Accuracy Assessment } \\
\hline \multirow{2}{*}{ Alcorn EE Truth Models } & \multicolumn{3}{c|}{ Calibration Indices } \\
\cline { 2 - 5 } & \multicolumn{2}{|c|}{ MBE } & Cv(RSME) \\
\hline Truth Model 2 vs Truth Model I & $40.4 \%$ & Fail & $196.9 \%$ & Fail \\
\hline Truth Model 3 vs Truth Model I & $49.5 \%$ & Pass & $54.7 \%$ & Fail \\
\hline Truth Model 3 vs Truth Model 2 & $15.2 \%$ & & \\
\hline Notes & & & \\
\hline Maximum acceptable calibration tolerance for MBE less than $\pm 10-20 \%$ & \\
\hline Maximum acceptable calibration tolerance for Cv(RSME) less than 15-30\% \\
\hline
\end{tabular}

Table 6.2.4c shows the comparison calibration accuracy assessment results at a building elemental level of analysis. Comparing truth models 2 and 3, the $\mathrm{MBE}_{\text {elemental }}$ remains $15.2 \%$. This is because the total EE value does not change, just its distribution throughout the building. Reflecting this, the $\operatorname{Cr}(\mathrm{RSME})_{\text {elemental }}$ is improved to $40.1 \%$, still outside the calibration requirement. Graph 6.2.4b shows that the external cavity walls external skin element is the leading cause of imprecision. However, this is the result of removing the material detail in the buildings glass and stainless steel balustrades. They are not insignificant, contributing $319 \mathrm{MJ} / \mathrm{m} 2$ GFA or $10.6 \%$ of the buildings total iEE. Adding them improves the $\mathrm{MBE}_{\text {elemental }}$ and $\mathrm{Cv}(\mathrm{RSME})$ elemental to $6.2 \%$ and $16.4 \%$. Nonetheless, they are not a sketch design decision, so are not included in an iEE LCA BPS. 
Table 6.4.2c: Elemental Analysis Of iEE Case Study Building Truth Models I And 3

\begin{tabular}{|l|c|c|c|c|}
\hline \multicolumn{4}{|c|}{ Elemental Level Breakdown: Accuracy Assessment } \\
\hline \multirow{2}{*}{ Alcorn EE Truth Models } & \multicolumn{4}{c|}{ Calibration Indices } \\
\cline { 2 - 5 } & \multicolumn{3}{|c|}{ MBE } & \multicolumn{2}{c|}{ Cv(RSME) } \\
\hline Truth Model 3 vs Truth Model 2 & $15.2 \%$ & Pass & $40.1 \%$ & Fail \\
\hline Adjusted for Balustrade Inclusion & $6.2 \%$ & Pass & $16.4 \%$ & Pass \\
\hline Notes \\
\hline Maximum acceptable calibration tolerance for MBE less than $\pm 10-20 \%$ \\
\hline Maximum acceptable calibration tolerance for Cv(RSME) less than I5-30\% \\
\hline
\end{tabular}

Graph 6.2.4b: iEE Elemental Analysis For Case Study Building Truth Models 2 And 3

\section{Truth Model's Embodied Energy Per Building Element}

External Single Skin Walls Structure

Basement Walls Structure

Roofs Structure

Upper Floors Structure

External Cavity Walls External Skin

External Single Skin Walls External Skin

Structure

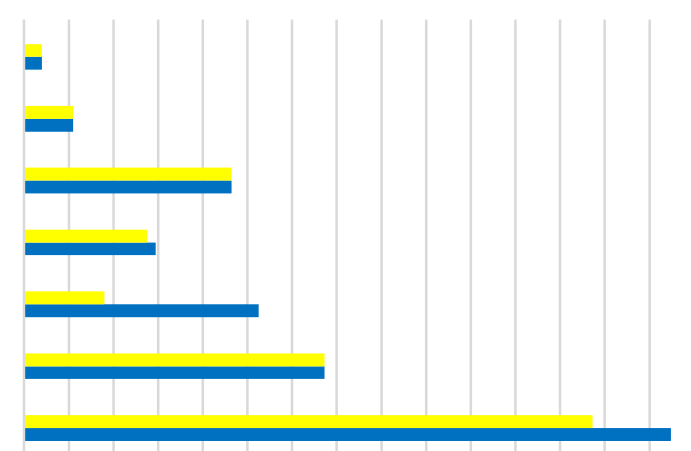

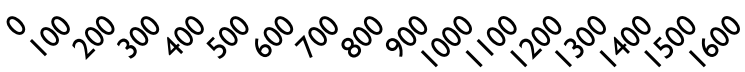

EE MJ/m2 GFA

Note: Alcorn (2010) NZ Hybrid EE Coefficient Truth

Models

Truth Model 3: SOQ Sketch Design. Total EE $3.0 \mathrm{GJ} / \mathrm{m} 2$

GFA.

- Truth Model 2: SOQ Detailed Design. Total EE $3.6 \mathrm{GJ} / \mathrm{m} 2$

GFA.

\section{Discussion Of EE Truth Model Results:}

Answering research question I.I, an iEE BPS model represents $59.6 \%$ of the total full building iEE if constructed using detailed design information (truth model 2 ), or $57.7 \%$ if using the information available at sketch design (truth model 3).

Using BIM To Calculate Accurate Building Material Quantities For Early Design Phase LCA 
This is also a question of the reliability, and completeness of the calculation. While the individual simulation inputs have been quality assured by adhering to best practices, the iEE value needs to be checked. The current best practice method is to compare the calculated iEE results to published benchmarks. This method has its limitations, but is currently accepted in other areas of building performance simulation such as operative energy (CIBSE, 1998, 2006). The full building iEE value (truth model I) of 6.0-15.I GJ/m2 GFA, is in line with Yung's et al., (2013) published iEE benchmark of $8.47 \mathrm{GJ} / \mathrm{m} 2 \mathrm{GFA}$. Compared to New Zealand specific buildings, Table 6.3.2d shows the 6.0 GJ/m2 GFA (Alcorn, 2010), is in line with other published results. The case study building's mix of reinforced concrete and steel structure fits almost equally in the middle of the reported concrete and steel values. Graph 6.3.2c shows the $6.0 \mathrm{GJ} / \mathrm{m} 2 \mathrm{GFA}$ is inside the range of results from buildings with the same reinforced concrete structure. This proves that the truth model results are reliable.

Table 6.3.2d: iEE Savings From Structural Design Changes

\begin{tabular}{|l|c|c|}
\hline Main Structural System & EE GJ/m2 GFA *I & $\begin{array}{c}\text { \% Difference to Truth } \\
\text { Model I (Alcorn) 6.0 } \\
\text { GJ/m2 GFA }\end{array}$ \\
\hline Timber & 4.61 & $76.8 \%$ \\
\hline Concrete & 4.91 & $81.8 \%$ \\
\hline $\begin{array}{l}\text { Thesis Case Study: } \\
\text { Truth Model I (Alcorn) }\end{array}$ & 6.0 & $100.0 \%$ \\
\hline Steel & 7.34 & $122.3 \%$ \\
\hline $\begin{array}{l}\text { Reference: } \\
* \text { I Table 4.7 (Fernandez, 2008, p. 76). }\end{array}$ \\
\hline
\end{tabular}

Research question I.Ib, questioned if the iEE BPS model represents enough of a building's total iEE value to be useful for decision-making to lower environmental impact. Two points prove the answer to this question is yes. Firstly, the iEE of a sketch design building is significant. Table 6.2.4a showed that the truth models 2 and 3 represented $59.6 \%$ and $57.7 \%$ of the building total iEE. This is approximately $3 / 5$ of the total iEE. The $-1.9 \%$ difference between truth models 2 and 3 proves that for the building elements assessed during sketch design, the information available at sketch design is sufficiently detailed, to make design

Using BIM To Calculate Accurate Building Material Quantities For Early Design Phase LCA 
decisions about the most iEE influencing materials. These account for $98 \%$ of iEE compared to detailed design.

Table 6.2.4e shows this compared to the case study building's Operative Energy (OE) consumption of $33.1 \mathrm{kWh} / \mathrm{m} 2 \mathrm{NLA}$, and expressed as the number of years for OE to equal iEE. The result is 72.3 years. This is well beyond the New Zealand building codes minimum building lifespan of 50 years. This OE figure was calculated as part of the building's design, by the design team. As Chapter Section 3.5.I discusses, it the base building OE only, meaning it excludes the OE of the tenant specific areas. This is a limitation of the data. Accounting for this, published figures say the base building EUI is commonly between $50-70 \%$ of the total EUI (New Zealand Green Building Council, 2008). This would change the number of years for OE to equal iEE to a worst case scenario, lowest payback period of 41.4 years, or $82.8 \%$ of the building's total 50 year lifespan.

This assessment of iEE significance is based on the OE consumption being very low. However, sketch design iEE is still important even if the case study building's OE was more representative of the wider New Zealand commercial building stock, e.g. OE of $150 \mathrm{kWh} / \mathrm{m} 2$ GFA (Bishop \& Isaacs, 2012, p. iv). If the case study building had an EUI of $150 \mathrm{kWh} / \mathrm{m} 2 \mathrm{GFA}$, the resultant payback period is 16.0 years, or $32.0 \%$ of the building total 50 year lifespan. This is still significant, proving that the iEE represented in a sketch design building, despite being $3 / 5$ of the total building's iEE is still worth designing building solution to reduce it, even when $\mathrm{OE}$ is typical of the wider New Zealand commercial building stock.

Table 6.2.4e: Truth Model 3 iEE Compared to Operative Energy Consumption.

\begin{tabular}{|c|c|c|c|c|c|c|c|}
\hline \multirow{4}{*}{} & \multicolumn{3}{|c|}{$\begin{array}{c}\text { Case Study Building's Operative Energy } \\
\text { (OE) Consumption }\end{array}$} & $\begin{array}{c}\text { Embodied Energy } \\
\text { (Alcorn) }\end{array}$ & $\begin{array}{c}\text { No. of } \\
\text { Years for } \\
\text { OE to }\end{array}$ \\
\cline { 2 - 9 } & $\begin{array}{c}\text { OE } \\
\text { Assessment } \\
\text { Scope }\end{array}$ & $\begin{array}{c}\text { kWh/m2 } \\
\text { NLA }\end{array}$ & $\begin{array}{c}\text { GJ } \\
\text { Primary }\end{array}$ & $\begin{array}{c}\text { GJ/m2 } \\
\text { GFA }\end{array}$ & $\begin{array}{c}\text { EE } \\
\text { GJ/m2 } \\
\text { GFA }\end{array}$ & EE GJ & Equal EE \\
\hline $\begin{array}{c}\text { Truth Model 3: } \\
\text { Sketch Design } \\
\text { SOQ }\end{array}$ & Base Build & 33.1 & 520.2 & 0.05 & 3.4 & 37628.7 & $\mathbf{7 2 . 3}$ \\
\cline { 2 - 9 } & I50\% Base Build & 49.7 & 781.1 & 0.07 & 3.4 & 37628.7 & $\mathbf{4 8 . 2}$ \\
\cline { 2 - 9 } & I70\% Base Build & 57.9 & 910.0 & 0.08 & 3.4 & 37628.7 & $\mathbf{4 1 . 4}$ \\
\hline \multicolumn{2}{|c|}{ Typical NZ Commercial } & 150.0 & 2357.4 & 0.22 & 3.4 & 37628.7 & $\mathbf{I 6 . 0}$ \\
\hline
\end{tabular}

Using BIM To Calculate Accurate Building Material Quantities For Early Design Phase LCA 
The second point answering research question I.Ib, is proving that sketch design decisions made to lower $\mathrm{iEE}$ are significant enough to be useful. This is a comparison of the energy savings that can be achieved by iEE reductions compared to OE reductions. For example, Cole and Kernan (1996, p. 310) proved that changing a building's man structural system from steel and concrete to timber, can reduce iEE by $5 \%$ and $13 \%$ respectfully. Table $6.2 .4 \mathrm{f}$ shows the results of using these savings applied to the case study building. These $5 \%$ and $13 \% \mathrm{iEE}$ savings expressed as the number of OE (33.I kWh/m2 GFA base build EUI) years of 3.6 and 9.4 respectfully. For a worst case scenario where the EUI is $170 \%$ of the base build, these saving are 2.I and 5.4 years. This is still a significant saving. This is further emphasised compared to OE savings. Kim (2010, p. 72) investigating the cost effectiveness of building envelope design changes to lower OE, reported a single largest OE reduction of $8.0 \%$ when decreasing the $U$-value of the windows by $60 \%$. Using this saving reduction, Table 6.2.4f shows the results applied to the case study building. An $8 \%$ OE (base build EUI) saving takes 45.2 years to equal the saving achieved by changing the building structure from concrete to timber, and II 7.5 years from steel to timber. For a worst case scenario OE (I70\% base build) the payback periods are 25.8 and 67.2 year. Still a significant part of a 50 building design life.

This is only an example for a single design change. The cumulative effect of OE directed energy conversation design changes has a significantly higher scope to lower a building's total energy consumption. Indeed, in Net Zero Energy Building's (NZEB) EUI's are been reported around $47.2 \mathrm{kWh} / \mathrm{m} 2$ GFA (Kurnitski et al., 20I I, PP. II-12). Compared to the typical New Zealand commercial building EUI (assumed I50kWh/m2 (Bishop \& Isaacs, 20I2, p. iv)), this is a $68.5 \%$ reduction. iEE will never be zero, as it always takes energy to build. However, this analysis proves that the design decisions made during sketch design are significant enough to matter.

Answering research question I.2, the information available at sketch design is detailed enough to produce accurate iEE results. This is proved by comparing truth models 2 and 3 . Their low difference $-1.9 \%$, and the MBE accuracy assessment results of $15.2 \%$ is less than the calibration accuracy requirement of $20 \%$, proving this conclusion. The failure of precision accuracy is caused by the simplification of the material quantities. Therefore, it was expected to be imprecise. Accounting for this, by removing the materials not accessed in both truth 
models 2 and 3, e.g. the stainless steel in the balustrades, and the carbon steel ribbed bar reinforcement in the reinforced concrete, neither of which are required or available during sketch design, the $\mathrm{Cv}(\mathrm{RSME})_{\text {material }}$ reduces to $22.1 \%$, with a $M B E_{\text {material }}$ of $6.7 \%$. This is reflected at an elemental analysis level, where the Cv(RSME) element improved from $40.1 \%$ to $15.4 \%$, and the $\mathrm{MBE}_{\text {elemental }}$ improved from $15.2 \%$ to $5.8 \%$. This analysis of the change in simulation precision, highlights the risk in its assessment. At elemental level, truth model 3 almost passed the calibration requirement of $<30.0 \%$, whereas, at material level it was not even close. The conclusion from this, is that the $\operatorname{Cv}(\mathrm{RSME})$ results of a building material LCA must be analysed, and pass at both analysis material and analysis levels. 
Table 6.2.4f: Analysis Of iEE Savings Versus OE Savings

\begin{tabular}{|c|c|c|c|c|c|c|c|c|c|c|c|}
\hline & \multicolumn{2}{|c|}{\begin{tabular}{|c|} 
Case Study Building's \\
Operative Energy (OE) \\
Consumption
\end{tabular}} & \multirow{3}{*}{\begin{tabular}{|c|}
$\begin{array}{c}\text { Embodied } \\
\text { Energy } \\
\text { (Alcorn) }\end{array}$ \\
\\
EE GJ/m2 \\
GFA
\end{tabular}} & \multirow{3}{*}{\begin{tabular}{|c|} 
No. of \\
Years for \\
OE to \\
Equal EE
\end{tabular}} & \multicolumn{4}{|c|}{$\begin{array}{l}\text { Cole \& Kernan (1996) EE \% Saving Changing to } \\
\text { Timber Structure From: }\end{array}$} & \multirow{2}{*}{\multicolumn{3}{|c|}{$\begin{array}{c}\text { Kim (2010) OE Energy Saving Improving Window U- } \\
\text { value by } 60 \%\end{array}$}} \\
\hline & \multirow[b]{2}{*}{$\begin{array}{l}\text { OE } \\
\text { Assessment } \\
\text { Scope }\end{array}$} & \multirow[b]{2}{*}{$\begin{array}{c}\text { kWh/m2 } \\
\text { NLA }\end{array}$} & & & & el $5 \%$ & Concr & cete $13 \%$ & & & \\
\hline & & & & & $\begin{array}{c}\text { GJ } / \mathrm{m}^{2} \\
\text { GFA }\end{array}$ & $\begin{array}{l}\text { Saving } \\
\text { Expressed } \\
\text { as No. of } \\
\text { OE Years }\end{array}$ & GJ $/ \mathrm{m} 2$ GFA & $\begin{array}{l}\text { Saving } \\
\text { Expressed as } \\
\text { No. of OE } \\
\text { Years }\end{array}$ & $\begin{array}{l}\text { 8\% Annual } \\
\text { OE Saving }\end{array}$ & \begin{tabular}{|} 
No. of Years for 8\% \\
Annual Energy Saving \\
to Equal 5\% EE \\
Stuctural Saving
\end{tabular} & $\begin{array}{c}\text { No. of Years for 8\% } \\
\text { Annual Energy } \\
\text { Saving to Equal I3\% } \\
\text { EE Stuctural Saving }\end{array}$ \\
\hline \multirow{3}{*}{$\begin{array}{c}\text { Truth Model 3: } \\
\text { Sketch Design } \\
\text { SOQ }\end{array}$} & Base Build & 33.1 & 3.4 & 72.3 & 0.2 & 3.6 & 0.4 & 9.4 & 0.004 & 45.2 & 117.5 \\
\hline & I50\% Base Build & 49.7 & 3.4 & 48.2 & 0.2 & 2.4 & 0.4 & 6.3 & 0.006 & 30.1 & 78.3 \\
\hline & 170\% Base Build & 57.9 & 3.4 & 41.4 & 0.2 & 2.1 & 0.4 & 5.4 & 0.007 & 25.8 & 67.2 \\
\hline \multicolumn{2}{|c|}{ Typical NZ Commercial } & 150.0 & 3.4 & 16.0 & 0.2 & 0.8 & 0.4 & 2.1 & 0.017 & 10.0 & 25.9 \\
\hline
\end{tabular}




\subsection{Test Two: Does A BIM Model Calculate Accurate iEE BIM LCA BPS Results?}

\subsection{A Recap Of The Testing Process:}

Test two is testing the thesis hypothesis that, by defining the accuracy required for iEE simulations, a BIM model of sketch design detail will calculate building material quantities accurately enough for a building material LCA assessment. To test this hypothesis, building materials calculated from the iEE BIM LCA BPS model using Revit, are compared to truth model 3's material quantities (presented in Graphs 6.2.4a and 6.2.4b). Both sets of material quantities are normalised to an iEE value. This is to determine the accuracy of the BIM model calculated material quantities compared to truth model 3 , and to investigate the influence, and significance, of any simulation inaccuracies.

This testing process is conducted in two stages, pre-calibration, and post calibration. Precalibration is the accuracy assessment of Revit calculated material quantities constructed prior to their comparison to the truth model. This means they are not biased by the truth model, and is a recreation of the modelling process that the building design team would follow for designing new buildings. The calibration accuracy assessment, identifies the areas and causes of simulation inaccuracies. Post-calibration is the result of making alterations to the BIM model to satisfy the EE maximum acceptable calibration tolerances if not achieved in pre-calibration.

\subsubsection{Pre-Calibration Accuracy Assessment Of The Revit iEE BIM LCA BPS}

\section{Results: Is The Revit iEE BIM LCA BPS Accuarte Enough?}

The iEE value of the Revit iEE BIM LCA BPS is $3.4 \mathrm{GJ} / \mathrm{m} 2$ GFA. Compared to truth model 3's 3.0 GJ/m2 GFA, this is a $+13.3 \%$ difference. Tables 6.3.2a and 6.3.2b, show that the Revit model representation of an iEE BIM LCA BPS achieves the accuracy MBE accuracy requirements of being $< \pm 10-20 \%$ compared to both truth models 2 and 3 , at both a material, and elemental level of analysis. However, the iEE BIM LCA BPS fails the Cv(RSME) precision 
requirement of being $<15-30 \%$. Failing either one of the EE maximum acceptable calibration tolerances means it does not pass the accuracy assessment requirements to be considered accurate enough for informed decision-making.

Consequently, adjustments need to be made to the Revit model. This is part of post calibration, and is discussed in Chapter Section 6.3.3. During this Chapter Section 6.3.2, the Revit model must be adjusted until it passes both EE maximum acceptable calibration tolerances for material and elemental analysis levels.

Table 6.3.2a: Pre-Calibration Accuracy Assessment at Material Level Analysis

\begin{tabular}{|c|c|c|c|c|}
\hline \multicolumn{5}{|c|}{ Revit EE BIM LCA Building Performance Sketch Results Compared to Truth Models: } \\
\hline \multirow{4}{*}{$\begin{array}{c}\text { Material Analysis Accuracy } \\
\text { Assessment }\end{array}$} & \multicolumn{4}{|c|}{ Building Performance Sketch Material Analysis } \\
\hline & \multirow{2}{*}{\multicolumn{2}{|c|}{$\begin{array}{c}\text { Truth Model 2: SOQ Detailed } \\
\text { Design }\end{array}$}} & \multirow{2}{*}{\multicolumn{2}{|c|}{$\begin{array}{l}\text { Truth Model 3: SOQ } \\
\text { Sketch Design }\end{array}$}} \\
\hline & & & & \\
\hline & MBE & Cv(RSME) & MBE & Cv(RSME) \\
\hline Pre-Calibration & $-3.2 \%$ & $9.7 \%$ & $12.5 \%$ & $41.4 \%$ \\
\hline Calibration Tolerances Achieved & Pass & Pass & Pass & Fail \\
\hline \multicolumn{5}{|l|}{ Notes } \\
\hline Revit Sketch Design BIM Model Total EE: & \multicolumn{2}{|c|}{$3.4 \mathrm{GJ} / \mathrm{m} 2 \mathrm{GFA}$} & & \\
\hline \multicolumn{5}{|c|}{ Alcorn (2010) NZ Hybrid EE Coefficient Truth Models } \\
\hline \multicolumn{5}{|c|}{ Maximum acceptable calibration tolerance for MBE less than $\pm 10-20 \%$} \\
\hline \multicolumn{5}{|c|}{ Maximum acceptable calibration tolerance for $\mathrm{Cv}$ (RSME) less than $15-30 \%$} \\
\hline
\end{tabular}

Table 6.3.2b: Pre-Calibration Accuracy Assessment at Elemental Level Analysis

\begin{tabular}{|c|c|c|c|c|}
\hline \multicolumn{5}{|c|}{ Revit EE BIM LCA Building Performance Sketch Results Compared to Truth Models: } \\
\hline \multirow{4}{*}{$\begin{array}{c}\text { Elemental Analysis Accuracy } \\
\text { Assessment }\end{array}$} & \multicolumn{4}{|c|}{ Building Performance Sketch Elemental Analysis } \\
\hline & \multirow{2}{*}{\multicolumn{2}{|c|}{$\begin{array}{c}\text { Truth Model 2: SOQ Detailed } \\
\text { Design }\end{array}$}} & \multirow{2}{*}{\multicolumn{2}{|c|}{$\begin{array}{c}\text { Truth Model 3: SOQ } \\
\text { Sketch Design }\end{array}$}} \\
\hline & & & & \\
\hline & MBE & Cv(RSME) & MBE & Cv(RSME) \\
\hline Pre-Calibration & $-3.1 \%$ & $8.3 \%$ & $12.5 \%$ & $33.1 \%$ \\
\hline Calibration Tolerances Achieved & Pass & Pass & Pass & Fail \\
\hline \multicolumn{5}{|l|}{ Notes } \\
\hline \multicolumn{2}{|l|}{ Revit Sketch Design BIM Model Total EE: } & \multicolumn{3}{|c|}{$3.4 \mathrm{GJ} / \mathrm{m} 2 \mathrm{GFA}$} \\
\hline \multicolumn{5}{|c|}{ Alcorn (2010) NZ Hybrid EE Coefficient Truth Models } \\
\hline \multicolumn{5}{|c|}{ Maximum acceptable calibration tolerance for MBE less than $\pm 10-20 \%$} \\
\hline \multicolumn{5}{|c|}{ Maximum acceptable calibration tolerance for $\mathrm{Cv}(\mathrm{RSME})$ less than $15-30 \%$} \\
\hline
\end{tabular}




\section{Discussion Of Pre-Calibration The Revit iEE BIM LCA BPS Accuracy Results.}

The iEE value of the Revit iEE BIM LCA BPS is 3.4 GJ/m2 GFA. Compared to truth model 3's 3.0 GJ/m2 GFA, Graph 6.3.2a of material analysis shows that the main source of the MBE $12.5 \%$ inaccuracy, and the $\mathrm{Cv}(\mathrm{RSME}) 4 \mathrm{I} .4 \%$ imprecision is the Autex GreenStuff R3.2 insulation. The Revit iEE BIM LCA BPS is over estimating this material by $10.6 \%$ of the total 3.4 GJ/m2 GFA iEE result. Graph 6.3.2b of elemental analysis shows that this over estimation is limited to the roof element.

Compared to truth model 2 (DD SOQ), the over estimation of the Autex GreenStuff R3.2 insulation increases the accuracy of the Revit iEE simulation. While overall the Revit model may be more accurate, in terms of decision-making this error remains a problem. Both Truth models 2 and 3, follow the same general coloration at a material level. By over estimating one particular material, its importance is over emphasised, and any subsequent design changes to reduce its environmental impact are also going to have their importance overestimated. This can lead to poor or incorrect design decisions, and a misplaced effort being spent to reduce the environmental impact of a material that may not be significant. For example, Graph 6.3.2a indicates the iEE of the Autex GreenStuff R3.2 insulation is greater than that of heat strengthened glazing. This is despite the Autex GreenStuff R3.2 insulation being used significantly less in the building's design, and its EE material coefficients only being an additional $18.5 \%$ of that for heat strengthened glazing (refer Table 6.3.2d). Following this result would indicate that the Autex if the more importance of the two materials to focus design changes on, leading to a poor design decision being made.

Table 6.3.2d: Difference In Building Materials Heat Strengthened Glass Sheets And Autex GreenStuff R3.2 Insulation

\begin{tabular}{|c|c|c|c|}
\hline \multirow[t]{2}{*}{ Building Material } & \multicolumn{2}{|c|}{$\begin{array}{l}\text { Material Quantity } \\
\text { Calculated }\end{array}$} & \multirow{2}{*}{$\begin{array}{c}\text { EE material } \\
\text { coefficient } \\
\text { MJ/m3 }\end{array}$} \\
\hline & kg & m3 & \\
\hline Heat Strengthened Glass Sheets & 199718 & 118 & 493 \\
\hline Autex GreenStuff R3.2 & 6670 & 9 & 584 \\
\hline $\begin{array}{l}\text { \% Difference Autex R3.2 } \\
\text { Compared to Heat Strengthened } \\
\text { Glass }\end{array}$ & $3.3 \%$ & $7.6 \%$ & I I 8.5\% \\
\hline
\end{tabular}

Using BIM To Calculate Accurate Building Material Quantities For Early Design Phase LCA 
Graph 6.3.2a: Pre-Calibration iEE BIM LCA BPS Material Analysis

\section{Truth Model to Revit Sketch Model Comparsion Per Building Material}

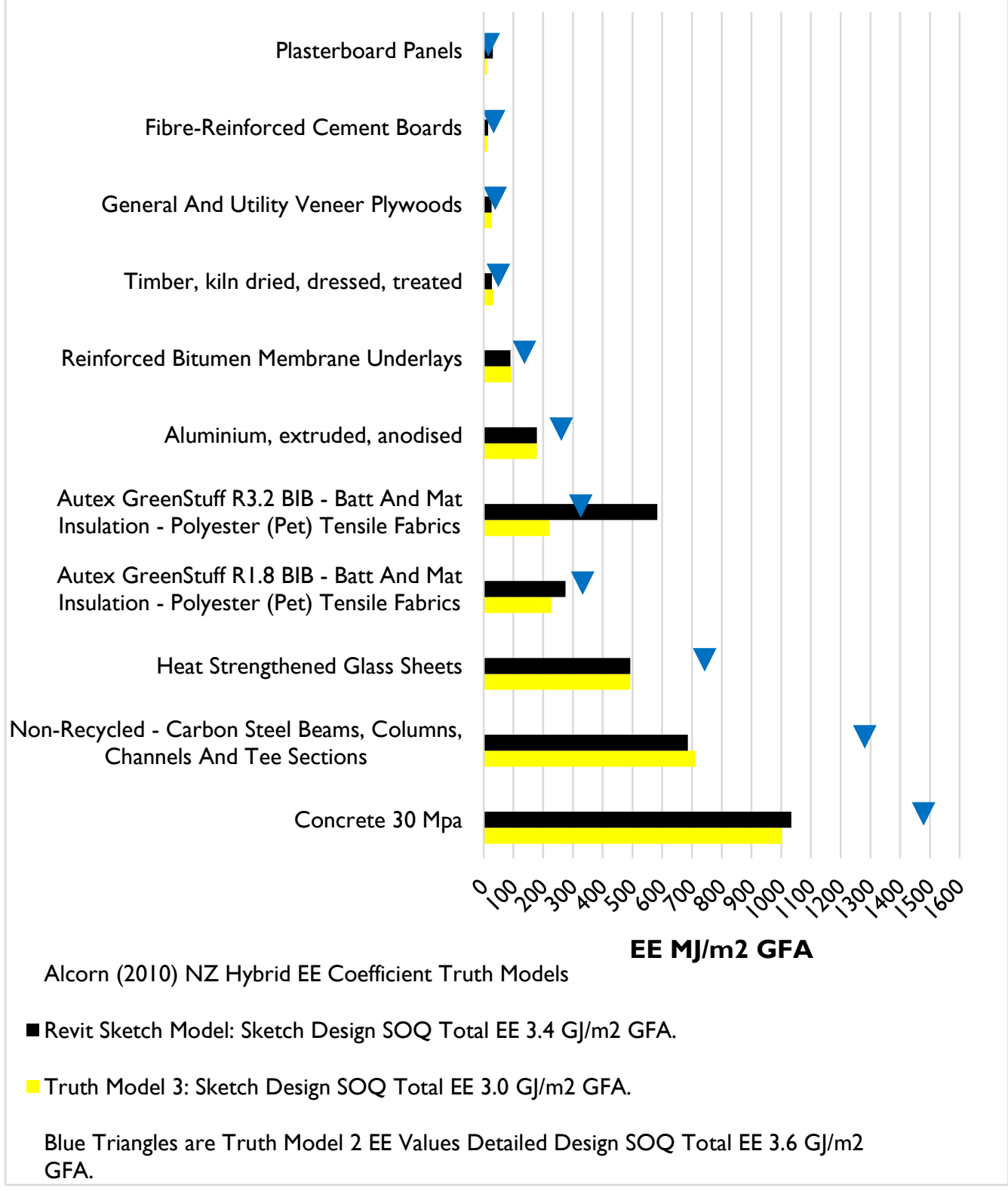

Using BIM To Calculate Accurate Building Material Quantities For Early Design Phase LCA 
Graph 6.3.2b: Pre-Calibration iEE BIM LCA BPS Elemental Analysis

\section{Truth Model to Revit Sketch Model Comparsion Per Building Element}

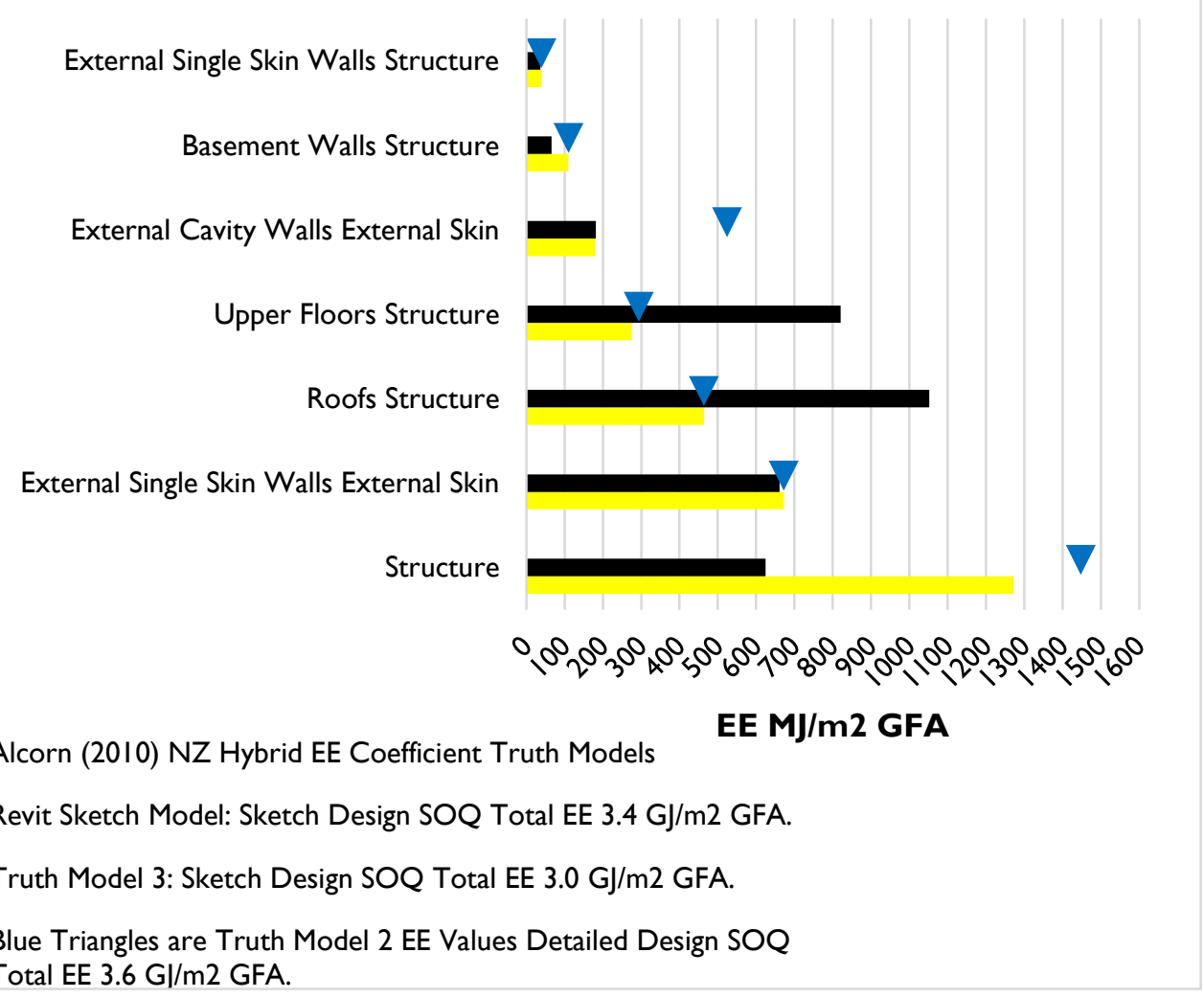

Graph 6.3.2b showing an elemental analysis highlights an additional simulation error. This is in the distribution of iEE of the upper floor structure element, and the structure element. The structural element is too low, and the upper floor structure element too high. Because the $M B E_{\text {material }}$ measure of inaccuracy is low, this is not an over or under estimation error. Instead it is a human error, caused by mislabelling which BIM objects from part of these two building elements in the Revit model. Evidence of this comes when adding the Revit model's calculated iEE for the two elements together, and then comparing their total against the same value from truth model 3 . The result is that the Revit model is $93 \%$ of the truth model's values for these two elements. There is a discrepancy between them, but not enough to cause the $M B E_{\text {material }}$ to be outside what is acceptable. Distribution errors of this type will not 
influence the decision-making of building designers, provided the overall $M B E_{\text {material }}$ of $\mathrm{iEE}$ is accurate.

\subsubsection{Post Calibration Accuracy Assessment Of The iEE BIM LCA BPS Method}

Table 6.3.3a shows the post calibration accuracy assessment results of the Revit model's representation of an iEE BIM LCA BPS compared to truth model 3, a sketch design SOQ.

This post calibration model is the result of changes made to the pre-calibration model. These changes were made to solve the issues of over calculating the Autex GreenStuff R3.2 roof insulation, and the incorrect distribution of BIM objects between the structural, and upper floor building elements. As Table 6.3.3a shows, the post calibration model meets all the required calibration tolerances for achieving decision-making requirements. Therefore, it is defined as being accurate compared to a truth model of current industry best practices for measuring building material quantities during sketch design. This proves the thesis hypothesis true, that a Revit model representation of an iEE BIM LCA BPS can calculate building material quantities accurately enough for building material LCA assessment.

Table 6.3.3a: Post Calibration Accuracy Results of Revit iEE BPS Compared to Truth Model 3

\begin{tabular}{|l|r|r|r|r|}
\hline Revit EE BIM LCA Building Performance Sketch Results Compared to Truth Model 3 - \\
QS Sketch Design SoQ
\end{tabular}

\section{Autex Insulation Over Estimation Error}

The problem identified in Chapter Section 6.3.2, and evident in Graphs 6.3.2a and 6.3.2b, was that the iEE and therefore, the material quantities of Autex GreenStuff R3.2 roof insulation was being over calculated by the Revit model. Analysis of this problem found that the error 
was caused by a human error in the LCA results analysis spreadsheet, not due to a Revit modelling error. Both the volume and area material quantities for the Autex GreenStuff R3.2 roof insulation were being calculated and used in the iEE assessment. Removing the area calculated iEE, the Revit model's iEE value reduced to approximately $-5.0 \%$ of truth model 3 . Evident in Graphs 6.3.3a and 6.3.3b, which show the distribution of iEE for both material and elemental analysis, this corrected the simulation error. The $-5.0 \%$ is accounted for by the Revit model's roof BIM objects being modelled slightly smaller than the truth model. The difference between their areas is $5 \%$. This is an error in the modelled BIM geometry. However, it is insignificant. A $5 \%$ increase in roof area translates to a $200 \mathrm{~mm}$ (approximate) increase in the roof overhang. With a total roof perimeter of $325 \mathrm{~m}$, this is a very easy modelling error to make, and an insignificant one, as the $5 \%$ difference in iEE translates to less than $1 \%$ of the total iEE value of $3.0 \mathrm{GJ} / \mathrm{m} 2 \mathrm{GFA}$. 
Graph 6.3.3a: Calibrated iEE BIM LCA BPS Material Analysis

\section{Truth Model to Revit Sketch Model Comparison Per Building Material}

Plasterboard Panels

Fibre-Reinforced Cement Boards I

General And Utility Veneer Plywoods

Timber, kiln dried, dressed, treated

Reinforced Bitumen Membrane Underlays

Aluminium, extruded, anodised

Autex GreenStuff R3.2 BIB - Batt And Mat Insulation - Polyester (Pet) Tensile Fabrics

Autex GreenStuff RI.8 BIB - Batt And Mat Insulation - Polyester (Pet) Tensile Fabrics

Heat Strengthened Glass Sheets

Non-Recycled - Carbon Steel Beams, Columns, Channels And Tee Sections

Concrete $30 \mathrm{Mpa}$

\section{1 \\ I}

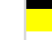
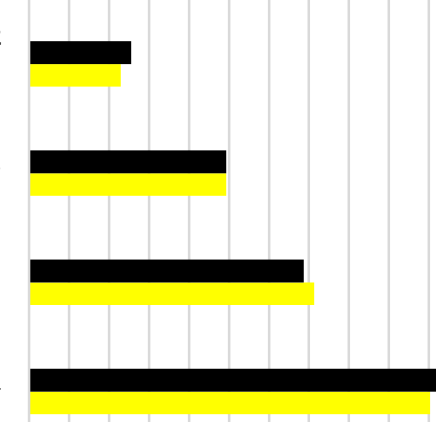

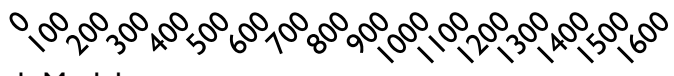

Alcorn (2010) NZ Hybrid EE Coefficient Truth Models

EE MJ/m2 GFA

- Revit Sketch Model: Sketch Design SOQ Total EE 3.0 GJ/m2 GFA.

Truth Model 3: Sketch Design SOQ Total EE 3.0 GJ/m2 GFA.

Using BIM To Calculate Accurate Building Material Quantities For Early Design Phase LCA 
Graph 6.3.3b: Calibrated iEE BIM LCA BPS Elemental Analysis

\title{
Truth Model to Revit Sketch Model
} Comparison Per Building Element

\author{
External Single Skin Walls Structure \\ Basement Walls Structure \\ External Cavity Walls External Skin \\ Upper Floors Structure \\ Roofs Structure \\ External Single Skin Walls External Skin \\ Structure
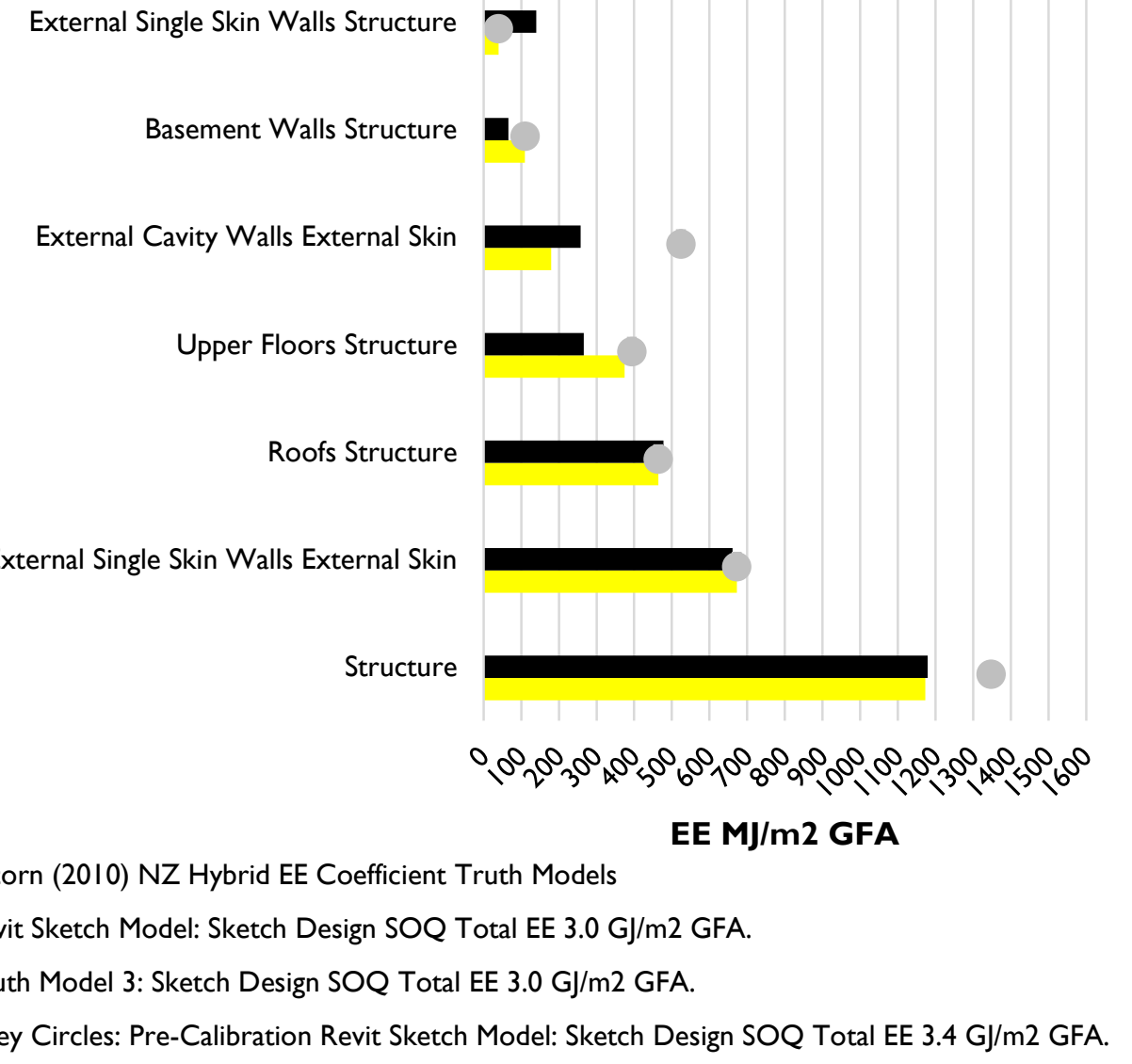

\section{iEE Element Distribution Error}

The distribution error between the structural, and upper floor elements, was caused by a human modelling error in labelling which BIM objects were a component of each element, compared to how Quantity Surveyor arranged the truth model's elemental analysis. The initial post-calibration modelling approach was to construct the BIM objects, and geometry, without consulting the truth model documentation. This was to remove the influence, and any potential bias in the results that may have occurred. The pre-calibration model was testing, how accurately a building designer could construct a BIM model without a truth 
model. This was recreating the scenario building designers would encounter in the design of new buildings. This was used to test the thesis hypothesis, and answer the question of whether a Revit BIM model of sketch design detail could calculate building material quantities accurately enough for building material LCA assessment. The post-calibration changes to the Revit model, were the reassignment, and reclassification of the BIM objects to match the truth model. This did not influence the Revit models iEE values, but corrected the elemental distribution error. This is evident in Graphs 6.3.3a and 6.3.3b, which show an improved distribution of iEE for both material and elemental analysis. They show that the post calibration Revit model is better correlated with truth model 3, compared to the precalibration, represented by the grey circle markers.

Graphs 6.3.3b, still shows some distribution differences between the wall and floor elements. Again this is due to differences in the organisation of the elemental classification, not Revit calculation errors. There will always be some differences of this type. This is due to the way BIM tools organise their information. Revit BIM objects are organised by family types.

Within each family type, there are contributing materials. The elemental classification of BIM objects is assigned to that family type, and applied to all the material within it. In many cases this will differ from the way a SOQ adhering to a standard method of measurement is organised.

For iEE, and LCA assessments, this distribution issue does not reduce the decision-making ability of building designers. Provided the building designer can; locate within which specific BIM objects the respective materials that will contribute the largest reduction in $\mathrm{EEE}$; and can apply and test design solutions, while maintaining sufficient accuracy, whether the iEE is in one element or another is not important.

Instead, for iEE and LCA assessments, it is critical that both the material level accuracy, and precision requirements are achieved. These are the results that determine if the modelling errors are occurring. Critically the elemental analysis, helps to identify where simulation errors are located. Therefore, a finding of this research has been that iEE results should be presented at material, and elemental level as per standard practices. But also specifically for BIM analysis by: 
- $\quad$ BIM Object (Revit family type): The iEE, and material quantities used, in each BIM object ranked from highest to lowest contributor. Table 6.3.3b shows an example from the LCA result analysis spreadsheet that was developed and used for this thesis research.

- The Building Materials per BIM Object (Revit family type): As a subset of the each BIM object, a presentation of the $\mathrm{iEE}$, and material quantities used, by each material in that specific BIM object. Table 6.3.3b shows an example from the LCA result analysis spreadsheet that was developed and used for this thesis research.

- Building Element: As a subset of the each building element, a presentation of iEE, and material quantities used, by each material in each. Table 6.3.3d shows an example from the LCA result analysis spreadsheet that was developed and used for this thesis research.

Table 6.3.3b: iEE LCA Results Expressed per BIM Object (Revit Family Type)

\begin{tabular}{|c|c|c|c|c|}
\hline \multirow{2}{*}{$\begin{array}{c}\text { Top } \\
\text { Ranking }\end{array}$} & \multicolumn{4}{|c|}{ Initial Embodied Energy (EE, MJ) } \\
\hline & Revit Family Type & $\begin{array}{c}\text { Value EE } \\
\mathrm{MJ} / \mathrm{m} 2\end{array}$ & Value $\mathbf{M J}$ & $\begin{array}{l}\text { Proportion of } \\
\text { Total Building }\end{array}$ \\
\hline $\mathbf{I}$ & Basic Roof: R0I & 427.2 & 4668837 & $14.0 \%$ \\
\hline 2 & Basic Wall: EW0I/EW02 & 323.6 & 3536603 & $10.6 \%$ \\
\hline 3 & FBI-3: FBI-3 & 235.2 & 2571144 & $7.7 \%$ \\
\hline 4 & Basic Wall: GT5 Inner Facade $17.5 \mathrm{~mm}$ & 210.0 & 2295664 & $6.9 \%$ \\
\hline 5 & Rectangular Mullion: $70 \times 300 \mathrm{~mm}$ & 179.1 & 1958054 & $5.9 \%$ \\
\hline 6 & Basic Wall: GTI Outer Facade $13.5 \mathrm{~mm}$ & 177.6 & 1941309 & $5.8 \%$ \\
\hline 7 & Floor: 200 Sketch Dycore/Hollow Core $+65 \mathrm{~mm}$ Topping & 165.7 & 1811501 & $5.4 \%$ \\
\hline 8 & Floor: $75 \mathrm{~mm}$ Unispan $125 \mathrm{~mm}$ Concrete Topping 655 mesh & 163.2 & 1784072 & $5.4 \%$ \\
\hline 9 & Column $\mathrm{Cl}$ CHS Concrete Filled Concrete Foundation Footing: $\mathrm{Cl} 457 \times 12.7 \mathrm{CHS}$ & 158.1 & 1728482 & $5.2 \%$ \\
\hline 10 & Column C2 CHS Concrete Filled Concrete: C2 406×12.7 CHS & 112.1 & $1225 \mid 25$ & $3.7 \%$ \\
\hline
\end{tabular}


Table 6.3.3c: iEE LCA Results Expressed per Building Material per BIM Object (Revit family type)

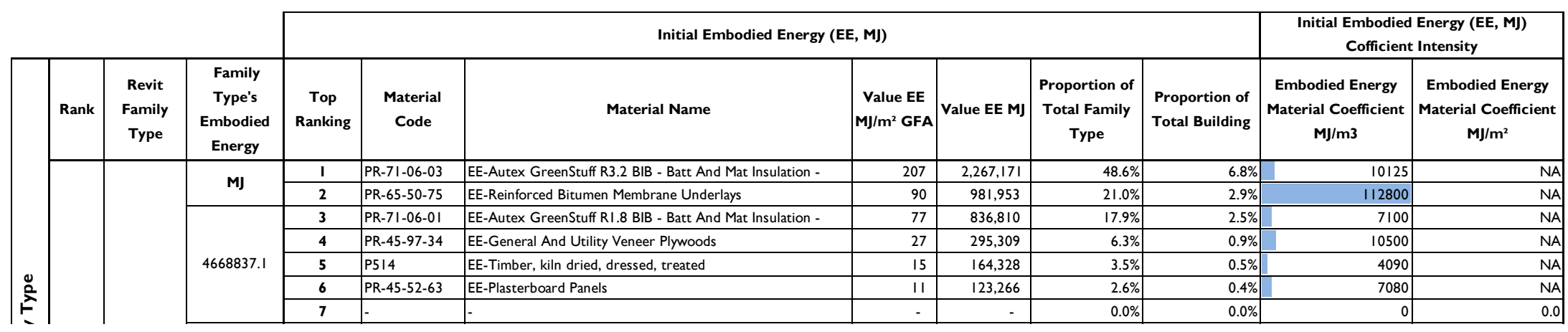

Table 6.3.3d: iEE LCA Results Expressed per Building Element

\begin{tabular}{|c|c|c|c|c|c|c|c|c|c|c|c|c|}
\hline \multirow[b]{2}{*}{$\begin{array}{c}\text { Element } \\
\text { Rank }\end{array}$} & \multirow[b]{2}{*}{$\begin{array}{l}\text { Element } \\
\text { Code }\end{array}$} & \multirow[b]{2}{*}{$\begin{array}{l}\text { Element } \\
\text { Name }\end{array}$} & \multirow[b]{2}{*}{$\begin{array}{c}\text { Element's } \\
\text { Embodied } \\
\text { Energy }\end{array}$} & \multicolumn{7}{|c|}{ Initial Embodied Energy (EE, MJ) } & \multicolumn{2}{|c|}{$\begin{array}{l}\text { Initial Embodied Energy (EE, MJ) } \\
\text { Cofficient Intensity }\end{array}$} \\
\hline & & & & $\begin{array}{l}\text { Top } \\
\text { Ranking }\end{array}$ & Material Code & Material Name & $\mid \begin{array}{c}\text { Value EE } \\
\mathrm{MJ} / \mathrm{m}^{2} \text { GFA }\end{array}$ & Value EE & $\begin{array}{l}\text { Proportion of } \\
\text { Total Element }\end{array}$ & $\begin{array}{l}\text { Proportion of } \\
\text { Total Building }\end{array}$ & \begin{tabular}{|c|} 
Embodied Energy \\
Material Coefficient \\
$\mathrm{MJ} / \mathrm{m} 3$
\end{tabular} & $\begin{array}{l}\text { Embodied Energy } \\
\text { Material Coefficient } \\
\mathrm{MJ} / \mathrm{m}^{2}\end{array}$ \\
\hline & & & & $\mathrm{I}$ & PR-71-06-03 & EE-Autex GreenStuff R3.2 BIB - Batt And Mat Insulation - & 207 & $2,267,171$ & $43.4 \%$ & $6.8 \%$ & 10124.6 & $\overline{\mathrm{NA}}$ \\
\hline & & & & 2 & PR-65-50-75 & EE-Reinforced Bitumen Membrane Underlays & 90 & 981,953 & $18.8 \%$ & $2.9 \%$ & 112800.0 & $\mathrm{NA}$ \\
\hline & & & & 3 & PR-71-06-01 & EE-Autex GreenStuff RI.8 BIB - Batt And Mat Insulation - & 77 & 836,810 & $16.0 \%$ & $2.5 \%$ & 7100.3 & $\mathrm{NA}$ \\
\hline & & & & 4 & $P R-60-5|-| 2-0 \mid$ & EE-Non-Recycled - Carbon Steel Beams, Columns, Channels & 51 & 552,995 & $10.6 \%$ & $1.7 \%$ & 155359.8 & $\mathrm{NA}$ \\
\hline & & & & 5 & PR-45-97-34 & EE-General And Utility Veneer Plywoods & 27 & 295,309 & $5.7 \%$ & $0.9 \%$ & 10500.0 & $\mathrm{NA}$ \\
\hline & & & & 6 & P514 & EE-Timber, kiln dried, dressed, treated & 15 & 164,328 & $3.1 \%$ & $0.5 \%$ & 4090.0 & $\mathrm{NA}$ \\
\hline & & & & 7 & PR-45-52-63 & EE-Plasterboard Panels & 11 & 123,266 & $2.4 \%$ & $0.4 \%$ & 7080.0 & $\mathrm{NA}$ \\
\hline & & & & 8 & & & & & $0.0 \%$ & $0.0 \%$ & 0.0 & 5.0 \\
\hline
\end{tabular}

Using BIM To Calculate Accurate Building Material Quantities For Early Design Phase LCA 


\subsection{Test Three: Is The Revit iEE BIM LCA BPS Model}

\section{Robust?}

\subsection{EE \& Embodied Carbon Dioxide}

The Revit iEE BIM LCA BPS was proven to meet the calibration accuracy requirements using Alcorn's (2010) hybrid process / input-out EE calculated material coefficients. This proved for one example of an LCA assessment result the methodology is feasible. This Chapter Section tests the applicability of using the Revit iEE BIM LCA BPS modelling method for EE databases for countries other than New Zealand, and for different LCA-based indicators beyond EE.

This robustness test normalises the post calibration Revit model's material quantities using two different material databases. Firstly, to Crawford's (2004) hybrid input-output / process EE dataset, and secondly, to Alcorn's (2010) hybrid process / input-output Embodied Carbon Dioxide (ECO2) dataset. Tables 6.4.Ia and 6.4. Ib show the post calibration results for the Crawford's iEE, and Alcorn's ECO2 post calibration Revit model. These results show strong model simulation robustness, as in both datasets the Revit model achieved the maximum acceptable calibration tolerance requirements. However, both showed greater inaccuracies than the Alcorn iEE post calibration model. This is because in each data set the environmental intensities for each material are different. This means, any over, or under estimations and their impact on cancellation errors in the material quantities, when normalised have a different level of impact on the overall simulation accuracy. Concrete 30 Mpa for example, has a much higher ECO2 intensity than its iEE. That is why it represents $56 \%$ of the total ECO2, compared to $33 \%$ of the Alcorn iEE, and $19 \%$ for Crawford's iEE.

The results highlighted several key attributes of building materials, and elements that classify them as 'high risk', as they are likely to be have a high impact on the $\mathrm{iEE}, \mathrm{ECO}_{2}$ consumption of a building. 'High risk' means that they may require a high level of modelled detail beyond their proportional influence. Building materials and elements are defined as high risk is defined in a number of ways:

Using BIM To Calculate Accurate Building Material Quantities For Early Design Phase LCA 
I. They that are likely to have high or low proportion of iEE or ECO2 relative to the material quantities used.

2. They that are likely to be highly influenced by other design decisions. Therefore they are likely to change substantially across different design iterations.

3. Their $\mathrm{iEE}$ and ECO2 results vary significantly adversely influencing simulation accuracy.

Table 6.4.Ia: Revit Calculated iEE Results Using Crawford's (2004) Hybrid EE Database

\begin{tabular}{|c|c|c|c|c|}
\hline \multicolumn{5}{|c|}{ Revit EE BIM LCA Building Performance Sketch Results Compared to Truth Model 3} \\
\hline \multirow{3}{*}{$\begin{array}{c}\text { Building Performance Sketch Elemental } \\
\text { Analysis: Post Calibration }\end{array}$} & \multicolumn{2}{|c|}{$\begin{array}{c}\text { Material Analysis Accuracy } \\
\text { Assessment }\end{array}$} & \multicolumn{2}{|c|}{$\begin{array}{c}\text { Elemental Analysis Accuracy } \\
\text { Assessment }\end{array}$} \\
\hline & \multicolumn{4}{|c|}{ EE Truth Model 3: SOQ Sketch Design } \\
\hline & MBE & Cv(RSME) & MBE & Cv(RSME) \\
\hline Post-Calibration & $6.2 \%$ & $18.8 \%$ & $6.2 \%$ & $16.5 \%$ \\
\hline Calibration Tolerances Achieved & Pass & Pass & Pass & Pass \\
\hline \multicolumn{5}{|l|}{ Notes } \\
\hline Revit Sketch Design BIM Model Total EE: & \multicolumn{2}{|c|}{$7.7 \mathrm{GJ} / \mathrm{m} 2 \mathrm{GFA}$} & & \\
\hline \multicolumn{5}{|c|}{ (Crawford, 2004) Hybrid Input-output / Process database specific for Australia. } \\
\hline \multicolumn{5}{|c|}{ Maximum acceptable calibration tolerance for MBE less than $\pm 10-20 \%$} \\
\hline \multicolumn{5}{|c|}{ Maximum acceptable calibration tolerance for Cv(RSME) less than $15-30 \%$} \\
\hline
\end{tabular}

Using BIM To Calculate Accurate Building Material Quantities For Early Design Phase LCA 
Table 6.4. I b: Revit Calculated ECO2 Results Using Alcorn's (2010) Hybrid ECO2 Database

\begin{tabular}{|l|c|c|c|c|}
\hline \multicolumn{3}{|c|}{ Revit ECO2 BIM LCA Building Performance Sketch Results Compared to Truth Model 3 } \\
\hline \multirow{2}{*}{$\begin{array}{c}\text { Building Performance Sketch Elemental } \begin{array}{c}\text { Material Analysis Accuracy } \\
\text { Assessment }\end{array} \\
\text { Analysis: Post Calibration }\end{array}$} & \multicolumn{3}{|c|}{$\begin{array}{c}\text { Elemental Analysis Accuracy } \\
\text { Assessment }\end{array}$} \\
\cline { 2 - 5 } & MBE Truth Model 3: SOQ Sketch Design \\
\cline { 2 - 5 } & $1.6 \%$ & $4.3 \%$ & $1.9 \%$ & Cv(RSME) \\
\hline Post-Calibration & Pass & Pass & Pass & Pass \\
\hline Calibration Tolerances Achieved & & & \\
\hline Notes & \multicolumn{3}{|c|}{$261.90 \mathrm{~kg} / \mathrm{m} 2$ GFA } \\
\hline Revit Sketch Design BIM Model Total ECO2: \\
\hline (Alcorn, 2010) ECO2 Hybrid Process / Input-output database specific for New Zealand. \\
\hline Maximum acceptable calibration tolerance for MBE less than $\pm 10-20 \%$ \\
\hline Maximum acceptable calibration tolerance for Cv(RSME) less than 15-30\% \\
\hline
\end{tabular}

\subsubsection{Cancellation Errors In The BIM Geometry}

The robustness testing of the post calibration Revit model highlighted the presence of cancellation errors. Using concrete beams as an example, in total, 91 instances were modelled, spread across 22 unique BIM objects. Comparing the values of each individual beam member as modelled in Revit to the truth model showed significant variation between the two. The maximum reported difference was 129\%, an over estimation. Whereas, the minimum was $32 \%$, an under estimation. Both the Revit, and truth model 3 calculated material volume from beams that had the same cross sectional dimensions e.g. Ground Beam 2: $665 \mathrm{~mm}$ deep $\times 800 \mathrm{~mm}$ wide. This means, the cause of these differences was due to the modelling of the BIM geometry, e.g. their modelled length. Analysis showed most of the over, and under estimation errors were caused by differences in the formatting of the truth model's SOQ, and the Revit calculated SOQ. This is a misalignment error. In the Revit modelling process, several beams of the same cross sectional size were modelled as a single type, instead of having their own unique BIM object. This was done to simplify the BIM model, as part of 'sketching' iEE to reduce modelling time and effort. Accounting for these errors, and removing these beam instances, there were still cancellation errors caused by inaccuracies in the BIM geometry. This is to be expected, as no model is without errors. However, the maximum reported differences were $102 \%$, an over estimation, whereas, the 
minimum was $68 \%$, an under estimation. These averaged to be a $2.5 \%$ under estimation error by the Revit model, which is an insignificant modelling error.

Expressing these estimation differences as modelled BIM geometry, these range from being a maximum of $683 \mathrm{~mm}$ too long, to $375 \mathrm{~mm}$ too short. This is well within acceptable model discrepancies for BIM geometry modelling during sketch design, where the building form is still subject to design uncertainties. Additionally, their impact when considered in the overall context of the building's total iEE is insignificant. This averaged out across all total beam lengths to be less than $1 \%$. This finding is supported by the total iEE of the all concrete beams in the building, as their total iEE (Alcorn) values were II5.4 MJ/m2 GFA and II 6.6 $\mathrm{MJ} / \mathrm{m} 2$ GFA for the truth model, and the post calibration Revit model respectfully. This equates to only a - I.0\% difference between the two, proving the over and under estimation errors effectively cancel one another out and are not a concern to simulation accuracy.

Overall, the modelling of BIM geometry in the iEE BIM LCA BPS methodology is far less precise than typical BIM or CAD drawing conventions during detailed design. This the cause of a $4.3 \%$ combined cancellation error in the building material analysis of the $3.0 \mathrm{GJ} / \mathrm{m} 2 \mathrm{GFA}$ post calibration model. However, as no individual material had an error greater than $1.0 \%$, and the robustness testing proved that imprecise modelling of BIM geometry causing cancellation errors was not a notable influence on simulation accuracy, this is not cause simulation errors that effect the iEE BIM LCA BIM BPS suitability for decision-making.

\subsection{Modelled Detail Of The Pre-Calibration Revit iEE}

\section{BIM BPS}

Chapter Section 6.3.I proved that the building information defined within an iEE LCA BPS model is sufficiently detailed e.g. complete enough, to be effective as a design tool for reducing environmental impact. Chapter Sections 6.3.2 and 6.3.3 have proven, that a Revit representation of an iEE BIM LCA BPS can calculate building material quantities accurately. Together, these two sections prove this thesis' hypothesis to be true, and that is satisfies the thesis' aim of, developing a methodology for how to use a BIM LCA tool (Revit) correctly to enable its effective integration into sketch design. 
This Chapter Section, answers the research question for this thesis of, how detailed does the Revit BIM model need to be to calculate accurate building material quantities for a building material LCA (LCA) assessment?

\subsection{How Detailed Is The Revit Pre-Calibration BIM Model?}

\section{Overall BIM Model Detail}

To date, there is no standard practice for communicating the level of detail/development for a BIM model at whole building level that enables a fair comparison of one BIM model's detail to another. Leite et al., (20I I) faced this issue in their research investigating BIM modelling effort, and modelling time relative to BIM modelled detail. The author's followed standard convention, and published their results of complexity based around the total number of BIM objects used in their models. However, this approach lacks an expression of the building's size, which effects BIM geometry detail and complexity, and for LCA purposes, an expression of the number of building materials being assessed. This is currently a gap in BIM research. Recognising this gap, an expression of the total number of building materials being assessed is an important parameter in a metric for communicating BIM model complexity for LCA purposes. Table 6.5. Ia presents a sample of metrics used to communicate BIM model complexity. Many of these were developed for this thesis research, but may have an application in wider BIM research if specifically tested and verified to be proven effective. Comparing research results of BIM model complexity from Leite et al., (201 I), to the precalibration iEE Revit BIM LCA BPS model, the Revit model's detail is almost equal between the authors precise, and fabrication level of detail models. Comparing the total number of BIM objects, the difference to the pre-calibration Revit BIM model is $66 \%$, (-34\%), and $233 \%$ $(+33)$, for the respective precise, and fabrication levels of detail. It was outside the scope of this research to measure the time spent constructing the pre-calibration Revit BIM model, however, as an approximate estimate is that it is similar to the 67.5 hours required by the precise level of detail. Although, this was influenced by the modeller (Brian Berg) having to use the Revit BIM tool for the first time, and the trial and error approach in developing an iEE calculation methodology. 
Leite et al., (20II) concluded that modelled time and effort, was directly linked to the number of total BIM objects used in the BIM model. This is a combination of the time taken to construct the BIM objects, and geometry. By comparison, for iEE purposes, this research found that creating the BIM objects and embedding the necessary metadata, such as the material, and building classification system codes, and descriptions, were the most time intensive activities. Constructing the BIM geometry, was the easier, and therefore faster task in the modelling process. This conclusion aligns with the wider research in $\mathrm{EEE}$, where reducing the number different building materials being accessed is the single most common calculation complexity reduction technique used by building LCA researchers. 
Table 6.5. Ia: BIM Modelled Detail Of iEE BIM LCA BPS

\begin{tabular}{|c|c|c|c|}
\hline \multirow[b]{2}{*}{$\begin{array}{c}\text { Modelled Detail / Complexity } \\
\text { Metric }\end{array}$} & \multirow{2}{*}{$\begin{array}{c}\text { Pre- } \\
\text { Calibration } \\
\text { Revit BIM } \\
\text { Model }\end{array}$} & \multicolumn{2}{|c|}{$\begin{array}{l}\text { Project I Leite et al., (20II) } \\
* I\end{array}$} \\
\hline & & $\begin{array}{c}\text { Precise } \\
\text { Level of } \\
\text { Detail } * 2\end{array}$ & $\begin{array}{c}\text { Fabrication } \\
\text { Level of Detail } \\
*_{3}\end{array}$ \\
\hline Total number of BIM objects & 1730 & 1140 & 4028 \\
\hline $\begin{array}{l}\text { Total number of individual BIM } \\
\text { objects }\end{array}$ & 73 & & \\
\hline Total number of building materials & 6047 & & \\
\hline $\begin{array}{l}\text { Total number of individual building } \\
\text { materials }\end{array}$ & II & & \\
\hline $\begin{array}{l}\text { Total number of BIM objects / Total } \\
\text { number of individual BIM objects }\end{array}$ & 23.4 & & \\
\hline $\begin{array}{l}\text { Total number of BIM objects } I \\
\text { GFA }\end{array}$ & 0.158 & $\begin{array}{c}\mathbf{0 . 0 6 5} \\
\text { Diff. to Pre- } \\
\text { Calibration } \\
\quad-0.09\end{array}$ & $\begin{array}{c}\mathbf{0 . 2 2 9} \\
\text { Diff. to Pre- } \\
\text { Calibration } \\
\quad+0.07\end{array}$ \\
\hline $\begin{array}{l}\text { Total number of BIM objects / Total } \\
\text { number of building materials }\end{array}$ & 0.29 & & \\
\hline $\begin{array}{l}\text { Total number of building materials / } \\
\text { GFA }\end{array}$ & 0.55 & & \\
\hline $\begin{array}{l}\text { Total number of building materials } \\
\text { modelled / Total number of BIM } \\
\text { objects }\end{array}$ & 3.5 & & \\
\hline $\begin{array}{l}\text { Total number of building materials } \\
\text { modelled / Total number of } \\
\text { individual materials }\end{array}$ & 549.7 & & \\
\hline
\end{tabular}

Using BIM To Calculate Accurate Building Material Quantities For Early Design Phase LCA 
- $\quad$ Project I Building GFA 189,000 sq ft, converted to $17558.7 \mathrm{~m} 2$.

- 5 storey commercial office building.

- Building elements modelled limited to foundations, external walls (brick veneer, curtain wall), main structure (steel column and beams), and roof.

*2 Precise level of detail is equivalent to a best match 100-200 Level Of Development

*3 Fabrication level of detail is equivalent to a best match 400 Level Of Development

\section{BIM Object Detail}

For data confidentiality reasons, the identity of the case study building used in this research must remain anonymous. This limits the use of visual imagery to describe the BIM modelled detail required to produce an accurate pre-calibration Revit iEE BIM LCA BPS. As a solution, the BIM Level Of Development (LOD) specification (Level of Development Specification, 2013) is used. This describes the detail of the specific BIM objects used in the Revit iEE BIM LCA BPS model using an international specification, which is now a specified standard in the newly developed New Zealand BIM Handbook specification (The Building and \& Construction Productivity Partnership, 2014).

Table 6.5. Ib presents a breakdown of the 74 different BIM objects into 17 categories. The remaining 57 BIM objects are simply different size variations of these 17 BIM objects. For example, there were 18 different rectangular concrete beams, all modelled to a LOD of 200. 
Table 6.5. I b: Modelled Detail Of BIM Objects In The iEE BIM LCA BPS

\begin{tabular}{|c|c|c|c|}
\hline Revit Object & $\begin{array}{c}\text { Revit Object } \\
\text { Modelling Tool } \\
\end{array}$ & \multicolumn{2}{|c|}{$\begin{array}{c}\text { 3D Modelled Detail Level Of Development } \\
\text { (LOD) }\end{array}$} \\
\hline $\begin{array}{l}\text { Foundation Strip } \\
\text { Footing }\end{array}$ & $\begin{array}{l}\text { Beam tool - Not } \\
\text { Footing Tool }\end{array}$ & $\begin{array}{l}\text { AI0I0.30 - Column Foundations } \\
\text { (Deep Foundations) }\end{array}$ & LOD 200 \\
\hline Concrete Pile & Column Tool & AI0I0-Standard Foundations & LOD 200 \\
\hline $\begin{array}{l}\text { CHS Column with } \\
\text { Foundation } \\
\text { Footing }\end{array}$ & $\begin{array}{l}\text { Custom Object } \\
\text { Parametric Object }\end{array}$ & $\begin{array}{l}\text { BI0I0.10 - Floor Structural } \\
\text { Frame (Steel Framing Columns) }\end{array}$ & LOD 300 \\
\hline $\begin{array}{l}\text { Concrete } \\
\text { Foundation Slab }\end{array}$ & Floor Tool & A40I0 - Standard Slabs-on-Grade & LOD 200 \\
\hline $\begin{array}{l}\text { Dycore Precast } \\
\text { Floor Slab }\end{array}$ & Floor Tool & \multirow{3}{*}{$\begin{array}{l}\text { BI0I0.20 - Floor Decks, Slabs, } \\
\text { and Toppings (Composite Floor } \\
\text { Deck) }\end{array}$} & \multirow{3}{*}{ LOD 200} \\
\hline $\begin{array}{l}\text { Insitu Concrete } \\
\text { Floor }\end{array}$ & Floor Tool & & \\
\hline $\begin{array}{l}\text { UniSpan Concrete } \\
\text { Floor }\end{array}$ & Floor Tool & & \\
\hline $\begin{array}{l}\text { Circular Hollow } \\
\text { Section (CHS) } \\
\text { Column }\end{array}$ & Column Tool & $\begin{array}{l}\text { BI0I0.10 - Floor Structural } \\
\text { Frame (Steel Framing Columns) }\end{array}$ & LOD 300 \\
\hline $\begin{array}{l}\text { Steel Universal } \\
\text { Column (UC) }\end{array}$ & Column Tool & $\begin{array}{l}\text { BI0I0.10 - Floor Structural } \\
\text { Frame (Concrete) }\end{array}$ & LOD 300 \\
\hline $\begin{array}{l}\text { Steel Universal } \\
\text { Beam (UB) }\end{array}$ & Beam tool & $\begin{array}{l}\text { BI0I0.10 - Floor Structural } \\
\text { Frame (Steel Framing Beams) }\end{array}$ & LOD 300 \\
\hline $\begin{array}{l}\text { Concrete Beam - } \\
\text { Rectangular }\end{array}$ & Beam tool & $\begin{array}{l}\text { BI0I0.10 - Floor Structural } \\
\text { Frame }\end{array}$ & LOD 200 \\
\hline $\begin{array}{l}\text { Insitu Concrete } \\
\text { Wall }\end{array}$ & Wall Tool & \multirow{4}{*}{ B2010 - Exterior Walls } & \multirow{4}{*}{ LOD 300} \\
\hline $\begin{array}{l}\text { Concrete Masonry } \\
\text { Block Wall }\end{array}$ & Wall Tool & & \\
\hline $\begin{array}{l}\text { Precast Concrete } \\
\text { Wall }\end{array}$ & Wall Tool & & \\
\hline $\begin{array}{l}\text { Timber Framed } \\
\text { Wall }\end{array}$ & Wall Tool & & \\
\hline $\begin{array}{l}\text { Double Skin } \\
\text { Façade }\end{array}$ & $\begin{array}{l}\text { Wall + Curtain Wall } \\
\text { Tool }\end{array}$ & $\begin{array}{l}\text { B2020.30 - Exterior Window } \\
\text { Wall }\end{array}$ & LOD 350 \\
\hline Roof & Roof & BI 020.10 - Roof Structural Frame & LOD 200 \\
\hline \multicolumn{4}{|l|}{ Notes: } \\
\hline $\begin{array}{l}\text { Refer to Appendix } \\
\text { description of the B }\end{array}$ & $\begin{array}{l}6.3 \text { for the Level of } \\
\text { BIM object details. }\end{array}$ & -ification 2013 & ication \\
\hline
\end{tabular}

Using BIM To Calculate Accurate Building Material Quantities For Early Design Phase LCA 
Overall the Revit iEE BIM LCA BPS model is predominantly a mix of BIM objects constructed to a LOD 200 or 300. This classification is based on their 3D modelled information. The key difference between LOD 200, and 300, is that LOD 200 is a representation of a generic system. A LOD 200 BIM object is constructed from approximate dimensions, and therefore can only calculate approximate material quantities. Some metadata is embedded, but this is not a consistent requirement across all LOD 200 BIM objects (Level of Development Specification, 2013, p. 10). By comparison, LOD 300 BIM objects represent specific systems, and are constructed from specific dimensions, and they all must have metadata embedded (Level of Development Specification, 2013, p. 10).

An iEE BIM LCA BPS sits between LOD level 200 and 300. A LOD 200 is not detailed enough because it does not specify the detail required of 3D information to calculate building the many different material quantities that are present in a single BIM object. A LOD 200 object is suitable for homogeneous single material layers such as, concrete walls, or concrete beams. It is not suitable for homogeneous construction systems with multiple homogeneous material layers, or for non-homogeneous material layers such as timber studs. In these cases BIM objects must be modelled to a LOD of 300 . Furthermore, the specification of metadata is essential for conducting an iEE assessment, such as, material and element classification system codes, and descriptions, is not a consistent requirement in LOD 200 BIM objects. A LOD 300 BIM object does achieve this requirement. Visually, LOD suitability for the iEE BIM LCA BPS is best illustrated by a wall BIM object. This example is presented in Table 6.5.Ic. 
Table 6.5.I c: The Modelled of the Timber Stud Exterior Wall LOD B2010.20 - Exterior Wall Construction (Level of Development Specification, 2013, p. 38):

Description: Example of case study building timber stud wall:

- RAB fibre cement board $6 \mathrm{~mm}$.

- Treated timber cavity battens at $600 \mathrm{~mm}$ centres.

- Building wrap.

- Timber studs at $90 \times 45 \mathrm{~mm}$ at $600 \mathrm{~mm}$ centres.

- Autex R2.2 insulation cavity infill between timber framing.

- Plasterboard lining $13 \mathrm{~mm}$.

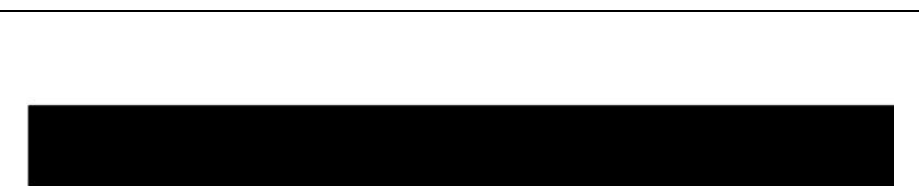

At LOD 100 not suitable for iEE modelling.

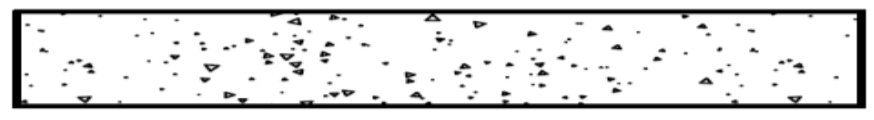

At LOD 200 suitable for iEE modelling of homogeneous single material building elements such as concrete walls.
LOD 100: Sold mass generic wall. Materiality not distinguishable.

LOD 200: Sold mass generic wall. Single overall thickness represented by a single assembly. Materiality distinguishable.

LOD 300: Composite assembly with specific overall thickness. Individual material elements e.g. studs and insulation not modelled, or distinguishable. A thickness volume represents their location. Not suitable for non- 


\begin{tabular}{|c|c|}
\hline $\begin{array}{l}\text { standard practice in operation energy modelling to account for } \\
\text { thermal bridging. }\end{array}$ & $\begin{array}{l}\text { homogeneous } \\
\text { construction systems }\end{array}$ \\
\hline 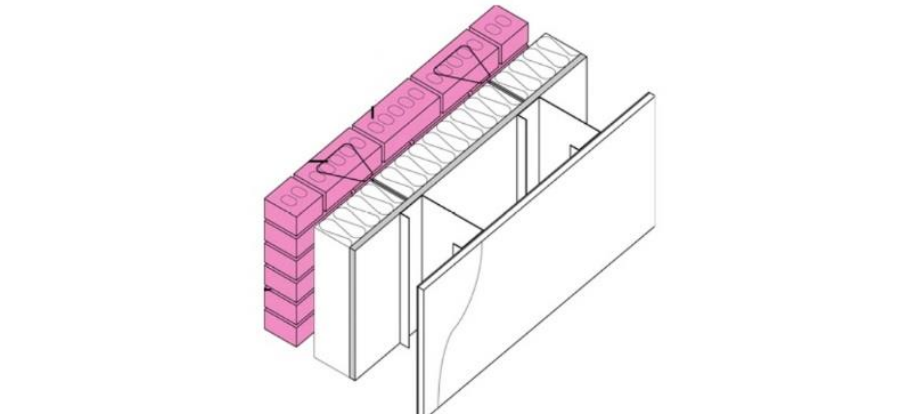 & $\begin{array}{l}\text { LOD 400: Individually } \\
\text { modelled all building } \\
\text { material elements as } \\
\text { listed above, plus } \\
\text { weather proofing } \\
\text { components e.g. } \\
\text { flashings. }\end{array}$ \\
\hline $\begin{array}{l}\text { Suitable for iEE modelling of non-homogeneous construction } \\
\text { systems. }\end{array}$ & \\
\hline
\end{tabular}

\section{Discussion Of BIM Level Of Development And The iEE BPS}

BIM object LOD and the design process are not co-ordinated (Level of Development Specification, 20I3, p. II). There is no correspondence between the design process phases, the information available at each phase, the design decisions that must be made at each phase, and the LOD required to achieve this. This is because different building elements are developed at different rates throughout the design process. For example, during sketch design, the building's main structural elements must be defined, whereas, the internal finishes are not resolved until developed, or detailed design (American Institute of Architects (AIA), 2008; New Zealand Construction Institute Council (NZCIC), 2004; Ostime, 20I3). Therefore, in practice a BIM model will consist of many different BIM objects, constructed to many different LOD levels (Level of Development Specification, 20I3, p. II).

This is true for single integrated BIM models developed using the BIM concept. However, for the BIM iEE LCA BPS, it does not apply. The BIM iEE LCA BPS is defined by the information, and design decisions made during sketch design. Therefore the specification of the BIM objects LOD is linked to sketch design. Knowing that at sketch design, for iEE assessment, a LOD between 200 and 300 for most objects is sufficiently detailed to produce accurate simulation results. This makes the LOD standard much more useful for building designers. 


\subsubsection{How Was Revit Used To Construct The iEE BIM BPS?}

The Revit BIM modelling process involved constructing both the BIM objects, and geometry. This is standard practice for BIM modelling. To assist building designers with this, BIM object libraries are being developed. One such example is the UK's National Building Specification (NBS) BIM National Library (The National Building Specification (NBS) \& BIM Technologies Alliance, 20I4). This is a free database of downloadable BIM objects, each with embedded with metadata such as cost, material density, lifespan, etc. To date, the New Zealand construction industry lacks an equivalent database of BIM objects with LCA building information. Therefore, the BIM objects used in this research were constructed as required within the Revit BIM tool. This is standard of BIM modelling, and the Revit help documentation provides step by step instructions to assist building designers. To create the BIM geometry, the building documentation plans, such as floor plans, elevations, and cross sections, were imported into Revit. These plans were scaled appropriately, and then traced over to place the BIM objects, and construct the BIM geometry. This was conducted with a level of care, and detail, approximate to a 1:50 - I:100 drawing scale, where dimensions were rounded, or adjusted to roughly align to produce a rudimentary visual representation.

This is all in accordance with standard BIM modelling practices when reconstructing an existing building from project documentation. As a result of this process, several specific modelling practices were identified as critical modelling techniques:

- Set up and using building grids. This ideas seems at odds with the BPS concept of 'sketching'. However, to fully utilise the Revit BIM tool productivity features, such as automated beam placement, building grid are critical. Building grid layout is a design decision made during sketch design, therefore this information should be available. Refer to Appendix 4.0 Table 4.2.2a.

- Setup the building height levels, such as floor to floor heights.

- Use Revit family type project parameters for assigning metadata building classification codes, and descriptions, for building elements.

- The Revit material browser must be used to manage, and assign the material codes, and descriptions, for each of the materials within a family type. Refer Figure 6.5.2a. 
Figure 6.5.2a: Revit Material Browser

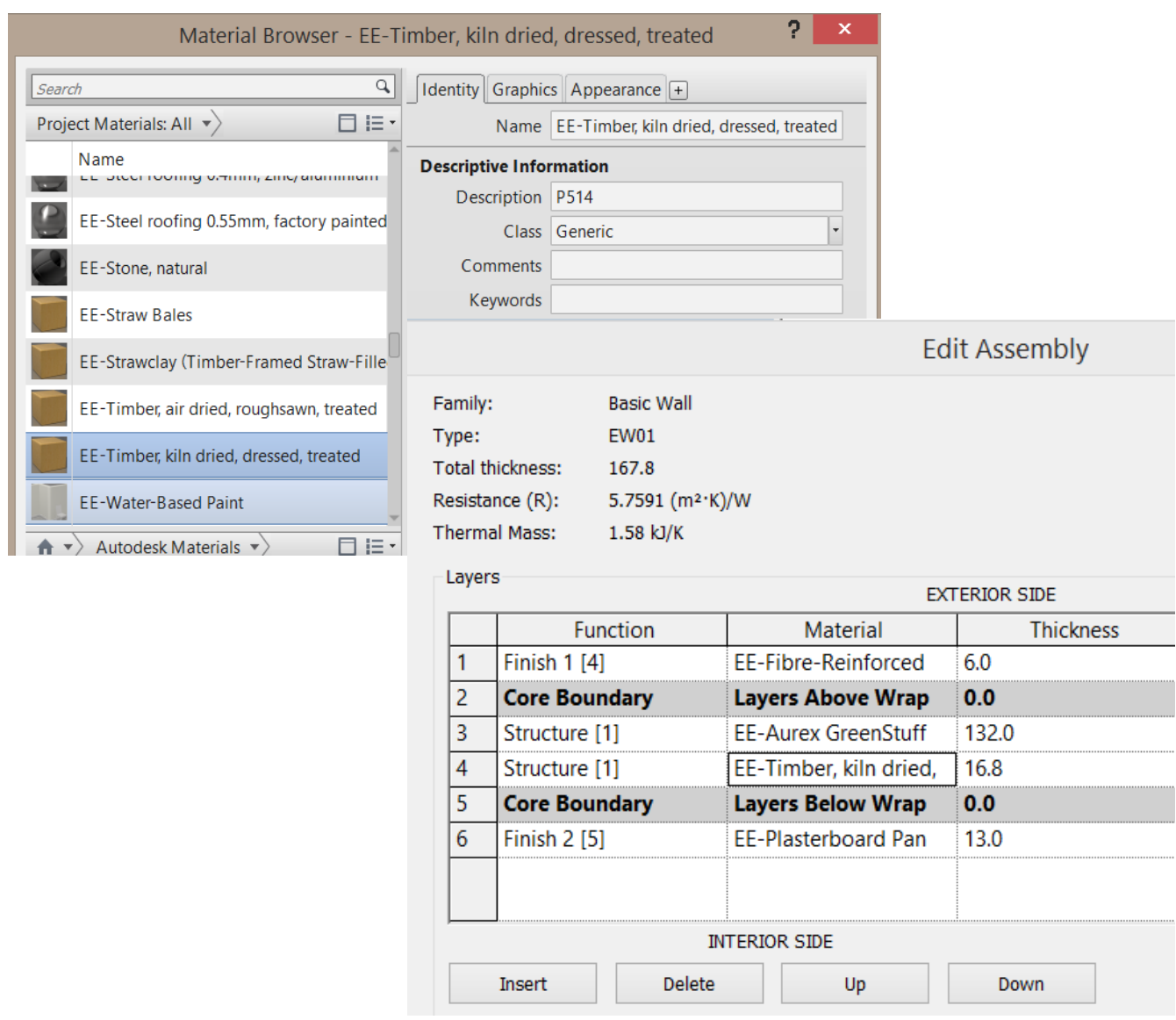

- Some specific materials will only be listed on specific material or schedule of quantity lists, or are not able to calculate the volume material quantity of a material. This can vary depending on the BIM object and material. For example, window mullions report only their length, and only on a specific mullion schedule. The modeller needs to quality assure their material quantities lists ensuring that all objects and materials are listed, and calculate material quantities that match the functional definition of the material coefficient being applied. Furthermore, there must be no hidden or unused BIM objects or geometry associated with a project template, as these will be included in the iEE assessment.

- The Revit schedules report the material quantities with a unit expression such as $\mathrm{m}^{3}$ included. This will cause excel errors in the LCA results analysis spreadsheet. Using 
a formula to divide the calculated quantity by I, within the Revit schedule will solve this problem.

- Overlapping of BIM geometry, such as beam and column connections can be ignored. This reduces modelling time and effort considerable, and did not result in modelling errors that made the BIM calculated iEE inaccurate.

- It is easier, and therefore faster to model BIM objects and geometry using the Revit system family types e.g. wall, floor, roof, beams, and columns, rather than loadable families. A component is an instance of a loadable family. It is usually used to model building elements, or construction systems that are delivered and installed on site. Examples include, windows, and precast slabs (Dycore). Constructing BIM objects of these components, and their respective BIM geometry is time consuming. This is because they are often extremely detailed, and they must be placed individually to construct the BIM geometry. Figure 6.5.2b shows an example of the Dycore floor slab constructed using a modelling simplification developed for the iEE BIM LCA BPS modelling process. On the left, is a cross sectional view of a detailed Revit family component representation of the Dycore slab. On the right, is the iEE sketch design Revit system family that was used instead. To account for the reduction in concrete saved by the hollow cores, which is not modelled in the sketch design BIM object, a volume multiplier of 0.6478 was embedded into the BIM object. This was automatically multiplied by the total volume using a formula in the Revit SOQ. This is the same process used for the timber studs, and other non-homogenous constructions such as timber roofs, and walls (as described in Figure 6.5.Ic), and the millions (as described in Figure 6.5.2c).

Figure 6.5.2b: Solutions For Quickly Sketching Detailed BIM Objects

\section{Dycore Floor Slab \\ Revit Compont Family Type}

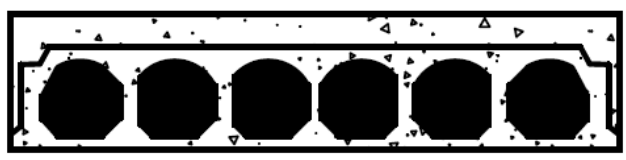

Cross sectional area:

$65 \mathrm{~mm}$ topping $0.0875 \mathrm{~m} 2$

Dycore exclude hollow cores $0.1174 \mathrm{~m} 2$

Total $0.2049 \mathrm{~m} 2$

\section{EE Building Performance Sketch Dycore Floor Slab Revit System Family Type}

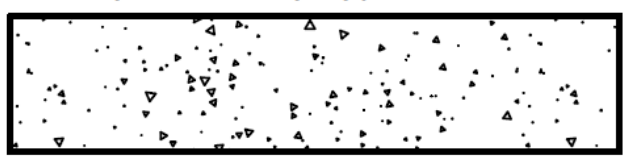

Cross sectional area:

Total $0.3163 \mathrm{~m} 2$

Volume multiplier 0.6478

Recalculated $0.3163 \times 0.6478=0.2049 \mathrm{~m} 2$ 
Figure 6.5.2c: The Modelled Detail of the Double Skin Façade BIM Object LOD B2020.30 - Exterior Window Wall (Level of Development Specification, 2013, p. 40):

\section{Modelled LOD 350}

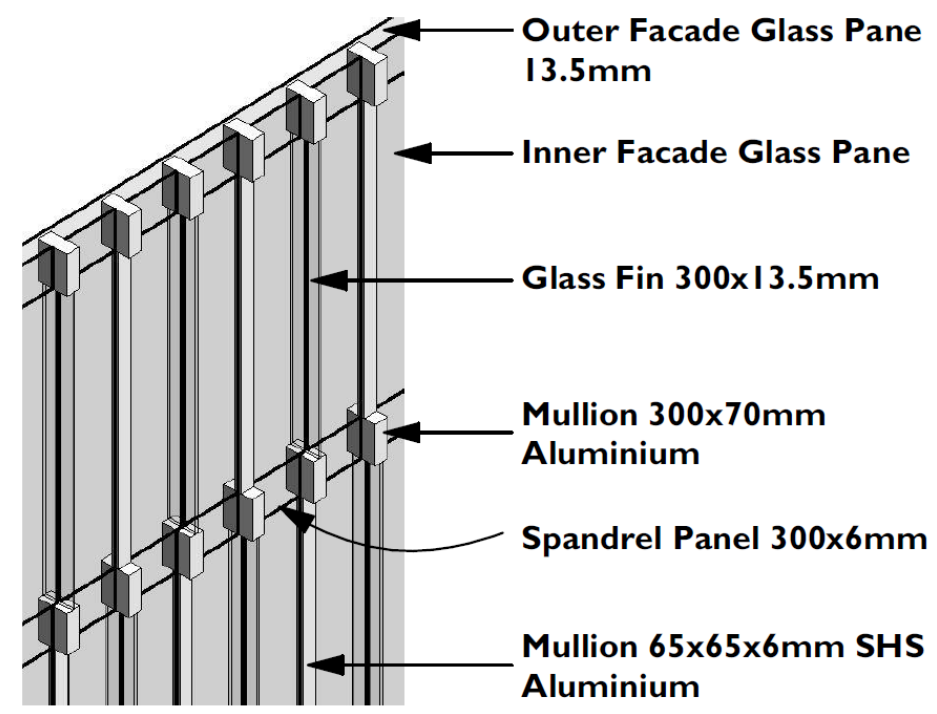

The double skin façade BIM object is modelled to a LOD 350. This is because it requires modelling a specific glazing thickness, the structural support systems, and the mullion profile shape. By comparison, a LOD 200 would be a generic system with an overall wall thickness represented by a single assembly. The modelled object is more detailed than a LOD 300 because the mullion shapes, and geometry are defined, but not to an extrusion profile level of detail as required by LOD 400 . In addition, LOD 400 requires modelling the support systems such as, sealants, and flashings.

The Revit mullion schedule tool only measures the length of the mullion accurately. To accurately calculate the volume of the mullions, the mullion cross sectional area of $0.0072 \mathrm{~m} 2$ was entered as metadata embedded information and multiplied by the measured length. This removed the need for the excessive modelling time, and complexity required to construct an accurate million profile extrusion. 
Chapter Seven:

\section{THESIS CONCLUSIONS}

\section{I Conclusions Surrounding The Failings Of BIM LCA Tools}

This thesis research aimed to improve the integration of LCA into the early phases of the design process (sketch design) by developing a methodology for using BIM LCA tools quickly, easily, and accurately. The intent is to increase building designers using them as a sketch design phase design tool for lowering the environmental impact of building's design. This thesis explored a fundamental issue causing excessive complexities when conducting a building material LCA assessments, the calculation of accurate building material quantities. Within the context of BIM LCA tools, this posed the research question of:

"How detailed does a BIM model need to be to calculate accurate LCA (LCA) results?"

BIM (BIM) LCA tools were developed to solve the problems associated with the LCA calculation complexities, specifically those involved in calculating building material quantities. Research has proven that BIM LCA tools do reduce calculation complexity, and that they do have the request technical capabilities to produce LCA results. However, this thesis found no research that has investigated if BIM LCA tools can do this, while fulfilling requirements that ensure its integration into sketch design is effective. Such requirements are well documented, and stipulate that design tools must be:

- Developed to fit within the day-to-day realities of work practices, processes, and into building design tools building designers actually use.

- Capable of rapidly testing a multitude of different design iterations, whilst ensuring the simulation results are accurate, and trusted enough to enable the design team to make informed design decisions to achieve their project's performance goals.

Using BIM To Calculate Accurate Building Material Quantities For Early Design Phase LCA 
A critique of the existing BIM LCA tools, IMPACT, and Tally, concluded that the current methodology focusing them, the BIM concept's single integrated BIM model, did not satisfy the requirements of effective integration. The specific cause is that it takes too long to construct a single integrated BIM model. As a result, by the time the model is completed, the building design process has progressed beyond the sketch design phase, and therefore, the time in the building design process when design changes for lowering environmental impact can most effectively be tested, and implemented. The primary cause of this excessive BIM modelling time is that there is no defined best practice method for how to conducting an accurate sketch design phase LCA assessment. Absent, are definitions for:

- What building material information e.g. individual materials, and their quantities, must be modelled?

- How detailed the BIM model must be to represent, and calculate the required building material information?

Lacking these definitions, the BIM concept advocates modelling every aspect of the building's design in the highest level of detail possible, during each phase of the design process. As a result, instead of resolving the problem that LCA remains unused by building designers, this thesis research concluded that the current BIM concept methodology contributes to it.

In respect to meeting the requirements of effective integration, the BIM concept is fundamentally is flawed. Therefore, to realise this thesis' aim, an alternative methodology concept had to be applied to BIM LCA tools. The BPS concept (BPS) developed by Donn et al., $(2012)$ is the most appropriate. Being derived from the requirements of effective integration, developing a BIM LCA BPS would achieve effective integration of LCA into sketch design. However, a critique of the BPS framework concluded that, like the BIM concept, it also lacked the same specific details and definitions of a best practice method dictating how to conducting an accurate sketch design phase LCA assessment. Translated, this informed the thesis results hypothesis, whereby, defining the accuracy required for $E E(E E)$ simulations, a BIM model of sketch design detail will calculate building material quantities accurately enough for a building material LCA assessment. 


\subsection{Proving The Thesis Hypothesis}

Testing the thesis hypothesis involved using the BIM tool Revit, to calculate building material quantities, and normalise them to an iEE result so they are comparable to a truth model SOQ (SOQ). This enabled the accuracy of the simulation to be tested, to determine if the BIM model is sufficiently detailed to calculate these results accurately enough.

Testing this hypothesis, three methodology research objectives had to be fulfilled, and then tested. This are discussed below in Chapter Sections 7.2.I and 7.2.2. The outcome of this process, concluded that the BIM LCA BPS methodology does fulfil the thesis aim of enabling the effective integration of LCA into sketch design. Evidence of this comes from the three hypothesis tests conducted in Chapter 6.0, and discussed below.

\subsection{Conclusions: Is A Sketch Design iEE BPS Assessment Complete Enough?}

The first hypothesis test was of the completeness of a sketch design iEE LCA BPS. This tested determined that the sketch design iEE LCA BPS assesses enough of a building's total iEE to be useful for sustainable building design, and that it is detailed enough to produce accurate results.

The iEE LCA BPS is made up of the roof, substructure, wall and barrier, upper floor, and substructure building elements. These are the elements that influence, or are influenced, by the most important design decisions that must be considered if the building is to be designed to have the lowest environmental impact possible. Traditionally, these changes have been passive design solutions for reducing Operative Energy (OE) consumption, not iEE. Such changes can severely alter the building's form, and function. Therefore, to be effective, they must be designed, iteratively tested, and resolved during sketch design. The case study building iEE results showed that an iEE LCA BPS of detailed design information represents 3.6 $\mathrm{GJ} / \mathrm{m} 2 \mathrm{GFA}$, or $59.6 \%$ of the fully detailed as-built SOQ (SOQ) iEE assessment. This means that the design decisions made for OE during sketch design, also impact on the majority of a building's total iEE. 
The importance of iEE is also greatly underestimated in building design. Typically reported as accounting for 7.8 years of total annual OE, approximately $81.7 \mathrm{kWh} / \mathrm{m} 2 \mathrm{GFA}$ (Yung et al., 2013 , p. 49). The initial iEE of this case study showed that the $3.6 \mathrm{GJ} / \mathrm{m} 2 \mathrm{GFA}$ equates to between $4 \mathrm{I} .4$ years, for an EUI of $33.1 \mathrm{kWh} / \mathrm{m} 2 \mathrm{NLA}$, and 72.3 years, for an EUI of 57.9 $\mathrm{kWh} / \mathrm{m} 2 \mathrm{NLA}$, of annual OE. This is between 5.3 and 9.3 times greater than what is commonly accepted as typical for existing office buildings. This reinforces the obvious relationship that as a building's OE consumption is reduced, the importance of iEE increases. The conclusion reached from this research, is that building designers must consider iEE as part of the design decision-making process, as it is far more important than commonly believed. Even if the OE of this thesis' case study building's EUI were to be to the New Zealand average EUI of $150 \mathrm{kWh} / \mathrm{m} 2$ GFA for commercial buildings, the iEE would equate to I6.0 years' of annual OE consumption. This is still a significant proportion of a building's 50 year design life.

The level of influence iEE design changes have on a building is also under appreciated. Changing structural systems from concrete to timber is one common iEE design solution. Typically, this reduces iEE by 13\%. Applied to this thesis case study building's OE worst case payback scenario of $57.9 \mathrm{kWh} / \mathrm{m} 2 \mathrm{NLA}$, this equates to between 5.4 years of $\mathrm{OE}$, or 2.1 years for New Zealand average commercial building EUI. Compared to an OE design solution, a $60 \%$ U-Value improvement (reducing the U-vale) in window façade design, is reported as achieving an $8 \%$ annual OE saving. This would take 25.9 years to equal the iEE structural design change, even if the OE was equal to the New Zealand average commercial building EUI. For the case study building's actual OE, this is 67.2 years. The conclusion reached from this, is that while the total scope of OE design solutions will have the greater influence on reducing environmental impact, iEE needs to be jointly considered. Even in buildings designed to existing building stock EUI levels, iEE is important. When the average commercial building design's OE EUl's decreases towards levels common of Net Zero Energy Buildings (NZEB), $47.2 \mathrm{kWh} / \mathrm{m} 2 \mathrm{GFA}$, like this thesis case study building, iEE is going to become even more significant.

Having redefined the importance of iEE in sustainable building design, making it easier, by making it faster for building designers to accurately calculate it becomes even more important. The iEE BPS of detailed design information was proven to represents enough iEE 
to be useful for building design decision-making. However, this is based on information not available until after these decisions must be made. This thesis research, examined if sketch design information could also be complete enough. The iEE LCA BPS of sketch design information represented $3.0 \mathrm{GJ} / \mathrm{m} 2 \mathrm{GFA}$, or $57.7 \%$ of the fully detailed as-built SOQ (SOQ) iEE assessment. This was only a $1.9 \%$ reduction compared to the iEE LCA BPS of detailed design information. The significance being that only $1.9 \%$ less, is that only $1.9 \%$ of the required $\mathrm{iEE}$ information is lost if conducting this this assessment during sketch design, when the results can be most effectively implemented. For building designers, this proves they can conduct detailed enough iEE assessments of the most influential design decisions during sketch design, using the design processes and practices they already use do, and use. This is possible because their current design process produces the requisite building information when required, and to the level of detail required. Therefore, all they require is the BIM LCA tool, complete with a BPS methodology defining how detailed the BIM model must be to calculate these results, while making the assessment easier, and faster.

\subsubsection{Conclusions: Does A BIM Model Calculate Accurate iEE BIM LCA BPS Results?}

The second hypothesis test was of the methodology for using the BIM tool Revit, and if it could calculate the iEE LCA BPS sketch design results accurately. The critical component in this test was how detailed did the Revit BIM model need to be?

This was tested by using the iEE simulation calibration accuracy assessment framework. The iEE BIM LCA BPS was considered accurate if the material and elemental analysis results for MBE and $\mathrm{Cv}(\mathrm{RSME})$ were below the range of $\pm 10-20 \%$, and $15-30 \%$ respectfully.

The pre-calibration BIM model passed the decision-making simulation accuracy requirements with an MBE accuracy of $12.5 \%$, but it failed the $\mathrm{Cv}(\mathrm{RSME})$ precision requirements. Failure was due to human error, and differences in the formatting between the Revit calculated results and the truth model. These were errors easily corrected, and unlikely to impact on a building designer using this method. The post calibration BIM model with these corrections passed both maximum acceptable calibration metrics with an MBE of $+1.1 \%$, and Cv(RSME) of $3.7 \%$ and $3.1 \%$ for material and elemental analysis. This proves the thesis hypothesis true, whereby defining the EE simulation accuracy requirements as MBE $\pm 10-20 \%$, and $\mathrm{Cv}$ (RSME)

Using BIM To Calculate Accurate Building Material Quantities For Early Design Phase LCA 
I5-30\%, a BIM model of sketch design detail is sufficiently detailed to calculate the building material quantities accurately enough to satisfy them, and be used for building material LCA assessments.

The pre-calibration iEE BIM model was constructed by tracing over the project documentation. Care was taken to ensure the truth model 3 results did not influence this modelling process, to recreate the fact that building designers will not have access to a truth model when designing a new building. As per standard sketch design modelling practices, the BIM model was constructed ignoring overlapping geometry, such as beam and column joins, and the BIM geometry roughly constructed to an approximate $\pm 50 \mathrm{~mm}$ to $\pm 100 \mathrm{~mm}$ in rounding of member lengths, and spacing. This is much less precise than typical BIM or CAD drawing conventions during detailed design, which did cause a combined cancellation error in the building material analysis of $4.3 \%$ of the total $3.0 \mathrm{GJ} / \mathrm{m} 2 \mathrm{GFA}$ in the post calibration model. However, no individual material had an error greater than $1.0 \%$, and the robustness tests proved that the imprecise modelling of BIM geometry that caused cancellation errors were not an influence on simulation accuracy that detracted from the building designer's ability to make design decisions.

To produce accurate iEE results from an iEE BIM LCA BPS model requires no more additional information, or modelling effort than building designers already have and do during sketch design. The conclusion reached, is that building designers can easily use their existing sketch design modelling processes, and practices for creating BIM models, to produced accurate iEE results during sketch design.

\subsection{Answering The Thesis Research Question:}

\subsection{How Detailed Is An Accurate iEE BIM LCA BPS Model?}

Having proved that a BIM model, and the Revit BIM tool can calculate accurate building material quantities that can be used for a building material LCA assessment, answering the research question is the description of how detailed the pre and post calibration iEE BIM LCA BPS model were. Due to data confidentiality reasons, the identity of the case study building must remain anonymous. This meant that specific images cannot be used to answer this question. Therefore, using the BIMFORUM'S 2013 Level Of Development (LOD) 
specification, the BIM objects constituting the iEE BIM LCA BPS model are mix of predominantly LOD 200 and 300 . The double skin façade is the exception, requiring a LOD of 350 .

Overall the BIM model had 73 unique BIM objects, constituting a BIM geometry of 1730 total BIM object instances. Compared to research conducted Leite et al., (20I I), the iEE BIM LCA BPS model is a detail equivalent to the middle of their definitions, precise, and fabrication detail levels. This is significantly less detailed than the LOD 400 BIM object shown in the tutorial for the BIM LCA tool Tally. The conclusion reached is that building designers do not have to construct a BIM model as detailed as the Tally tutorial indicates for calculating iEE or other LCA-based indicators. This has the effect of reducing modelling time, and effort, and makes the LCA calculation process easier.

\section{4 iEE And LCA Conclusions Beyond This Research}

Having no definitive definition for the level of detail a SOQ must be for EE or LCA assessment, there is a risk that significant variation exits between building projects. This may have an influence on the completeness testing, and suitability of the IEE BIM LCA BPS to represent enough of a building's total iEE to be useful. As a quality assurance check, the $\mathrm{EEE}$ BIM LCA BPS simplification framework was applied to case study results published by Y. L. Langston \& Langston (20I2). The iEE BIM LCA BPS represented $40.1 \%$ of the total iEE. This was a reduction of $17.6 \%$ compared to the thesis case study building. This $40.1 \%$ is still a significant proportion, proving outside this thesis research case study that conducting an $\mathrm{IEE}$ assessment during sketch design is worth doing.

This conclusion highlighted the need for building researchers to define based on LCA-based indicators, the detail a SOQ must be to produce accurate results. This thesis research has adhered to existing best practices, and defined them as the truth models. This means the methodology for using BIM tools to calculate accurate iEE results is limited to calculating results that are accurate to current best practices that are based on cost planning, not iEE or LCA.

Lacking a defined assessment criteria for iEE or LCA simulation accuracy, one had to be developed to test this thesis' hypothesis. The critical component of the iEE calibration 
accuracy assessment framework is the definition of how close is close enough? This is expressed by the maximum acceptable calibration tolerances, MBE for accuracy, and Cv(RSME) for precision. The values for these two metrics were derived from cost planning, and OE respectfully. They are only a working definition used to conduct this research. Their values were selected based on the calibration accuracy assessment guidelines set by the United States Department Of Energy (US DOE) M\&V Guidelines (2008, pp. 4-20) that suggests that whenever project specific calibration tolerances are required, that "specific calibration goals should be set for each project based on the appropriate level of effort [...]". Based on the results of this research, the conclusion can be made that both the MBE, and Cv(RSME) values selected, $\pm 10-20 \%$, and $15-30 \%$, are too lenient. The iEE BIM LCA BPS by its very definition equals an appropriate level of modelling effort, and it calculated both the MBE and $\mathrm{Cv}$ (RSME) metrics below $5 \%$. This suggests that $5 \%$ may be a more appropriate value for both MBE and $\mathrm{Cv}$ (RSME) for EE or LCA accuracy assessment. However, further research is required to substantiate this conclusion.

\subsection{Key Outputs Of Thesis Research}

The following items are a list of the tools, and the definitions that were developed as part of this research to assist building designers in conducting an $\mathrm{iEE}$ assessment.

- The EE Data Quality Indicator Pedigree Matrix for assisting building designers in the selection of the most appropriate iEE databases.

- A methodology for using the BIM Too Revit for calculating LCA-based indicators without the need for specialist software, such as the BIM LCA tools IMPACT, and Tally. This removes the need for building designers to purchase this additional software.

- The LCA results analysis spreadsheet. This is a Microsoft Excel document that automate the multiplication of building material coefficients by building material quantities, and organises the results for analysis.

- The iEE benchmark database for commercial office buildings classified by building structural system. This assists in both the quality assurance of iEE simulation results, and the setting of iEE performance goals. 
- The definition of iEE maximum acceptable calibration tolerances defining iEE simulation accuracy, where MBE $< \pm 10-20 \%$, and $\mathrm{Cv}(\mathrm{RMSE})<15-20 \%$.

- The definition of iEE best practice modelling practices. For EE material coefficients, best practice is defined as either of the two EE hybrid coefficient calculation methods. For estimating building material quantities, best practice is defined as a SOQ based on cost planning.

\subsection{BIM Conclusions Beyond This Research}

The use of BIM was a critical component to this thesis research. The results proved that a BIM model can be used for LCA assessments of building materials. However, it highlighted a number of gaps in current BIM practices within the New Zealand construction industry. Compared to the United Kingdom, and the United States of America, the New Zealand construction industry is far behind in the research, development, implementation, and use of BIM. However, the 2013 National BIM Survey identified that the construction industry's use of BIM is forecasted to increase significantly in I-5 years' time. The following four conclusions are recommendations for the development of BIM support systems that the New Zealand construction industry must developed for BIM to be used successful in New Zealand.

Firstly, the New Zealand construction industry lacks the support tools necessary for using a BIM model effectively. The most time consuming component of the iEE BIM LCA BPS modelling process was constructing the 73 unique BIM objects. Not limited to their 3D form, this included finding, and embedding the necessary metadata, e.g. the material and element building classification codes and descriptions. The New Zealand construction industry needs a free national BIM library of BIM objects, which have the necessary metadata embedded from manufacturers for building products, and materials. The UK's NBS National BIM Library is one precedent to consider.

Secondly, underpinning all BIM modelling is a building classification system. This is used in BIM objects, BIM geometry, the analysis of results such as cost, and LCA indicators, and the organisation of building specifications and BIM object libraries. The New Zealand construction industry currently uses the Co-ordinated Building Information (CBI) system. This is based on the now superseded European CAWS (Common Arrangement of Work 
Sections) building classification system, which has been replaced by the redeveloped UniClass (UniClass 2.0). UniClass 2.0 is compliant with ISO I2006. The ISO I 2006 standard was developed to standardise international building classification systems, to improve the sharing of building information between countries. This is particularly important for New Zealand, with its high volume of building related imports, and exports. The New Zealand construction industry needs to develop an ISO I 2006 compliant building classification system for this, and to use BIM effectively. Internationally, the UK and USA are already doing this, developing their respective UniClass 2.0, and OmniClass building classification systems.

Thirdly, the current methods of describing BIM modelled detail need to be improved. The BIMFORUMS LOD specification is an adequate starting point. However, to be truly useful for building designers, LOD requirements for BIM objects must be aligned to the requirements of the design process, and the specific requirements for building performance simulation. For example, the iEE LCA BPS method has defined that to produce an accurate iEE result, a BIM model of sketch design information must consist of BIM objects with a LOD of 200-300, that constitute the BIM geometry for the roof, substructure, wall and barrier, upper floor, and substructure building elements. Developing an equivalent set of BIM best practice modelling guidelines for other areas of building performance is needed.

The final issue of BIM interoperability. BIM interoperability encompasses both cultural, and technology concepts. The cultural concepts defines how the design team works, communicates, and shares building information, e.g. how to use the BIM tool and model. In contrast, the technology concept is simply the means for making cultural BIM interoperability possible. A conclusion from this research, is that this definition is misunderstood within the New Zealand construction industry. Commonly interoperability is just thought of as file sharing, and IFC models. Those that do use BIM models, and tools do not embrace the full cultural concept of BIM which is where the true potential of BIM lies. The main problem, is that to be truly effective, the information required of a BIM model needs to be better defined. The current standard practice of constructing a fully detailed iBIMis not used by the New Zealand construction industry, and is likely to never be standard practice. This is because constructing these models is too time consuming for them to be effective. Instead, by defining what information must be in a BIM model, for a specific purpose, as the iEE BIM LCA BPS methodology did, BIM will be far more useful for the construction industry. 


\section{WORKS CITED}

Alcorn, A. (2010). Global Sustainability and the New Zealand House (PhD Thesis). Victoria University of Wellington, Wellington New Zealand.

American Institute of Architects (AIA). (2007). Integrated Project Delivery: A Guide.

American Institute of Architects (AIA). Retrieved from

http://www.aia.org/about/initiatives/AIAS07698I

American Institute of Architects (AIA). (2008). The Architect's Handbook of Professional Practice (14th Edition). New Jersey U.S.A: John Wiley \& Sons Inc.

Annex 57: "Evaluation of Embodied energy and Carbon Dioxide Emissions for Building Construction.” (n.d.). Retrieved January 22, 20I4, from http://www.annex57.org/ ASHRAE. (2002). ASHRAE Guideline 14-2002: Measurement of Energy and Demand Savings. ASHRAE Standards Committee. Retrieved from https://gaia.lbl.gov/people/ryin/public/Ashrae_guideline I42002_Measurement\%20of\%20Energy\%20and\%20Demand\%20Saving\%20.pdf

Ashworth, A., Hogg, K., \& Higgs, C. (2007). Willis' Practice and procedure for the Quantity Surveyor (12th Edition). Oxford England: Blackwell Publishing Ltd.

Attia, S. (2012). A Tool for Design Decision Making: Zero Energy Residential Buildings in Hot Humid Climates (PhD Thesis). Louvain School of Engineering, Louvain-La-Neuve, Belgium. Retrieved from http://www.google.co.nz/url?sa=t\&rct=j\&q=\&esrc=s\&source=web\&cd=5\&cad=rja\&ve $\mathrm{d}=0 \mathrm{CD} 8 \mathrm{QFjAE \& url=http} \% 3 \mathrm{~A} \% 2 \mathrm{~F} \% 2 \mathrm{Fwww}$.bwk.tue.nl\%2Fbps\%2Fhensen\%2Fteam\%2

Using BIM To Calculate Accurate Building Material Quantities For Early Design Phase LCA 
Fpast\%2FAttia.pdf\&ei=GkwBU63HDOWUiAeq94DoAw\&usg=AFQjCNG6dBahNNI 4CDbHL8ppFcK4Nh35Gg\&sig2=G72mwGBrx0SOltV0fyJjqw\&bvm=bv.6 I 535280,d.a Gc

Augenbroe, G. (1992). Integrated building performance evaluation in the early design stages.

Building and Environment, 27(2), I49 - I6I. http://doi.org/10.1016/03601323(92)90019-L

Augenbroe, G. (2002). Trends in building simulation. Building and Environment, 37(8-9), 89I902. http://doi.org//0.1016/S0360-1323(02)0004I-0

Baird, G., \& Chan, S. A. ( 1983). Energy Cost of Houses and Light Construction (No. 76). Wellington New Zealand: School of Architecture, Victoria University of Wellington. Bensouda, N. (2004). Extending and formalizing the energy signature method for calibrating simulations and illustrating with application for three California climates (Master's Thesis). Texas A\&M University, Texas USA. Retrieved from http://repository.tamu.edu/bitstream/handle// 969.I// 080/etd-tamu-2004B-MEENBensouda-2.pdf?sequence $=1$

Berggren, B., Hall, M., \& Wall, M. (20I3). LCE analysis of buildings - Taking the step towards Net Zero Energy Buildings. Energy and Buildings, 62(0), 38I-39I. http://doi.org//0.1016/j.enbuild.2013.02.063

Bishop, R., \& Isaacs, N. (20I2). Building Energy End-use Study (BEES) Year 5: Energy use outliers (No. SR277/3). Wellington New Zealand: BRANZ. Retrieved from http://www.branz.co.nz/cms_show_download.php?id=| 8e079430fb79| 7f536ee7488b 865d7ababceab4

Björklund, A. E. (2002). Survey of approaches to improve reliability in LCA. The International Journal of Life Cycle Assessment, 7(2), 64-72.

Using BIM To Calculate Accurate Building Material Quantities For Early Design Phase LCA 
Bownass, D. (200I). Building Services Design Methodology: A Practical Guide. London: Spon Press.

Brand, S. (1994). How buildings learn: What happens after they're built. London: Phoenix Illustrated.

Bribián, I. Z., Usón, A. A., \& Scarpellini, S. (2009). Life cycle assessment in buildings: State-ofthe-art and simplified $\{\mathrm{LCA}\}$ methodology as a complement for building certification. Building and Environment, 44(12), 2510 - 2520.

http://doi.org/10.1016/j.buildenv.2009.05.00I

Brook, M. (2004). Estimating and Tendering for Construction Work (Third Edition). England: Elsevier Ltd.

Brownass, D. (200I). Building Services Design Methodology: A Practical Guide. New York U.S.A: Spon Press.

BuildingSMART UK. (n.d.). buildingSMART United Kingdom \& Ireland: Products. Retrieved January 28, 20I4, from http://www.buildingsmart.org.uk/about

CIBSE. (1998). CIBSE AM I I Building Energy and Environmental Modelling (CIBSE Applications Manual I I). England: Chartered Institution of Building Services Engineers (CIBSE).

CIBSE. (2006). CIBSE Guide A: Environmental Design (7th Edition). England: Chartered Institution of Building Services Engineers (CIBSE).

Ciroth, A. (2009). Cost data quality considerations for eco-efficiency measures. Ecological Economics, 68(6), 1583-1590. http://doi.org//0.1016/j.ecolecon.2008.08.005

Cole, R. J., \& Kernan, P. C. (1996). Life-cycle energy use in office buildings. Building and Environment, 3 I (4), 307 - 317. http://doi.org/I0.1016/0360-1323(96)000I7-0 Construction Information Ltd. (20I3). New Zealand National BIM Survey Report 2013. Retrieved from http://www.masterspec.co.nz/news/reports-1243.htm 
Crawford, R. (2004). Using input-output data in life cycle inventory analysis (DPhil Thesis). Deakin University, Geelong Australia.

Crawford, R. (2008). Validation of a hybrid life-cycle inventory analysis method. Journal of Environmental Management, 88(3), 496-506. http://doi.org//0.1016/j.jenvman.2007.03.024

Crawford, R. (20I I). Life cycle assessment in the built environment. Abingdon Oxon, England: Spoon Press.

Creswell, J. W. (2009). Research Design Qualitative, Quantitative, and Mixed Methods Approaches (Third Edition). New Delhi, India: Sage Publications Inc.

Dixit, M. K., Culp, C. H., \& Fernández-Solís, J. L. (20I3). System boundary for embodied energy in buildings: A conceptual model for definition. Renewable and Sustainable Energy Reviews, 21, I53-164. http://doi.org/10.1016/j.rser.2012.12.037

Dixit, M. K., Fernández-Solís, J. L., Lavy, S., \& Culp, C. H. (20I0). Identification of parameters for embodied energy measurement: A literature review. Energy and Buildings, 42(8), I238-1247. http://doi.org/10.1016/j.enbuild.2010.02.016

Dixit, M. K., Fernández-Solís, J. L., Lavy, S., \& Culp, C. H. (20I2). Need for an embodied energy measurement protocol for buildings: A review paper. Renewable and Sustainable Energy Reviews, I6(6), 3730-3743.

http://doi.org/10.1016/j.rser.2012.03.021

Donn, M. (1999). Quality assurance simulation and the real world. In Conf. Proc. IBPSA'99 Buildings Simulation (pp. II39-|46). Citeseer. Retrieved from http://citeseerx.ist.psu.edu/viewdoc/download?doi= $\mid 0.1 .1 .121 .2017 \&$ rep=rep $\mid$ \&type= pdf 
Donn, M., Selkowitz, S., \& Bordass, B. (20I2). The Building Performance Sketch. Building Research \& Information, 40(2), 186-208.

http://doi.org//0.1080/096/3218.2012.655070

Dowdell, D. (2013). Application of Environmental Profiling to Whole Building Whole of Life Assessment - A Plan for New Zealand. Wellington New Zealand: BRANZ.

Dowdell, D. (20I4). Study Report (Draft): New Zealand Whole Building Whole of Life Framework: Life Cycle Assessment-based Indicators: For Consultation (Draft No. SR 293 (2014)). Wellington New Zealand: BRANZ. Retrieved from http://www.branz.co.nz/cms_show_download.php?id= I I af33c627ad42a02e5c6e62b5 d4a9cfb280efca

Emmitt, S. (2007). Design Management for Architects. Oxford England: Blackwell Publishing Ltd. Emmitt, S. (2010). Managing Interdisciplinary Projects: A Primer for Architecture, Engineering and Construction. Oxon, Canada: Spon Press.

EPLCA. (2014). The European Platform On Life Cycle Assessment. Retrieved August 20, 20 I4, from http://eplca.jrc.ec.europa.eu/

Feagin, J. R., \& Orum, A. M. (I99I). A Case for the Case Study. (G. Sjoberg, Ed.). Chapel Hill, North Carolina: University of North Carolina Press.

Fernandez, N. P. (2008). The influence of construction materials on life-cycle energy use and carbon dioxide emissions of medium size commercial buildings (Master's Thesis). Victoria Univeristy of Wellington, Wellington New Zealand.

Ferry, D. J., Brandon, P. S., Ferry, J. D., \& Kirkham, R. J. (2007). Ferr and Brandon's Cost Planning of Buildings (8th Edition). Oxford England: Blackwell Publishing Ltd.

Flyvbjerg, B. (2006). Five Misunderstandings About Case-Study Research. Qualitative Inquiry, I2(2), 2 |9-245. http://doi.org//0.I I77//077800405284363

Using BIM To Calculate Accurate Building Material Quantities For Early Design Phase LCA 
Golafshani, N. (2003). Understanding Reliability and Validity in Qualitative Research. The Qualitative Report, 8(4), 597-607.

Grilo, A., \& Jardim-Goncalves, R. (2010). Value proposition on interoperability of BIM and collaborative working environments. Building Information Modeling and Collaborative Working Environments, 19(5), 522-530. http://doi.org/10.1016/j.autcon.2009.1 I.003

Hammond, G., \& Jones, C. (20II). Inventory of Carbon \& Energy (ICE) Version 2.0.

University of Bath. Retrieved from https://www.circularecology.com/icedatabase.html\#.UxUo8IUZGQw

Hand, J. W., Crawley, D. B., Donn, M., \& Lawrie, L. K. (2008). Improving non-geometric data available to simulation programs. Part Special: Building Performance Simulation, 43(4), 674-685. http://doi.org/10.1016/j.buildenv.2006.06.022

Haponava, T., \& Al-jibouri, S. (2010). Establishing influence of design process performance on end-project goals in construction using process-based model. Benchmarking: An International Journal, I 7(5), 657-676. http://doi.org/I0.। I08/|463577/0I I076425

Heijungs, R., \& Huijbregts, M. A. (2004). A review of approaches to treat uncertainty in LCA. In iEMSs 2004 International Congress:“ Complexity and Integrated Resources Management.” Osnabrueck, Germany. Retrieved from http://www.iemss.org/iemss2004/pdf/lca/heijarev.pdf

Hjelseth, E. (2010). Exchange of relevant information in BIM-objects defined by the Life cycle Information Model (LIM). Architectural Engineering and Design Management, 6, 279_ 287.

Holm, L., Schaufelberger, J. E., Griffin, D., \& Cole, T. (2005). Construction Cost Estimating: Process and Practices (First). Pearson Education. 
Hopfe, C. J., \& Hensen, J. L. M. (20I I). Uncertainty analysis in building performance simulation for design support. Energy and Buildings, 43(10), 2798-2805. http://doi.org/I0.1016/j.enbuild.201 I.06.034

Huijbregts, M. A. (1998). Application of uncertainty and variability in LCA. The International Journal of Life Cycle Assessment, 3(5), 273-280.

Ibn-Mohammed, T., Greenough, R., Taylor, S., Ozawa-Meida, L., \& Acquaye, A. (2013).

Operational vs. embodied emissions in buildings-A review of current trends. Energy and Buildings, 66, 232-245. http://doi.org/10.1016/j.enbuild.2013.07.026

IMPACT. (n.d.). IMPACT: Integrated Material Profile And Costing Tool. Retrieved January 29, 20I4, from http://www.impactwba.com/index.jsp International Energy Agency. (2002). International Energy Agency: Solar Heating and Cooling Programme Task 23 Optimization of Solar Energy Use in Large Buildings: Subtask C Tools for Trade-Off Analysis: Multi-Criteria Decision-Making MCDM-23: A Method for Specifying and Prioritising Criteria and Goals in Design. (D. Balcomb, I. Andresen, \& A. G. Hestnes, Eds.). Retrieved from http://archive.ieashc.org/publications/downloads/MCDM_booklet.pdf International Energy Agency. (2004a). International Energy Agency: Annex 3 I Energy-Related Environmental Impact of Buildings: Decision-Making Framework (International Energy Agency Annex 31: Energy-Related Environmental Impact of Buildings). Canada: Canada Mortgage and Housing Corporation.

International Energy Agency. (2004b). International Energy Agency: Annex 3 I Energy-Related Environmental Impact of Buildings: Environmental Framework (International Energy Agency Annex 31: Energy-Related Environmental Impact of Buildings). Canada: Canada Mortgage and Housing Corporation.

Using BIM To Calculate Accurate Building Material Quantities For Early Design Phase LCA 
International Standards Organisation. (200I). ISO 12006-2: Building Construction -

Organisation of Information About Construction Work - Part 2: Framework for

Classification of Information. International Standards Organisation.

Isaacs, N., \& Hills, A. (2013). Understanding the New Zealand non-domestic building stock.

Building Research \& Information, 42(1), 95-108.

http://doi.org/10.1080/096/3218.2013.831274

Jiao, Y., Lloyd, C. R., \& Wakes, S. J. (20I2). The relationship between total embodied energy and cost of commercial buildings. Energy and Buildings, 52(0), 20-27.

http://doi.org/I0.10I6/j.enbuild.2012.05.028

Jones, S. A. (2007). Interoperability SmartMarket Report. (J. E. Gudgel, Ed.). McGraw-Hill

Construction. Retrieved from

http://www.aia.org/aiaucmp/groups/aia/documents/pdf/aias077485.pdf

Kim, D. (2010). Optimizing Cost Effective Energy Conservation Measures For Building

Envelope. Energy Engineering, 107(3), 70-80.

http://doi.org//0.1080/01998591009709877

Kofoworola, O. F., \& Gheewala, S. H. (2009). Life cycle energy assessment of a typical office building in Thailand. Energy and Buildings, 4I(10), 1076 - 1083

http://doi.org//0.1016/j.enbuild.2009.06.002

KT Innovations, PE International, \& AutoDesk. (20I4). Tally Environmental Impact Tool.

Retrieved April 3, 2014, from http://choosetally.com/

Kurnitski, J., Allard, F., Braham, D., Goeders, G., Heiselberg, P., Jagemar, L., ... Railio, J.

(20II). How to define nearly net zero energy buildings NZEB. REHVA Journal, 48(3),

$6-12$.

Using BIM To Calculate Accurate Building Material Quantities For Early Design Phase LCA 
Langston, C. (20I2). The role of coordinate-based decision-making in the evaluation of sustainable built environments. Construction Management and Economics, 3I(I), 62-77. http://doi.org//0.1080/01446193.2012.738920

Langston, C. A. (2005). Life-Cost Approach to building Evaluation (First Edition). Australia: University of New South Wales Press Ltd.

Langston, Y. L., \& Langston, C. A. (2008). Reliability of building embodied energy modelling: an analysis of 30 Melbourne case studies. Construction Management and Economics, 26(2), |47-160. http://doi.org/I0.1080/01446/9070I7/6564

Langston, Y. L., \& Langston, C. A. (20I2). Building energy and cost performance: An analysis of thirty Melbourne case studies. Australasian Journal of Construction Economics and Building, 7(I), I-I8.

Lawson, B. (2006). How Designers Think: The Design Process Demystified (Fourth Edition). Oxford England: Architectural Press.

Leite, F., Akcamete, A., Akinci, B., Atasoy, G., \& Kiziltas, S. (20I I). Analysis of modeling effort and impact of different levels of detail in building information models. Automation in Construction, 20(5), 601-609. http://doi.org/10.1016/j.autcon.2010.11.027

Level of Development Specification. (2013, August). Level of Development Specification For Building Information Models. BIMForum.

Levy, S. J. (1988). Information Technologies in Universities: An Institutional Case Study. Northern Arizona University.

Löhnert, G., Dalkowski, A., \& Sutter, W. (2003). Integrated Design Process: A Guideline for Sustainable and Solar-Optimised Building Design (Design Guide) (p. 62). Berlin / Zug: International Energy Agency.

Using BIM To Calculate Accurate Building Material Quantities For Early Design Phase LCA 
Lou, E. C. W., \& Goulding, J. S. (2008). Building and Construction Classification Systems.

Architectural Engineering and Design Management, 4(3), 206-220.

http://doi.org// 0.3763/aedm.2008.0079

Nebel, B. (n.d.). Is It Valid To Use International Data In New Zealand LCA Studies?. Rotorua, New Zealand: Sicon. Retrieved from http://www.google.co.nz/url?sa=t\&rct=j\&q=\&esrc=s\&source=web\&cd= I \&cad=rja\&ua

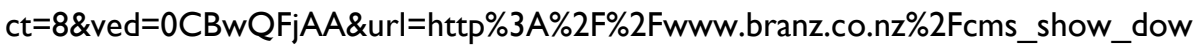
nload.php\%3Fid\%3D0fb692aafd30348c96dbf730a68cac0ccdcfb77e\&ei=kjQaVMDWG Yy8uATg3oHQCw\&usg=AFQjCNE-

ArkRDtLMUB8FTfimpxMi4rTC5A\&sig2=jq5qlyy4W4lchISmzLe IfQ\&bvm=bv.750972 0I,d.c2E

New Zealand Construction Institute Council (NZCIC). (2004). New Zealand Construction Institute Council (NZCIC) Design Documentation Guidelines. New Zealand Construction Institute Council (NZCIC). Retrieved from http://www.nzcic.co.nz/

New Zealand Green Building Council. (2008). Technical Manual: Green Star NZ - Office Design \& Built (Version I). New Zealand: New Zealand Green Building Council.

Optis, M., \& Wild, P. (20I0). Inadequate documentation in published life cycle energy reports on buildings. The International Journal of Life Cycle Assessment, I5(7), 644-65I. http://doi.org// 0.1007/s I | 367-010-0203-4

Ostime, N. (20I3). RIBA Job Book (9th Edition). London: RIBA Publishing.

Pazlar, T., \& Turk, Ž. (2008). Interoperability in practice: geometric data exchance using the IFC standard. ITcon, I3(Case Studies of BIM use), 362-380.

Property Council of New Zealand. (n.d.). Quality Grading Matrix and Retial Classifications. Retrieved from http://www.propertynz.co.nz/index.asp?pagelD=2 | 45860546 
Raftery, P., Keane, M., \& Costa, A. (2009). Calibration of a detailed simulation model to energy monitoring system data: a methodology and case study. In Proceedings of the I Ith IBPSA Conference, Glasgow, UK.

Ross, S., Evans, D., \& Webber, M. (2002). How LCA studies deal with uncertainty. The International Journal of Life Cycle Assessment, 7(I), 47-52.

Samphaongoen, P. (2010). A Visual Approach to Construction Cost Estimating (Master's Thesis). Marquette University, Wisconsin, U.S.A.

Sidoroff, S. (2004a). International Energy Agency: Annex 3 I Energy-Related Environmental Impact of Buildings: Data Needs and Sources (International Energy Agency Annex 3 I: EnergyRelated Environmental Impact of Buildings). Canada: Canada Mortgage and Housing Corporation.

Sidoroff, S. (2004b). International Energy Agency: Annex 3 I Energy-Related Environmental Impact of Buildings: Glossary (International Energy Agency Annex 31: Energy-Related Environmental Impact of Buildings). Canada: Canada Mortgage and Housing Corporation.

Sinclair, D. (Ed.). (20I2). BIM Overlay to the RIBA Outline Plan of Work. RIBA Publishing. Smith, J., \& Jaggar, D. M. (2006). Building Cost Planning for the Design Team (2 Edition). Routledge.

Stake, R. E. (1995). The Art of Case Study Research. Thousand Oaks, California: Sage Publications Ltd.

Tellis, W. (1997). Application of a Case Study Methodology. The Qualitative Report, 3(3).

The Building and, \& Construction Productivity Partnership. (20I4). New Zealand BIM Handbook. BIM Acceleration Committee. Retrieved from www.buildingvalue.co.nz/BIM-in-NZ

Using BIM To Calculate Accurate Building Material Quantities For Early Design Phase LCA 
The National Building Specification (NBS), \& BIM Technologies Alliance. (20I4). NBS National BIM Library. Retrieved March 4, 20I4, from http://www.nationalbimlibrary.com/

Tims, G. (2007). House Insulation Guide. (T. Pringle, Ed.) (Third Edition). Wellington New Zealand: BRANZ.

Treloar, G. J., Fay, R., llozor, B., \& Love, P. E. D. (200I). An analysis of the embodied energy of office buildings by height. Facilities, 19(5/6), 204-214.

Treloar, G. J., Love, P. E., \& Faniran, O. O. (200I). Improving the reliability of embodied energy methods for project life-cycle decision making. Logistics Information Management, I4(5/6), 303-318.

Treloar, G. J., McCoubrie, A., Love, P. E. D., \& lyer-Raniga, U. ( 1999). Embodied energy analysis of fixtures, fittings and furniture in office buildings. Facilities, I ( (I I), 403-4I 0.

Types of Case Studies. (2002). In Embedded Case Study Methods (pp. 9-15). Thousand Oaks, California, USA: Sage Publications Inc.

US DOE. (2008). M\&V Guidelines: Measurement and Verification for Federal Energy Projects Version 3.0. U.S. Department of Energy Federal Energy Management Program. Retrieved from http://wwwl.eere.energy.gov/femp/pdfs/mv_guidelines.pdf

Wang, E., \& Shen, Z. (2013). A hybrid Data Quality Indicator and statistical method for improving uncertainty analysis in LCA of complex system - application to the wholebuilding embodied energy analysis. Journal of Cleaner Production, 43, 166-173. http://doi.org/10.1016/j.jclepro.2012.12.010

Weidema, B. P., \& Wesnæs, M. S. (1996). Data quality management for life cycle inventories - an example of using data quality indicators. Journal of Cleaner Production, 4(3-4), I67-174. http://doi.org/10.1016/S0959-6526(96)00043-I

Using BIM To Calculate Accurate Building Material Quantities For Early Design Phase LCA 
Wu, S., Ginige, K., Wood, G., \& Wee Jong, S. (20I4). How Can Building Information Modelling (BIM) Support The New Rules of Measurement (NRMI). London: Royal Institution of Chartered Surveyors (RICS).

Yin, R. K. (1984). Case Study Research: Design and Methods (Ist ed.). Newbury Park, California: Sage Publications Ltd.

Yohanis, Y. G., \& Norton, B. (2006). Including embodied energy considerations at the conceptual stage of building design. Proceedings of the Institution of Mechanical Engineers, 220(3), 27I-288.

Yung, P., Lam, K. C., \& Yu, C. (20I3). An audit of life cycle energy analyses of buildings. Habitat International, 39(0), 43 - 54. http://doi.org/10.1016/j.habitatint.20I2.10.003 


\title{
APPENDIX FOR CHAPTER 3.0
}

\author{
Definition Of Grade 'A' Office Space
}

(Property Council of New Zealand, n.d.)

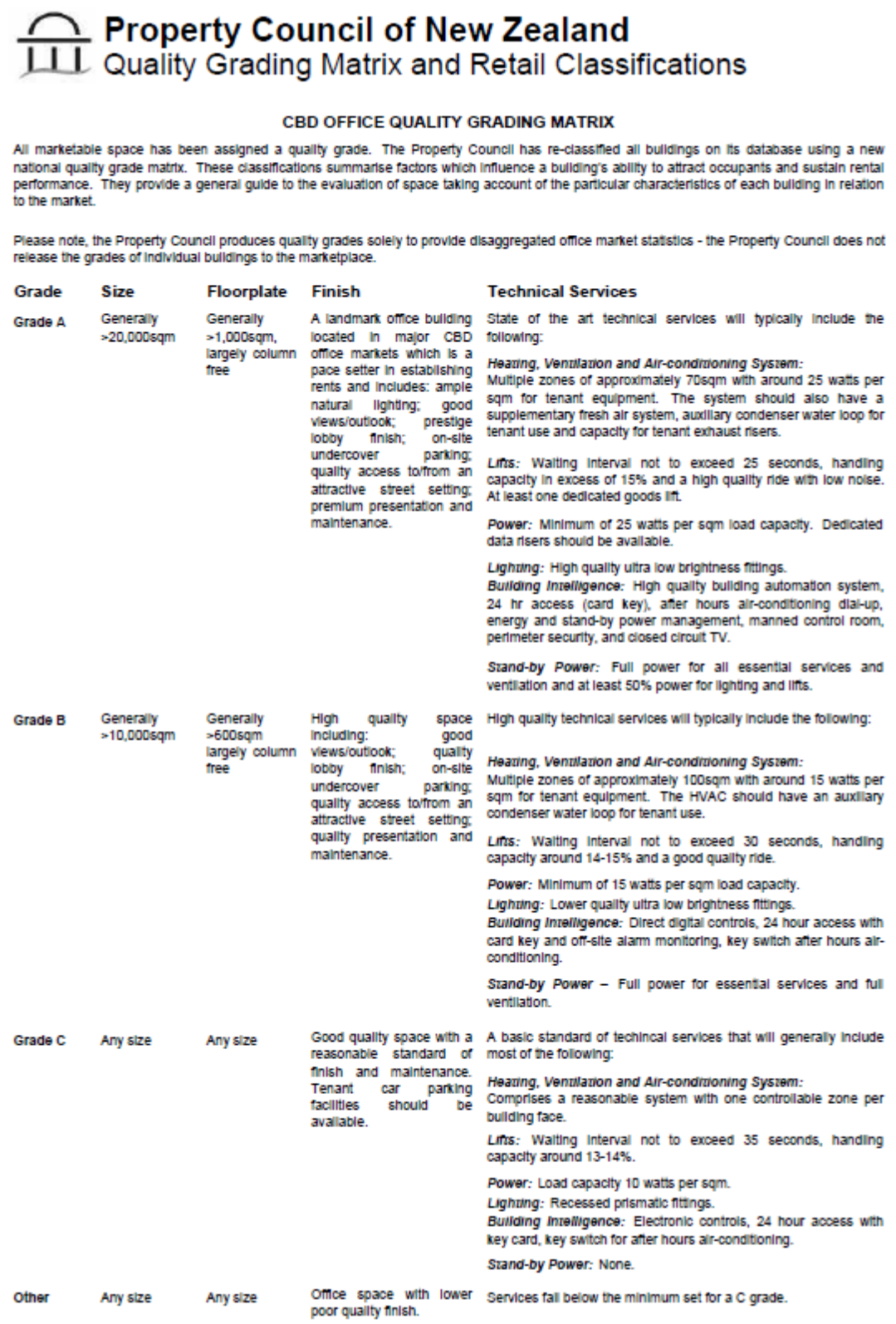

Using BIM To Calculate Accurate Building Material Quantities For Early Design Phase LCA 


\title{
APPENDIX FOR CHAPTER 4.0
}

\author{
The Working Definition Of Sketch Design
}

Appendix 4.0 Table 4.2. Ia: The Working Definition of the Decisions and Building Information Available During Sketch Design

Source: (American Institute of Architects (AIA), 2008; New Zealand Construction Institute Council (NZCIC), 2004; Ostime, 20I3)

\begin{tabular}{|c|c|c|}
\hline & \multicolumn{2}{|c|}{ Design Decisions / Activities / Considerations } \\
\hline & Sketch Design Decisions & Developed Design Decisions \\
\hline \multirow{7}{*}{ ד } & $\begin{array}{l}\text { Selection of key materials and assess the embodied } \\
\text { impacts of building materials over the building's } \\
\text { lifespan. }\end{array}$ & $\begin{array}{l}\text { Specify sustainable materials and products, balancing } \\
\text { life-cycle assessment, maintenance, durability, and cost } \\
\text { - what materials? }\end{array}$ \\
\hline & $\begin{array}{l}\text { Design to minimise the quantity of materials and } \\
\text { construction waste. }\end{array}$ & Determine / select building components and materials \\
\hline & $\begin{array}{l}\text { Determine building plan depths for natural } \\
\text { ventilation, daylight, and views. }\end{array}$ & $\begin{array}{l}\text { Outline specifications that identify major materials and } \\
\text { systems and establish in general their quality levels. }\end{array}$ \\
\hline & $\begin{array}{l}\text { Design solutions to maximise adaptation of building } \\
\text { for use, components, and materials. }\end{array}$ & $\begin{array}{l}\text { Specifications and details of selected materials and } \\
\text { systems }\end{array}$ \\
\hline & $\begin{array}{l}\text { Determine which passive design solutions can be } \\
\text { used to reduce MEP demand. }\end{array}$ & Production of typical construction details \\
\hline & Determine building areas. & \\
\hline & $\begin{array}{l}\text { Determine building volumes, including defining } \\
\text { building floor to floor heights. }\end{array}$ & Building areas and volumes fixed \\
\hline \multirow{8}{*}{$\stackrel{\Perp}{*}$} & $\begin{array}{l}\text { Determine building orientation for daylight, glare, } \\
\text { solar gains and losses. }\end{array}$ & Design concept elaboration \\
\hline & $\begin{array}{l}\text { Assess building site shadowing for daylight, glare, } \\
\text { solar gains and losses. }\end{array}$ & \\
\hline & $\begin{array}{l}\text { Determine general shape, and building size e.g. } \\
\text { massing. }\end{array}$ & \\
\hline & Situate building on site & Initial site plan \\
\hline & Determine site access and circulation. & Schematic grading, planting, paving plans \\
\hline & Design for views to and from the building. & $\begin{array}{l}\text { Recommendations are needed for the design of } \\
\text { pavements and retaining walls, as well as for dealing } \\
\text { with utility and transportation issues. }\end{array}$ \\
\hline & Concepts for grading, planting, paving etc. & $\begin{array}{l}\text { overall concepts for utilities, site drainage, earth } \\
\text { retention, and water retention }\end{array}$ \\
\hline & $\begin{array}{l}\text { Determine shading strategies and design for each } \\
\text { orientation for daylight, glare, solar gains and losses. }\end{array}$ & Suggestions for groundwater management \\
\hline \multirow{5}{*}{ 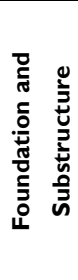 } & Subsurface conditions and requirements & Schematic basement plan \\
\hline & $\begin{array}{l}\text { Impacts of program, energy on under-ground } \\
\text { building }\end{array}$ & Refinement of special foundation requirements \\
\hline & & $\begin{array}{l}\text { Recommendations for basement and other earth } \\
\text { retention structures }\end{array}$ \\
\hline & Exploration of special problems & Selection of foundation systems \\
\hline & & Sizing of key foundation elements \\
\hline
\end{tabular}

Using BIM To Calculate Accurate Building Material Quantities For Early Design Phase LCA 


\section{Appendix 4.0 Table 4.2.I a: The Working Definition of the Decisions and Building Information Available During Sketch Design}

\begin{tabular}{|c|c|c|}
\hline & \multicolumn{2}{|c|}{ Design Decisions / Activities / Considerations } \\
\hline & Sketch Design Decisions & Developed Design Decisions \\
\hline \multirow{11}{*}{ 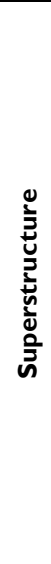 } & $\begin{array}{l}\text { Relation of structure to spatial organisation, } \\
\text { elevations, etc. }\end{array}$ & $\begin{array}{l}\text { Determine structural design profiles, basic } \\
\text { specifications }\end{array}$ \\
\hline & Selection of use modules & Outline framing plan \\
\hline & Basic structural module & Sizes of key elements - floor beam depth \\
\hline & Initial system selection & \\
\hline & Set structural grid and exterior modules & \\
\hline & Define Structural systems & \\
\hline & Determine beam depths & \\
\hline & $\begin{array}{l}\text { Construction materials noted for major building } \\
\text { elements }\end{array}$ & \\
\hline & Major vertical element laid out & \\
\hline & Size major structural components & \\
\hline & lateral design defined & \\
\hline \multirow{11}{*}{ 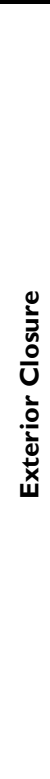 } & Approach to elevations, fenestration & Design concept elaboration \\
\hline & Views to and from buildings & Selection of wall systems, materials \\
\hline & Initial envelope elements sizing and selection & Schematic elevations fenestration \\
\hline & $\begin{array}{l}\text { Determine element thickness for insulation } \\
\text { requirements }\end{array}$ & $\begin{array}{l}\text { alternative designs / trade-offs for glazing strategies } \\
\text { for solar control, daylighting, and visual comfort }\end{array}$ \\
\hline & Determine thermal mass & $\begin{array}{l}\text { During DD, refining the enclosure strategies } \\
\text { established in schematic design includes evaluating } \\
\text { window size and location, shading, and glass type }\end{array}$ \\
\hline & Determine insulation requirements & $\begin{array}{l}\text { Determine window washing and skylight maintenance } \\
\text { cleaning }\end{array}$ \\
\hline & Determine WWR & Window, skylight, and glazing design \\
\hline & $\begin{array}{l}\text { Assess building form complexity in terms of thermal } \\
\text { performance, airtightness, material quantity usage } \\
\text { e.g. wasteful or inefficient }\end{array}$ & \\
\hline & $\begin{array}{l}\text { Design for light air, views, water collections, reduced } \\
\text { site disturbance, }\end{array}$ & \\
\hline & defined exterior module & \\
\hline & Select exterior materials & \\
\hline
\end{tabular}


Appendix 4.0 Table 4.2.I a: The Working Definition of the Decisions and Building Information Available During Sketch Design

\begin{tabular}{|c|c|c|}
\hline & \multicolumn{2}{|c|}{ Design Decisions / Activities / Considerations } \\
\hline & Sketch Design Decisions & Developed Design Decisions \\
\hline \multirow{2}{*}{$\stackrel{4}{\grave{0}}$} & Roof type and pitch & Selection of roof system, materials \\
\hline & Initial system selection & \\
\hline \multirow{4}{*}{ 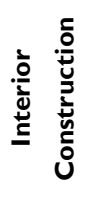 } & Approach to partitioning built-in furnishings & Room designs \\
\hline & Interior design vocabulary & Layout of key areas \\
\hline & Layout of key spaces & Selections of partition systems, finishes \\
\hline & & Important fixtures or theme elements \\
\hline \multirow{4}{*}{ 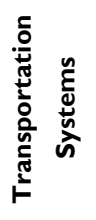 } & Basic organisation and circulation scheme & Detailed systems selection \\
\hline & Need for and types of vertical circulation & Sizing of exits, other circulation areas \\
\hline & Need for special conveying systems & Basic elevator and escalator concepts \\
\hline & & Other conveying systems concepts \\
\hline \multirow{6}{*}{ 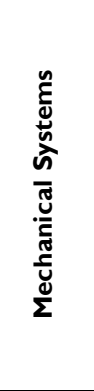 } & Impact of mechanical concepts on building planning & Mechanical systems selections \\
\hline & Initial systems selection & Refinement of service, distribution concepts \\
\hline & Initial distribution ideas & Input to plans, sections and elevations \\
\hline & Space allocation for mechanical areas & Optimising / fine tuning building controls \\
\hline & Define MEP systems & $\begin{array}{l}\text { Evaluation of alternative systems for mechanical, } \\
\text { electrical, and plumbing - optimal systems should be } \\
\text { selected and incorporated into the building design } \\
\text { and the document }\end{array}$ \\
\hline & Define Fire Protection systems & Initial equipment list \\
\hline \multirow{6}{*}{ 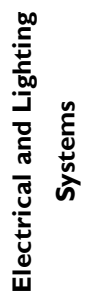 } & Approaches to natural, artificial lighting & Key room lighting layouts, ceiling plans \\
\hline & Light quality and character & Selection of lighting, electrical systems \\
\hline & Impact of site, design on electrical systems & Service power and distribution concepts \\
\hline & Space allocation for electrical systems & Input to plans, sections, and elevations \\
\hline & & $\begin{array}{l}\text { Determine artificial lighting and daylighting strategies } \\
\text { and controls }\end{array}$ \\
\hline & & Optimising / fine tuning building controls \\
\hline \multirow{2}{*}{ 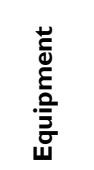 } & Impact of key equipment items on sitting and design & $\begin{array}{l}\text { Impact of key items on room design, framing plans, } \\
\text { etc. }\end{array}$ \\
\hline & & Initial equipment list \\
\hline
\end{tabular}

Using BIM To Calculate Accurate Building Material Quantities For Early Design Phase LCA 


\title{
LCA Data Sources Uncertainty and Variability Sources
}

\section{Table 4.3. I a: Sources of Uncertainty and Variability in LCA Data}

\author{
Parameter uncertainty: \\ These are uncertainties in the data parameters (LCA inventory) caused by imprecise measurements \\ (empirical inaccuracy), incomplete or outdated measurements (unrepresentatively), or a lack of data.
}

\section{Model uncertainty:}

These are uncertainties that are caused by not being able to model certain processes and therefore not including it in the LCA calculation. This can be either as a limitation of the modelling method, data availability or a choice by the individual modeller. A calculation with large model uncertainties cause parameter uncertainties to be misleading as their influence may be increase of decrease proportionally to the total overall calculation result.

\section{Uncertainty due to choices:}

These are uncertainties caused by the modeller conducting the LCA assessment. This can be the selection of a certain parameter over another, or a model uncertainty by including or excluding process.

\section{Spatial variability:}

This is a variability that causes uncertainties due to locational variability. Environmental impacts are reported regardless of the spatial context of the intervention. This introduces model uncertainty by not accounting for the spatial variability. In LCA calculation the feasibility of dealing with spatial variability is limited as data of all the individual plants is not available or practical. Best practice is to be country-specific.

\section{Temporal variability:}

Uncertainties caused by the age of the data being used.

\section{Variability between sources and objects:}

Uncertainties caused by the inherent differences between the same or similar/ comparable products despite their different methods of production. For example the use of different technologies in factories which produce the same material cause variability in life cycle inventories.

For product system optimisation aim to reduce the sources contributing to the upper tail of data variability.

For product comparison the average environmental impact is important, variability is reported as the uncertainty of the mean. 


\section{Data Quality Pedigree Matrix}

\section{Table 4.3.I c: Data Quality Pedigree Matrix}

Source: Table I Pedigree Matrix with 5 data quality indicators (Weidema \& Wesnæs, 1996, p. 169)

\begin{tabular}{|c|c|c|c|c|c|}
\hline \multirow{2}{*}{ DQI Indicator } & \multicolumn{5}{|c|}{ DQI Indicator Score } \\
\hline & I & 2 & 3 & 4 & 5 \\
\hline Reliability & $\begin{array}{l}\text { Verified data based } \\
\text { on measurements }\end{array}$ & $\begin{array}{l}\text { Verified data partly } \\
\text { based on } \\
\text { assumptions or non- } \\
\text { verified data based } \\
\text { on measurements }\end{array}$ & $\begin{array}{l}\text { Non-verified data } \\
\text { partly based on } \\
\text { assumptions }\end{array}$ & $\begin{array}{l}\text { Qualified estimate } \\
\text { (e.g. by industrial } \\
\text { expert) }\end{array}$ & $\begin{array}{l}\text { Non-qualified } \\
\text { estimate }\end{array}$ \\
\hline Completeness & $\begin{array}{l}\text { Representative data } \\
\text { from a sufficient } \\
\text { sample of sites over } \\
\text { an adequate period } \\
\text { to even out normal } \\
\text { fluctuations }\end{array}$ & $\begin{array}{l}\text { Representative data } \\
\text { from a smaller } \\
\text { number of sites but } \\
\text { for adequate } \\
\text { periods }\end{array}$ & $\begin{array}{l}\text { Representative data } \\
\text { from an adequate } \\
\text { number of sites but } \\
\text { from shorter } \\
\text { periods }\end{array}$ & $\begin{array}{l}\text { Representative data } \\
\text { but from a smaller } \\
\text { number of sites and } \\
\text { shorter periods or } \\
\text { incomplete data } \\
\text { from an adequate } \\
\text { number of sites and } \\
\text { periods }\end{array}$ & $\begin{array}{l}\text { Representativeness } \\
\text { unknown or } \\
\text { incomplete data } \\
\text { from a smaller } \\
\text { number of sites } \\
\text { and/or from shorter } \\
\text { periods }\end{array}$ \\
\hline $\begin{array}{l}\text { Temporal } \\
\text { correlation }\end{array}$ & $\begin{array}{l}\text { Less than three } \\
\text { years of difference } \\
\text { to year of study }\end{array}$ & $\begin{array}{l}\text { Less than six years } \\
\text { difference }\end{array}$ & $\begin{array}{l}\text { Less than } 10 \text { years } \\
\text { difference }\end{array}$ & $\begin{array}{l}\text { Less than } 15 \text { years } \\
\text { difference }\end{array}$ & $\begin{array}{l}\text { Age of data } \\
\text { unknown or more } \\
\text { than } 15 \text { years of } \\
\text { difference }\end{array}$ \\
\hline $\begin{array}{c}\text { Geographical } \\
\text { correlation }\end{array}$ & $\begin{array}{l}\text { Data from area } \\
\text { under study }\end{array}$ & $\begin{array}{l}\text { Average data from } \\
\text { larger area in which } \\
\text { the area under } \\
\text { study is included }\end{array}$ & $\begin{array}{l}\text { Data from area with } \\
\text { similar production } \\
\text { conditions }\end{array}$ & $\begin{array}{l}\text { Data from area with } \\
\text { slightly similar } \\
\text { production } \\
\text { conditions }\end{array}$ & $\begin{array}{l}\text { Data from unknown } \\
\text { area or area with } \\
\text { very different } \\
\text { production } \\
\text { conditions }\end{array}$ \\
\hline $\begin{array}{c}\text { Further } \\
\text { technological } \\
\text { correlation }\end{array}$ & $\begin{array}{l}\text { Data from } \\
\text { enterprises, } \\
\text { processes and } \\
\text { materials under } \\
\text { study }\end{array}$ & $\begin{array}{l}\text { Data from } \\
\text { processes and } \\
\text { materials under } \\
\text { study but from } \\
\text { different } \\
\text { enterprises }\end{array}$ & $\begin{array}{l}\text { Data from } \\
\text { processes and } \\
\text { materials under } \\
\text { study but from } \\
\text { different technology }\end{array}$ & $\begin{array}{l}\text { Data on related } \\
\text { processes or } \\
\text { materials but same } \\
\text { technology }\end{array}$ & $\begin{array}{l}\text { Data on related } \\
\text { processes or } \\
\text { materials but } \\
\text { different technology }\end{array}$ \\
\hline
\end{tabular}

Using BIM To Calculate Accurate Building Material Quantities For Early Design Phase LCA 
Table 4.3. Id: Description of Data Quality Indicators

Source: (Weidema \& Wesnæs, 1996, pp. 169-170)

\begin{tabular}{|l|l|}
\hline \multicolumn{1}{|c|}{$\begin{array}{c}\text { Data Quality } \\
\text { Indicators }\end{array}$} & \multicolumn{1}{c|}{ Description } \\
\hline Reliability & $\begin{array}{l}\text { Relates to the sources, acquisition methods and verification procedures } \\
\text { used to obtain the data. }\end{array}$ \\
\hline Completeness & $\begin{array}{l}\text { Relates to the statistical properties of the sample used for form the } \\
\text { data. }\end{array}$ \\
\hline $\begin{array}{l}\text { Temporal } \\
\text { correlation }\end{array}$ & $\begin{array}{l}\text { Age of data, the time difference between the published data and the } \\
\text { year of the assessment. Potential uncertainty due to technology } \\
\text { developments, old versus new methods of production. }\end{array}$ \\
\hline correlation & $\begin{array}{l}\text { Location of data source. Potential uncertainty due to technology } \\
\text { differences between countries, large versus small scale production, old } \\
\text { versus new technologies, electricity generation, renewable versus non- } \\
\text { renewable. }\end{array}$ \\
\hline $\begin{array}{l}\text { Further } \\
\text { technological } \\
\text { correlation }\end{array}$ & $\begin{array}{l}\text { Relates to technological differences not covered under temporal or } \\
\text { geographical correlation. For example, data may not represent specific } \\
\text { enterprises, processes or materials under study. Thus it can be } \\
\text { necessary to use data from related processes or material, which in } \\
\text { some instances can be regarded as preferable to old data or data from } \\
\text { a different geographical area. }\end{array}$ \\
\hline
\end{tabular}

Using BIM To Calculate Accurate Building Material Quantities For Early Design Phase LCA 


\section{APPENDIX FOR CHAPTER 6.0}

\section{Level Of Development Specification}

\section{Level of Development (LOD) Specification Introduction}

\section{Overview}

The Level of Development ( $L O D)$ Specification is a reference that enables practitioners in the AEC Industry to specify and articulate with a high level of clarity the content and reliability of Building Information Models (BIMs) at various stages in the design and construction process. The LOD Specification utilizes the basic LOD definitions developed by the AIA for the AIA G202-2013 Building Information Modeling Protocol Form' and is organized by CSI Uniformat $2010^{2}$. It defines and illustrates characteristics of model elements of different building systems at different Levels of Development. This clear articulation allows model authors to define what their models can be relied on for, and allows downstream users to clearly understand the usability and the limitations of models they are receiving.

The intent of this Specification is to help explain the LOD framework and standardize its use so that it becomes more useful as a communication tool. It does not prescribe what Levels of Development are to be reached at what point in a project but leaves the specification of the model progression to the user of this document. To accomplish the document's intent, its primary objectives are:

- To help teams, including owners, to specify BIM deliverables and to get a clear picture of what will be included in a BIM deliverable

- To help design managers explain to their teams the information and detail that needs to be provided at various points in the design process

- To provide a standard that can be referenced by contracts and BIM execution plans.

It should be noted that this Specification does not replace a project BIM Execution Plan (BIMXP), but rather is intended to be used in conjunction with such a plan, providing a means of defining models for specific information exchanges, milestones in a design work plan, and deliverables for specific functions.

\section{Background}

In 2011 the BIMForum initiated the development of this LOD Specification and formed a working group comprising contributors from both the design and construction sides of the major disciplines. The working group first interpreted the AIA's basic LOD definitions for each building system, and then compiled examples to illustrate the interpretations. Because BIM is being put to an ever increasing number of uses, the group decided that it was beyond the initial scope to address all of them. Instead, the definitions were developed to address model element geometry, with three of the most common uses in mind - quantity take-off, 3D coordination and 3D control and planning. The group felt that in taking this approach the interpretations would be complete enough to support other uses.

${ }^{1}$ AlA Contract Document G202-2013, Building Information Modeling Protocol Form is part of a new series of digital practice documents the AIA published in June 2013. The AIA's updated digital practice documents consist of AIA E203 ${ }^{\mathrm{m}}-2013$, Building Information Modeling and Digital Data Exhibit, AlA G201 $1^{\mathrm{M}}-2013$, Project Digital Data Protocol Form, and AIA G202 ${ }^{\mathrm{M}}-2013$, Project Building Information Modeling Protocol Form. For general information on the documents and downloadable samples see www.aia.org/diqitaldocs. For executable versions of the documents see

http://WwW. aia.org/contractdocs. Specifications Canada (CSC), and are used with permission from CSI. For a more in-depth explanation of UniFormat ${ }^{\mathrm{TM}}$ and its use in the construction industry visit http://www.csinet.org or contact CSI, 110 South Union Street, Suite 100, Alexandria, VA 22314 . (800) 689-2900. 


\section{Levels of Development}

The Level of Development (LOD) framework addresses several issues that arise when a BIM is used as a communication or collaboration tool, i.e., when someone other than the author extracts information from it:

- During the design process, building systems and components progress from a vague conceptual idea to a precise description. In the past there has been no simple way to designate where a model element is along this path. The author knows, but others often don't.

- It's easy to misinterpret the precision at which an element is modeled. Hand drawings range from pen strokes on a napkin to hard lines with dimensions called out, and it's easy to infer the precision of the drawing from its appearance. In a model though, a generic component placed approximately can look exactly the same as a specific component located precisely, so we need something besides appearance to tell the difference.

- It is possible to infer information from a BIM that the author doesn't intend - unstated dimensions can be measured with precision, assembly information often exists before it's been finalized, etc. In the past, this issue has been sidestepped with all-encompassing disclaimers that basically say, "Since some of the information in the model is unreliable, you may not rely on any of it." The LOD framework allows model authors to clearly state the reliability of given model elements, so the concept. becomes "Since some of the information in the model is unreliable, you may only rely on it for what I specifically say you can."

- In a collaborative environment, where people other than the model author are depending on information from the model in order to move their own work forward, the design work plan takes on high importance - it is necessary for the model users to order to move their own work forward, the design work plan takes on high importance - it is necessary
know when information will be available in order to plan their work. The LOD framework facilitates this.

The LOD Framework addresses these issues by providing an industry-developed standard to describe the state of development of various systems within a BIM. This standard enables consistency in communication and execution by facilitating the detailed definition of BIM milestones and deliverables.

3.1 Level of Development vs. Level of Detail

LOD is sometimes interpreted as Level of Detail rather than Level of Development. This Specification uses the concept of Levels of Development. There are important differences.

Level of Detail is essentially how much detail is included in the model element. Level of Development is the degree to which the element's geometry and attached information has been thought through - the degree to which project team members may rely on the in the model. In essence, Level of Detail can be thought of as input to the element, while Level of Development is reliable output.

\section{LOD Definitions}

In 2008, the AIA developed its first set of Level of Development definitions in AIA Document E202 ${ }^{*}$-2008 Building Information Modeling Protocol. Due to the rapidly evolving nature of the use of BIM, the AIA evaluated the AIA E202-2008, including the LOD definitions. The result is the updated and reconfigured Digital Practice documents, AIA E203"N-2013, Building Information Modeling and Digita Data Exhibit, AIA G201 Protocol Form, which are accompanied by a detailed guide document entitled Guide and Instructions to the AlA Digital Practice Documents. The AIA's updated Digital Practice documents include revised LOD definitions.

To help further the standardization and consistent use of the LOD concept, and to increase its usefulness as a foundation for collaboration, the AIA agreed to allow the BIMForum to utilize its latest LOD definitions in this Specification. The LOD definitions that are used in this Specification are identical to those published in the AIA's updated Digital Practice Documents, with two exceptions.

First, the working group identified the need for an LOD that would define model elements sufficiently developed to enable coordination between disciplines - e.g. clash detection/avoidance, layout, etc. The requirements for this level are higher than those for 300 , but not as high as those for 400 , thus it was designated LOD 350 . The AIA documents do not include LOD 350 , but the associated Guide and Instructions references it.

Second, while LOD 500 is included in the AIA's LOD definitions, the working group did not feel it was necessary to further define and illustrate LOD 500 in this Specification because it relates to field verification. Accordingly the expanded descriptions and graphic illustrations in this Specification are limited to LOD $100-400$. 


\subsection{Fundamental LOD Definitions ${ }^{3}$}

LOD 100

The Model Element may be graphically represented in the Model with a symbol or other generic representation, but does not satisfy the requirements for LOD 200. Information related to the Model Element (i.e. cost per square foot, tonnage of HVAC, etc.) can be derived from other Model Elements.

LOD 200 The Model Element is graphically represented within the Model as a generic system, object, or assembly with approximate quantities, size, shape, location, and orientation. Non-graphic information may also be attached to the Model Element.

LOD 300 The Model Element is graphically represented within the Model as a specific system, object or assembly in terms of quantity, size, shape, location, and orientation. Non-graphic or assembly in terms of quantity, size, shape, location, and
information may also be attached to the Model Element.

LOD 350 The Model Element is graphically represented within the Model as a specific system, object, or assembly in terms of quantity, size, shape, orientation, and interfaces with other building systems. Non-graphic information may also be attached to the Model Element.

LOD 400 The Model Element is graphically represented within the Model as a specific system, object or assembly in terms of size, shape, location, quantity, and orientation with detailing. fabrication, assembly, and installation information. Non-graphic information may also be attached to the Model Element.

LOD 500 The Model Element is a field verified representation in terms of size, shape, location, quantity, and orientation. Non-graphic information may also be attached to the Mode Elements.

\section{Example - light fixture:}

- 100 cost/sf attached to floor slabs

- 200

300

ght fixture, generic/approximate size/shape/location

As 350 , plus special mounting details, as in a decorative soffit

Glossary

The expanded definitions use the following interpretations of these terms:

- Specific: The quantity, size, shape, location, and orientation of the element as designed can be measured directly from the model without referring to non-modeled information such as notes or dimension call-outs.

- Actual: The model element includes all the qualities of a specific element and is representative of the manufacturer's model to be installed or the construction intent of an assembly.

\section{Order of Precedence}

The body of this Specification expands on these Fundamental Definitions as they apply to specific building systems and sub-systems. In the event of any conflict, more specific expansions take precedence over less specific expansions and Fundamental Definitions, e.g. the expanded definitions for $\mathrm{C} 1010$ take precedence over those for C10, which in turn take precedence over the Fundamental Definitions.

${ }^{3}$ The definitions for LOD 100, 200, 300, 400, and 500 included in this Specification represent the updated language that appears in the AIA's most recent BIM protocol document, G202-2013, Building Information Modeling Protocol Form. The LOD $100,200,300,400$ and 500 definitions are produced by the AIA and have been used by permission. Copyright $\Theta 2013$. The American Institute of Architects. All rights reserved. LOD 350 was developed by the BIMForum working group. Copyright (6) 2013. The BIMForum and the American Institute of Architects. All rights reserved 


\section{$\underline{\text { LOD Definitions as Minimum Requirements }}$}

The LODs provide five snapshots of the progression of an element from conceptual to specified -there are many steps in this progression between the defined LODs. The LOD definitions, then, should be considered minimum requirements - i.e. an element has progressed to a given LOD only when all the requirements stated in the definition have been met. It should also be noted that the requirements are cumulative - for a given element each LOD definition includes the requirements of all previous LODs. Thus for an element to qualify for LOD 300 it must meet all the requirements for 200 and 100 as well as those stated in the LOD 300 definition.

\section{Model Element Author}

This document does not prescribe who the author of a particular component at a certain LOD should be - the sequence of responsibility for modeling various systems will vary from one project to another. To accommodate this variation this document defers to the concept of Model Element Author (MEA) as defined in the AIA E203-2013: "The Model Element Author is the entity (or individual) responsible for managing and coordinating the development of a specific Model Element to the LOD required for an identified Project milestone, regardless of who is responsible for providing the content in the Model Element." 4

\section{D Supplementary Drawings}

In current practice models are often supplemented with $2 \mathrm{D}$ information such as detail drawings. This Specification does not address this supplementation, but rather deals only with what is actually modeled in 3D and any non-graphic information associated with the modeled elements.

\subsection{Caveats}

There is no strict correspondence between LODs and design phases. Building systems are developed at different rates through the design process - for example, design of the structural system is usually well ahead of the design of interior construction. At completion of the schematic design phase, for example, the model will include many elements at LOD 200, but will also include many at LOD 100, as well as some at LOD 300 , and possibly even LOD 400 .

Similarly, there is no such thing as an "LOD _ model". As previously stated, project models at any stage of delivery will invariably contain elements and assemblies at various levels of development. As an example, it is not logical to require an "LOD 200 model" at the completion of the schematic design phase. Instead, the "schematic design model deliverable" may contain modeled elements at various levels of development.

\subsection{Project-Specific Information}

As mentioned in the Overview above, this Specification is intended to be used in conjunction with a project BIMXP. Many information needs will vary from project to project, even for identical elements. This kind of information is therefore not included in the LOD definitions specified here, but rather is left to be addressed in individual BIMXPs. The following are some notable examples.

\section{Size Thresholds}

In most projects a determination is made to model certain elements only if they are over a specified size - e.g. conduit less than $1 / 2^{\prime \prime}$ $(10 \mathrm{~mm})$ diameter is not modeled. These size thresholds do not consistently correspond to certain LODs, and they vary from project to project. Thus they are not specified in the LOD definitions but rather in the project's BIMXP, for example through the "Notes" cells in the Model Element Table of the AIA G202-2013.

\section{Clearances}

Clearances such as door swings, maintenance access zones, and accessibility requirements can be critical design issues and in many cases are geometrically modeled to reserve the space. The implementation of this type of spatial coordination can be accomplished in various ways; therefore it is neither practical nor useful for this Specification to dictate particular requirements, for example, all door swings to be modeled as quarter-cylinder solids. Implementation of required clearances is to be established with individual BIMXPs.

${ }^{4}$ AIA Document E203-2013 Building Information Modeling and Digital Data Exhibit. Copyright @ American Institute of Architects 2013. All rights reserved. Definition quoted here by permission. 


\section{A: SUBSTRUCTURE}

\section{A10 Foundations}

\begin{tabular}{|c|c|c|c|}
\hline & & 100 & $\begin{array}{l}\text { Assumptions for foundations are included in other modeled } \\
\text { elements such as an architectural floor element or volumetric } \\
\text { mass that contains layer for assumed structural framing depth. } \\
\text { Or, schematic elements that are not distinguishable by type or } \\
\text { material. Assembly depth/thickness and locations still flexible. }\end{array}$ \\
\hline & & 200 & $\begin{array}{l}\text { Element modeling to include: } \\
\text { - Approximate size and shape of foundation element } \\
\text { Structural building grids for local project coordinate } \\
\text { system are defined in model and coordinated with } \\
\text { global civil coordinate system (State Plane Coordinate } \\
\text { System, etc). }\end{array}$ \\
\hline
\end{tabular}

A1010 - Standard Foundations

\begin{tabular}{|l|l|l|}
\hline 100 & See $\underline{A 10}$ & \\
\hline 200 & See $\underline{A 10}$ & \\
\hline 300 & $\begin{array}{l}\text { Elements are modeled to the design-specified size and shape of } \\
\text { the foundation. } \\
\text { Element modeling to include: }\end{array}$ & \\
- Overall size and geometry of the foundation element & Sloping surfaces or floor depressions \\
& $\begin{array}{l}\text { Required non-graphic information associated with model } \\
\text { elements includes: }\end{array}$ & \\
- Concrete strength & Reinforcing strength & \\
\hline
\end{tabular}


A1010.10 - Wall Foundations (Shallow Foundations)

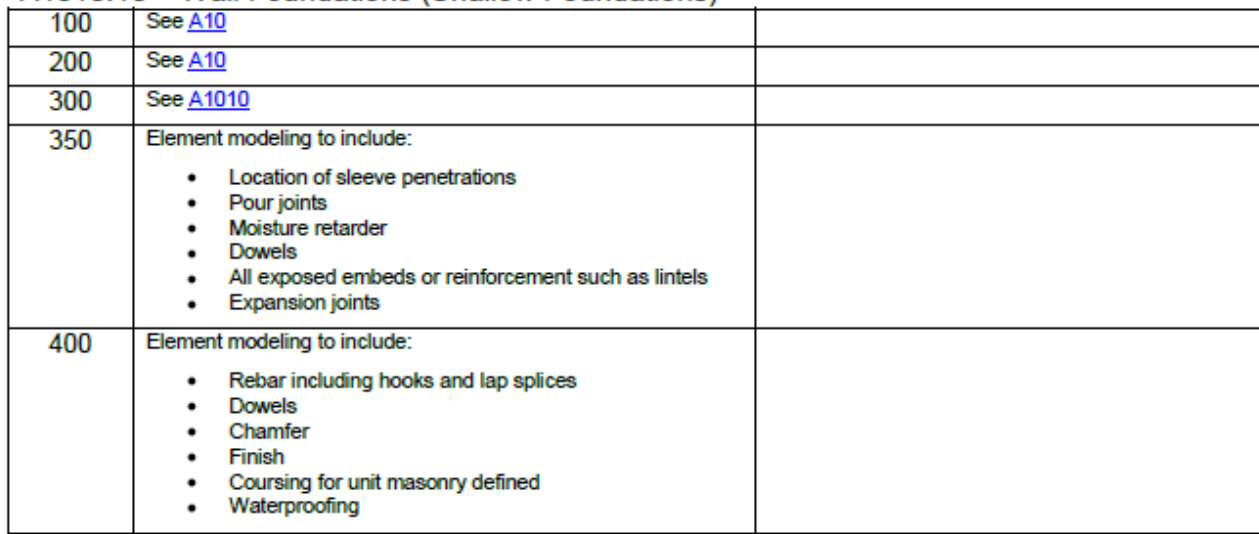

A1010.30 - Column Foundations (Deep Foundations)

\begin{tabular}{|c|c|}
\hline 100 & See A10 \\
\hline 200 & See A10 \\
\hline 300 & $\begin{array}{l}\text { Element modeling to include: } \\
\text { - Assumed bearing depth noted with anticipated } \\
\text { penetrations modeled. } \\
\text { - Top of Pier } \\
\text { Size of Pier }\end{array}$ \\
\hline 350 & $\begin{array}{l}\text { Element modeling to include: } \\
\text { - Actual Top of Pier (TOP) and expected Bottom of Pier } \\
\text { (BOT) modeled per engineers review of site conditions }\end{array}$ \\
\hline 400 & $\begin{array}{l}\text { Element modeling to include: } \\
\text { - Depth to bearing stratum } \\
\text { - Penetration into bearing stratum } \\
\text { Locations of lap splices }\end{array}$ \\
\hline
\end{tabular}


A40 Slabs-on-Grade

\begin{tabular}{|c|c|}
\hline 100 & $\begin{array}{l}\text { Assumptions for slabs are included in other modeled elements } \\
\text { such as a volumetric mass or architectural floor element that } \\
\text { contains a layer for assumed structural framing depth. }\end{array}$ \\
\hline 200 & $\begin{array}{l}\text { Element modeling to include } \\
\text { - Generic slab with approximate thickness. } \\
\text { Structural building grids for local project coordinate } \\
\text { system are defined in model and coordinated with } \\
\text { global civil coordinate system (State Plane Coordinate } \\
\text { System, etc). }\end{array}$ \\
\hline
\end{tabular}

\begin{tabular}{|c|c|c|}
\hline 100 & See $\underline{A 40}$ & \\
\hline 200 & See $\underline{A 40}$ & \\
\hline 300 & $\begin{array}{l}\text { Element modeling to include: } \\
\text { - Overall size, thickness and geometry of the slab } \\
\text { Edge tum downs } \\
\text { - Material strength } \\
\text { All sloping surfaces included in model element with } \\
\text { selection. } \\
\text { Required non-graphic information associated with model } \\
\text { elements includes: } \\
\text { - Moisture retarder } \\
\text { - Air entrainment }\end{array}$ & 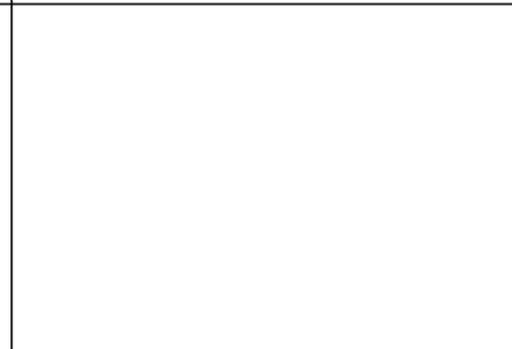 \\
\hline 350 & $\begin{array}{l}\text { Element modeling to include: } \\
\text { - Sleeve penetrations } \\
\text { - } \text { Pour joints } \\
\text { - } \text { Expansion joints } \\
\text { - Rebar stops } \\
\text { congested any embedded elements modeled at } \\
\text { which is typically with in a set distance from the area of } \\
\text { congestion. } \\
\text { - Void boxes } \\
\text { - Mnchor rods } \\
\text { - Doisture retarder } \\
\text { Powels } \\
\text { BIMXP. }\end{array}$ & \\
\hline 400 & $\begin{array}{l}\text { Element modeling to include: } \\
\text { - Actual slab dimensions and profiles with fully modeled } \\
\text { rebar } \\
\text { - Post tensioning components } \\
\text { - } \text { - Water proofing } \\
\text { - Finish }\end{array}$ & \\
\hline
\end{tabular}


A4020 - Structural Slabs-on-Grade

\begin{tabular}{|c|c|c|}
\hline 100 & See A40 & \\
\hline 200 & See $A 40$ & \\
\hline 300 & $\begin{array}{l}\text { Element modeling to include: } \\
\text { - Overall size, thickness and geometry of the slab-on- } \\
\text { grade } \\
\text { Slab depressions } \\
\text { - } \text { Mdge tum downs } \\
\text { All slopial strength surfaces included in model element with } \\
\text { exception of elements affected by manufacturer } \\
\text { selection which are not known at this LOD. Such } \\
\text { conditions could include floor geometry differences } \\
\text { where different specified manufacturers will not be } \\
\text { known until the actual system is selected. } \\
\text { Required non-graphic information associated with model } \\
\text { elements includes: } \\
\text { - Concrete strength } \\
\text { - Reinforcing strength } \\
\text { - Mir entrainment } \\
\text { Moisture Retarder } \\
\text { Slab penetrations }\end{array}$ & (1) \\
\hline 350 & 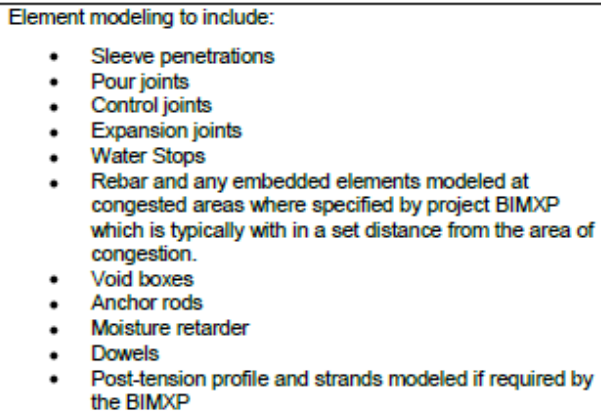 & \\
\hline 400 & $\begin{array}{l}\text { Element modeling to include: } \\
\text { - Actual slab dimensions and profiles with fully modeled } \\
\text { rebar } \\
\text { - Post tensioning components } \\
\text { - Watl joints } \\
\text { - Finish }\end{array}$ & \\
\hline
\end{tabular}




\section{B: SHELL}

\section{B10 Superstructure}

\begin{tabular}{|l|l|l|}
\hline 100 & $\begin{array}{l}\text { Assumptions for structural framing are included in other modeled } \\
\text { elements such as an architectural floor element that contains a } \\
\text { layer for assumed structural framing depth; or, schematic } \\
\text { structural elements that are not distinguishable by type or } \\
\text { material. } \\
\text { Assembly depth/thickness or component size and locations still } \\
\text { flexible. }\end{array}$ & \\
\hline
\end{tabular}

\section{B1010 - Floor Construction}

\begin{tabular}{|c|l|l|}
\hline 100 & See B10 & \\
\hline 200 & Model elements to include: & \\
& - Floor with approximate dimensions & \\
& - Spproximate supporting framing members & \\
\end{tabular}

B1010.10 - Floor Structural Frame

Description: Structural elements required for support of floor construction within basements and above grade. Includes columns, girders, beams, trusses, joists. Includes cast-in-place concrete, precast concrete, unit masonry, metal framed, and wood framed systems. Includes framed and sleeved openings for services. Includes Floor Construction Supplementary Components as appropriate. Specific structural systems within this section are listed as follows:

- Concrete

- Masonr

- Steel Framinq Columns

- Steel Framing Beams

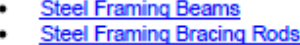

- Steel Joists

- Cold-Formed Metal Framino

- Wood Floor Trusses 
B1010.10 - Floor Structural Frame (Concrete)

\begin{tabular}{|c|c|c|}
\hline 100 & See B10 & \\
\hline 200 & $\begin{array}{l}\text { Element modeling to include: } \\
\text { - Type of structural concrete system } \\
\text { - Approximate geometry (e.g. depth) of structural } \\
\text { elements }\end{array}$ & \\
\hline 300 & $\begin{array}{l}\text { Element modeling to include: } \\
\text { - Specific sizes and locations of main concrete structural } \\
\text { members modeled per defined structural grid with } \\
\text { correct orientation } \\
\text { - Concrete defined per spec (strength, air entrainment, } \\
\text { - Aggregate size, etc.) } \\
\text { exception of elements affected by manufacturer } \\
\text { selection } \\
\text { Required non-graphic information associated with model } \\
\text { elements includes: } \\
\text { - Penetrations for items such as MEP } \\
\text { - Finishes, camber, chamfers, etc. } \\
\text { - Eypical details } \\
\text { - Aggregate, clear clover } \\
\text { - Reinforcing spacing } \\
\text { - Reinforcing } \\
\text { - Sive loads }\end{array}$ & 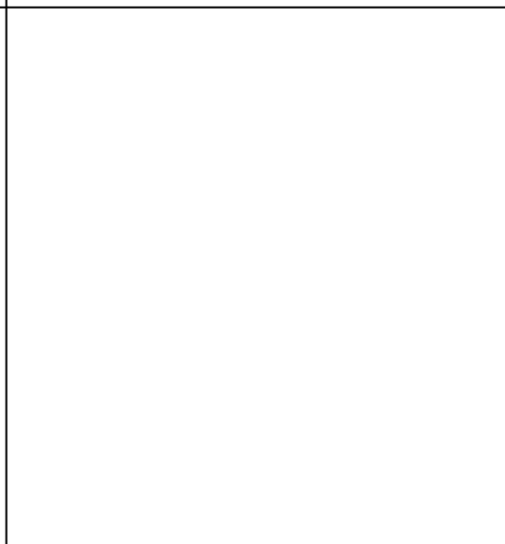 \\
\hline 350 & $\begin{array}{l}\text { Element modeling to include: } \\
\text { - Reinforcing Post-tension profiles and strand locations } \\
\text { - Reinforcement called out, modeled if required by the } \\
\text { BIMXP, typically only in congested areas } \\
\text { - Pour joints and sequences to help identify reinforcing } \\
\text { - lap splice locations, scheduling, etc. } \\
\text { - Expansion Joints } \\
\text { - Post-tension profile and strands modeled if required by } \\
\text { - } \text { the BIMXP } \\
\text { - Any perrations for items such as MEP } \\
\text { - Shear reinforcing and stud rails }\end{array}$ & \\
\hline 400 & $\begin{array}{l}\text { Element modeling to include: } \\
\text { - All reinforcement including post tension elements } \\
\text { detailed and modeled } \\
\text { - Finishes, camber, chamfer, etc. }\end{array}$ & \\
\hline
\end{tabular}


B1010.10 - Floor Structural Frame (Steel Framing Columns)

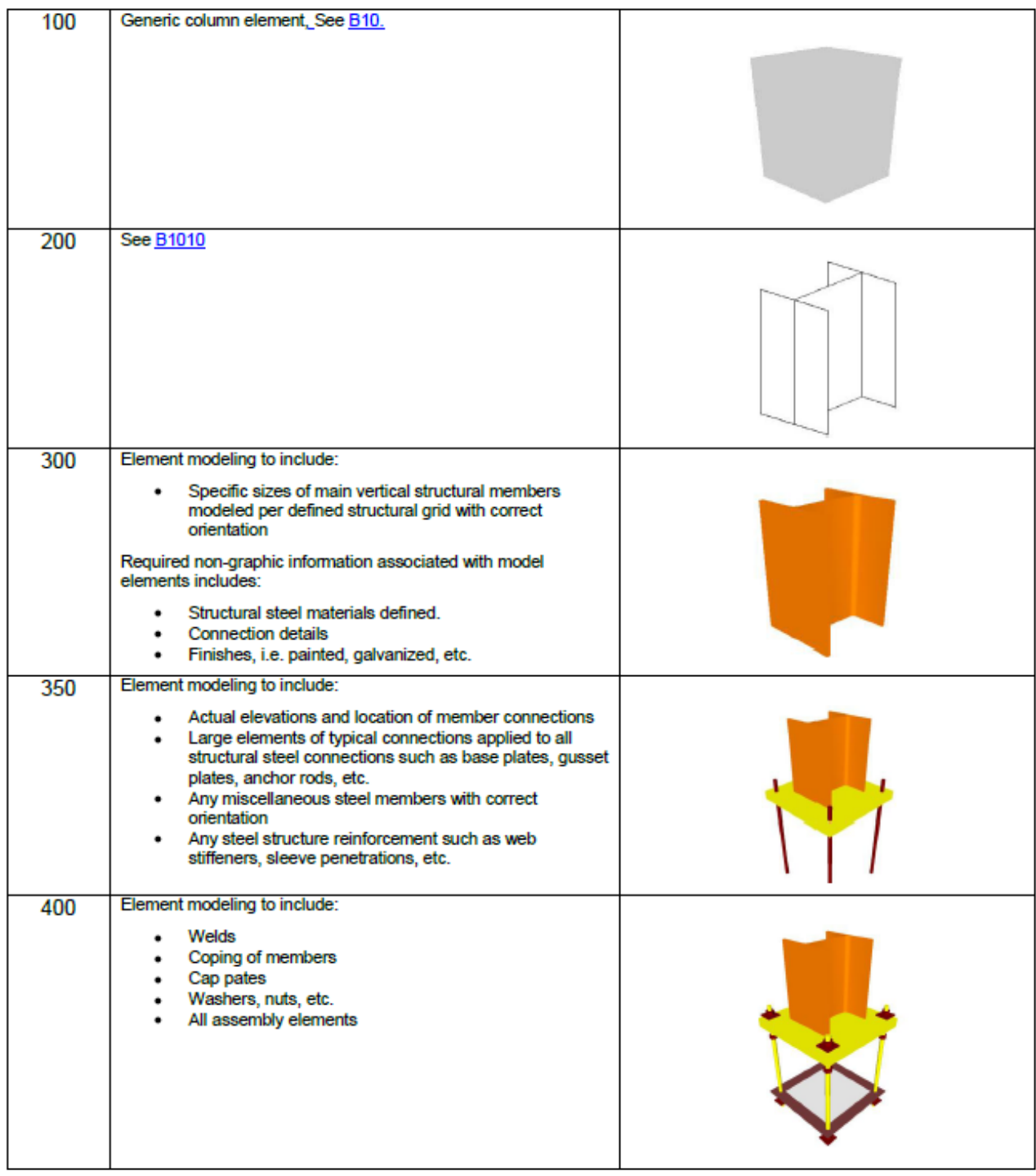


B1010.10 - Floor Structural Frame (Steel Framing Beams)

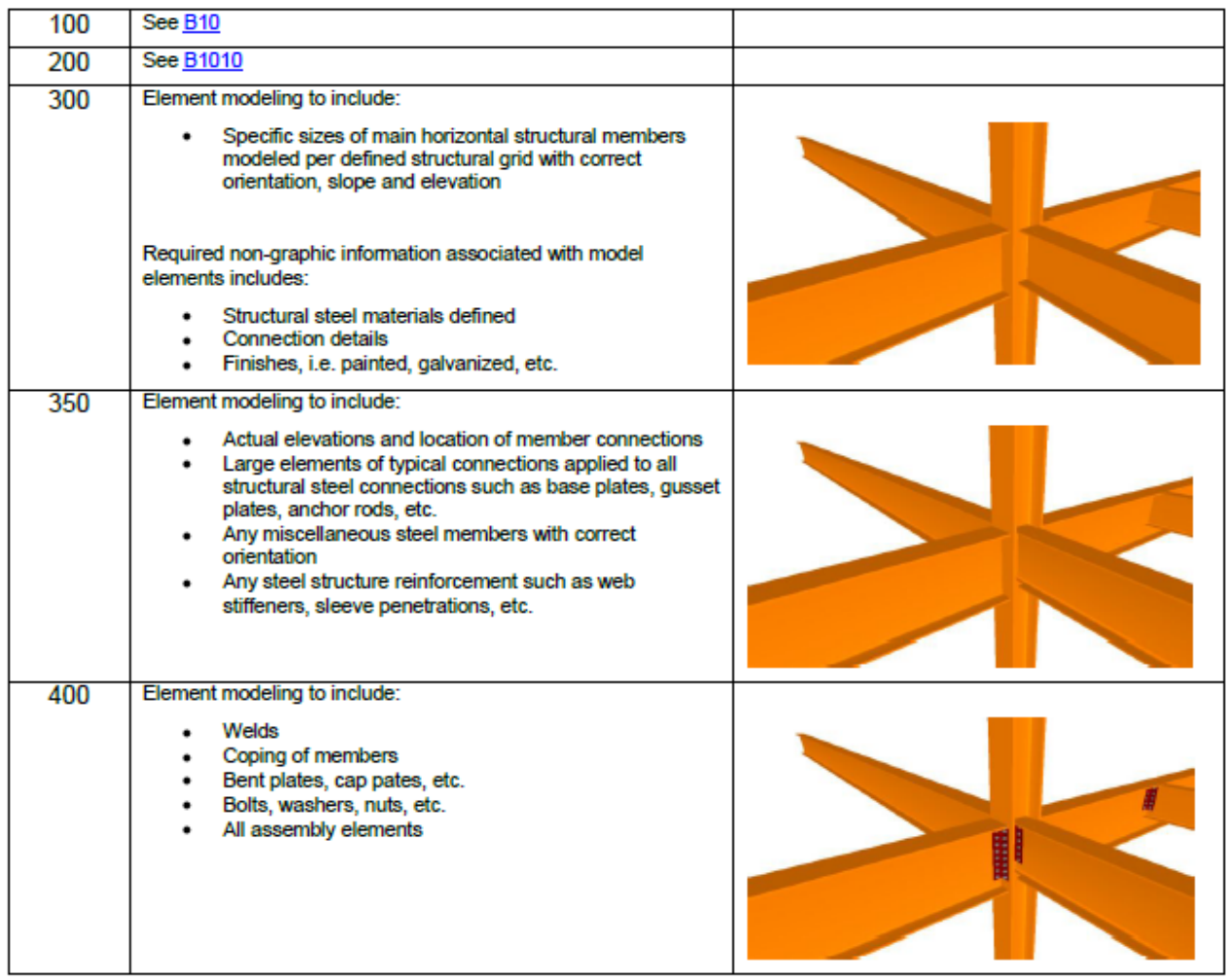


B1010.20 - Floor Decks, Slabs, and Toppings

Description: Structural slab, deck, and sheathing floor construction at intermediate floors of basement construction and above grade. Includes cast-in-place concrete, precast concrete, cementitious decks and toppings, metal decking, wood sheathing, and wood decking. Includes framed and sleeved penetrations for services and housekeeping pads for equipment. Includes Floor Construction Supplementary Components as appropriate.

Specific structural systems within this section are listed as follows:

- Wood Floor Deck

- Metal Floor Deck

- Composite Floor Deck

- Concrete

B1010.20 - Floor Decks, Slabs, and Toppings (Wood Floor Deck)

\begin{tabular}{|c|c|c|}
\hline 100 & See B10 & \\
\hline 200 & See B10 & \\
\hline 300 & $\begin{array}{l}\text { Element modeling to include: } \\
\text { - Applicable slopes } \\
\text { material } \\
\text { Required non-graphic information associated with model } \\
\text { elements includes: } \\
\text { - Deck orientation } \\
\text { - Deck material layer thicknesses } \\
\text { - Diaphragm load and deflection criteria } \\
\text { - Deck Material } \\
\text { Deck fasteners }\end{array}$ & \\
\hline 350 & $\begin{array}{l}\text { Element modeling to include: } \\
\text { - Deck edge location } \\
\text { - Actual framing member and location per manufacture } \\
\text { - Deck openings modeled with support framing around } \\
\text { openings } \\
\text { - Point load locations } \\
\text { Actual opening locations and sizes defined }\end{array}$ & \\
\hline 400 & $\begin{array}{l}\text { Element modeling to include: } \\
\text { - All framing accessory and fasteners modeled per } \\
\text { expected installation } \\
\text { - Waterproofing }\end{array}$ & \\
\hline
\end{tabular}


B1010.20 - Floor Decks, Slabs, and Toppings (Composite Floor Deck)

\begin{tabular}{|c|c|c|}
\hline 100 & See B10 & \\
\hline 200 & See B10 & \\
\hline 300 & $\begin{array}{l}\text { Element modeling to include: } \\
\text { - Specific deck thickness } \\
\text { - Opecific Framing member profiles, spacing, material } \\
\text { for additional miscellaneous framing } \\
\text { Required non-graphic information associated with model } \\
\text { elements includes: } \\
\text { - Specific deck material } \\
\text { - Deck fasteners } \\
\text { : Typical weld specifications } \\
\text { : Shear studs } \\
\text { - Toppings }\end{array}$ & 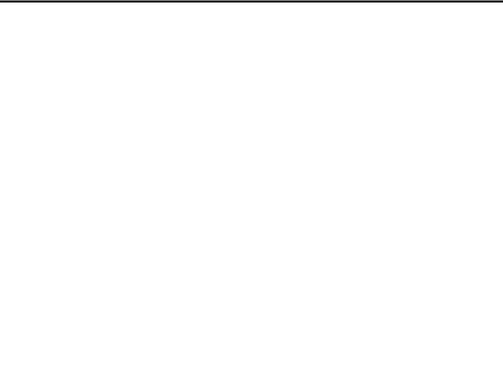 \\
\hline 350 & $\begin{array}{l}\text { Element modeling to include: } \\
\text { - Deck edge location } \\
\text { - Actual deck profile and flute locations per manufacture } \\
\text { - Actual framing mend lap locations } \\
\text { All miscellaneous framing ing incluation per manufacture } \\
\text { - closure, shear studs, etc. } \\
\text { Slab openings modeled with support framing around } \\
\text { - Poinings } \\
\text { - Slab read locations } \\
\text { Surcing modeled if specified in BIMXP }\end{array}$ & \\
\hline 400 & $\begin{array}{l}\text { Element modeling to include: } \\
\text { - All framing accessory and fasteners modeled per } \\
\text { expected installation } \\
\text { All slab reinforcing } \\
\text { - Welds } \\
\text { Waterproofing }\end{array}$ & \\
\hline
\end{tabular}

B1010.20 - Floor Decks, Slabs, and Toppings (Concrete)

\begin{tabular}{|l|l|l|}
\hline 100 & See B10 & \\
\hline 200 & $\begin{array}{c}\text { Element modeling to include: } \\
\text { - Type of structural concrete system } \\
\text { Approximate geometry (e.g. depth) of structural } \\
\text { elements }\end{array}$ & \\
\hline 300 & $\begin{array}{l}\text { Element modeling to include: } \\
\text { - Specific sizes and locations of main concrete structural } \\
\text { members modeled per defined structural grid with } \\
\text { correct orientation } \\
\text { All sloping surfaces included in model element with } \\
\text { exception of elements affected by manufacturer } \\
\text { selection }\end{array}$ & \\
\hline
\end{tabular}




\begin{tabular}{|c|c|c|}
\hline & $\begin{array}{l}\text { Required non-graphic information associated with model } \\
\text { elements includes: } \\
\text { - Concrete strength, } \\
\text { - Reinforcing strength } \\
\text { - Air entrainment, } \\
\text { - Tygregate size } \\
\text { Typal details }\end{array}$ & \\
\hline 350 & $\begin{array}{l}\text { Element modeling to include: } \\
\text { - Reinforcement called out, modeled if required by the } \\
\text { BIMXP, typically only in congested areas } \\
\text { - Pour joints and sequences to help identify reinforcing } \\
\text { - } \text { lap splice locations, scheduling, etc. } \\
\text { - Emberion Joints } \\
\text { - Post-tension profile and strands modeled if required by } \\
\text { - Penetrations for items such as MEP } \\
\text { - Any permanent forming or shoring components } \\
\text { Required non-graphic information associated with model } \\
\text { elements includes: } \\
\text { - Embeds and anchor rods } \\
\text { - Rggregate, clear clover } \\
\text { - Reinforcing spacing } \\
\text { - Live loads } \\
\text { - Shear reinforcing and stud rails } \\
\text { - Reinforcing post-tension profiles and strand locations } \\
\text { - Penetrations for items such as MEP } \\
\text { Finishes, camber, chamfers, etc. }\end{array}$ & \\
\hline 400 & $\begin{array}{l}\text { Element modeling to include: } \\
\text { - All reinforcement including post tension elements } \\
\text { - detailed and modeled } \\
\text { - Finishes, camber, chamfer, etc. }\end{array}$ & \\
\hline
\end{tabular}




\section{B1020 - Roof Construction}

[See B1010]

\section{B1020.10 - Roof Structural Frame}

Description: Structural elements required for support of floor construction within basements and above grade. Includes columns, girders, beams, trusses, joists. Includes cast-in-place concrete, precast concrete, unit masonry, metal framed, and wood framed systems. Includes framed and sleeved openings for services. Includes Floor Construction Supplementary Components as appropriate. [See B1010.10]

B1020.20 - Roof Decks, Slabs, and Sheathing

Includes: Structural roof deck, slab, and sheathing construction. Includes cast-in-place concrete, precast concrete, cementitious decks and toppings, metal decking, wood sheathing, wood decking, timber decking and expansion control. Includes framed and sleeved penetrations for services and housekeeping pads for equipment. Includes Roof Construction Supplementary Components as appropriate.

[See B1010.20]

B1020.30 - Canopy Construction

Includes: Structural frame and decks, slabs, and sheathing for canopy construction.

These components are typically modeled as part of other assemblies listed in the tables above. Do not assign this Uniformat classification unless a supplementary component is modeled independently of another assembly.

[See B1010.20]

\section{B1080 - Stairs}

\begin{tabular}{|l|l|l|}
\hline 100 & $\begin{array}{l}\text { Assumptions for all stair systems (including railings, fire escapes, } \\
\text { walkways, and ladders) are included in other modeled elements } \\
\text { such as a spatial or massing element; or, schematic model } \\
\text { element that indicates the approximate overall dimensions of the } \\
\text { stair layout. }\end{array}$ & \\
\hline
\end{tabular}

B1080.10 - Stair Construction

Includes: Structural framing for exterior and interior stairs including treads, risers, and landings. Includes fire escapes and ladders.

\begin{tabular}{|c|l|l|}
\hline 100 & See B1080 & \\
\hline 200 & $\begin{array}{l}\text { Generic model element with simplified treads and risers. } \\
\text { Nominal overall unit scope shall include: }\end{array}$ & \\
\hline$\quad \begin{array}{l}\text { Nominal plan dimensions (length, width) } \\
\text { Nominal vertical dimensions (levels, landings) }\end{array}$ & \\
\hline 300 & $\begin{array}{l}\text { Major stair support elements are modeled (stringers). } \\
\text { Treads and risers are modeled to indicate design-specified } \\
\text { nosing conditions. }\end{array}$ & \\
\hline 400 & $\begin{array}{l}\text { Secondary stair support elements are modeled (hangers, } \\
\text { brackets, etc.). } \\
\text { Required clearance/code zones are modeled. }\end{array}$ & $\begin{array}{l}\text { All stair elements are modeled to support fabrication and } \\
\text { installation. }\end{array}$ \\
\hline
\end{tabular}




\section{B20 Exterior Vertical Enclosures}

\begin{tabular}{|l|l|}
\hline 100 & $\begin{array}{l}\text { Solid mass model representing overall building volume; or, } \\
\text { schematic wall elements that are not distinguishable by type or } \\
\text { material. } \\
\text { Assembly depth/thickness and locations still flexible. }\end{array}$
\end{tabular}

B2010 - Exterior Walls

Solid wall construction that is composite in nature; in other words, multiple layers of materials to form an overall assembly.

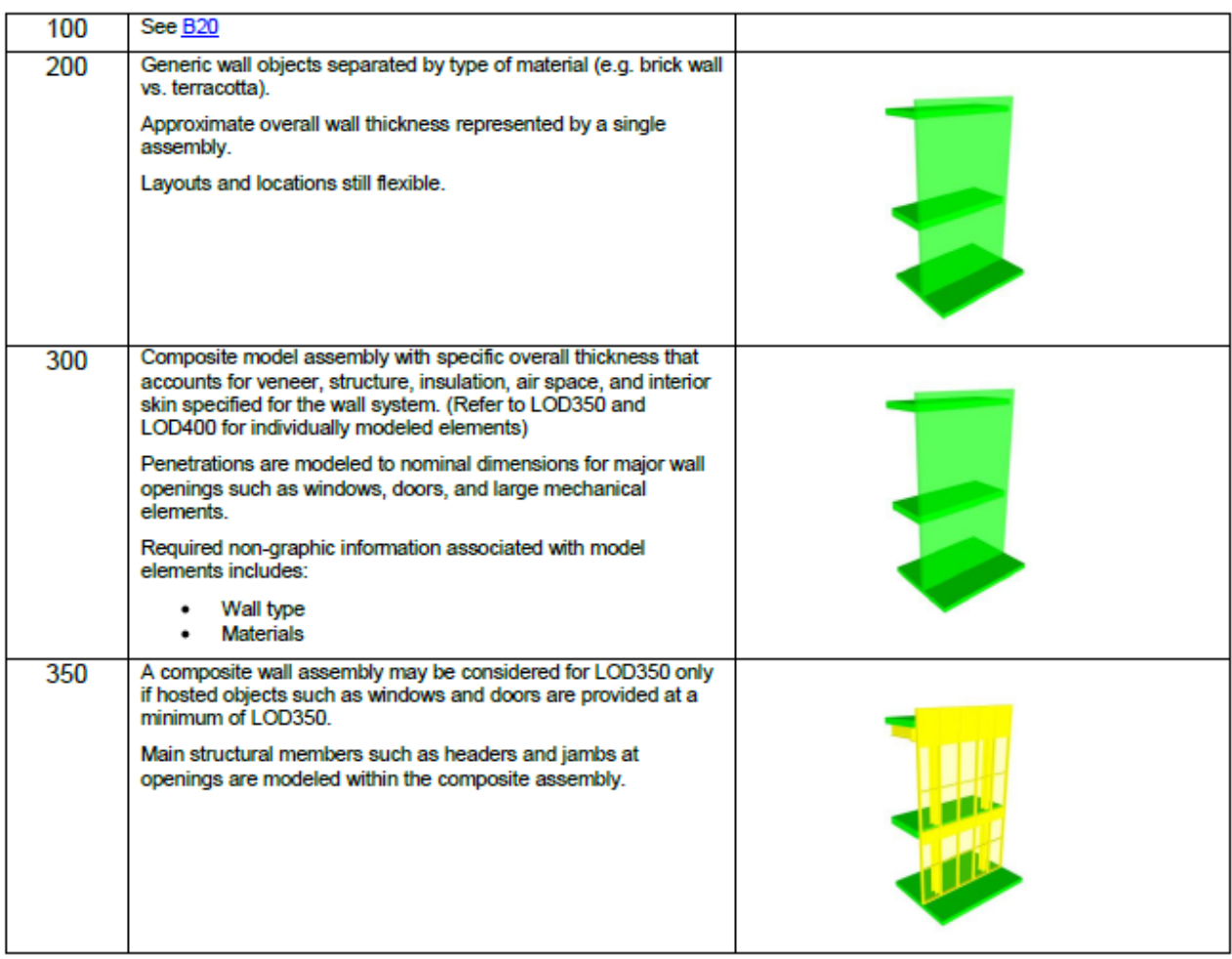




\section{B2020.30 - Exterior Window Wall}

\begin{tabular}{|l|l|l|}
\hline 100 & See B20 & \\
\hline 200 & $\begin{array}{l}\text { Generic wall objects representing major types of proposed } \\
\text { window wall assemblies. } \\
\text { Overall window wall assembly depth represented by a single } \\
\text { model object. } \\
\text { Layouts and locations still flexible. }\end{array}$ & \\
\hline 300 & $\begin{array}{l}\text { Specified location and orientation of face of glass. } \\
\text { Nominal face dimensions and thickness of glazing. } \\
\text { Structural support systems of wall to be modeled. } \\
\text { Spacing, location, size and orientation of mullions. } \\
\text { Operable components defined (windows, louvers and doors) and } \\
\text { included in model. }\end{array}$ & \\
\hline 350 & $\begin{array}{l}\text { Mullion shapes and geometry defined. } \\
\text { Actual anchorage layouts and types defined. } \\
\text { Actual panel dimensions (including seating). }\end{array}$ & \\
\hline 400 & $\begin{array}{l}\text { Complete mullion extrusion profiles. } \\
\text { Interface details between wall systems (within) and wall and } \\
\text { support systems including sealants, end dams, flashings and } \\
\text { membranes. }\end{array}$ & \\
\hline
\end{tabular}

B2020.50 - Exterior Special Function Windows

[See B2020.10]

B2050 - Exterior Doors and Grilles

\begin{tabular}{|c|l|l|}
\hline 100 & $\begin{array}{l}\text { Simple representation of a door unit. Size, count, and location } \\
\text { are approximate. }\end{array}$ & \\
\hline 200 & $\begin{array}{l}\text { Units are modeled as a simple, monolithic component; or } \\
\text { represented with simple frame and panel. } \\
\text { Nominal unit size is provided. }\end{array}$ & \\
\hline
\end{tabular}

